\title{
THE USE OF ELECTRICAL RESISTIVITY \\ TO DETERMINE POROSITY OF MARINE SEDIMENTS
}

\section{RONALD ANTON ERCHUL}


LIBRARY

NAVAL POSTGRADUATE SCHOOL

MONTEREY, CALIF. 93940 
T147657 



POROSITY DETERMINATION BY ELECTRICAL MEANS 

DOCTOR OF PIILOSOPHY THESIS

OF

RONALD ANTON ERCHUL 

THE USE OF ELECTRICAL RESISTIVITY TO DETERMINE

POROSITY OF MARINE SEDIMENTS

BY

RONALD ANTON ERCHUL

II

^ THESIS SUBMITTED IN PARTIAL FULFILLMENT OF THE

REQUIREMENTS FOR THE DEGREE OF

DOCTOR OF PHILOSOPHY

IN

OCEAN FNGINEERING

UNIVERSITY OF RIODE ISLAND

1972 
$E 5: 02$ 
ABSTRACT

$\Lambda$ method using electrical resistivity measurements to determine the in situ porosity of marine sediments was investigated in the laboratory, and equipment for this purpose was designed, fabricated and tested. Formation Factor-porosity relationships determined in the laboratory for three clays (kaolinite, illite, and montmorillonite), Providence silt, four sands, and four marine sediments showed that porosity was predicted within \pm 2 percent. The Formation Factors ranged from 1.1 to 5.9 while porosity ranged from 26 to 93 percent. The particle sizc and distribution influenced the electrical resistivity of these sediments independent of porosity while particle shape did not. The laboratory equipment was economical, safe, easy to operate and could be used to determine permeability, tortuosity and void ratio-log consolidation pressure of sediments .

The Electrical Resistivity Measuring System designed for the Deep Ocean Sediment Probe consists of three interchangeable elcctrode arrays, the electronic circuit and the FM telemetry data link with 6000 feet of coaxial cable. The predicted porosity values obtained with the System in the laboratory were within \pm 2 percent of the line of best fit obtained with the earlier laboratory equipment. Using the inner corer ring electrode array, the Systein was tested in the shallow water of Narragansett Bay and most of the data agreed well 

with the value obtained later with the laboratory equipment on the same sediment.

The inner corer ring electrode array read continuous conductivity through the water/sediment column thus permitting a value of salinity to be obtained. The bottom water salinity obtained in this way was in good agreement with the interstitial water salinity of the cores. The system detected a core loss, touch down, and sample disturbance. This relatively low cost system allows accurate, quick in situ porosity determination and shows promise in other arcas such as the monitoring of pollution, the prediction of other bottom sediment properties and as a warning system on ocean structures. 



\section{ACKNOWLEDGENENTS}

This work was made possible through a co-operative effort of the United States Navy and the University of Rhode Island. Through the Navy the author obtained support to carry out the research, while the University of Rhode Island, especially the Department of Ocean Engineering, provided the atmosphere, equipment, and most important, the pcople to aid in this research.

The use of $X$-ray Diffraction equipment, the Graduate School of Oceanography electron microscope, and the services of the University of Rhode Island Fngineering Instrument Shop is greatly appreciated.

\section{Sincere gratitude is expressed to Professor V. A. Nacci} who had the wisdom, courage and patience to assist this investigation by his encouragement, funds and interest in its progress. The author also wishes to acknowledge the other professionals such as Professor G. A. Brown and Professor V. C. Rose who reviewed this dissertation and made valuable suggestions and constructive comments.

Thanks is expressed to my fellow workers: Milton lluston, Americo Volpigno, Cecil Williams, James Roney, Buff Chace, David Killoy, Wilson Lamb and Don Sargent, all of whom shared their special areas of skill and knowledge.

The author is especially grateful to James Gallagher and Robert Ball of the Navy Underwater Systems Center, New London Labora- 

tory, who helped in fabricating and obtaining electronic equipment used in this study.

My thanks also goes to Captain John Miller of the Ocean

Engineering research vessel for his able assistance during the sea tests.

Finally, I should like to acknowledge the continual help provided to me by my wife who was never too busy to offer her conments and aid. 

ACKNOHLEDGFMENTS $\ldots \ldots \ldots \ldots \ldots \ldots \ldots \ldots \ldots \ldots \ldots \ldots \ldots \ldots \ldots \ldots \ldots$ ii

'TABLE OF CONTENTS $\ldots \ldots \ldots \ldots \ldots \ldots \ldots \ldots \ldots \ldots \ldots \ldots \ldots \ldots$ iv

LIST OF TABIES $\ldots \ldots \ldots \ldots \ldots \ldots \ldots \ldots \ldots \ldots \ldots \ldots \ldots \ldots \ldots \ldots \ldots \ldots \ldots$

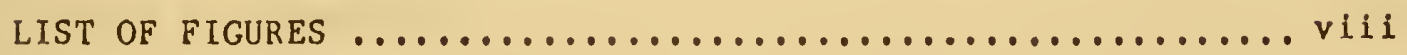

PREFACE $\ldots \ldots \ldots \ldots \ldots \ldots \ldots \ldots \ldots \ldots \ldots \ldots \ldots \ldots \ldots \ldots \ldots \ldots \ldots \ldots \ldots \ldots \ldots \ldots \ldots \ldots$

\section{SECTION I}

THE USE OF ELECTRICAL RESISTIVITY TO PREDICT

THE POROSITY OF SATURATED SEDIMENTS

\section{INTRODUCTION}

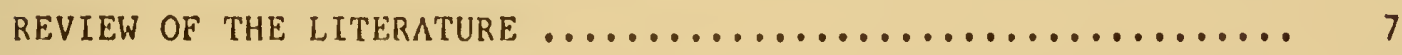

Mathematical Models ......................... 21

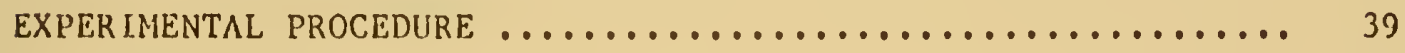

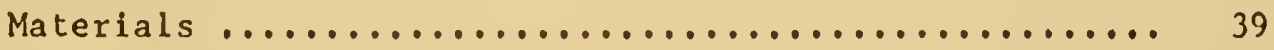

Laboratory Apparatus ..................... 43

Simple apparatus ..................... 44

Modified apparatus ................... 49

Redesigned apparatus $\ldots \ldots \ldots \ldots \ldots \ldots \ldots \ldots . .60$

Methods of Testing ....................... 56

Simple apparatus ..................... 56

Modified apparatus ..................... 61

Redesigned apparatus $\ldots \ldots \ldots \ldots \ldots \ldots \ldots \ldots \ldots, 62$

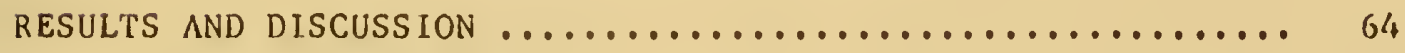

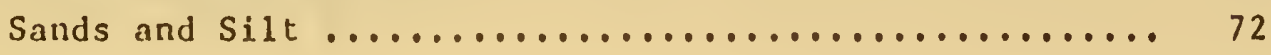

Clays and silt $\ldots \ldots \ldots \ldots \ldots \ldots \ldots \ldots \ldots \ldots \ldots \ldots \ldots \ldots, 91$

Marine Sediments ......................... 111

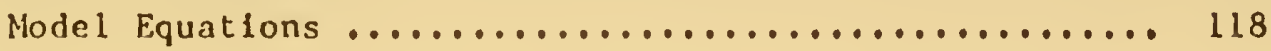



Page

CONCLUSIONS 124

\section{SECTION II \\ AN ELECTRICAL RESISTIVITY MEASURING SYSTEM FOR THE DETERMINATION OF POROSITY OF MLRINE SEDIMENTS IN SITU}

INTRODUCTION $\ldots \ldots \ldots \ldots \ldots \ldots \ldots \ldots \ldots \ldots \ldots \ldots \ldots \ldots \ldots$

REVIEW OF LITERATURE ......................... 132

IN SITU MEASURING SYSTEM ........................ 144

Electrode $\Lambda$ rays .................................. 144

Electronic Measuring Component .................. 154

FM Multiplex Telemetry Component ................ 159

PROCEDURE ....................................... 160

Laboratory Tests ............................ 160

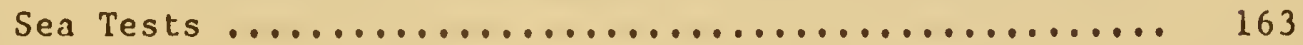

RESULTS AND DISCUSSION $\ldots \ldots \ldots \ldots \ldots \ldots \ldots \ldots \ldots \ldots \ldots \ldots \ldots$

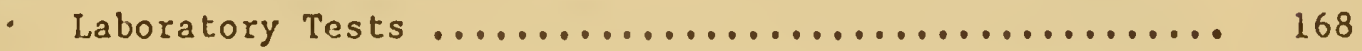

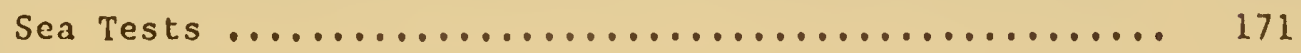

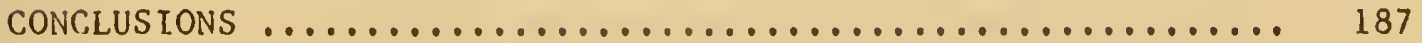

FURTHER STUDIES .............................. 190

$\triangle P P E N D$ ICES

A. Detalied development of SOME EquATions ............ A 1

B. DETAILS . OF EQUIPMENT AND CALIBRATION ............. B 1

C. TEST METHOdS AND dATA ...................... . . 1

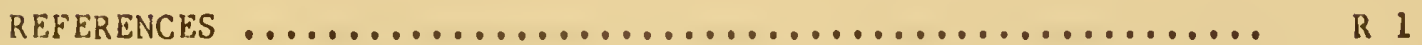


The Catjon Exchange Capacity and Specific Surface of Kaolinite, Illite and Mont-

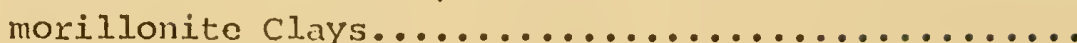

Mincralogy, Classification, Grain Size, Shap?, Specific Gravity, Liquid Limit, Plastic Limit, pH, and Organic content of the sediments Tested..............................40,41 Sands, Silt, Clays and Marine Sediments

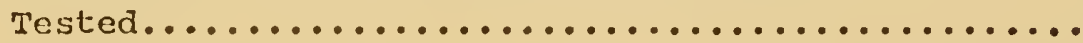

6.

Slope, Jntercept, Standard Error of Estimate, Numbor of Data points, Percentage of Data that: Fall within $t 2$ Percent of the Line of Rest Fit, and the Maximum and Mininum Formation Factors and Forosity Values of the sediments Tested.

Formation Factors at 40 percent and 32 percent Forosity, the Percentage Change in Fonnation Factor and lieasure of Spread for Five sands.

Coefficients of Permeability, Formation Factors, Forosity, Tortuosity, and the Product of the Fonnation Factor and the coefficient of Penneability for Five Joosely and Densely Packed Sands. and the Product of Fonnation Factor and the coefficient of Permeability at 36 Porcent

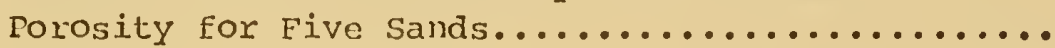

The Average Tntensity Counts of the Two Major d-spacing Values of Two structures of Kaolinite C.lay................................. 

13.

The Coefficients of the Model Equation, Forosity Range and Formation Factor Range of Thirtecn

sediments............................. 120 



\section{IIST OF FIGURES}

Fj.gure

Title

Page

1.

2.

3.

4.

5.

6.

7.

8.

9.

10.

11.

12.

13.

14.

15.

16.

Spherical Particles in a Densely and a Loosely

Packed Configuration....................

Orientation of Clay Particles in a Flocculant

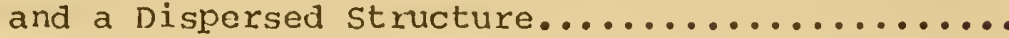

Formation Factor-Porosity Relationships Proposed by Maxwe11, Wiener, Meredith, woodsice and

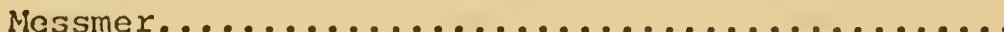

Formation Factor-Porosity Relationships Proposed by Archie, Dakhnov, Semenov and the fiumble

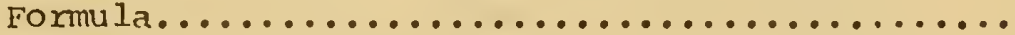

Formation Factor-Porosity Relationships Proposed by Boyce, Kennabon et. al. and Smith..........

Formation Factor-Porosity Relationships Proposed by $\lambda$ tkins and Smith for sodium Montmorillonite, IJlite, Kaolinite and sand.

The Simple Cell Apparatus.................

The Four Side PJatinum Elcctrodes of the Simple

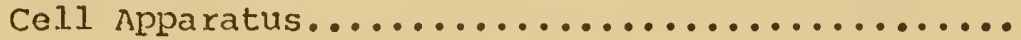

Simple Cell Apparatus Used to Test Samples of Various Jengths.....................

Testing Apparatus and Eloctronic Equipment Used to Test Marine sediments in the Ixboratory........

One Cell of the Modified Test Apparatus.........

One Chamber of the Modified Test Apparatus.

Elcctronic Equipment, Used with tho Simp]e and

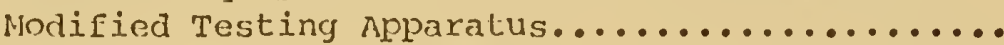

Cell, Pressure Vessels, Regulator and Guage Assembly Used with the Redesigned Equipment.....

Elcctrical Conductivity of the sediment versus the Condurtivity of the Interstitial whter for Illite clay, Kaolinito clay, Providenco

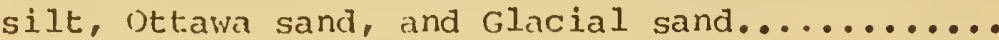

Formation Factor Versus the Conductivity of the Interstitial. Water for Kaolinite, I.llite and Montmoxillonite cl.ay.................... 

Fonnation Factor-Porosity Relationship for

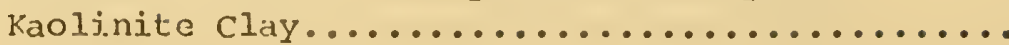

18.

Formation Factor-Forosity Felationship for all

Seriments Tested.

Formation Factor-Porosity Relationships for Eive Sands and Providence Silt.

20.

a to $\mathrm{f}$

21

22 .

23.

$a, b$

24.

25.

$a, b$

26.

$a, b$

27.

28.

29.

30.

Photographs of (a) Ottawa Sand, (b) Glacial Sand

(1-a), (c) Glacial Sand (1-b), (d) Glacial

Sand (2), (e) Naxragansett Bay Sand, and (E)

Providence s.i.t...................... 79,80,81,82,

83,84

Porosity versus the Product of the Formation

Factor and the coefficient of Permeability

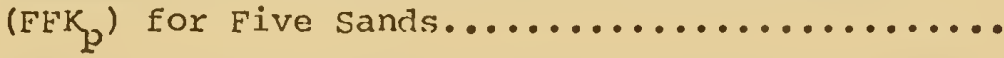

Formation Factor-Porosity Relationships for

Kaolinitc, Illite and Montmorillonite Clays

and Proviclence silt.

Photographs of (a) Kaolinitc Clay Enlarged 2000

Times by Electron Microscope; (b) Kaolinite

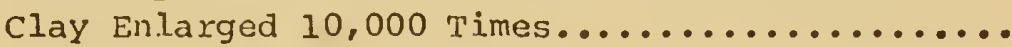

Photograph of Providence silt Enlarged 10,000

Times by Electron Microscope..............

Photographs of (a) Illite Clay Enlarged 2000 Times by Electron Microscope, (b) Illite clay Enlarged 10,000 rimes.

Photographs of (a) Montmorillonitc clay Enlarged 2000 'rimes by Electron Microscope, (b) Montmorillonite Clay Enlarged 10,000 Times........

x-ray Diffractograms of Two structures of Kaoli-

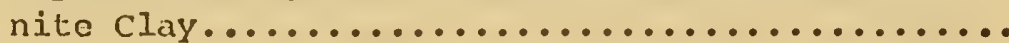

Conductivity versus Time Curves of Illite clay at Consolidation Pressures of $0.25,1.00,4.00$ and 16.00 psig.

Conductivity, Formation Factor, Forosity, Void Ratio and Water content Versus Time of Kaolinite Clay at a Consolidation pressure.........

Formation Factor, Porosity and void Fitio Versus the Iog of the Consolidation Pressure of Illito clay. 

31.

32.

$a, b$

33.

34.

35.

36.

37.

38.

$a, b$

39.

40.

41.

42.

43.

41.

45.

46.
Formation Factor, Porosity and Void Ratio Versus the Coefficient of Perneability

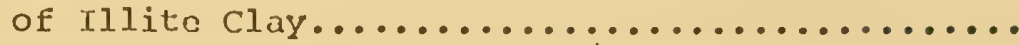

Two Vertical Depth Profiles of Porosity, water Content and Flectrical Resistivity of a Marine sediment........................

Formation Factor-Forosity Relationships of Four

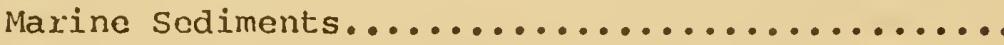

Photograph of a Marine sediment from station B Enlarged 575 Times by Electron Microscope......

Photograph of the Decp Ocean Sediment Probe (DOSP)

Nose of the DOSP Corer Tube with the Inmer Corex Ring Electrode Array and the Corer cuttorCatcher Assembly.

Vertical Cross scction of the Inner Corer Ring Electrode Array and Equipotential rijnes........

Microlateralog Pad Electrode Array and the 80

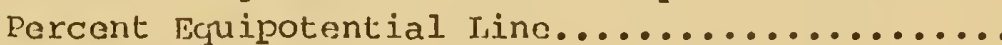

Photograph of tho Inner Corer Ring Electrode Array with the Flat Transmission Cable Hook Up.

Photograph of the Microlateralorg Pad Electrode Array and the Miniature Guard...............

Photograph of the Inner Corer Ring Flectrode Array...............................

Prossure Case and Flcctronic Moasuring Components: Signal Conditioner, $\mathrm{DC} / \mathrm{AC}$. Inverter, Constant Voltago Transformer and a Thermistor Assembly...

Skomatic Diayram of Electronic Measuring System and the Inner Corer Ring Electrode Array.......

Survey Pattorn Planned for Narragansett Bay

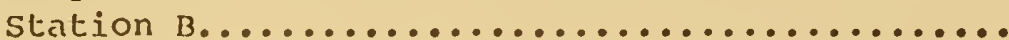

Corer Barrel with white Tape Marks Every Six Inches.

Calibration of FM I'clemetry Channel showing Voltage Imput from the siynal conditioner and the Response Recorded Through FM Telemeliy Channel.............................. 
47.

48.

49.

50.

51.

52.

53.

54.

55.

56.

Calibration Curves for the Innex Corer Ring El.ectrode Arxay, licrolatexalog Pad Electrocie Array and the Guard Mode Electrode Array........

Formation Factor-Porosity Data Points of Ottawa Sant Obtained with the Inner Corer Ring Electrode Array and the line of Eest Fit from Earlier Laboratory Data of Ottawa Sand..........

Formation Factors Versus Depth Obtained with the Miniature Guard lode Electrode Array, the Corresponding Predicted Porosity and the Measured values of porosity.................

In-situ Formation Factors Obtained with the Inner Corer Ring Electrode Array Versus the Measured Iaboratory porosity Values for station $A$ and $B$ and the Jines of Best Fit for stations $A$ and $B$ Obtained From the Redesigned Laboratory Equipment.

Measured Porosity and Predicted Porosity Versus Depth for the Cores Taken at Stations $A$ and B with the Inner Corer Ring Electrode Array.....

Measurements from Three Methods of Determining Bottom Water Salinities and the Interstitial water Salinity of the Cores Taken at the

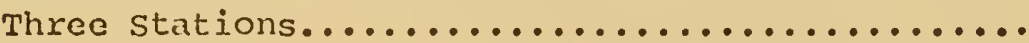

Formation Factor-Porosity Relationship at Different stages of sediment Disturbance in the Inner Corer Ring Electrode Array and the Isine of Bost Fit of the Same sediment Obtained by Using the Redesigned Iaboratory Equipment........

Predicted Porosity Versus Depth for Six Positions at station B Obtained by Using the Microlateralog Pad and the Measured Iaboratory Porosity........

In situ Formation Factors Porosity, Waler Content, Void Ratio, Cone Penetrameter, Organic conl:ent, Atterberg I,imits, and pH of Two Cores from station $\lambda$.

In situ Formation Factor, Porosity, Water Content, Voj.d Ratio, Cone Penetrameter, Organic content, Atterberg Iimits and pll of the Coxe from station 



\section{PRFFACE}

This dissertation is organized according to the standard plan. The text is divided into two sections. The first section includes a report of laboratory experiments on an indirect method of determining porosity of sediments and a review of the literature involving similar work. The instrumentation used in the laboratory is described in this section.

The second section describes the design, fabrication, testing, and evaluation of an in situ system used to determine porosity of marine sediments and the equipment used by others for similar work. 

THE USE OF ELECTRICAL RESISTIVITY TO PREDICT

THE POROSITY OF SATURATED SEDIMENTS 



\section{IN'TRODUCTION}

The purpose of this work is to investigate the accuracy of using an electrical resistivity method to predict the porosity of soil-water mixtures. Porosity in a two phase soil water mixture is the ratio between the volume of water to the total. volume. The determination of porosity is important to ocean engineering projects such as underwater acoustics, foundation engineering, submarine soil mechanics and bottom survey work. At present, porosity is determined in the laboratory. If electrical resistivity is found to be an accurate method of predicting porosity, a practical method of in situ testing would be available. This method would be quicker, more economical, and allow more data to be taken than the present method.

To verify the accuracy of the electrical resistivity method, extensive laboratory tests were conducted and the results were compared with theoretical and empirical work reported in the literature. Most of the earlier work studying the relationship between electrical resistivity and porosity was conducted on formation rocks or dispersions. The geophysical techniques used in well logging analysis involve electrical resistivity measurements in order to obtain:

1. Subsurface correlation with formations in other wells, structural mapping.

2. Lithology of the formations.

3. Depth and thickness of productive zones. 

4. Formation porosities.

5. Oil and gas saturation.

6. Volume of oil in a reservoir.

The porosity of formation rocks ranges from 5 to 30 percent, while the porosity of emulsions and dispersions ranges from 50 to 90 percent. Although these ranges cover the porosity values of sediments (which range from 26 to 90 percent), extensive testing is necessary before it can be considered valid to apply the models and theories used for rocks, emulsions, and dispersions to sediments. Electrical resistivity has also been used in order to determine the dielectric constant of pure crystals, the volume concentration of certain biological materials such as red blood cells, and ground water detection. (Meredith ${ }^{1}$, Patten and Bennett ${ }^{2}$ )

Very little electrical resistivity work has been conducted on sediments. The limited work that has been conducted on sediments generally has not considered clay mineral content and type, particle size, shape, distribution and structure, and consolidation pressure.

In this study the following parameters were varied in order to measure their influence on the prediction of porosity as determined by electrical resistivity measurements:

1. Type of sediment (sands, silt, kaolinite, illite, and montmorillonite clays, and marine sediments),

2. Size of particles,

3. Shape of particles,

4. Distribution of particle size,

5. Structure of particles, 

6. Consolidation pressure,

7. Salinity of interstitial water.

The temperature was measured and a correction factor was applied in order to standardize all electrical resistivity measurements to $25^{\circ}$ Centigrade. By measuring the electrical resistivity as each parameter was varied, while at the same time determining porosity by the standard method, the influence of each parameter on the accuracy of this method of porosity prediction could be evaluated.

Since the terms found in this work are used both in submarine soil mechanics and geophysics, they are defined below in order to eliminate confusion.

The two-phase mixture of soil and water is considered a saturated sediment, or simply a sediment. The electrical resistivity measurements are taken on both the sediment and the interstitial water. The resistivity of the sediment is divided by the resistivity of the interstitial water to obtain a ratio called the Formation Factor. This ratio is used as a direct index of porosity. Electrical resistivity (specific resistance) is a measure of the ability of a solution, solid or mixture of unit length and cross section to resist the flow of electric current. In solids, current is carried by free electrons; in solutions, the current is carricd by ions. As electrons and ions move through solids and solutions, a frictional drag results. This frictional drag per unit volume is considered the electrical resistivity of the solid or solution. Electrical conductivity (specific conductance) is a measure of the 
ability of a solution, solid, or mixture, of unit length and cross section to carry an electrical current. Consequently resistivity and conductivity are inversely related measures of the same property. Studles dealing with formation rocks have related resistivity to porosity while studies dealing with emulsions and dispersions have usually related conductivity to porosity.

Listed below are some of the symbols, assumptions, and definitions used in this paper:

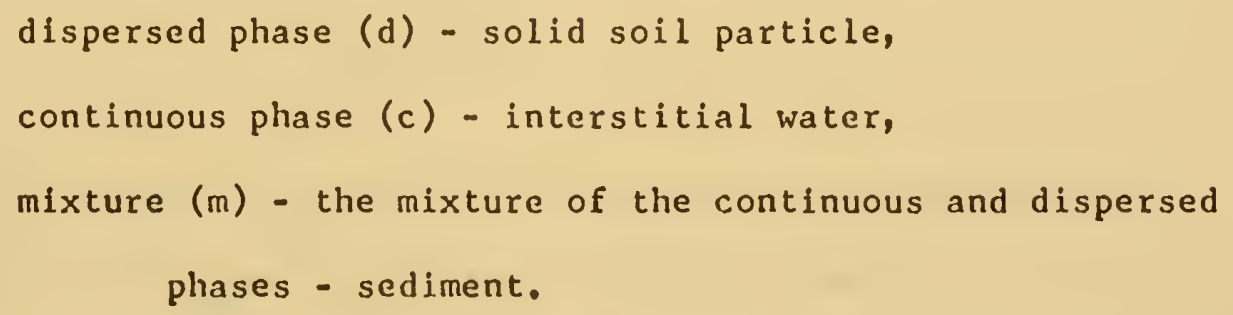

The properties of these phases are assumed to be isotropic and uniform.

$$
\begin{gathered}
r_{c, d, m} \text { - resistivity of the continuous phase dispersed } \\
\text { phase and mixture respectively. } \\
k_{c, d, m} \text { - conductivity of the continuous phases dispersed } \\
\text { phase and mixture respectively. }
\end{gathered}
$$

In order to make relationships dimensionless the resistivity and the conductivity of the continuous phase is considered unity. These dimensionless notations are denoted by Roman capital letters:

$$
\begin{aligned}
& R_{c}=\frac{r_{c}}{r_{c}}=1, \\
& R_{d}=\frac{r_{d}}{r_{c}},
\end{aligned}
$$





$$
\begin{aligned}
& R_{m}=\frac{r_{m}}{r_{c}}, \\
& k_{c}=\frac{k_{c}}{k_{c}}=1, \\
& k_{d}=\frac{k_{d}}{k_{c}}, \\
& k_{m}=\frac{k_{m}}{k_{c}} .
\end{aligned}
$$

Formation Factor (FF) which is often used in the Geophysical Literature is equal to $R_{m}$ and the reciprocal of $K_{m}$ :

$$
F F=R_{m}=\frac{1}{K_{m}} \text {. }
$$

Porosity is normally defined as the volume of the voids to the total volume. Porosity in a saturated sediment (two phase system) can be defined as the ratio of the volume of water to the total volume:

$$
\text { Porosity }(n)=\frac{v_{\text {voids }}}{V_{\text {total }}}
$$

if saturated

$$
n=\frac{v_{\text {water }}}{V_{\text {total }}} .
$$





\section{REVIEW OF THE I.ITERATURE}

The literature contains many theoretical and empirical models that were developed in order to predict porosity from electrical measurement. The following review examines the models that might logically be applied to a saturated sediment. No one model can cover the wide range of sediment types and mixtures (sands, silts and clays). Factors such as particle size, shape, distribution and structure, and consolidation pressure influence model selection. In addition conduction of the clay fraction changes as the ionic concentration of the interstitial water varies. The first part of this review lists some of the properties peculiar to sedinents that need to be considered in models in order to enable accurate porosity prediction from electrical measurement.

Except for native metals, sulfides, a few oxides, graphite, and high-grade coal, the resistivity of most minerals that make up sediments is measured in millions of ohm-meters. Although the soil mineral is non-conductive, the soil particle carries an electrical charge. The net electrical charge may arise from any one or a combination of the following factors:

1. Isomorphous substitution (important in illite and montmorillonite clays),

2. Broken bond charges (important in kaolinite clays),

3. Exposed hydroxyl groups, 

4. Absence of cations in the crystal lattice,

5. Presence of organic matter.

The cation exchange capacity is a measure of the electrical charge carried by a soil particle. The magnitude of the cation exchange capacity of a sediment depends on the amount and type of clay fraction present and the clay particle surface area. The clay fraction is usually defined as that part of the soil mass which has an equivalent Stokes diameter of less than two microns. Particles smaller than one micron are considered in the colloidal range. It is in the colloidal range that surface properties begin to dominate the physical and chemical properties of materials.

For most clay particles the specific surface (the magnitude of the surface area per unit mass) is a good indicator of the relative influence of electric forces on the behavior of the particle. Table 1 shows the cation exchange capacity and specific surfaces of the common clay minerals. 

TABLE 1

THE CATION FXCHANGE CAPACITY AND SPECIFIC SURFACE

OF KAOLINITE, ILLITE, AND MONTNORILLONITE CLAYS

\begin{tabular}{|l|c|c|}
\hline \multirow{2}{*}{ CLAY MINERAL } & $\left(\frac{\text { meq. }}{100}\right)$ & $\left(\frac{\mathrm{m}^{2}}{\mathrm{~g}}\right)$ \\
\hline Kaolinite & CATION EXCHANGE CAPACITY & SPECIF IC SURFACE ${ }^{* * *}$ \\
\hline Illite & $3-15$ & 10 \\
\hline Montmorillonite & $80-40$ & 100 \\
\hline
\end{tabular}

$$
{ }^{*} \mathrm{Wu}^{3}
$$

When individual clay particles are dropped into water the ions on the surface of the particle tend to move out from the surface to become exchangeable ions. Water molecules are attracted to these ions and the two together form what is called the double layer around the clay particle. The thickness of the double layer is defined as the distance from the soil surface to the point where the ion concentration is in equilibrium with the interstitial water.

Many factors influence the size of the double layer. The Gouy-Chapman Double layer theory is often used to explain the double layer and the factors affecting it. This theory assumes that there is no interaction between clay particles and that the clay particles are plates. This theory states that the size of the double layer is directly proportional to the temperature and diclectric constant of 

the solution and inversely proportional to the concentration and ionic valence of the electrolyte in the interstitial water and the electric charge on the clay particle. Other factors influencing the double layer are pll and size of ions in solution.

If the cation exchange capacity and the specific surface are low and a small double layer exists, almost all the interstitial water would be free water and would not be attracted to the mineral skeleton. Conversely if the cation exchange capacity and the specific surface are high and a large double layer exists, it would be quite difficult to separate the clay mineral and interstitial water phases.

One of the earliest works examining the effect of charged clay particles and the associated double layer on electrical resistivity was done on reservoir rocks by Winsauer et al. ${ }^{5}$ These investlgators concluded that charged clay particles do influence the conductivity of shaly sand and limestone formations, but that this influence became negligible at high ionic concentrations of interstitial water.

After conducting laboratory experiments, Hill and Milburn ${ }^{6}$ made similar conclusions and developed empirical equations for reservoir rocks relating Formation Factor to the resistivity of the interstitial water, porosity and the cation exchange capacity. In their equations as the electrical resistivity of the interstitial water decreased, i.e., became more saline, the effect of the cation exchange capacity decreased.

One of the first works to study the effect of the cation ex- 
change capacity on the electrical resistivity of a sedinent was conducted by Berg. 7 Using kaolinite clay and sodium chloride solutions, he showed that the Formation Factor remained constant when the water resistivity was less than $80 \mathrm{ohm}-\mathrm{cm}$. However when water resistivity was greater than $80 \mathrm{ohm}-\mathrm{cm}$, the Formation Factor decreascd. Water that has an electrical resistivity of $80 \mathrm{ohm}-\mathrm{cm}$ would have a salinIty of seven parts per thousand. Sea water having a salinity of 35 parts per thousand would have a resistivity of 25 olm-cm. This work agrees with the work on reservoir rocks. 5,6 The effect of the charge of kaolinite clay particles on the electrical resistivity appeared to be negligible at high ionic concentrations of interstitial water.

Sheeler et al. 8 expanded the knowledge on sediments by studying several types of clay. He found that for kaolinite clay the effect of cation exchange capacity on the electrical conductivity and thus Formation Factor persisted up to a 3 percent sodium chloride solution, then became negligible. However when using montmorillonite the ion effect persisted up to an 8 percent sodium chloride solution. Sea water is approximatcly 3.5 percent sodium chloride. This study suggests that the type of clay present in a sediment such as montmorillonite may influence the electrical resistivity measurements due to the cation exchange capacity even though the salinity is higher than sea water.

Boyce ${ }^{9}$ reported that the percentage of clay size material varied inversely with the electrical resistivity of finc grained. marine sediments obtained from the Bering Sea. Boyce explained these 
results could be due to:

1. a specific conductivity increase resulting from a double ionic layer of clay mineral in the clay size fraction.

2. a secondary conductivity increase caused by an increase in porosity, since the clay size fraction and porosity are directly related.

Fritsch and Tauber ${ }^{10}$ studied kaolinite, illite, and montmorillonite clays at low and high salt concentrations. They observed that the electrical resistivity measurements were overwhelmingly influenced by the specific surface area of the clay particles when distilled water was used, but at high salt concentrations the resistivity measurements were independent of this influence. As illustrated in Table 1 , the specific surface area is an indicator of cation exchange capacity. These authors concluded that further work was necessary in order to establish the limits of this influence for different clays at different concentrations.

Atkins and Smith ${ }^{11}$ studied sodium montmorillonite, calcium montmorillonite and kaolinite, which have cation exchange capacities of $74.0,60.1$ and $16.1 \mathrm{meq} / 100 \mathrm{~g}$ respectively. They found that the Formation Factor remained constant even though the interstitial water conductivity ranges were 1.1 to $8.7,0.1$ to 19.7 , and 0.009 to $8.5 \mathrm{mho} /$ meter respectively. They found the same result with illite clay, but the range of interstitial water conductivity used was not given.

Kermabon et al. ${ }^{12}$ further studied the effect of ionic solu- 

tions on the cation exchange capacity of clay particles. In their laboratory experiments the marine clay particles had a grain size smaller than 3.9 microns and the sodium chloride solutions ranged from 0.7 to 10 percent. The porosity of the clay sediment samples was constant. Throughout this wide range of water salinity the relation between the conductivity of sediment and the conductivity of the interstitial water remained constant; therefore, any influence the charge of the clay particles had on conductivity was masked by the ionic solutions.

Smith ${ }^{13}$ found similar results in laboratory experiments with "coarsc" clay. He used sodium chloride solutions ranging from 0.5 to 10 percent.

The results of these studies indicate that in fresh water the charge on clay particles (cation exchange capacity) greatly influences the conductive properties of the sediment. This charge and consequently its effect on electrical resistivity measurements in fresh water depends on the amount and type of clay present. It is apparent that in a fresh water environment cation exchange capacity must be accounted for by the model or by empirically measuring and correcting for its effect on resistivity measurements if accurate porosity predictions are to be made. However in a marine environment, the influence of the cation exchange capacity of clays on electrical resistivity measurements appears to be negligible in most cases. The reason for this difference between fresh and salt water can be deduced by visualizing the current flow in solution as the migration of free ions. In a sediment of clay and fresh water, most 

of the ions in solution are under the influence of clay particles and therefore the current flow through the sediment is inhibited. If the interstitial water is saline, there are sufficient ions to neutralize the clay particles and allow the current to flow freely. If the clay's cation exchange capacity is high, more ions will be required to neutralize its effect on conductivity. Although cation exchange capacity is usually neglected in the marine environment, more testing is needed before this influence on electrical resistivity measurements for all types of clays can be assumed to be negligible.

The above studies indicate that the cation exchange capacity of some clays need not be considered as an influence on electrical resistivity measurements in the salinity of ocean water. However other characteristics of clay must be considered if accurate porosity predictions are to be made from electrical resistivity measurements. The clay type, sand and silt present in a sediment determine the size, shape, and distribution of particles, and influence particle structure.

The M.I.T. soil classification of sediment particle size 4 is given below:

$$
\begin{aligned}
& \text { from } 0.06 \mathrm{~mm} \text { to } 2.0 \mathrm{~mm} \text { is considered sand, } \\
& 0.002 \mathrm{~mm} \text { to } 0.06 \mathrm{~mm} \text { is considered silt, and } \\
& \text { a particle smaller than } 0.002 \text { is considered clay sized. }
\end{aligned}
$$

The particle distribution of a sediment is defined as a measure of spread such as standard deviation from the mean. If the results of past work are applied to sediments, it would appear that the parti- 

cle size and distribution might influence electrical resistivity in the following ways:

If the porosities, particle shapes, and standard deviations of two distributions are the same for samples with different mean particle sizes, the electrical resistivity will usually be lower for the larger particle size. This effect was suggested in cxperiments with glass beads by Meredith ${ }^{1}$ and by Wyllie and Gregory. ${ }^{14}$ As the particle size increased, the electrical resistivity decreased.

If the porosity a.d nean particle shape and size are the same while the distributions of two sediments are different, the electrical resistivity will be higher in the'sediment with the greater assortment of particles. This effect was suggested by studies on rocks by Semenov ${ }^{15}$ and work conducted on glass beads by Meredith. 1

The effect of shapes in a sediment is complicated. A sediment may be made up of particles of different shapes ranging from spheres to plates. Usually particles in the sand and silt size range are closer to a sphere in shape than the plate-like clay particles. The different particle shapes affect the path lengths that migrating ions take when current flows. If two sediments have approximately the sane particle size and spread and equal porosities but differ in particle shape, the electrical resistivity would be expected to be higher for a sediment composed of disc-shaped particles than a sediment made up of spherical shaped particles. This effect was suggested by studies on various shapes by Wyllie and Gregory. ${ }^{4}$ Discs, cubes, cylinders, and triangular prisms resulted in higher electri- 
cal resistivity values than spheres at the same porosity valucs. They also found that Ottara sand (sphericity $=0.895$ ) and glass beads (sphericity $=1.00$ ) had similar Formation Factor versus porosity relationships.

Meredith ${ }^{1}$ found that the conductivity of disparsions at a porosity of 50 percent resulted in a 10 to 20 percent error if the shape difference between spheres and discs was not taken into consideration. The error decreased with increasing porosity.

Semenov ${ }^{15}$ theoretically developed equations for formation rocks based on shape. Semenov's equations for rocks of spherical shaped grains and disc shaped grains (having the same distribution) resulted in Formation Factor values of 2.7 and 10.1 respectively at a porosity of 50 percent.

Atkins and Smith ${ }^{11}$ stated that at the same porosity angular particles have higher Formation Factors than spherical shaped particles. A shape factor was determined for five clays and one mica. Shape was inferred to be the major factor causing differences between the clays. No electron microscope photographs were taken, and data such as mean particle size and distribution were not given.

In this paper, particle structure will refer to the orientation of individual soil particles in the sediment miss. Particle structure in sands and silts usually depends on packing. The type of packing is important because it affects the porosity and the path length required for migrating ions ard consequently the electrical resistivity measurement. The two extreme types of packing of uniformly sized spherical particles are loose or cubic packing and 
dense or rhombohedral packing as shown in Figure 1.

\section{F IGURE 1}

\section{SPHERICAL PARTICLES IN A DENSELY AND A LOOSELY PACKED CONFIGURATION}

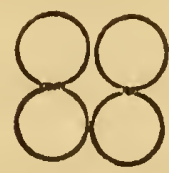

CUBIC PACKING

(loose)

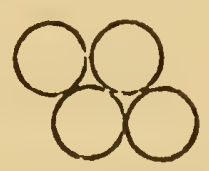

RHIOMBOHEDRAL PACKING (dense)

Structure in clays is greatly influenced by those factors affecting the size of the double layer. In clays the net electrical force between particles is the result of many repulsive and attractive forces. If the double layer of clay particles is small, the attractive forces are dominant and the clay particles will move toward each other and become attached (Flocculant Structure). If the double layer is large, the repulsive force is more dominant and the clay particles will tend to move away from each other (Dispersed Structure). The two clay structures are shown in Figure 2.

FIGURE 2

ORIENTATION OF CLAY PARTICLES IN A FLOCCULANT AND A DISPERSED STRUCTURE

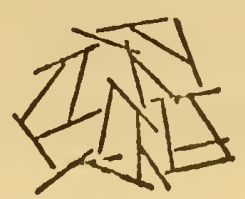

FIOCCULANT STRUCTURE

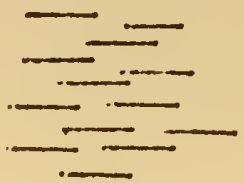

DJSPERSED STRUCTURE 

In the flocculant structure, large voids may be enclosed by the clay skeleton and result in sediments of very high porosities. On the other hand the dispersed structure results in lower porosity values. Aside from the facts of porosity differences, it would appear by visualizing the two structures that the flow of current through these two structures would also be different.

If the current path becomes more tortuous its length is increased. Tortuosity of the current path may be defined as the ratio of the average statistical length of current flow lines to the simple physical length in a straight line from one end of a sediment sample to the other.

By definition the resistance $(R)$ between flat faces of a cylindrical sediment sample is:

$$
R=r_{m} \frac{1}{A}=r_{c} \frac{1}{A_{e}},
$$

where:

1 is the length of the sedinent sample,

$A$ is the cross-sectional area of the sediment sample,

$I_{e}$ is the effective average statistical length of the sediment through the pore structure,

$\Lambda_{e}$ is the effective average statistical cross-sectional area of the pore structure.

In terms of Formation Factor: 



$$
F F=\frac{r_{m}}{r_{c}}=\frac{\frac{1}{l}}{\frac{A_{e}}{A}}=\frac{t}{\frac{A_{e}}{A}},
$$

where $t$ is the tortuosity factor previously defined. Porosity can be expressed as follows:

$$
n=\frac{V_{\text {voids }}}{V_{\text {total }}}=\frac{A_{e} l_{e}}{A l}=\frac{A_{e}}{A} \cdot t
$$

If the porosity is the same equations (11) and (12) can be combined and tortuosity may be defined as a function of porosity and Formation Factor:

$$
t=\sqrt{F F \cdot n}
$$

or

$$
F F=\frac{t^{2}}{n}
$$

As the structure of a sediment becomes more complex and the current paths become more devious, the electrical resistivity will increase. It is at this point that the knowledge of both the electrical and hydraulic properties of sediments and the relationship between them becomes important if physical properties are to be properly interpreted by electrical resistivity measurcments. Huch work has been done on the flow problem through porous media. The general flow formula, be the flow fluid, electrical, thermal or chemical, is:

$$
F=L \cdot X \cdot A
$$


$F$ is the flow rate,

$X$ is the gradient,

A is the cross-sectional area,

$L$ is a coefficient of conduction.

Numerous equations directly inter-relating hydraulic, thermal, and electrical properties of porous, solution-saturated materials have been derived. For example, Hutt and $\mathrm{Berg}^{16}$ developed prediction equations by investigating thermal and electrical conductivities of sandstone rock and ocean sediment and relating the two conductivities through the comnon parameter of porosity. Although such a system seems reasonable it is important to remember that the success of any electrical method for measuring thermal conductivity in a sediment would depend on the range of electrical conductivity of the soil particle encountered in a given situation. Therefore it is imperative when inter-relating flow problem that these differences be understood.

Schopper ${ }^{17}$ contends that if quantitative evaluations between electrical and hydraulic properties are to be improved, the differences between electrical and hydraulic tortuosity should be taken into consideration. The essential difference is that hydraulic tortuosity takes into account a direction factor in addition to the normal tortuous path length, while the normal tortuous path length is the only factor involved in electrical tortuosity. Hydraulic permeability is a good indicator of hydraulic tortuosity, and therefore improved relationships between porosity and Formation Factor would take into account hydraulic permeability. 

Fatt ${ }^{18}$ and Wyble 19 and Glanville 20 investigated the effects of applied pressure on electrical resistivity values of reservoir rocks and sandstone. These rocks of low porosity were placed under very high pressures ranging from 1,000 to 12,000 p.s.i.g. The effect of pressure on electrical resistivity seems to be much greater than the effect on porosity, since electrical resistivity was increased much more than porosity decreased. Similar work on sediments appears to be nonexistent.

\section{Mathematical iodels}

When selecting mathematical models which best fit a porous medium such as a saturated sediment, it is necessary to be aware of the influence of the charge on clay particles, clay type, salinity of the continuous phase, sediment particle size, shape, distribution, and structure. In order to further refine models, awareness of other factors such as hydraulic perneability and consolidation pressure may be useful. In addition the assumptions of theoretical models need special consideration, and extrapolation beyond the range of experimentation (in empirical models) is not recommended.

The electrical conductivity of dispersions has been studied extensively. Some studies date back over a hundred years. Only those theories that are most likely to apply to sediments are considered below.

In 1881 Maxtvel1 $1^{21}$ conducted one of the earliest theorctical investigations and derived an equation for the assemblage of spheres in a continuous media. The assemblage was a suspension of spheres 

that were not in physical contact with each other. Maxwell's equation, in non-dimensional conductivity terms, follows:

$$
k_{m}=\frac{3 k_{d}-2 n K_{d}+2 n}{K_{d} n-n+3}
$$

If the spheres are assumed to be non-conductive, i.e. $K_{d}$ approaches zero, Maxwell's equation reduces to:

$$
K_{m}=\frac{2 n}{3-n}
$$

or in resistivity terms:

$$
F F=R_{m}=\frac{3-n}{2 n}
$$

This equation can be applied to a sediment mixture consisting of a fluid of relatively low electrical resistivity and a network of soil grains, not in contact with each other, that are insulators of high electrical resistivity. For instance soil granules composed of the following common minerals shown in Table 2 would have a high resistivity.

\section{TABLE 2}

FLECTRICAL RESISTIVITY OF SOME COMMON SOIL MINERAIS

$$
\begin{array}{lc}
\text { Mineral } & \text { Resistivity (ohm meter) } \\
\text { Clay minerals } & 10^{11}-10^{12} \\
\text { Quartz } & 10^{12}-10^{14} \\
\text { Calcite } & 10^{7}-10^{12}
\end{array}
$$



When these soil granules of high resistivity $\left(r_{d}\right)$ are placed in a fluid such as sea water which has a relatively low resistivity ( $r_{c}$ ) $(0.25 \mathrm{ohm}$ meters), the non-dimensional resistivity of the dispersed phase (soil granule) can be expressed as:

$$
R_{d}=\frac{r_{d}}{r_{c}} \longrightarrow \infty,
$$

or the inverse relationship:

$$
\mathrm{k}_{\mathrm{d}}=\frac{\mathrm{k}_{\mathrm{d}}}{\mathrm{k}_{\mathrm{c}}} \longrightarrow 0
$$

Wiener ${ }^{22}$ and Woodside and Messmer ${ }^{23}$ developed the Series and Parallel Model Equations which are considered the limiting relationships for porosity deternination by means of conductivity. A complete development of these equations is given in Appendix A.

In the Parallel Equation, the interstitial water and solid soil particle are assumed to be parallel to current flow. The resulting equation in non-dimensional form follows:

$$
\text { (Parallel) } \quad K_{m}=K_{d}+n\left(1-K_{d}\right)
$$

The Series Equation evolves when the solid soil particles and interstitial water are assumed to be perpendicular to the flow of current:

$$
\text { (Series) } K_{m}=\frac{K_{d}}{1+n\left(K_{d}-1\right)}
$$



Wiener 22 recognized that other models would fall between the Series and Parallel Equations. He proposed a linear combination of the two models. Later this linear combination was referred to as the Three-Resistor Model by Woodside and Messmer. 23 The Three-Resistor Model is given below:

$$
K_{m}=p(\text { Parallel Model })+(1-p) \text { (Series Model). }
$$

In this combination $p$ represents the fraction of the sediment described by the Parallel Model.

Woodside and Messmer ${ }^{23}$ also proposed a Geometric Equation in which the sediment is assumed to be the geometric mean of the conductivities of the components of the sediment:

$$
K_{m}=K_{d}(1-n)
$$

However if it is assumed that the solid soil particle is nonconductive, then $K_{d}$ approaches zero. Consequently the Series Equation and the Geometric Equation have no meaning, and the Parallel Equation is reduced to:

$$
\mathrm{K}_{\mathrm{m}}=\mathrm{n}
$$

and the Three-Resistor Model is reduced to:

$$
K_{m}=p n
$$

$\Lambda n$ extensive review of the work up until 1959 including investigations by Rayleigh and Runge was conducted by Meredith. 

lle concluded that effects of particle size, shape, distribution and structure cannot be ignored if accurate theoretical predictions of dispersions are to be made. Meredith developed the Distribution Model for treating a concentrated dispersion of spherical and nonspherical particles. The relationships in the Distribution Model that are most applicable to a sediment environment follow:

$$
\begin{array}{ll}
\begin{array}{c}
\text { nonconducting } \\
\text { spheres: }
\end{array} & K_{m}=\frac{8 n(n+1)}{(5-n)(3+n)}, \\
\begin{array}{c}
\text { nonconducting } \\
\text { randomly oriented } \\
\text { rods: }
\end{array} & K_{m}=\frac{9 n(n+1)}{(4-n)(5+n)}, \\
\begin{array}{c}
\text { rods perpendicularly } \\
\text { oriented to field } \\
\text { current: }
\end{array} & K_{m}=\frac{n(n+1)}{3-n} .
\end{array}
$$

Although the above relationships are presented in non-dimensional conductivity terms, it is simple to convert them to Formation Factor by using the relationship:

$$
F F=\frac{1}{K_{m}}
$$

Formation Factor-porosity relationships proposed by Maxwel1, Wiener, Meredith, Woodside and Messmer are presented in Figure 3. Wherever $K_{d}$ is used in formulation $i t$ is assumed to be 0.01 . Since this value is assumed to be very small, 0.01 was arbitrarily chosen.

Electrical resistivity methods became established as a Geo- 



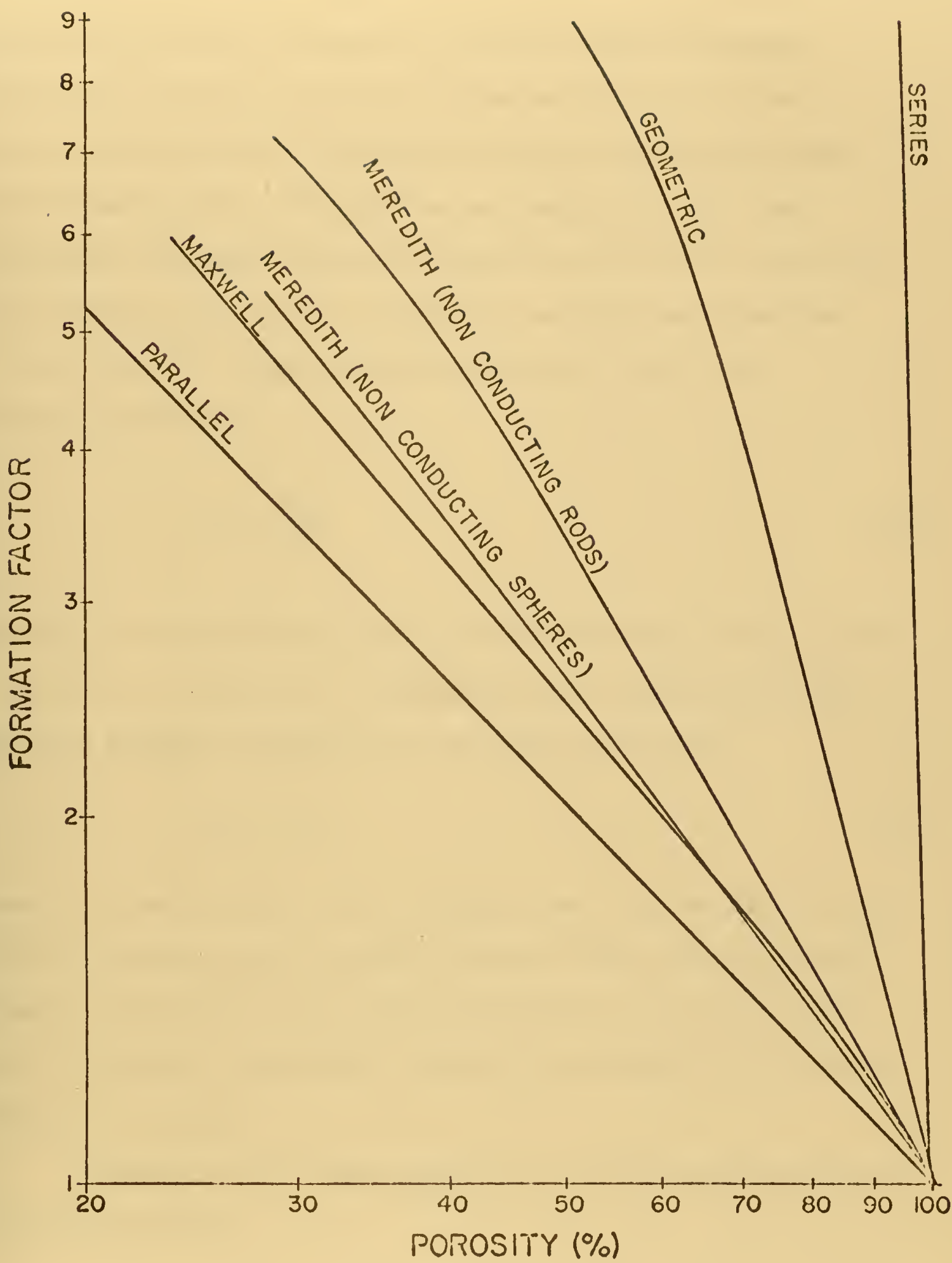

Figure 3. Formation Factor-Porosity Relationships Proposed by Maxwel1, Wiener, Meredith, Woodside and Messmer. (In the series and Geometric rquations the value of $\mathrm{K}_{\mathrm{d}}=0.0 \mathrm{l}$ is assumed; in all other equations $\mathrm{K}_{\mathrm{d}}=0$. ) 

physical exploration technique in 1927 when Conrad Schumberger showed that electrical resistivity measurements of an oil well (then called electrical coring), could distinguish between productive formation rocks and those that are non-productive. This development stimulated extensive research on electrical resistivity measurements as an indicator of physical and chemical properties. In 1941 Archie 24 defined formation resistivity factor i.e., Formation Factor, as:

$$
F F=\frac{r_{m}}{r_{c}}
$$

where $r_{m}$ is the resistivity of the saturated sediment and $r_{c}$ is the resistivity of interstitial water. Archie also empirically determined an equation relating FF to the formation porosity:

$$
F F=n^{-m},
$$

where $n$ is the porosity of the formation, and $m$ is the slope of the line in a $\log -\log$ plot of Formation Factor versus porosity diagram. From his experimental work, Archie determined $m$ to be in the range of 1.8 to 2.0 for consolidated sandstones, and about 1.3 for loosely consolidated sands.

Winsauer et al. ${ }^{5}$ investigated FF to $n$ plots and suggested the relation should be:

$$
F F=a n^{-m},
$$



where (a) is not always unity, but is often a factor accounting for the amount of cementation between mineral grains. Therefore (a) is referred to as the cementation factor. From equation (32) the "Humble Formula" was developed and is probably the most widely used equation in the well logging industry:

$$
F F=0.62 n^{-2.15}
$$

A comprehensive review of geophysical well logging through 1961 has been compiled by Dakhnov. ${ }^{25}$ He summarized the factors that affect electrical resistivity of a porous media by a general formula. If the equation is applied to a saturated sediment, it becomes:

$$
r_{m}=f_{1}(c) f_{2}(n) f_{3}(S) f_{4}(T) f_{5}(Q) f_{6}\left(r_{d}\right) f_{7}\left(r_{c}\right),(34)
$$

where $r_{m}$ is the resistivity of the sediment,

c the amount of clay/silt in the sediment,

$n$ the porosity of the sediment,

$S$ the partial saturation of the sediment,

$\mathrm{T}$. the temperature of the sediment,

Q the cation exchange capacity of the soil mineral,

$r_{d}$ the resistivity of the soil mineral,

$r_{c}$ the resistivity of the interstitial water.

Since some of the variables are sometimes omitted, the complexity of the above equation is often reduced. For example if the soil mineral $\left(r_{d}\right)$ is nonconductive, this term is omitted. In a saturated sediment $(S)$ is a constant equal to one. If the environment is 

saline the interstitial water reduces the effect of cation exchange capacity (Q) and cation exchange capacity is usually ignored. However if the interstitial water has a low ionic concentration this term must be considered. The temperature ( $T$ ) can usually be measured and a correction to electrical resistivity can be made based on the following formula:

$$
r_{25}=r_{T}\left[1+t_{c}\left(T-25^{\circ}\right)\right]
$$

where $r_{25}$ is the resistivity at $25^{\circ}$ Centigrade,

$r_{T}$ the resistivity measured at temperature $\mathrm{T}$,

$t_{c}$ the temperature coefficient of resistivity, which usually is about 2.5 percent per degree Centigrade. In most situations then, the resistivity of a saturated sediment (at a set temperature) will be determined by three parameters if the environment is saline: $r_{c}, c$, and $n$; and by four parameters if the ionic solution of the interstitial water is low: ${ }{ }_{c}, c, Q$ and $n$. Dakhnov also obtained a theoretical relation between Formation Factor and porosity of uniform nonconducting spheres in a conducting fluid:

$$
F F=\frac{1+0.25(1-n)^{1 / 3}}{1-(1-n)^{2 / 3}}
$$

Semenov $^{15}$ suggested a theoretical equation for cemented rocks consisting of grains which have the forms of ellipsoids of revolution. The formula for the Formation Factor along the axis of . 

revolution is:

$$
F F=\left[\frac{f+v_{0}}{1-v_{0}}\right]^{\frac{\ln n}{\ln \left(1-v_{0}\right)}} .
$$

In this equation $f$ is defined as:

$$
f=\frac{e^{3}}{\left(1-e^{2}\right)(\text { arthe }-e)}-1
$$

where

$$
e=\sqrt{1-\left(\frac{b}{a}\right)^{2}}
$$

e is the eccentricity of an ellipse, a and b being semimajor and semiminor axis of the ellipsoid. The extreme cases of this equation are when $\mathrm{f}=0$ (nonconducting grains of a flat disc shape) and when $\mathrm{f}=2$ (nonconducting grain would be spherical). This theoretical work, although developed for the electrical resistivity of rocks, combined two additional important factors, that of particle distribution which is termed the sorting coefficient ( $\left.v_{0}\right)$, and a particle shape factor (f). These two factors would also be important in a sediment environment.

Formation Factor, porosity relationships proposed by Archie, Dakhnov and Semenov are present in Figure 4. The Humble Formula is also presented in Figure 4. 



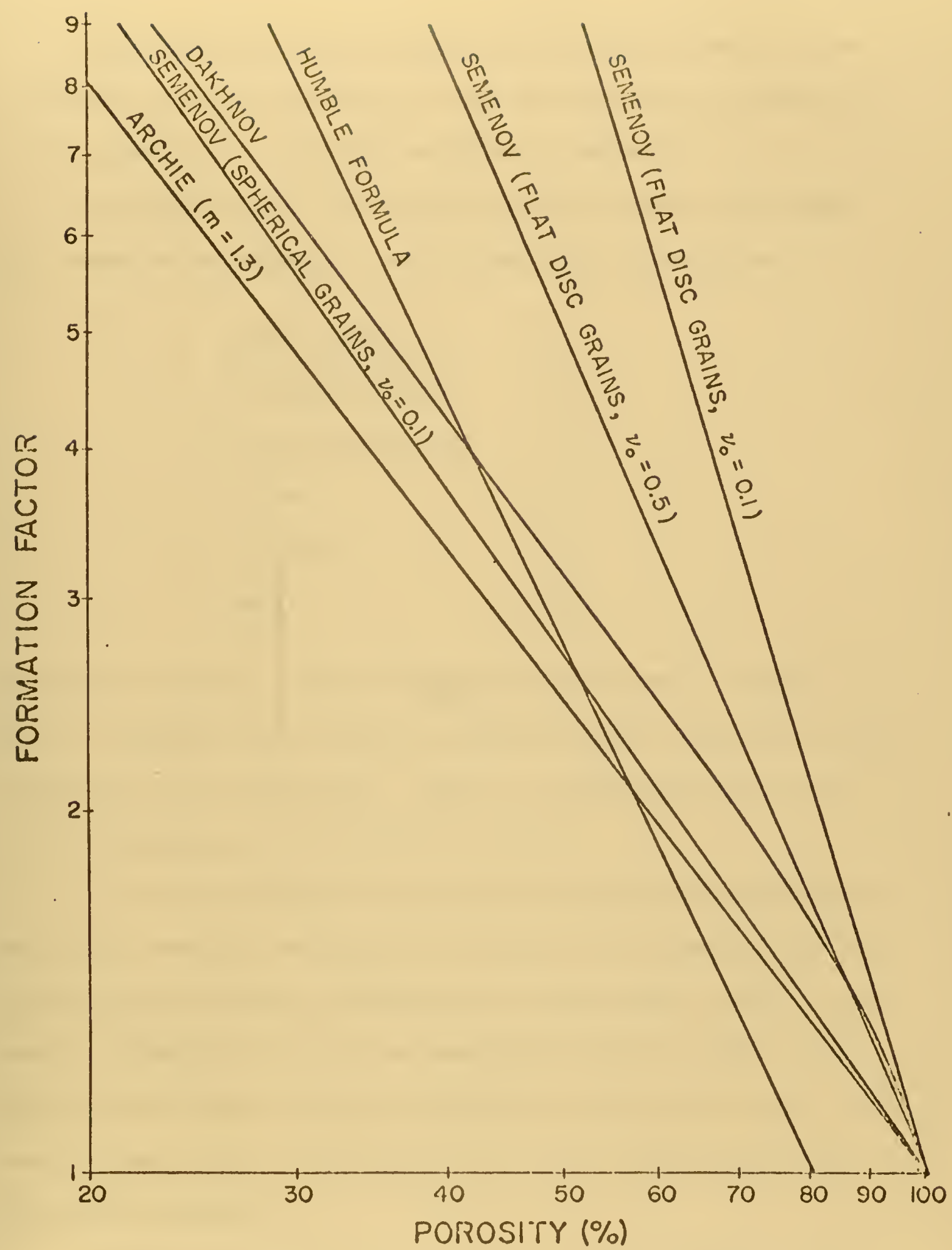

Figure 4. Fonnation Factor-forosity Relationships proposed by Archic, Dakhnov, Scmenov and the frumble Fonnula. 

More recent works which are not reviewed previously in the literature are discussed below. These recent works are either directly applicable or actually conducted on sediments.

Atkins and Smith ${ }^{11}$ have experimentally found $m$, which they call shape factor exponents, for various mineral particles:

$\begin{array}{lc}\text { Mineral Particle } & \text { m } \\ \text { Na Montmorillonite } & 3.28 \\ \text { Ca Montmorillonite } & 2.70 \\ \text { Illite } & 2.11 \\ \text { Kaolinite } & 1.87 \\ \text { Sand } & 1.60\end{array}$

They also concluded that (a) the cementation factor in formula 32 was not unity but was a factor of proportionality which accounts for amount of clay to sand ratio. Only if a system consisted of one type of mineral particle would (a) be unity.

It is interesting to note that if $m$ could be found by experimentation, then for that type of clay only the determination of the Formation Factor would be necessary and the porosity could be estimated. Although this study was conducted in order to understand how the clay mineral fraction influences reservoir rocks, the results could be very useful in the prediction of porosity from Formation Factors in sediments.

Boyce ${ }^{9}$ took 43 electrical resistivity measurements on sediments laken from cores obtained from seven locations in the Bering Sea, some of which wcre 600 nautical miles from each other. Using 

a consolidometer he squeezed the interstitial water out of these sediments and measured the electrical resistivity of this water in order to obtain Formation Factors. The porosity of these measurements ranged from 58.3 to 87.4 percent. By the inethod of least squares for an exponential function the following formula was derived:

$$
F F=1.30 n^{-1.45}
$$

Boyce found that this formula had an error of \pm 15 percent. He stated that this rather large error could be caused by different types and percentages of electrical conductors, clay minerals, and pore textures. The large error suggests that 600 miles is too large an area to attempt to define with one formula. Kermabon et al. ${ }^{12}$ studied the electrical resistivity of deep sediments from 21 long cores taken in a 4 by 10 square mile area in the Tyrrhenian Sea. The porosity of these sediments ranged from 50 to 87 percent. By assuming the resistivity of the interstitial water was the same as the bottom sea water, Formation Factors were determined. More than 2500 measurements of porosity and Formation Factors were compared. A third degree polynomial curve was found to best fit their data relating porosity and Formation Factor

$$
n(\%)=-5.9021 F F^{3}+40.0416 F F^{2}-105.3889 F F+171.2504,(41)
$$

or,

$$
F F=\frac{1+0.7193\left(1-n^{1.4615}\right)}{n^{1.4615}}
$$



According to Kermabon et al. the above equation fit the data obtained with only a \pm 2.5 percent porosity prediction error. Smith ${ }^{13}$ studied electrical resistivity measurements of North Atlantic deep-sea cores and in situ resistivity measurements on the continental shelf around Wales, England. The resistivity of the interstitial water was either estimated from bottom water salinity or actual core water salinity measurements were taken in the laboratory. $\Lambda$ best fit straight line through 99 measurements resulted in the following equation:

$$
F F=1.35 n^{-1.2}
$$

Smith noted that the data clearly grouped into two classes: for silts and clays of porosities greater than 60 percent,

$$
F F=n^{-2}
$$

and for sands and coarse silts of porosities less than 60 percent

$$
\mathrm{FF}=\mathrm{n}^{-1 \cdot 5}
$$

He concluded that there was no need to use a polynomial formula of the type described by Kermabon et al., ${ }^{12}$ but that once a Formation Factor is measured an approximate value of porosity could be obtained from a general empirical equation, and that after selective sampling a better value for porosity could be obtained by a more refined equation.

Porosity versus Formation Factor equations are plotted in 

Figure 5 from Boyce, Kcrmabon et al., and Smith. Figure 6 shows Atkins and Smith's formulations using equation (32) for sodium montmorillonite $(m=3.28)$, illite $(m=2.11)$, kaolinite $(1.87)$ and sand $(m=1.60)$.

Pautot $^{26}$ was able to correlate several sedimentary layers by taking electrical resistivity measurements on sediment cores obtained some distance apart. He did this work both in a lake and in a marine environment. Although no formulation between electrical resistivity and sediment properties was given, the ability to match horizontal layers may indicate a similarity between physical and chemical properties with electrical properties of sediments. Bouma et al. ${ }^{27}$ and Chmelik et al. ${ }^{28}$ developed laboratory and in situ electrical resistivity equipment for marine sediments. Their objective was to make correlations on lithology and geotechnical properties. Although no formulations were given, they attempted to correlate electrical properties with the chenical, physical and engineering characteristics of sediments. Properties such as $\mathrm{pH}$, Eh, water content, density, carbonate content, grain size analysis, X-ray radiographs, photographs, cone penetrameter and vane shear measurements were compared with electrical resistivity measurements. Certain trends were apparent from their data. Electrical resistivity was indirectly proportional to the water content and percentage of clay size present.

Bal1 ${ }^{29}$ studied the literature in order to determine the feasibility of using electrical conductivity techniques for sediment porosity prediction. He concluded that the following points need 



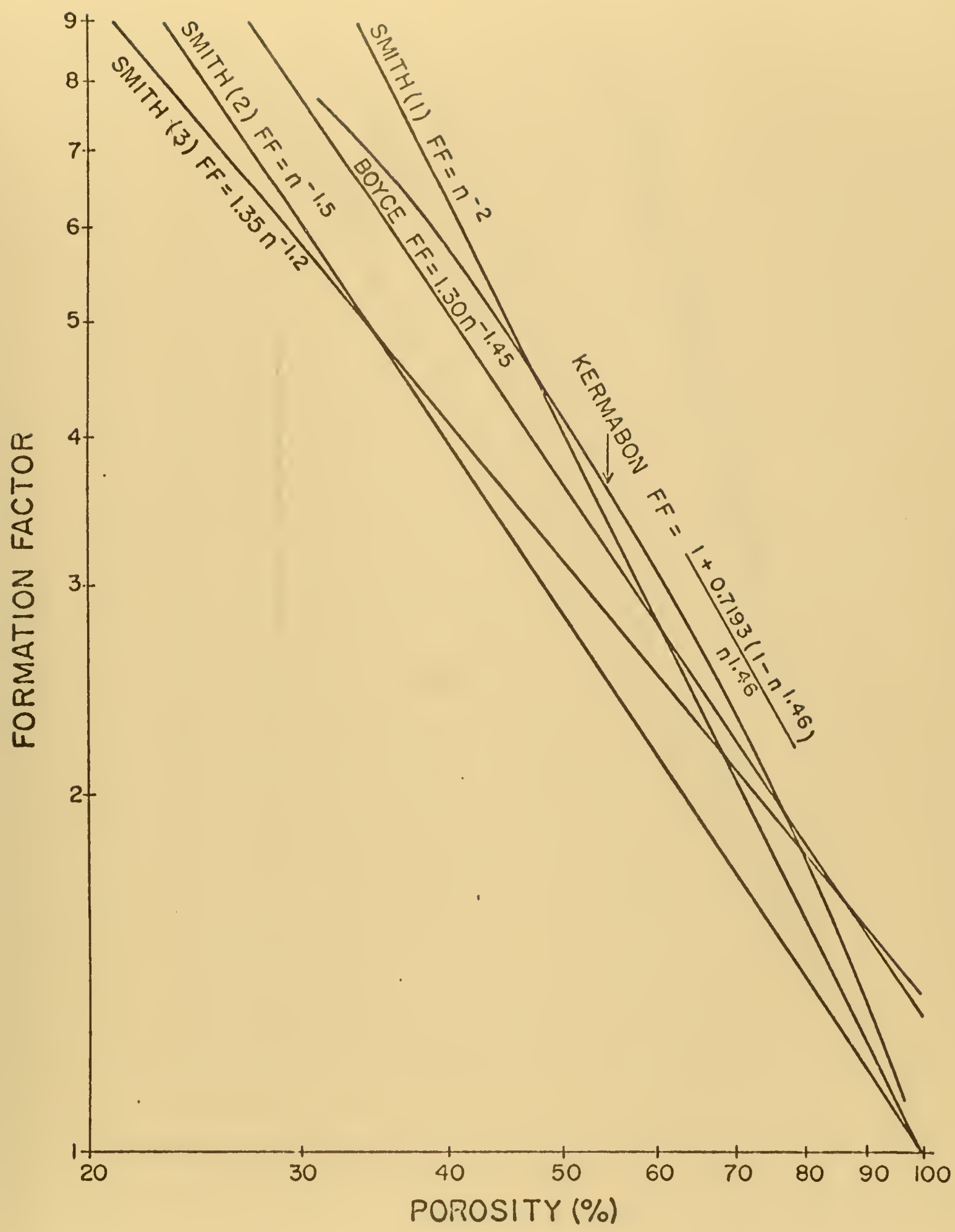

Figure 5. Formation Factor-Porosity Felationships Proposed hy Boyco, Kermalon, et. al., and Smith. 



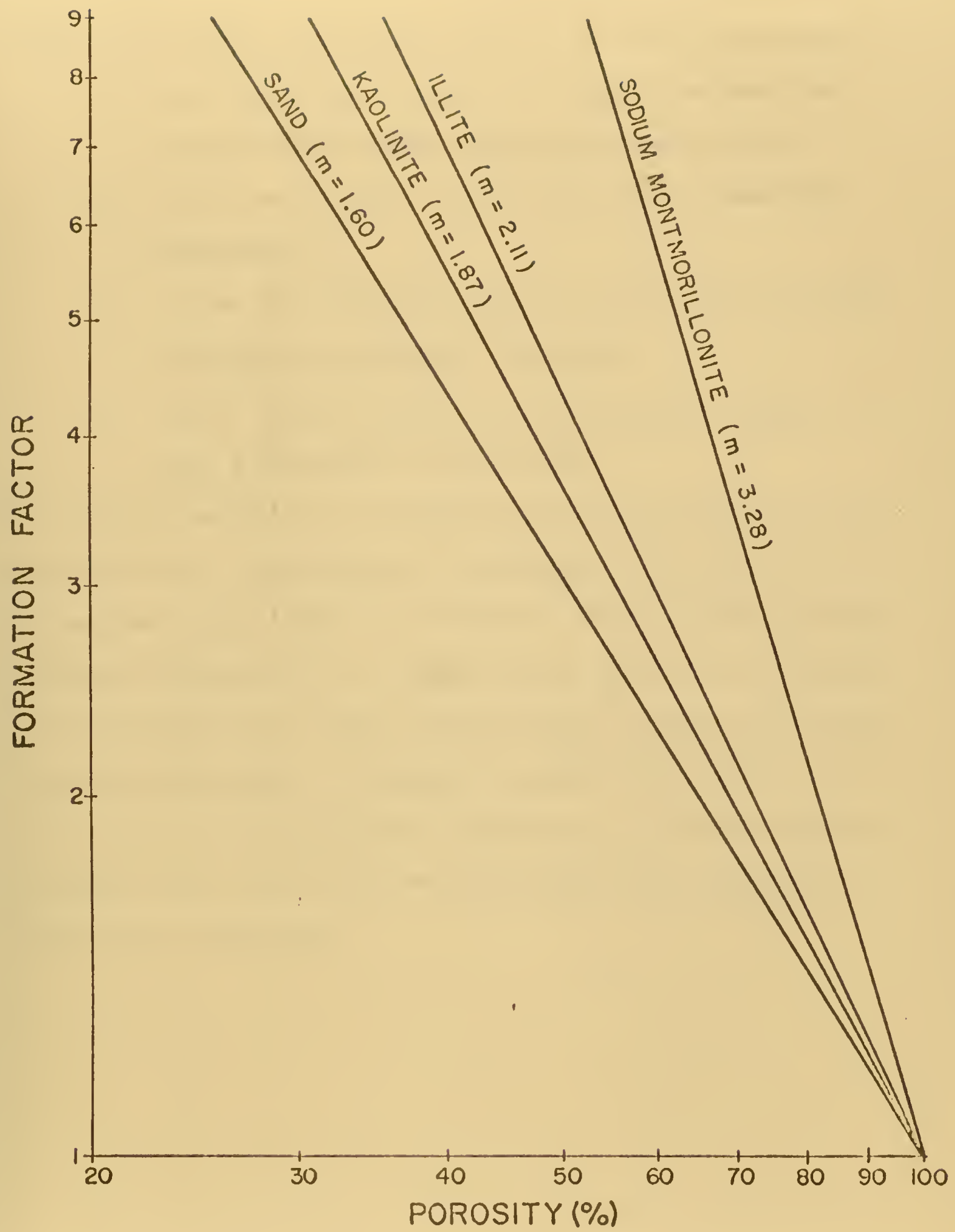

Figuro 6. Formation Factor-Porosity Relationships proposed by Atkins and Smith for sodium Montmorillonite, Illite, Kaolinite and Sand. 

further work both in the laboratory and in the marine environment.

1. What theoretical or empirical equation best describes the electrical conductivity-porosity relationship?

2. What is the effect of clay on electrical conductivity measurements?

3. How can the conductivity of interstitial water in marine sediments be conveniently determined?

4. What is the best method for restricting the volume over which a measurement would be made?

The first two questions are considered in this section of the paper, while the last two questions are investigated in the second section. The main motivation behind this literature review and the following laboratory experiments is to justify the use of electrical resistivity techniques as an in situ measuring method to predict porosity in a marine environment. Consequently sediment type, interstitial water salinity, and formulations applicable to the marine sediment environment were studied more extensively than those applicable to a fresh water environment. 



\section{EXPERIMENTAL PROCEDURE}

\section{Materials}

The following types of materials were obtained for testing:

i. Kaolinite clay (Albion Kaolin from Babcock and Wilcox Refractories Division),

2. Illite clay (Grundite from A. P. Green Refractories Company),

3. Montmorillonite clay (Black Hills Bentonite from International Minerals and Chemical Corporation).

4. Providence silt,

5. Ottawa sand (well-rounded grain shape),

6. Two types of glacial sands (angular grain shapes),

7. Four types of marine sediments.

One type of marine sediment was obtained by a Ewing gravity corer and the Deep Ocean Sediment Probe (DOSP) in April 1970 from shallow water near Ponce, Puerto Rico. The properties of this sediment were extensively investigated by Lewis. 30 The other three types of marine sediments were taken by an Electrical Resistivity Measuring System. These samples were taken during the Fall of 1971 from Narragansett Bay.

The properties of the marine sediments and the other laboratory materials are presented in Table 3. Co-ordinates of marine sediment cores measured in this investigation are given in Table 4. 

TABLE 3

MINERALOGY, CLASSIFICATION, GRAIN SIZE, SHAPE, SPECIFIC GRAVITY,

\begin{tabular}{|c|c|c|c|c|c|}
\hline \multirow[b]{2}{*}{ NAME OF SEDIMENT } & \multirow{2}{*}{ MINERALOGY ${ }^{1}$} & \multicolumn{3}{|c|}{ SEDIMENT CLASSIFICATION } & \multirow{2}{*}{$\begin{array}{l}\text { LIQUID } \\
\text { LIMIT }\end{array}$} \\
\hline & & $\%$ Sand & \% Silt & \% Clay & \\
\hline Kaolinite & $\begin{array}{l}\text { Kaolinite } \\
\text { Quartz }\end{array}$ & 2 & 68 & 30 & 37.4 \\
\hline Illite & $\begin{array}{l}\text { Illite } \\
\text { Quartz }\end{array}$ & 7 & 53 & 40 & 44.8 \\
\hline Montmorillonite & $\begin{array}{l}\text { Montmorillonite } \\
\text { K-Feldspar } \\
\text { Quartz }\end{array}$ & 10 & 12 & 78 & 135.0 \\
\hline Providence Silt & $\begin{array}{l}\text { Quartz } \\
\text { Plagioclase }\end{array}$ & 4 & 92 & 4 & 28.5 \\
\hline Ottawa Sand (a) & Quartz & 100 & - & - & - \\
\hline Ottawa Sand (b) & Quartz & 100 & - & - & - \\
\hline Glacial Sand $(1-a)$ & Quartz & 100 & - & - & - \\
\hline Glacial Sand $(1-b)$ & Quartz & 70 & 30 & - & - \\
\hline Glacial Sand (2) & Quartz & 98 & 2 & - & - \\
\hline $\begin{array}{l}\text { Puerto Rican } \\
\text { Sediment }\end{array}$ & $\begin{array}{l}\text { Aragonite } \\
\text { Calcite } \\
\text { Quartz } \\
\text { Plagioclase }\end{array}$ & $70-50$ & $18-24$ & $7-18$ & $\begin{array}{l}38.0 \\
\text { to } \\
72.2\end{array}$ \\
\hline $\begin{array}{l}\text { Narragansett Bay } \\
\text { (Station A) }\end{array}$ & $\begin{array}{l}\text { Quartz } \\
\text { K-Feldspar } \\
\text { Mica }\end{array}$ & $41-33$ & $57-51$ & $7-14$ & $\begin{array}{l}31.0 \\
\text { to } \\
36.0\end{array}$ \\
\hline $\begin{array}{l}\text { Narragansett Bay } \\
\text { (Station B) }\end{array}$ & $\begin{array}{l}\text { Quartz } \\
\text { K-Feluspar } \\
\text { Mica }\end{array}$ & $58-43$ & $34-53$ & $4-9$ & $\begin{array}{l}27.0 \\
\text { to } \\
28.1\end{array}$ \\
\hline $\begin{array}{l}\text { Narragansett Bay } \\
\text { (Station C) }\end{array}$ & Quartz & 97 & 3 & - & - \\
\hline
\end{tabular}

1. From X-ray Diffraction analysis (see Appendix C).

2. $\phi=-\log _{2}$ (diameter in millimeters), $\phi_{50}=$ diameter for which $50 \%$ of the sample is finer grained. 

LIQUID IIMIT, PLASTIC LIMIT, pH, AND ORGANIC CONTENT OF SEDIMENTS

\begin{tabular}{|c|c|c|c|c|c|c|}
\hline \multicolumn{2}{|c|}{ GRAIN SIZE } & \multirow[b]{2}{*}{ SHAPE $^{4}$} & \multirow[b]{2}{*}{$\begin{array}{l}\text { SPECIFIC } \\
\text { GRAVITY }\end{array}$} & \multirow[b]{2}{*}{$\begin{array}{l}\text { PLASTIC } \\
\text { LIMIT }\end{array}$} & \multirow[b]{2}{*}{$\mathrm{pH}$} & \multirow{2}{*}{$\begin{array}{c}\text { ORGANIC } \\
\text { CONTENT } \\
(\%)\end{array}$} \\
\hline$\phi_{50}^{2}$ & $6 \phi^{3}$ & & & & & \\
\hline 8.38 & 1.81 & platy & 2.60 & 26.3 & 4.1 & - \\
\hline 8.25 & 2.99 & platy & 2.79 & 26.5 & 2.0 & - \\
\hline - & - & platy & 2.73 & 54.1 & 7.2 & - \\
\hline 5.97 & 1.21 & $\left\{\begin{array}{c}\text { angu- } \\
\text { lar }\end{array}\right.$ & 2.75 & 23.0 & 5.6 & - \\
\hline .52 & .17 & $\begin{array}{l}\text { well- } \\
\text { rounded }\end{array}$ & 2.65 & - & - & - \\
\hline 1.26 & .30 & $\begin{array}{l}\text { well- } \\
\text { rounded }\end{array}$ & 2.65 & - & - & - \\
\hline 2.32 & .34 & $\begin{array}{l}\text { angu- } \\
\text { lar }\end{array}$ & 2.65 & - & - & - \\
\hline 3.47 & .50 & $\begin{array}{l}\text { angu- } \\
\text { lar }\end{array}$ & 2.65 & - & - & - \\
\hline 1.00 & 1.31 & $\begin{array}{l}\text { sub- } \\
\text { angular }\end{array}$ & 2.65 & - & - & - \\
\hline $\begin{array}{r}4.4 \\
\text { to } \\
6.2\end{array}$ & $\begin{array}{l}1.80 \\
\text { to } \\
4.40\end{array}$ & - & $\begin{array}{l}2.78 \\
\text { to } \\
2.86\end{array}$ & $\begin{array}{l}- \\
\text { to } \\
53.8\end{array}$ & $\begin{array}{r}7.3 \\
\text { to } \\
7.8\end{array}$ & 1 \\
\hline $\begin{array}{r}4.2 \\
\text { to } \\
4.9\end{array}$ & $\begin{array}{c}2.20 \\
\text { to } \\
2.70\end{array}$ & $\begin{array}{l}\text { mixed } \\
\text { platy } \\
\text { \& angu- } \\
\text { lar }\end{array}$ & 2.70 & $\begin{array}{c}27.0 \\
\text { to } \\
33.9\end{array}$ & $\begin{array}{r}4.5 \\
\text { to } \\
6.4\end{array}$ & $5-10$ \\
\hline $\begin{array}{r}3.3 \\
\text { to } \\
4.1\end{array}$ & $\begin{array}{l}1.90 \\
\text { to } \\
2.20\end{array}$ & $\begin{array}{l}\text { mixed } \\
\text { angular } \\
\text { \& platy }\end{array}$ & 2.70 & $\begin{array}{c}- \\
\text { to } \\
26.1\end{array}$ & $\begin{array}{r}6.2 \\
\text { to } \\
6.6\end{array}$ & $4-5$ \\
\hline 2.18 & 1.10 & angular & 2.65 & - & 7.3 & - \\
\hline
\end{tabular}

3. 6 (Dispersion measure) $=1 / 2\left(\phi_{84}-\phi_{16}\right)$

4. Obtained by electron microscope and conventional microscope. 



\section{TABLE 4}

LATITUDE AND LONGITUDE OF MARTNE SEDIMENTS

I. Puerto Rico Cruise, April 1970

$$
\begin{aligned}
& \text { 1. } 17^{\circ} 57.4^{\prime} \mathrm{N}-66^{\circ} 37.4^{\prime} \mathrm{w} \\
& \text { 2. } 17^{\circ} 57.2^{\prime} \mathrm{N}-66^{\circ} 27.7^{\prime} \mathrm{w} \\
& \text { 3. } 17^{\circ} 56.5^{\prime} \mathrm{N}-66^{\circ} 36.6^{\prime} \mathrm{W} \\
& \text { 4. } 17^{\circ} 56.2^{\prime} \mathrm{N}-66^{\circ} \mathrm{O}_{35.0^{\prime} \mathrm{W}} \\
& \text { 5. } 17^{\circ} 54.4^{\prime} \mathrm{N}-66^{\circ} 35.5^{\prime} \mathrm{W}
\end{aligned}
$$

II. Narragansett Bay, Fall 1971

$$
\begin{aligned}
& \text { station } \mathrm{A}-41^{\circ} 34.0^{\prime} \mathrm{N}-71^{\circ} 25.4^{\prime} \mathrm{W} \\
& \text { station } \mathrm{B}-41^{\circ} 29.5^{\prime} \mathrm{N}-71^{\circ} 24.7^{\prime} \mathrm{W} \\
& \text { station } \mathrm{C}-41^{\circ} 22.7^{\prime} \mathrm{N}-71^{\circ} 30.6^{\prime} \mathrm{W}
\end{aligned}
$$



The details of the tests used to obtain these properties are given in Appendix C. These include X-ray analysis, grain size analysis, hydrometer, specific gravity, liquid and plastic linit determination, $\mathrm{pH}$, and organic content.

The illite clay, kaolinite clay and Providence silt were made as nearly homoionic to sodium ion as possible by washing batches of clay in concentrated ( $1 N$ ) solutions of sodium chloride. The excess salt was then removed by leaching clays and silt with distilled water and the conductivity of the solution was checked after each dilution by means of a Beckman Conductivity Bridge (Model RC-16B2). When the solution conductivity was that of normal tap water, the clays and silt were subsequently dried in an oven at $105^{\circ} \mathrm{C}$, lightly pulverized, and stored in sealed jars. This preparation of samples was not conducted on Black-Hills Bentonite since it is a sodium montmorillonite clay and therefore is already homoionic to the sodium ion. The sands were sleved to insure proper grain size and then washed in tap water to remove as much ionic contamination as possible. The sands were then dried and stored.

\section{Laboratory Apparatus}

The laboratory testing apparatus was developed in the following stages:

1. a simple apparatus to determine the feasibility of the me thod.

2. a modified design to obtain variation of key parameters.

3. redesigned equipment to facilitate testing and allow an increased number of tests. 


\section{Simple apparatus}

The first resistivity cell was constructed from a seven inch length of ackylic tubing (I.D. 1.38 in., O.D. 1.75 in.) (see Figure 7). The aluminum top and bottom electrodes were machined down to fit the inner diameter of the tubing with 0-ring seals to allow for a tight seal. A small hole was drilled in the top electrode to provide an escape for excess water while the cell was being closed. The four side platinum electrodes were installed (see Figure 8) by drilling circumaxially two small holes, $1 / 8$ inch apart, and looping 0.025 in. platinum wire through the holes, thus providing four approximate point electrodes spaced $3 / 4$ inch apart vertically along the interior of the cell wall. The holes were then made air tight by using a GACO sealant. The platinum wire was then soldered to a standard copper wire in order to connect the cell to the instruments. For testing actual marine sediments the top and bottom electrodes were redesigned in order to allow sediment samples of various lengths to be used in the cell. (See Figure 9).

Another simple testing apparatus (see Figure 10) was made by placing top and bottom current electrodes on a marine sediment sample located in the original core liner used to obtain and store the sample. Top and bottom electrodes were machined to the same diameter as the core liner. A hole (3/16 in. in diameter) was drilled along the perimeter of the top electrode. This hole allowed an insulated $1 / 8$ inch diameter stainless steel tube to pass vertically through the top electrode into the sediment. Located at the end of the stainless steel tubing were two vertically separated, platinum potential 



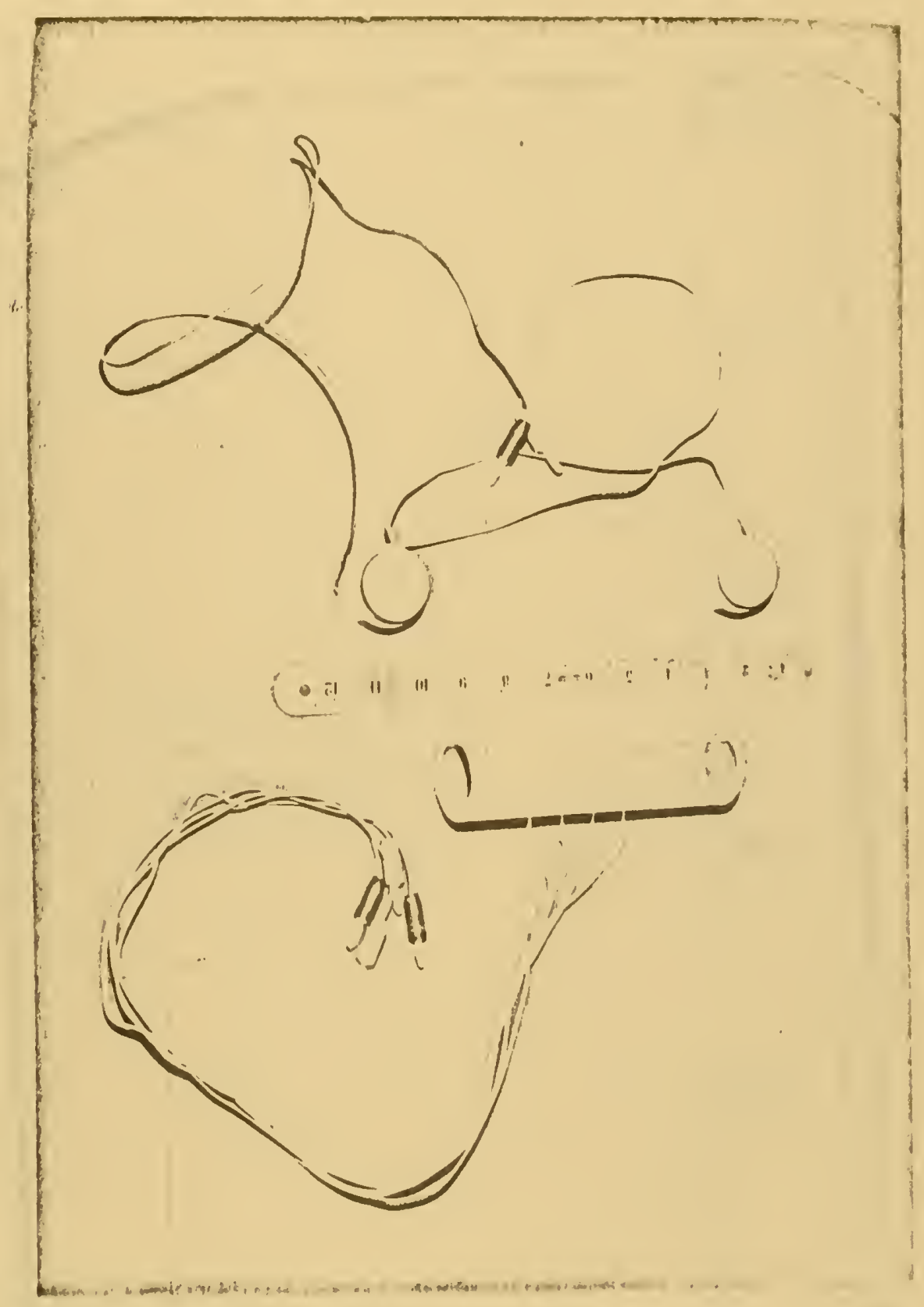

Figure 7. The simple Cell Apparatus. 



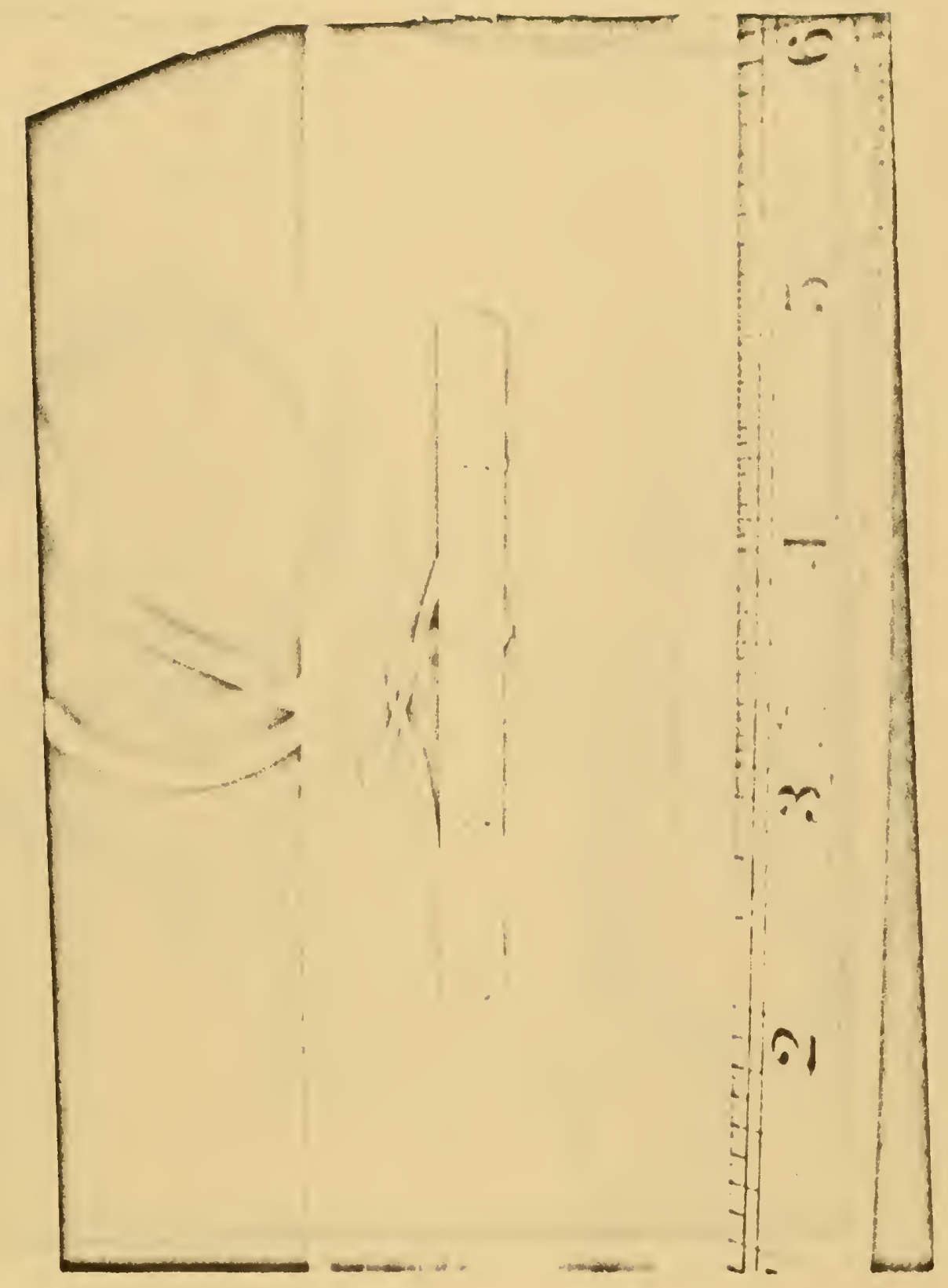

Figure 8. The Four side Platinum Electrodes of the simple Cell npparatus. 



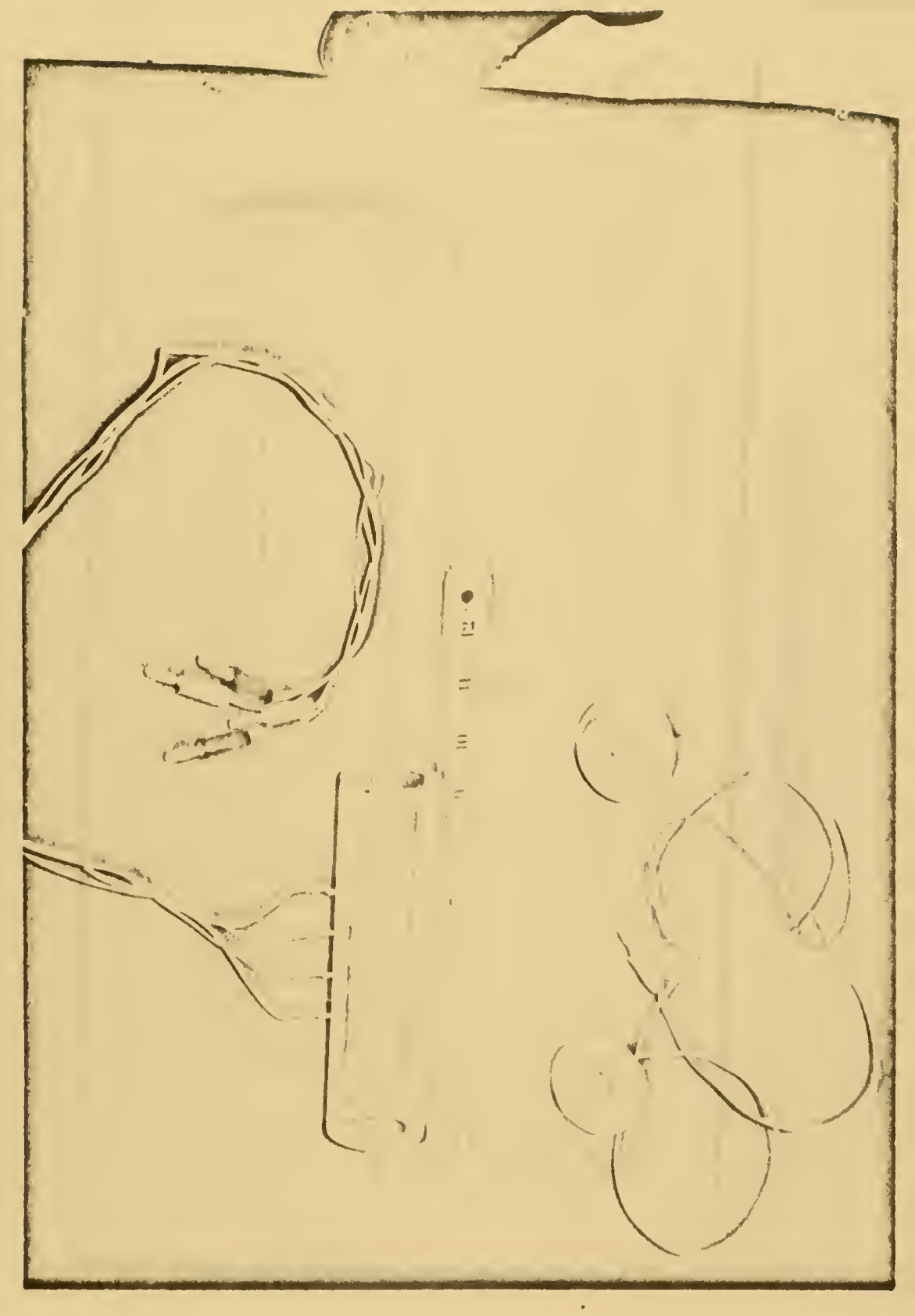

Figure 9. Simple Cell Apparatus Used to Test Samples of Various Lengths. 



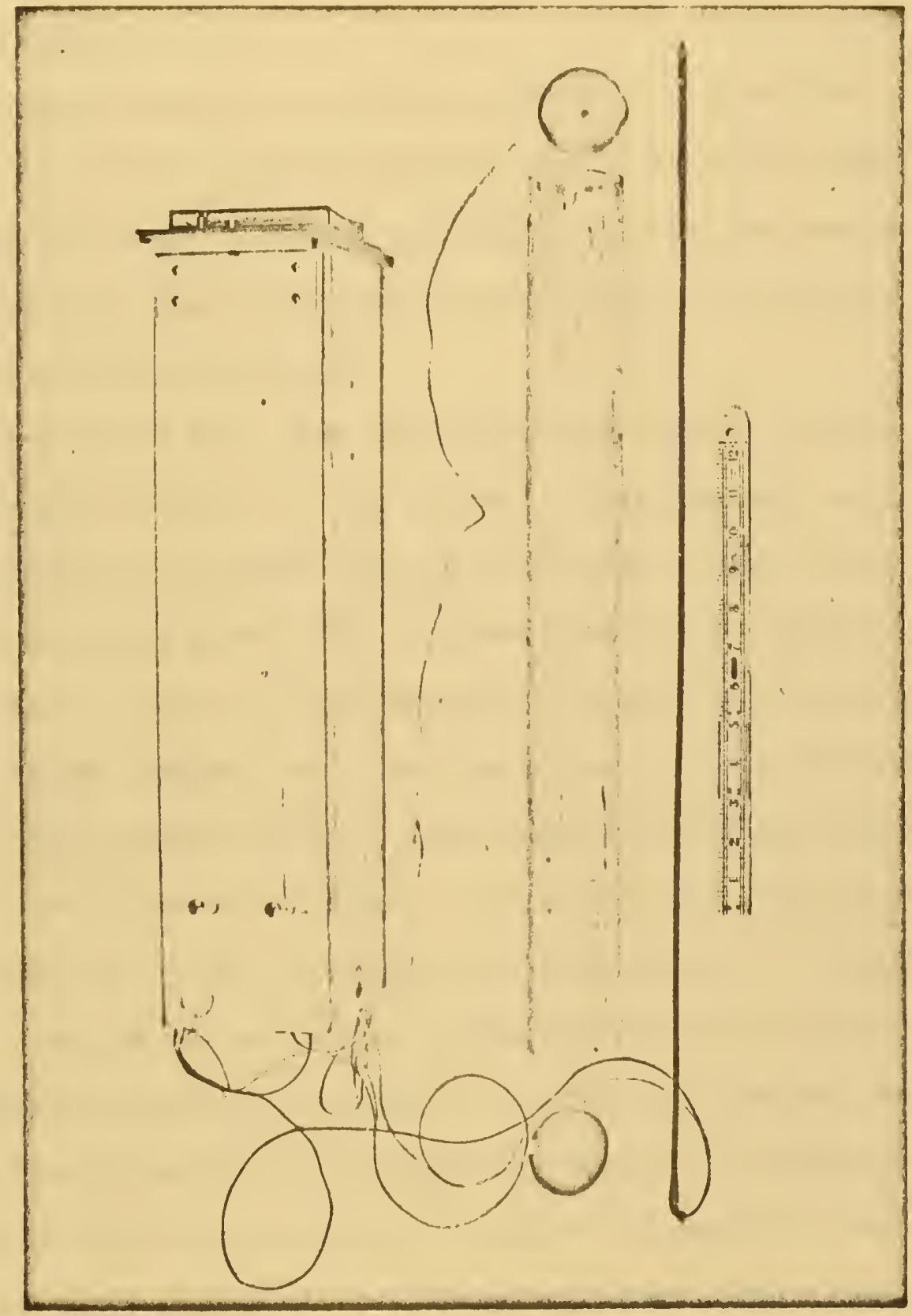

Figure 10. Testing Apparatus and Electronic Equipment Used to Test Marine sediments in the Laboratory. 

electrodes. The wiring from the platinum potential electrodes passed through the tubing to the instrumentation.

\section{Modified apparatus}

A modified design was required in order to test various porosities of the fine grained sediments such as silts and clays. This design also made it possible to see if consolidation pressure altered electrical resistivity measurements to such an extent as to mislead the porosity prediction.

Sedimentation tubes were fabricated with a piston loading rod which applied pressure to the sediment. This pressure could be applied incremently by adding weights to the loading rod. Each tube was constructed from a nine inch length of acrylic tubing $\left(I . D_{0}=1.42 \mathrm{in.}, \mathrm{O}_{0} \mathrm{D}_{0}=1.75 \mathrm{in}.\right)$. The tubes were bored to insure a concentric inner diameter, and allow the piston head and rod assembly to slide freely inside the tube. Small holes were drilled into the piston head to allow fluid drainage. The piston head was made of the same material as the tubes to prevent any binding due to temperature changes. A bottom cap of the same design and dimensions as the piston head was placed.in the bottom of the tubes to prevent sediment loss from the bottom when the pressure was applied. In addition micro-pore filters were used above the bottom cap and below the piston head to prevent the sediment from oozing out of the fluid drainage holes. A PVC (poly-vinyl-chloride) plastic piston rod was screwed into the piston head and supported a PVC loading plate. Five side platinum electrodes were installed in the same manner described for the first cell. Ribbon wire was used to connect the four cells to 
the instrumentation (see Figures 11 and 12). By connecting individual cells and by using a simple switching device, different electrode combinations could be used. The four cells conveniently fit into a beaker chamber and were held upright by a plastic support frame. Four of these chambers were fabricated at the URI Engineering Instrument Shop. Details of the design are given in Appendix B.

The electronic equipment (see Figure 13) used with the simple apparatus and modifled apparatus was obtained from New London Laboratory Naval Underwater Systems Center, New London, Connecticut. The $1 \mathrm{ma}, 1000 \mathrm{~Hz}$ signal sent to the current electrodes was supplied by a constant current generator and power supply. The voltage difference obtained from the potential electrodes was sent to an AC/DC converter. The potential difference between electrodes was measured from a digital frequency counter and the same signal monitored on an oscilloscope. The electronic instrumentation was calibrated and the accuracy of the system was determined to be within \pm 1 percent.

\section{Redesigned apparatus}

The laboratory apparatus was redesigned in order to reduce the time required to consolidate the fine grained sediments. A modified version of a pressure vessel designed and fabricated by Maus ${ }^{31}$ was incorporated. The pressure vessel was constructed from a $3 \frac{1}{2}$ inch length of aluminum pipe which was capped on both ends with cast iron pipe caps. The air pressure is regulated and enters the vessel through a top fitting. The porous disc sits on the bottom end cap. This cnd cap also acts as a reservoir for interstitial water draining out of the sediment when the pressure is applied. Pressures up to $19 \mathrm{psig}$ 



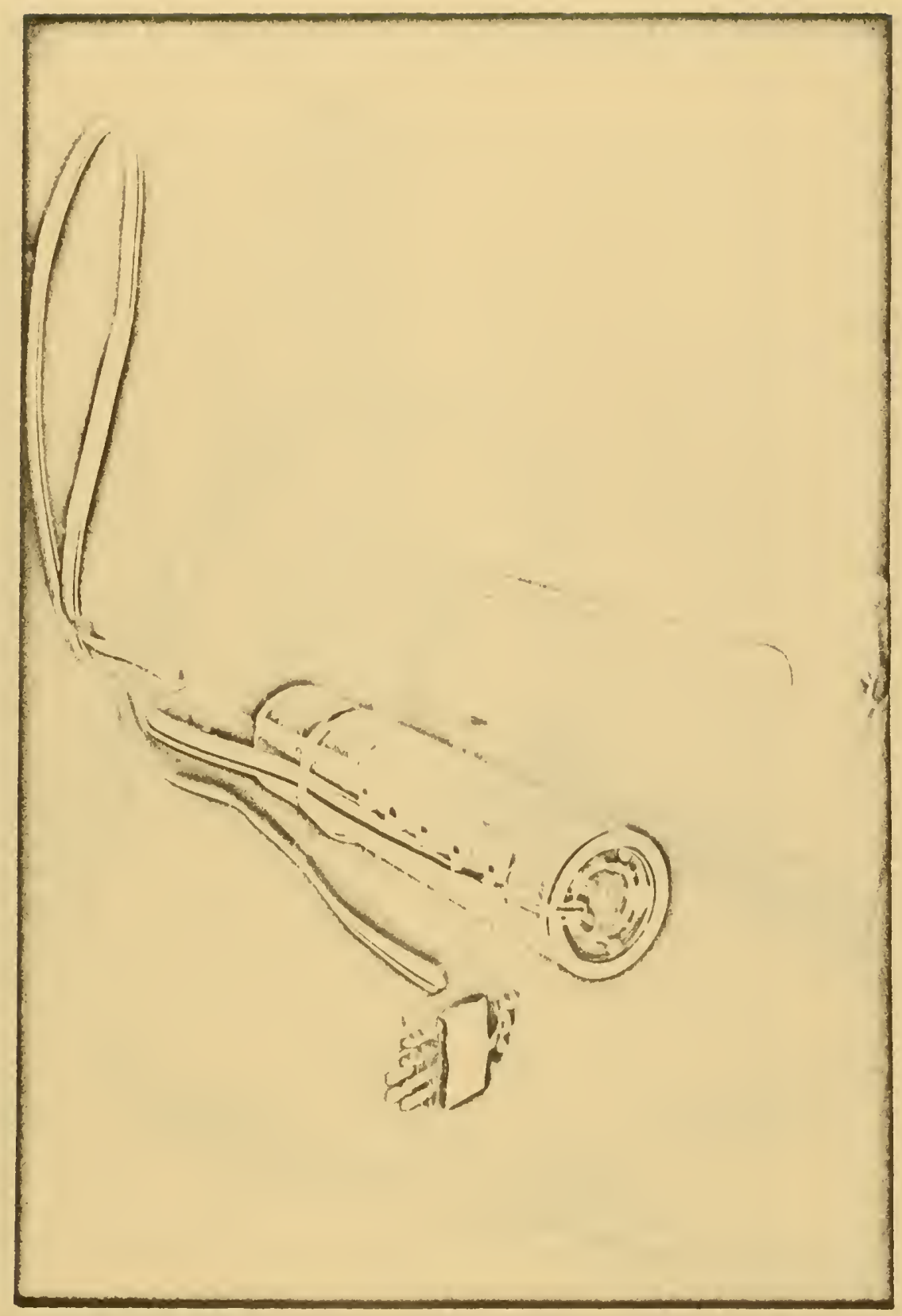

Figure 11. One Cell of the Modified Test Apparatus. 



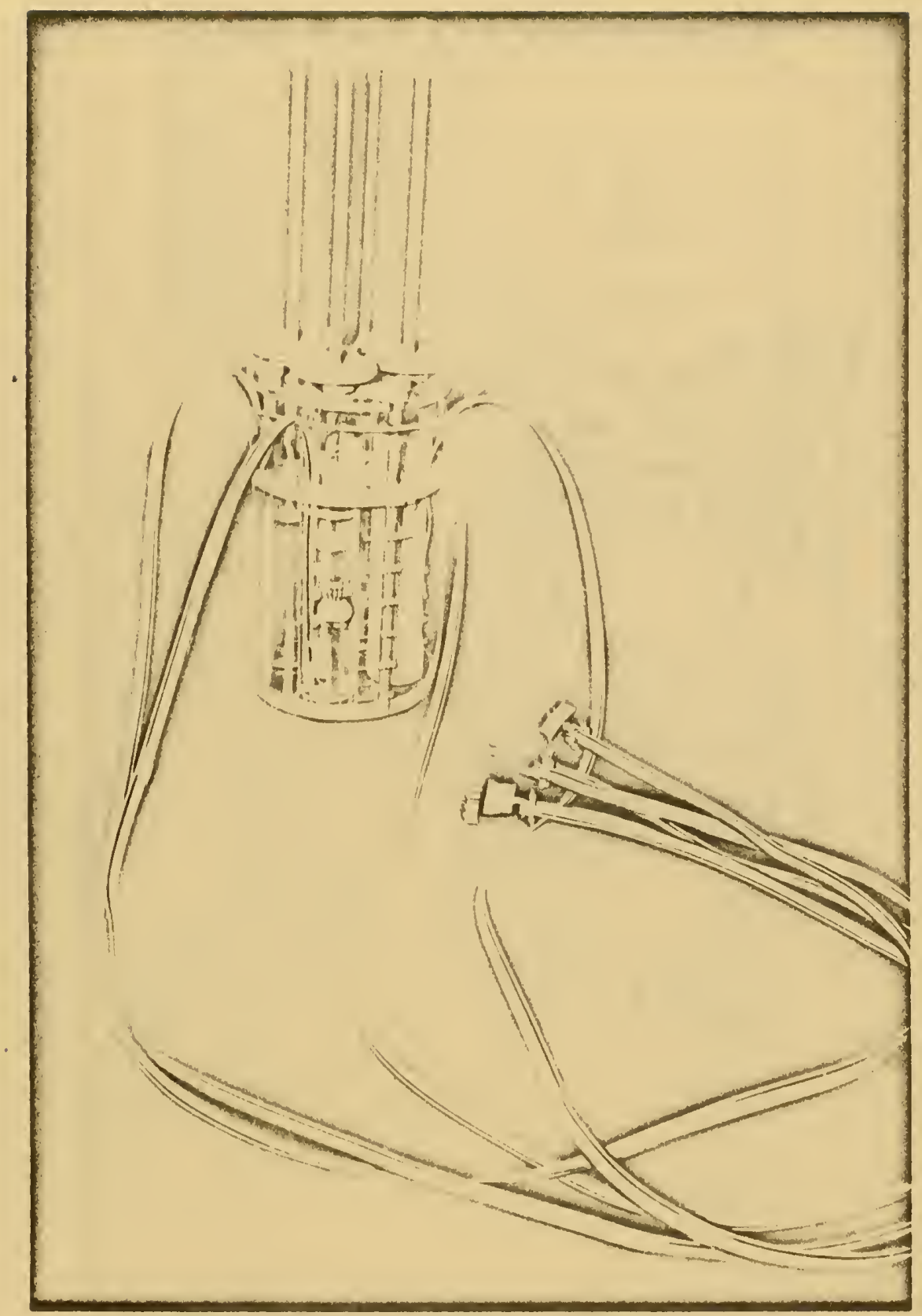

Figure 12. One Chamber of the Modjified Test Apparatus. 



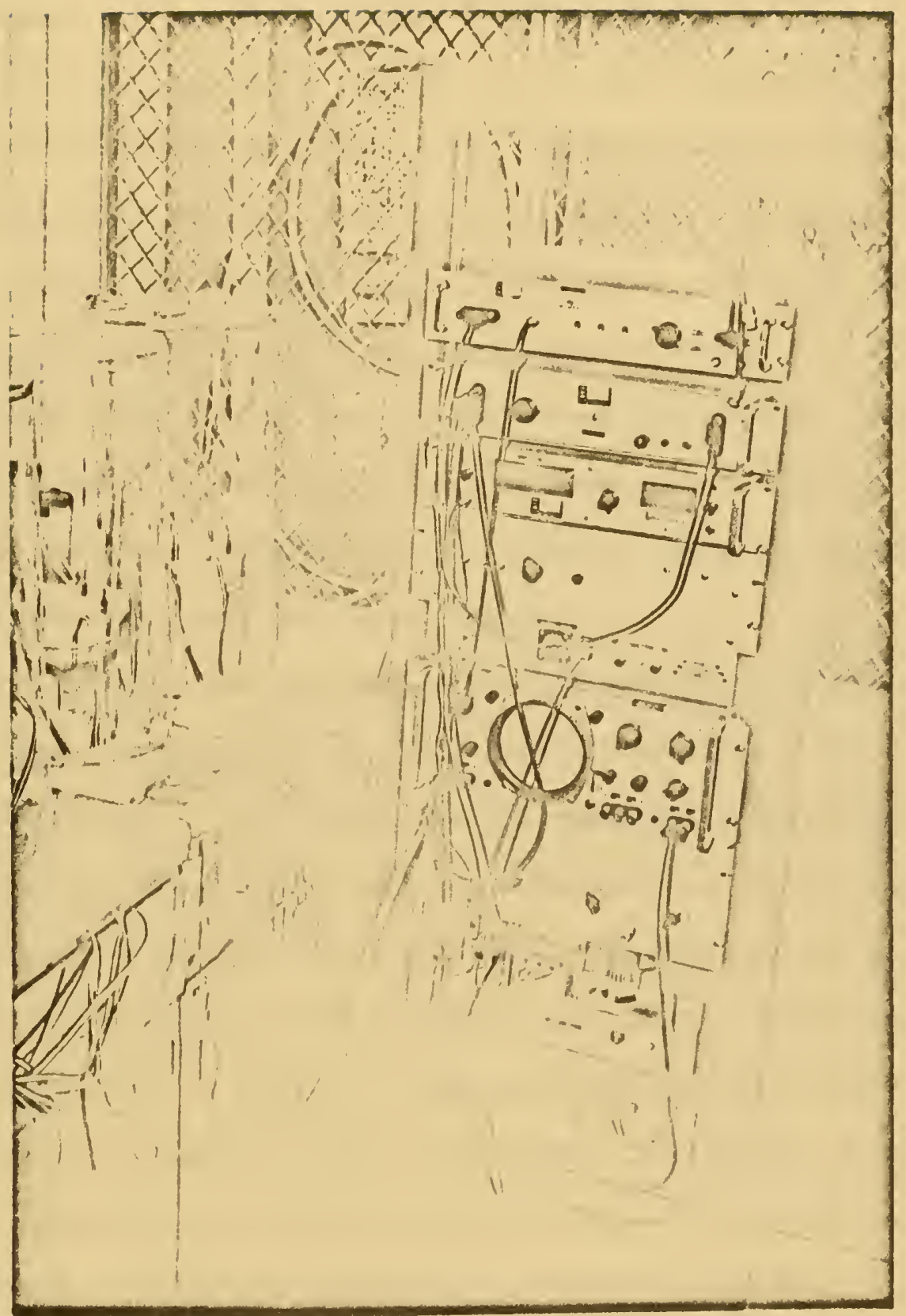

Figure 13. Electronic Equipment Used with the Simple and Modified Testing Apparatus. 

can be applied without bubbling air through the porous disc. The cell was constructed of thin walled plastic tubing (I.D. $=1.38$ in., 0.D. = 1.50in.) and 5.5 inches long. Four platinum wire (dia. $=0.025$ in.) electrode rings were cemented in grooved indentations on the inside tube wall with epoxy. The vertical separation between rings was $0.375 \mathrm{in}$. The cell was cemented to the porous disc with epoxy. The platinum ring electrodes and thermistor (used to measure temperature changes) were connected to wiring that fed through an air tight seal located at the top of the pressure vessel. This wiring connected the cell to the instrumentation. Figure 14 illustrates the cell, pressure vessel, regulator and gauge asscmbly. Appendix B contains other details. of design.

New electronic instrumentation allowed continuous electrical conductivity measurements during the consolidation process and recorded the results. This electronic instrumentation consisted of: (1) conductivity signal conditioner, (2) impedance matching amplifier, and (3) slow speed single channel recorder. The conductivity signal conditioner was manufactured by Honeywell Inc. (Model description 552022-1002-100-DOO) as part of a water quality measuring system (see Figure 10). Since the signal conditioner is basically a solid state null balancing A.C. amplifier only the sensor (electrodes) had to be modified to allow this system to be used on sediments. The signal conditioner supplies a $60 \mathrm{~Hz} 0.6 \mathrm{ma}$ current to drive the sensor array, and compares the resultant output of the sensor voltage electrodes with a stable reference voltage. A differential voltage is used to regulate the drive current and it produces an output linearly 



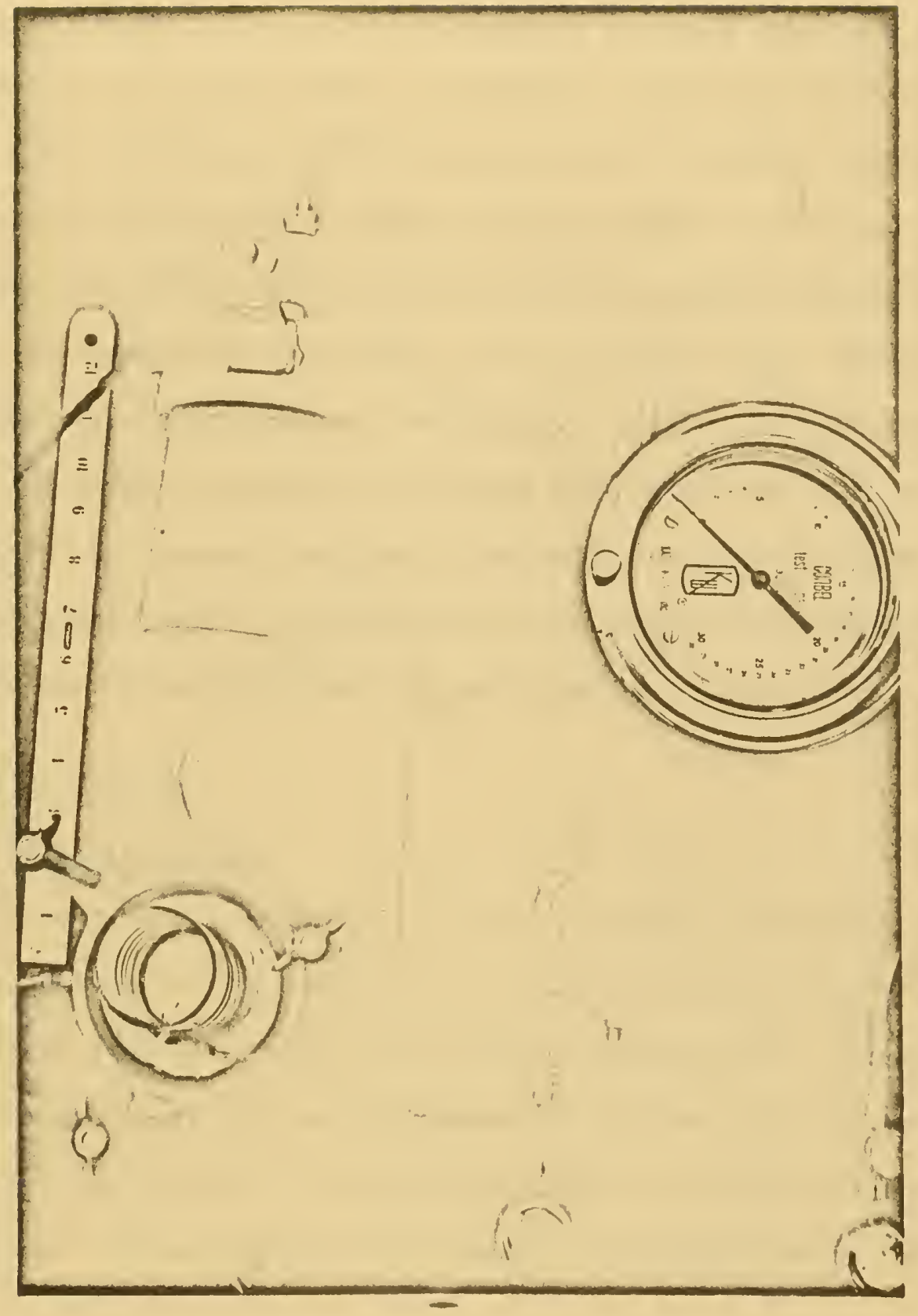

Figure 14. Cel.1, Pressure Vessels, Regulator and Guage Assembly Used, with the Redesigned Equipment. 

proportional to the conductivity of the measured medium. This output voltage can be read on the signal conditioner panel meter, a digital voltmeter, or sent to an impedance matching amplifier and then to a chart recorder where a continuous record can be maintained. Since sediment conductivity varies with operating temperature, compensation is required to refer the measurement to standard conditions (usually $25^{\circ} \mathrm{C}$ ). The thermistor, located inside the pressure vessel and attached to the plastic cell, directly alters sensor current, thereby compensating for temperature changes during testing.

According to Honeywell operating specifications, the calibrated accuracy of the signal conditioner and sensor is \pm 0.50 percent for the full scale range. Calibration curves, schematic diagrams and detailed operating principles are presented in Appendix B.

\section{Methods of Testing}

\section{Simple apparatus}

In the simple apparatus first described, an electrical current was allowed to flow between the top and bottom electrodes of the resistivity test cell, and a flow pattern developed that was analogous to Darcy's Law for one dimensional fluid flow. In this study when a voltage potential was measured between two platinum potential electrodes, the resistivity of the sample was calculated as follows:

$$
r_{m}=\frac{A \Delta E}{a I}=K \frac{\Delta E}{I}
$$

where: 



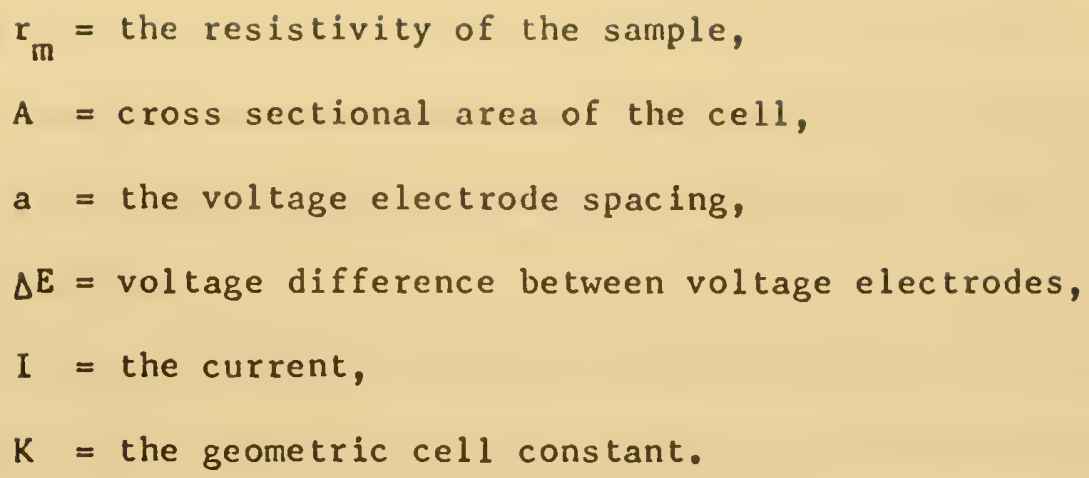

If the current was allowed to flow between the top and bottom platinum electrodes, a different flow pattern developed. The second part of Equation 46 is still applicable if the voltage potential is measured between the two inner platinum electrodes. The geonetric cell constant (K) can no longer be determined simply by dividing the cross sectional area by the distance between potential electrodes but is usually determined empirically by using solutions of known resistivities.

The cell constant was determined by making measurements with the cell filled with standard solution of sodium or potassium chloride, for which the resistivity may be found in chemical tables. In this study, cell constants for all the geometrical electrode configurations were obtained using $0.01 \mathrm{~N} \mathrm{KCl}, 0.1 \mathrm{~N} \mathrm{NaCl}, 0.5 \mathrm{~N} \mathrm{NaCl}$, and $1 \mathrm{~N} \mathrm{NaCl}$ solutions. All cell constants of simple geometric configuration were cornpared with measured values and less than 1 percent deviations were encountered between the two values.

Since variation of interstitial water was desired in the laboratory both to simulate ocean as well as estuary conditions and to observe the effect solution concentration has on the electrical resistivity of the sediment, sodium chloride solutions of $3.5,7.0,17.5$ 

and 35.0 parts per thousand were used in the early stages of testing. In later testing standard sodium chloride solutions of $0.1,0.2,0.3$, 0.5 and 0.6 normality were used as the interstitial fluid of the sediment matrix.

In early laboratory testing using the simple cell the electrical resistivity of sands was tested using the following procedure:

The interstitial salt solution was first poured into the cell and the sand was added slowly. The sand settled out rapidly in a loose packed configuration. The temperature and length of the sandwater system was recorded and the top electrode of the cell was then secured. The resistance measurements were taken using at least three separate configurations of electrodes. Ten measurements of each configuration were taken and the average value was multiplied by its appropriate geometric cell constant to give the sediment resistivity. Electrode configuration resistivity measurements were compared with each other and if variations greater than 3 percent existed, the test was re-run. On completion of the first series of tests the cell was tapped approximately twenty times and the sand densified into a closely packed configuration. Sediment resistivity measurements were again taken and the length of the sand-water system was recorded. On completion of these tests, the top electrode was removed and the temperature again recorded. Temperature variations were seldom more than a degree Centigrade, since the sand and solution were usually at room temperature prior to mixing. The sand matrix was then dried at $105^{\circ} \mathrm{C}$ for 24 hours and the weight of sand was obtained for porosity measurements. 

Clays and silt were tested in a similar manner in the simple cell apparatus, with the exception that the clays and silt were allowed to equilibrate 24 hours in the respective salt solution under a partial vacuum to remove entrapped air. Slurries were then added to the cell and allowed to settle under a partial vacuum in order to avoid formation of air bubbles. The settling period varied depending on the individual sediment. Approximately six or seven slurry replenishments with total time periods of 24 to 36 hours for settling were required to make a cell ready for testing. Due to the long settling periods the clay measurements were only made for $7.0,17.5$ and 35.0 parts per thousand sodium chloride solution. In addition densification of the highly porous clays and silt were not performed since tapping the cell caused the resuspension of the sediment. The procedure previously explained for sand samples was used to measure electrical resistivity and porosity of clays and silt. The total time to run sand tests was approximately twenty minutes. Although the actual testing time for clays and silt was ten minutes, a test cell was occupied for an average period of 24 hours due to the long settling periods.

A natural marine sediment was studied in the early stages of this investigation in order to (a) determine a sediment resistivity profile versus porosity and water content, (b) determine the Formation Factor by measuring or estimating the resistivity of interstitial water, and (c) gain experience for more extensive future testing. As previously mentioned, the first marine sediment was obtained by both a gravity corer and the DOSP. Certain sections of these cores had 

previously been segmented into four inch sections for storage. Sixteen of these short segmented sections were tested in the acrylic resistivity cell. $13 / 8$ inch diameter samples were taken. The electro-osmosis sample cutter was used in order to reduce sample disturbance and core shortening. The samples were transferred to a plastic tube of the same dimensions and sealed with rubber stoppers. This tube was then placed in a constant temperature bath $\left(25^{\circ} \mathrm{C}\right)$ for 24 hours prior to testing.

In order to determine water content a sample was taken from the excess sediment. Approximately the same amount of sample was placed in a test tube and diluted with $100 \mathrm{ml}$ of distilled water. The tube was sealed and the mixture was shaken vigorously. After the slurry in the tube settled, a conductivity measurement of the solution was taken using the Beckman conductivity meter. If it is assumed that the number of ions in solution remained constant and conductivity changes are linear for small dilution changes, it is possible to approximate the original conductivity of the interstitial water. In addition, when a small quantity of interstitial water was avallable, an American Optical Corp. salinity $\mathrm{T} / \mathrm{C}$ refractometer (Model 10402) was used to measure salinity. This permitted the determination of the resistivity of the interstitial water.

After 24 hours the marine sediment sample was removed from the temperature bath and placed in the testing cell. Three resistivity measurements were taken for each sample. These measurements corresponded to a segment of the sample which was dissected upon removal of the sample froin the testing cell. The individual porosity 
was then obtained for each sample.

Those marine samples not dissected into small segments were analyzed directly in their original plastic corer liner. The stainless steel tube containing the potential electrodes was guided through the hole on the top current electrode and vertically pushed down through a core sample. Electrical resistivity versus depth for the entire length of the core was obtained. Since the tubing passes along the plastic corer liner interior wall, negligible sample disturbance resulted in the central area of the core samples. This allowed electrical resistivity measurements to be obtained without destroying the sediment sample for other engineering soil tests.

\section{Modified apparatus}

The procedure used to test the effect of consolidation pressure on clays and silts with the modified apparatus was as follows: A layer of Ottawa sand was placed in the four liter beaker chamber. This layer allowed the load applied by the loaded cells to be equally distributed over the base of the beaker. The support frame containing the four cells was placed on the layer of sand. A micropore filter was placed in the bottom of each cell. The chamber was then filled with a solution of known normality. A slurry was prepared in the manner previously described, with a solution of the same normality as the chamber solution. Approximately $50 \mathrm{ml}$ of the slurry was introduced to the cells. After the slurry settled, a new charge was added. This process was continued until all four cells in the chamber were filled. A micro-pore filter was placed on top of the sediment in each cell and the piston and loading rod was 

placed on the sediment giving an initial pressure of about $0.01 \mathrm{~kg} / \mathrm{cm}^{2}$.

The initial vertical length between the loading plate and the support frame was measured. The weight of the loading plate decreased the length. After two or three days the movement stopped. The change in the length indicated sediment consolidation. The load was then doubled and the procedure repeated. The loads used resulted in pressures of $0.018,0.036,0.073,0.110,0.146,0.292$, $0.366,0.438$ and $0.511 \mathrm{~kg} / \mathrm{cm}^{2}$. Electrical resistivity measurements and changes in lengths were taken daily.

Four to six weeks were required to complete a chamber test. During this time period the test apparatus was placed under a clear plastic hood in order to prevent evaporation which would change the salinity of the chamber water (see Figure 13). A foam rubber mat, saturated with water, was placed under the test chamber. A humidity dial was placed inside the hood. A thermometer was located in the beaker chamber in order to allow temperature corrections to be made. At the end of the tests the cells were lifted from the chamber and the sediment height in each cell was recorded. $\Lambda 11$ of the sediment was then extruded from the cell cylinder and analyzed for solid soil weight, water content and porosity.

\section{Redesigned apparatus}

For the redesigned equipment a calibration curve was obtained by filling the cell with standard solutions of sodium chloride of known conductivity and measuring the signal conditioner output voltage. Sodium chloride of solutions of $0.1,0.15,0.2,0.5$ and 0.6 

normality were used to obtain calibration curves. Flow patterns, cell constants and calibration curves are given in Appendix B. The method used to test clays, silt and marine sediments in the redesigned test apparatus was as follows: a slurry was prepared in the manner previously described. Water from the slurry was extracted and placed in the cell to determine an interstitial water conductivity. The water was removed from the cell, the slurry was poured into the cell and 1 ts height was recorded. The slurry was analyzed for water content. The vessel was then assembled and pressure was applied. All sediments were tested at four different pressures: $0.25,1.00,4.00$, and 16.00 psi. Each pressurized test ran approximately 12 hours or until consolidation at the pressure tested had ceased. The pressure vessel was disassembled. The sample height and the volume of water in the bottom reservoir was measured. The sample was extruded and analyzed for water content and porosity. The electrical conductivity of the sediment sample was continuously recorded during the entire test period. Sample calculations for porosity and water content are presented in Appendix C. 



\section{RESULTS AND DISCUSSION}

The conductivity of kaolinite clay, illite clay, Providence silt, Ottawa sand (a) and angular glacial sand (1-a) were plotted against the conductivity of the interstitial water (see Figure 15). The results from Kermabon et al. ${ }^{12}$ for a clay having a porosity of 50 percent is also presented in this figure. For each of the sediments a linear relation was plotted by the method of least squares. The slope of these lines is FF, the Fornation Factor. The porosity for each sediment is given on Figure 15. The variation of porosity for each type of sediment was within \pm 2 percent, and this is probably the cause of deviation from the least square line in the larger grained sediments. In the clays this deviation could also be influenced by the cation exchange capacity. The effect that ions on the clay surface have on the Formation Factor is illustrated by the results presented in Figure 16. In this figure the Formation Factor for the three clays used in laboratory experiments (kaolinite, illite, and montmorillonite) were plotted against increasing interstitial water conductivity. Though porosity was held constant the curves show that the Formation Factors of sodium montmorillonite and 111 ite clays increased with increasing interstitial water conductivity from 1.1 to 3.0 mho/meter. From this point on the Formation Factor became relatively constant. This result differs from the result found by Atkins and Smith; in their work the cation exchange capacity of 


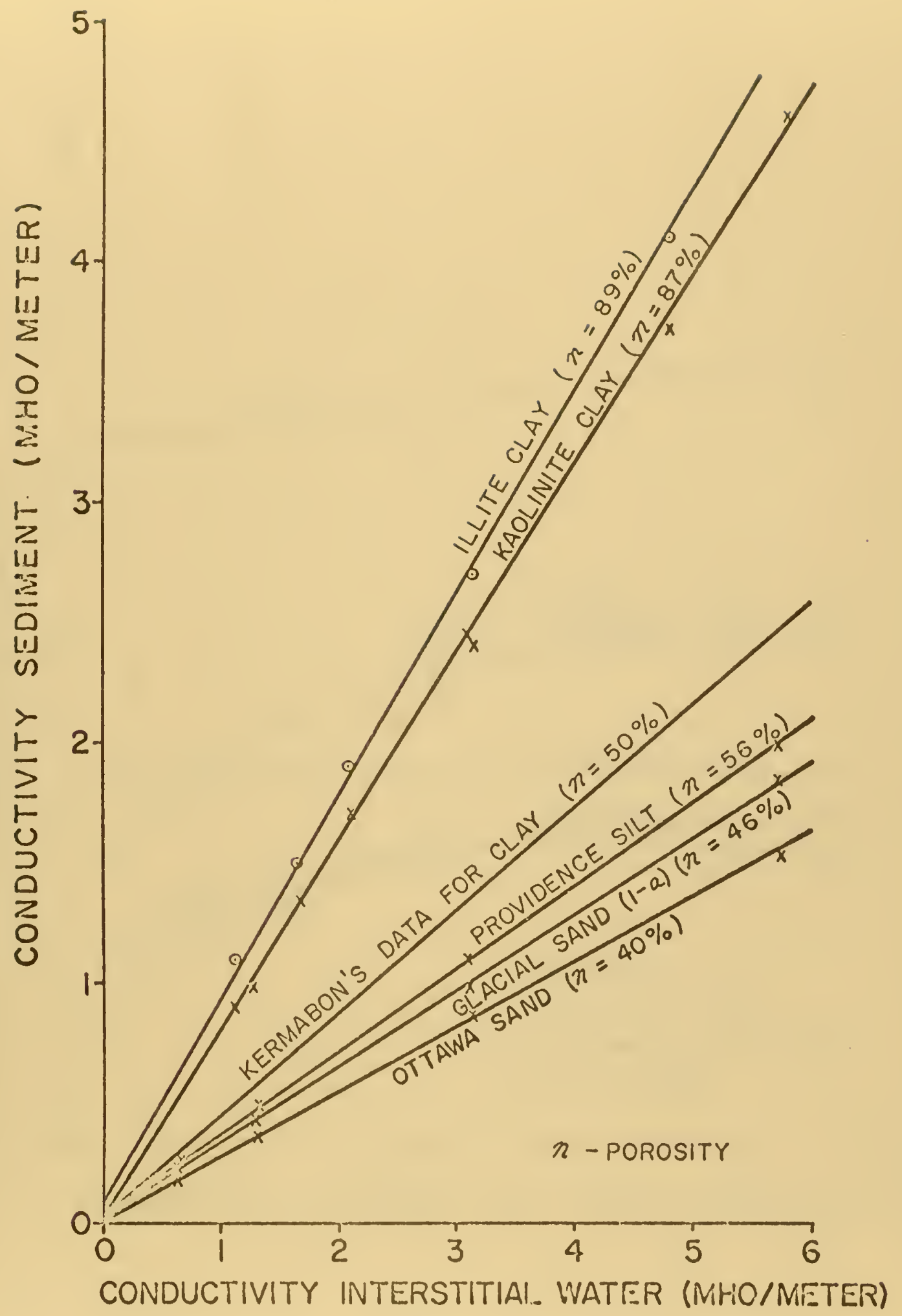

Figure 15. Elcctrical Conductivity of the sediment Versus the Conductivity of the Interstitial water for rllitc clay, Kalinite clay, Providence silt, Ottawa sand, and Glacial sand. 



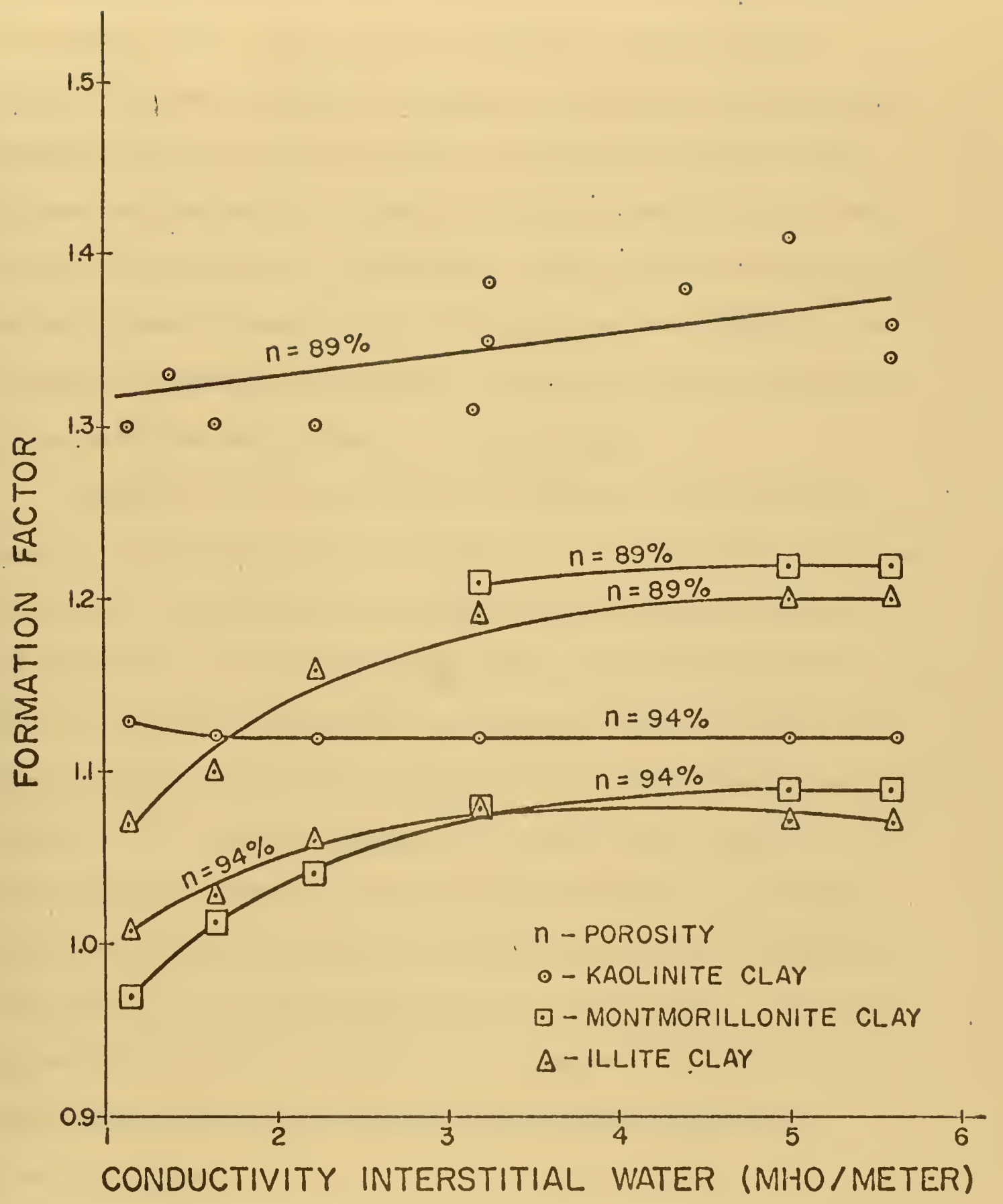

Figure 16. Formation Factor versus the Conductivity of the Interstitial water for Kaolinite, Illite and Montmorillonite clay. 

sodium montmorillonite was of no influence on resistivity at an interstitial water salinity of $1.1 \mathrm{mho} / \mathrm{meter}$. Although the kaolinite clay data presented in Figure 16 had more scatter, it is apparent that the Formation Factor for this clay remained fairly constant over the range of interstitial water conductivities used in these tests ( 1.1 to $5.6 \mathrm{mho} / \mathrm{meter}$ ). These results agree with the conclusion made by $\mathrm{Berg}^{7}$ that the effect of cation exchange capacity on Formation Factor was negligible for kaolinite clay above interstitial water conductivities of 1.25 mho/meter.

Sheeler et al. ${ }^{8}$ stated that the effect of cation exchange capacity on Formation Factor persisted up to interstitial water conductivities of approximately 6 mho/meter for kaolinite clay, and $11.8 \mathrm{mho} / \mathrm{meter}$ for montmorillonite clay. However examination of the data on kaolinite clay presented by Sheeler et al. indicates that above an interstitial water conductivity of 1.6 mho/meter the rate of increase of the Formation Factor is so small that it could be considered constant. In the case of the montmorillonite clay the low porosities could account for the increase in Formation Factors with interstitial water conductivities up to 11.8 mho/meter. The porosities of clays used by Sheeler et al. ranged from 48 to 67 percent, while the porosities used in this investigation ranged from 87 to 94 percent.

Although Boyce ${ }^{9}$ offered cation exchange capacity as a possible explanation of the variation in his data (in which the lovest interstitial water conductivity encountered in the cores was approximately 5 mho/meter), the results of the present investigation 

Indicate that above $3 \mathrm{mho} / \mathrm{meter}$ the effect of cation exchange capacity on Formation Factor is negligible for sediments. Five mho/meter is equivalent to a salinity of 32.6 parts per thousand at 25 degrees Centigrade, while 3 mho/meter is equivalent to 18.5 parts per thousand. Although no cation exchange capacity values were given by Kermabon et al. ${ }^{12}$ and Smith, ${ }^{13}$ after conducting laboratory experiments on marine clays having porosities of approximately 50 percent, both concluded that there was no appreciable change in Formation Factor when using interstitial water conductivities ranging from 1.4 to 13 mho/meter.

Another interesting result of the present investigation is that below 1.5 mho/meter the Formation Factor for montmorillonite clay was less than one. This means the sediment has become more conductive than the interstitial water. This was also noted by Sheeler et $a .^{8}$ when working with montmorillonite clay of lower porosities. This fact would be extremely important when working with montmorillonite clay with low interstitial water conductivities, since a correction factor would have to be developed before Formation Factor could be considered an accurate index of porosity.

The Formation Factor and the porosity data of a specific sediment are given in Appendix C. A relationship using Equation 32 was developed. If Equation 32 is re-written the following relationship is obtained:

$$
\log F F=\log a-m \log n .
$$



From the above relationship it is evident that (m) is actually the slope of the line and (a) is the value of the Formation Factor at a porosity of 100 percent or the intersection of the $y$-axis of a log-log plot. Using a linear regression technique these coefficients ( $m$ and $a$ ) were determined by the least squares method. An example of a complete data scatter plot relating Formation Factor to porosity for kaolinite clay is presented in Figure 17. The dashed lines in Figure 17 are the \pm 2 percent error lines located from the line of best fit.

Data for all the sediments tested in this investigation are plotted as Formation Factor versus porosity in Figure 18. The lines of best fit are drawn for each sediment tested: the sands, silts, clays and marine sediments. The length of the line depends on the maximum and minimum values tested. This figure represents a graphical method of predicting porosity from Formation Factors obtained by electrical resistivity measurements. The ranges of porosity and Formation Factor obtained are presented in Table 5.

\section{TABLE 5}

THE POROSITY RANGE AND FORMATION FACTOR RANGE OF THE SANDS, SILT, CLAYS, AND MARINE SEDIMENTS TESTED

\begin{tabular}{|l|c|c|}
\hline SEDIMENT TYPE & POROSITY RANGE (\%) & $\begin{array}{c}\text { FORMATION FACTOR } \\
\text { RANGE }\end{array}$ \\
\hline Sands & $26-48$ & $3.1-5.9$ \\
Silt & $41-62$ & $2.6-5.3$ \\
Clays & $41-93$ & $1.1-3.1$ \\
Marine sediments & $44-83$ & $1.6-5.7$ \\
\hline
\end{tabular}





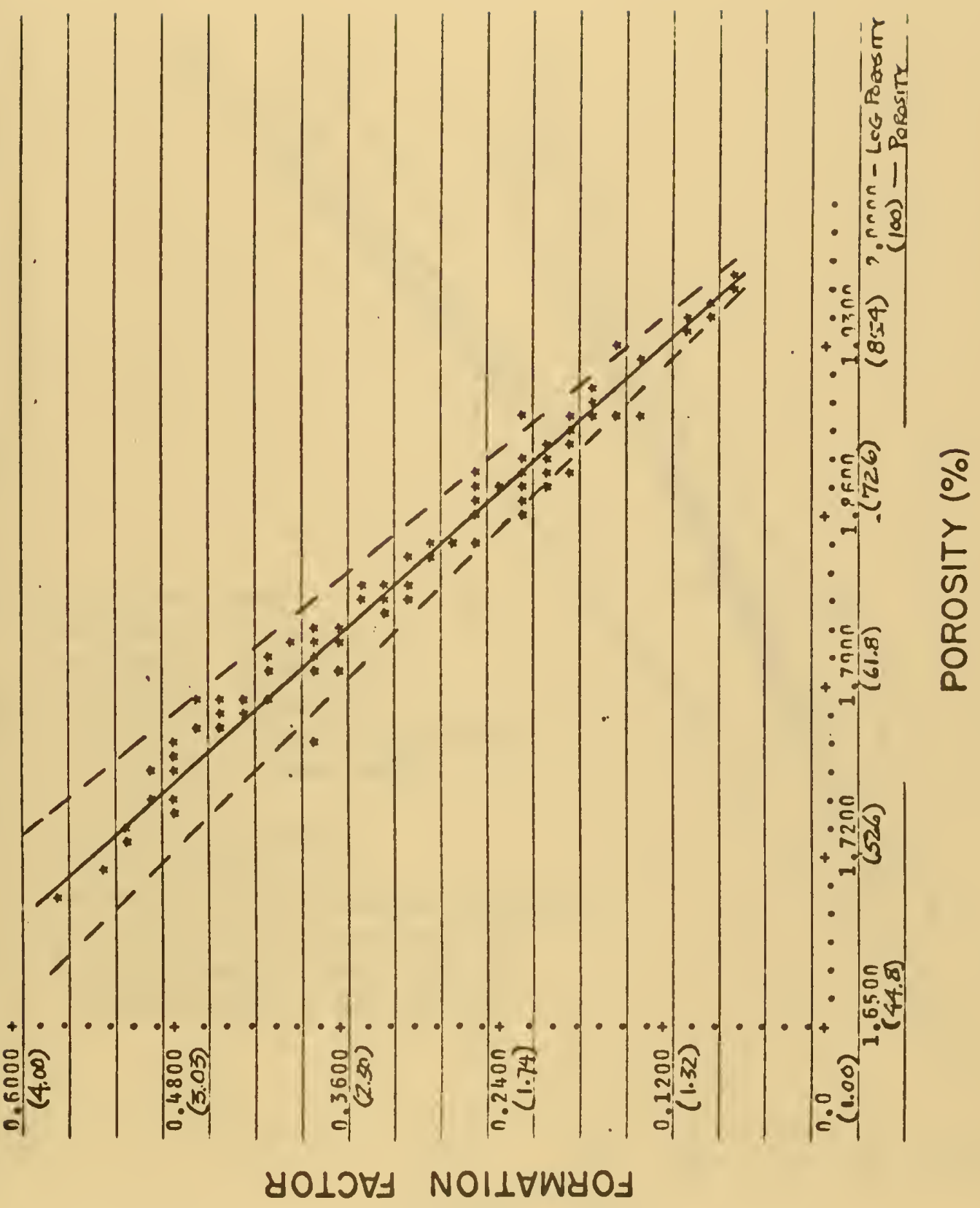

Figure 17. Formation Factor-Porosity Relationship for Kaolinite Clay. 



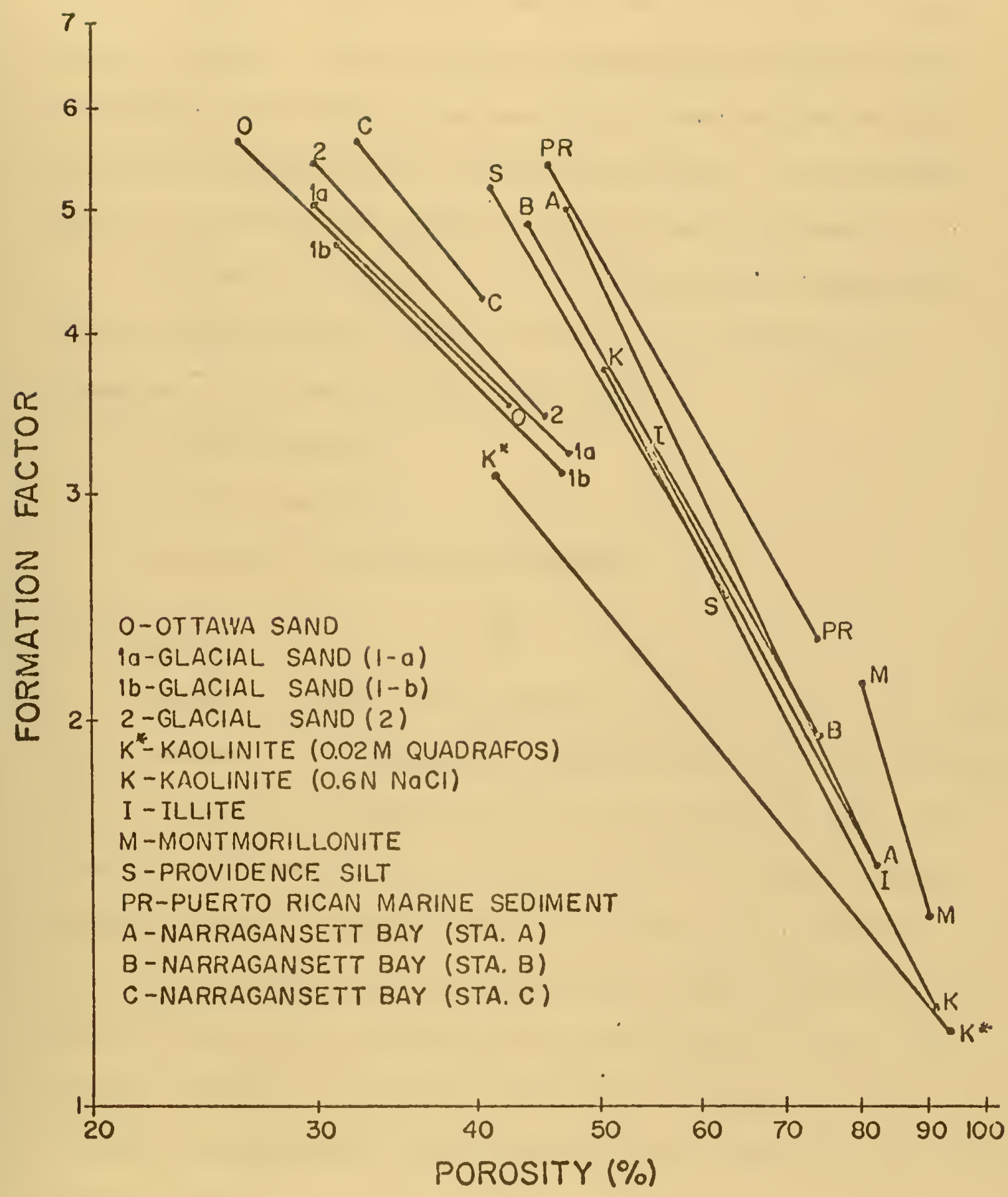

Figure 18. Formation Factor-Porosity Relationship for all sediments Tested. 

The following data for each sediment tested is presented in Table 6: number of data points used in the statistical analysis, slope, intercept, standard error of estimate, percentage of data points that fall within \pm 2 percent error lines, and the maximum and minimum Formation Factor and porosity values. The techniques used in this statistical analysis are discussed in Appendix $C$. Because of the ranges of Formation Factor and porosity (see Figure 18) the discussion will be facilitated by dividing the comparisons into the following three groups:
a) sands and silt,
b) clays and silt,
c) clays, silt and marine sediments.

Sands and silt

Formation Factor versus porosity is plotted for the five sands and Providence silt in Figure 19. Formation Factor for the sands and silt in this figure ranged from 3.12 to 5.90 , while porosity ranged from 26 to 48 percent. The Formation Factors for ottawa sands and glacial sands $(1-a)$ and ( $1-b)$ were very similar at the different porosities, while the more naturally occurring sediments (Providence silt, glacial sand (2) and Narragansett Bay sand (Station C)) were each uniquely different. Narragansett Bay sand, although actually a marine sediment, was considered under sands and silts since 97 percent of the particles were in the sand size range.

The lines of best fit for glacial sand (2) and Providence silt at porosities of 41 , to 46 percent visually'suggest that electrical 



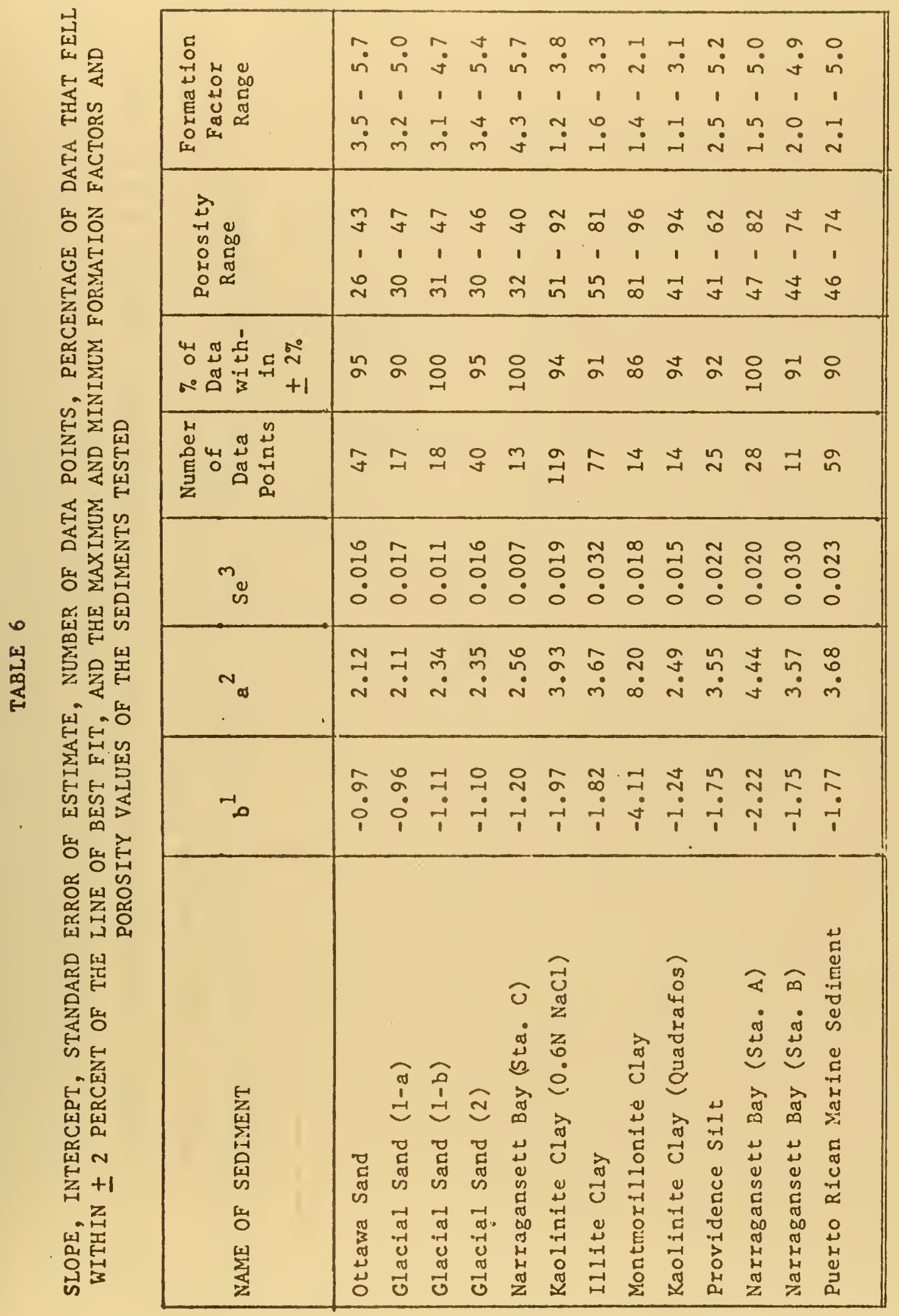





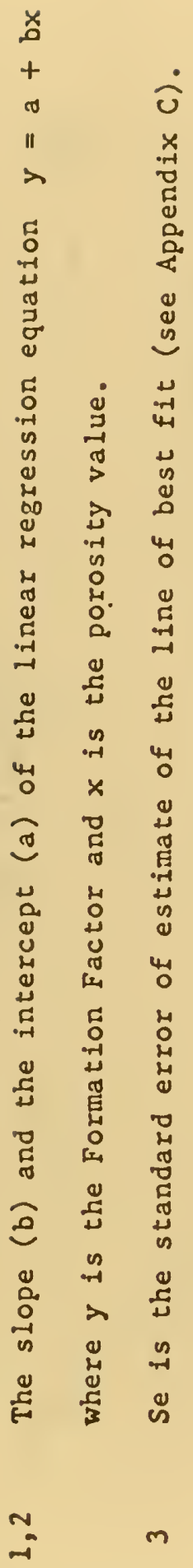



FORMATION FACTOR

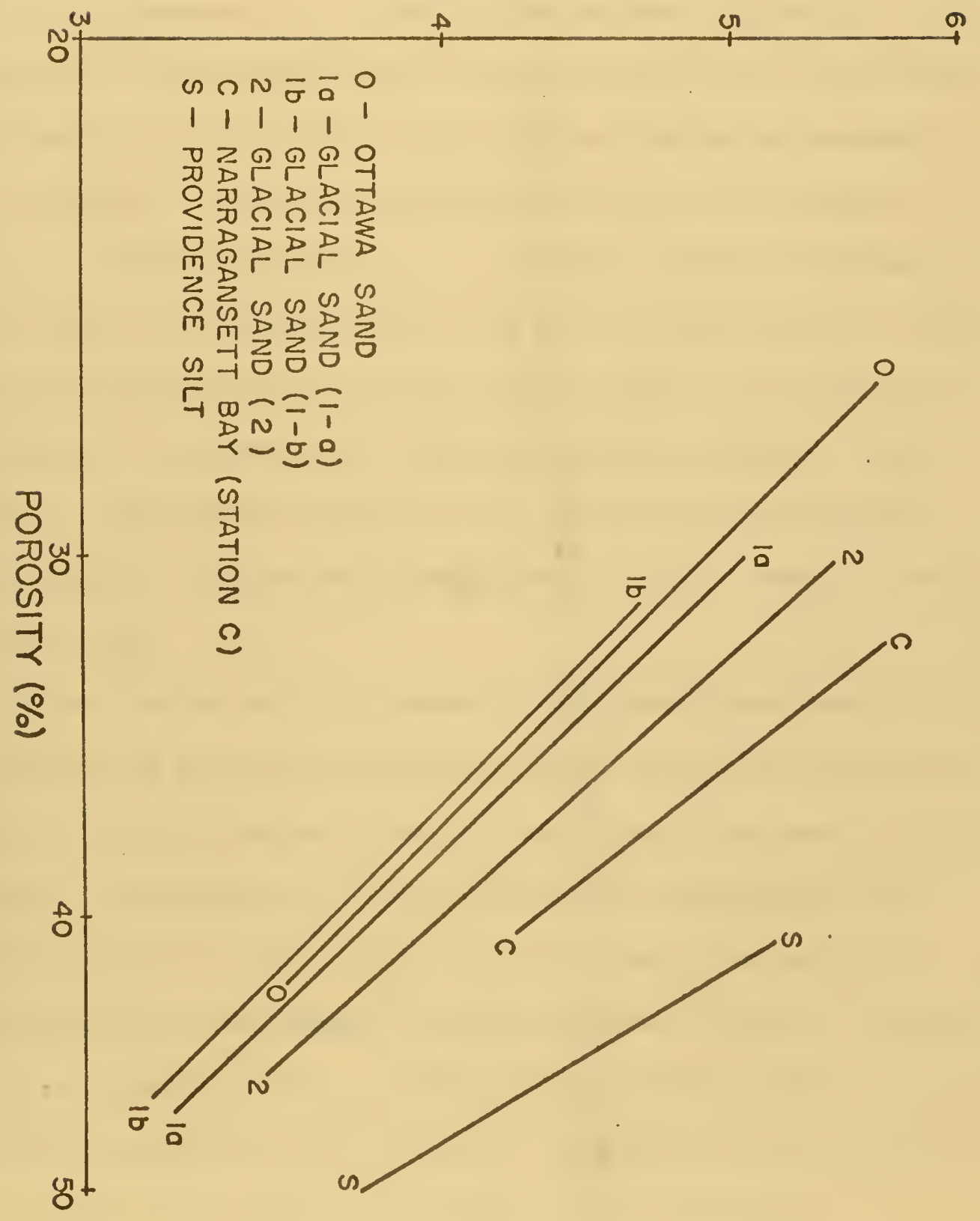

Figure 19. Formation Factor-Porosity Relationships for Eive Sands and Providence silt. 

resistivity decreases with increasing particle size. Providence silt which has a mean diameter of $0.016 \mathrm{~mm}$ had a higher Formation Factor than glacial sand (2) which has mean diameter of $0.50 \mathrm{~mm}$. At a porosity of 43 percent, the Formation Factors were 4.9 and 3.7 respectively. The distributions of these two sediments were similar. As discussed later, the shape of the silt was similar to the sand, that is angular. In addition to particle size, structure was also variable in these two sediments. At 43 percent porosity Providence silt is densely packed and glacial sand (2) is loosely packed. However the results discussed later show that structure of sands does not influence electrical resistivity measurements independent of porosity. Consequently it appears that particle size did account for the difference in the Formation Factor of glacial sand (2) and Providence silt.

These results are in agreement with Meredith, who reported that mixtures of particles that were smalier in size by 10 diameters resulted in slightly higher Formation Factors than mixtures of larger particles. The diameters of glass beads used in Meredith's work ranged from $6 \mathrm{~mm}$ to $0.02 \mathrm{~mm}$ while the size of sand was not given. The data of Wyllie and Gregory ${ }^{14}$ agreed that the effect of different sized glass spheres on Formation Factor was noticeable only when the difference in particle size was large. The diameters of the glass spheres used in their study ranged from $3 \mathrm{~mm}$ to $0.033 \mathrm{~mm}$.

An additional size test was conducted in order to see if small differences in particle size of a sediment could be detected. Electrical resistivity measurements of ottawa sand (a) with a diameter of 

$0,70 \mathrm{~mm}$ and ottawa sand (b) with a diameter of $0.42 \mathrm{~mm}$ resulted in Formation Factors of 3.6 and 3.5 respectively. The porosities, particle shapes, and standard deviations of these two sands were approximately the same. The work of Meredith ${ }^{1}$ on glass beads agrees with this work on sediments that the effect of particle size on conductivity is negligible when the size difference is small.

The effect of distribution on electrical resistivity can be seen in Figure 19 by comparing Narragansett Bay sand with glacial sand $(1-a)$. The Formation Factor of Narragansett Bay sand which had a larger distribution was higher than the Formation Factor of glacial sand $(1-a)$. For example at a porosity of 40 percent the Formation Factors were 4.36 and 3.85 respectively. The standard deviation of the particle size for Narragansett Bay sand was 1.10 while glacial sand $(1-a)$ was 0.34 . Particle size and shape were approximately the same (see Table 3 ). These results agree with the work of Semenov 15 on sedimentary rocks, and the work of Meredith ${ }^{1}$ on glass beads. Meredith found that Formation Factor was higher for a mixture of spheres $6 \mathrm{~mm}$ and $0.75 \mathrm{~mm}$ in diameter than for spheres $6 \mathrm{~mm}$ in diameter.

At lower porosities the effect of distribution was found to be even more pronounced. At a porosity of 32 percent the Formation Factor of Narragansett Bay sand was 5.70 and glacial sand (1-a) was 4.77. Therefore the difference between the two was 0.51 at 40 percent porosity and increased to 0.93 at 32 percent porosity. The increased assortment of particle sizes causes the current to take a more tortuous path and thus the sediment is more resistive. As 
the sediment becomes densified (lower porosity), the variety of particle sizes has an even greater effect on the tortuosity.

The Narragansett Bay sand had a small quantity of platy mica particles which could be thought to account for some of the difference between Narragansett Bay sand and glacial sand (1-a). However as discussed later in this paper, particle shape differences in sediments do not seem to significantly influence electrical resistivity measurements.

Figure 20 a to $f$ are photographs of Ottawa sand, glacial sands 1-a, 1-b, 2, Narragansett Bay sand and Providence silt respectively. An evaluation of angular and spherical shapes as an influence on electrical resistivity can be made by comparing ottawa sand with glacial sand (1-a). Although Ottawa sand is spherical in shape and the glacial sand $(1-a)$ is angular in shape, the Formation Factor versus porosity relationship is very similar. At a porosity of 35 percent Ottawa sand had a Formation Factor of 4.20 while glacial sand (1-a) had 4.35. Size, distribution and structure were approximately the same for these two sands. On Figure 1995 percent of the data points lie within \pm 2 percent of the line of best fit. Consequently the difference between the line of best fit for Ottawa sand and glacial sand $(1-a)$ is not significant. These results indicate that electrical resistivity is quite similar for angular and spherical shapes.

Wyllie and Gregory ${ }^{14}$ obtained a Formation Factor of 4.2 for glass spheres and spherical ottawa sand, 4.4 for angular beach and creek sands, and 4.7 for lucite triangular prisms at 35 percent 


$$
105
$$





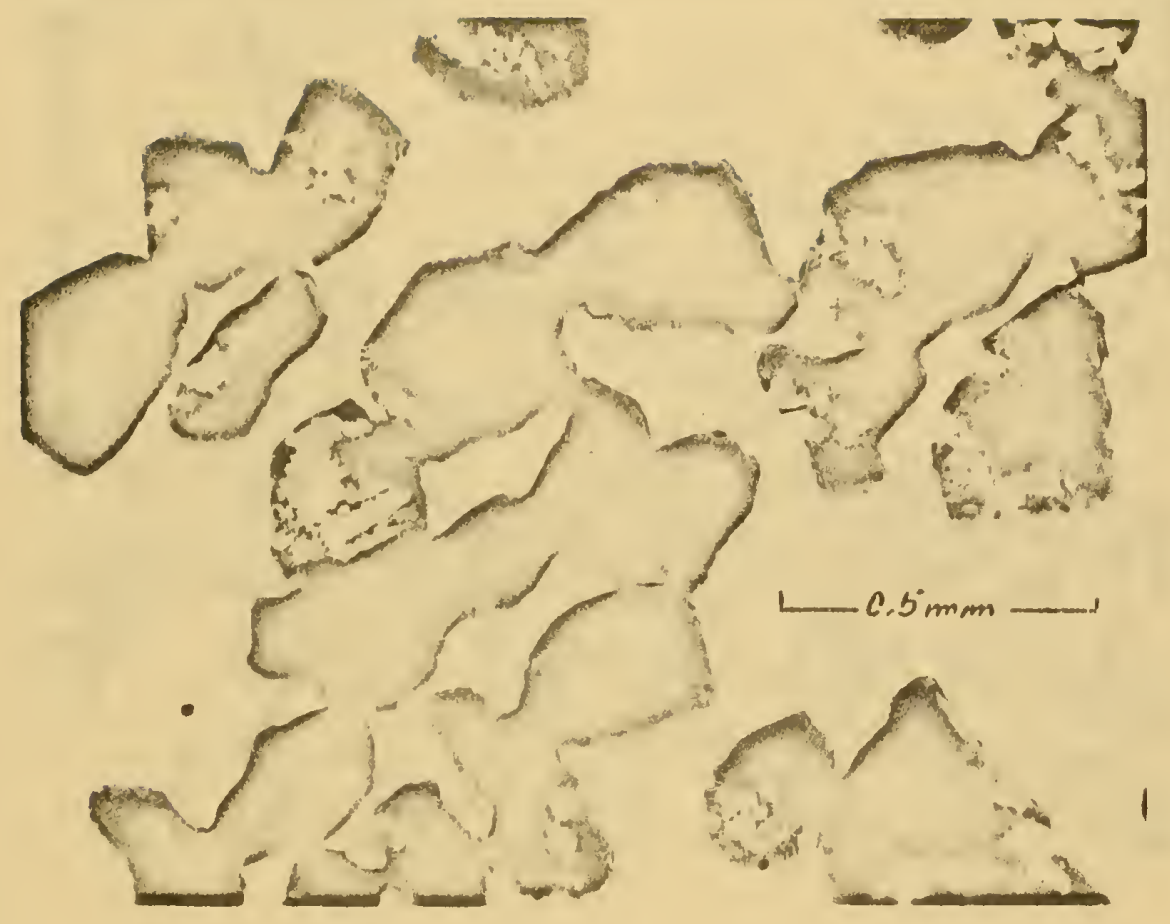

Figure 20-b. Glacial Sand (1-a). 



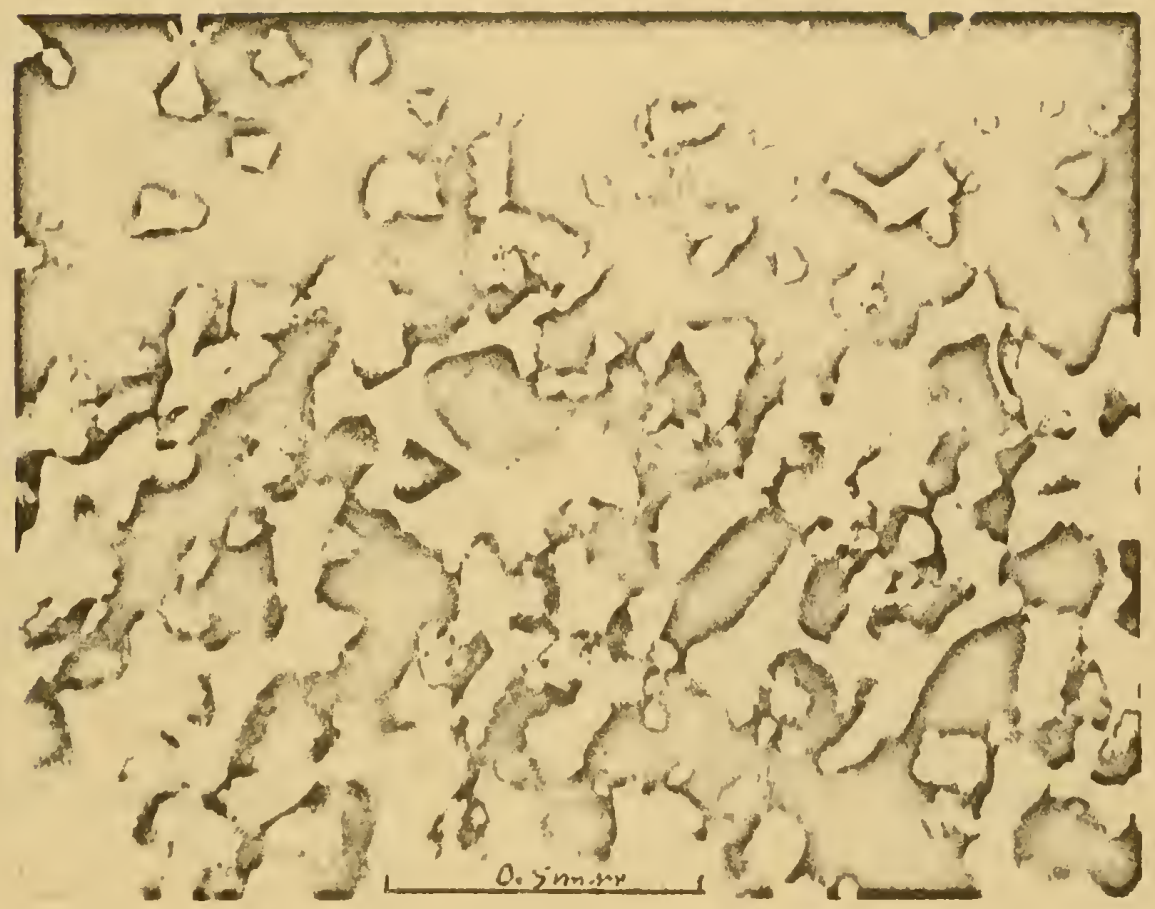





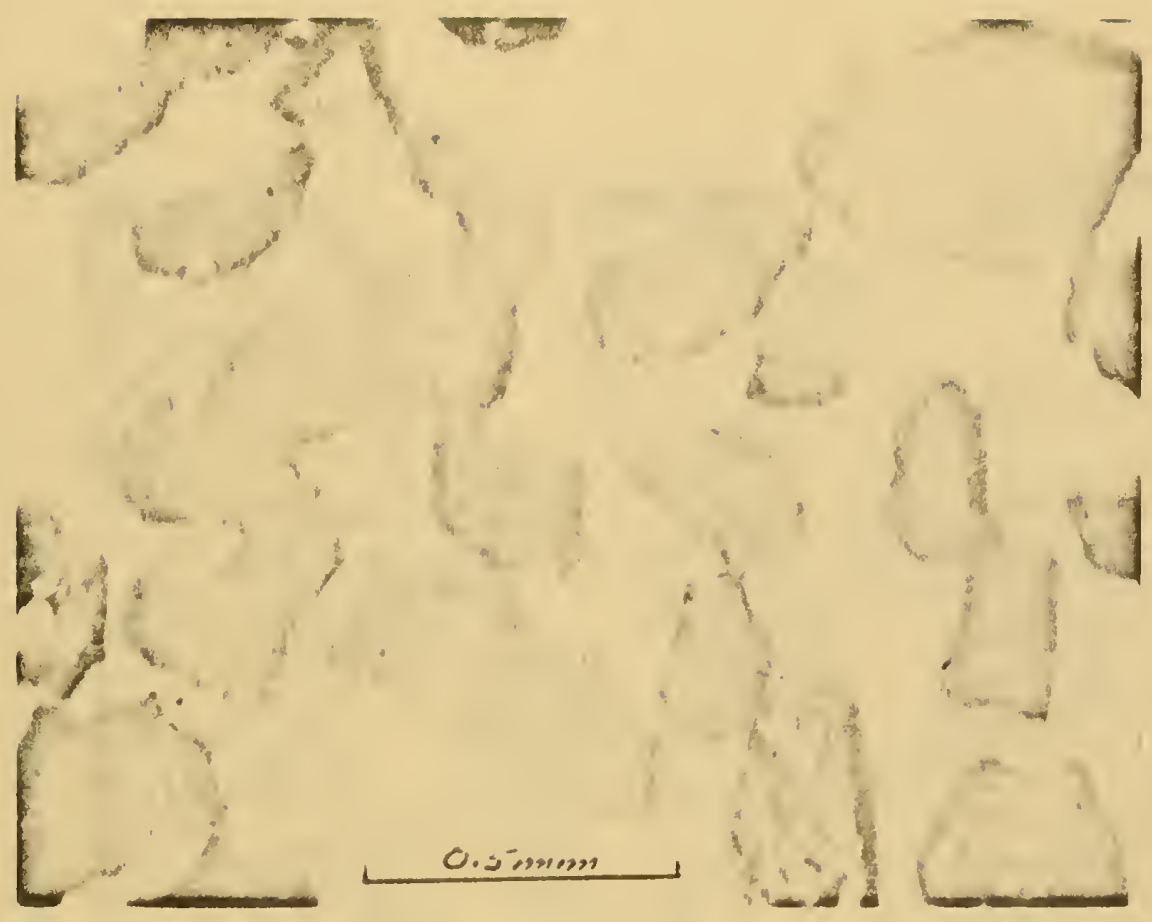

Figure 20-d. Glacial sand (2). 



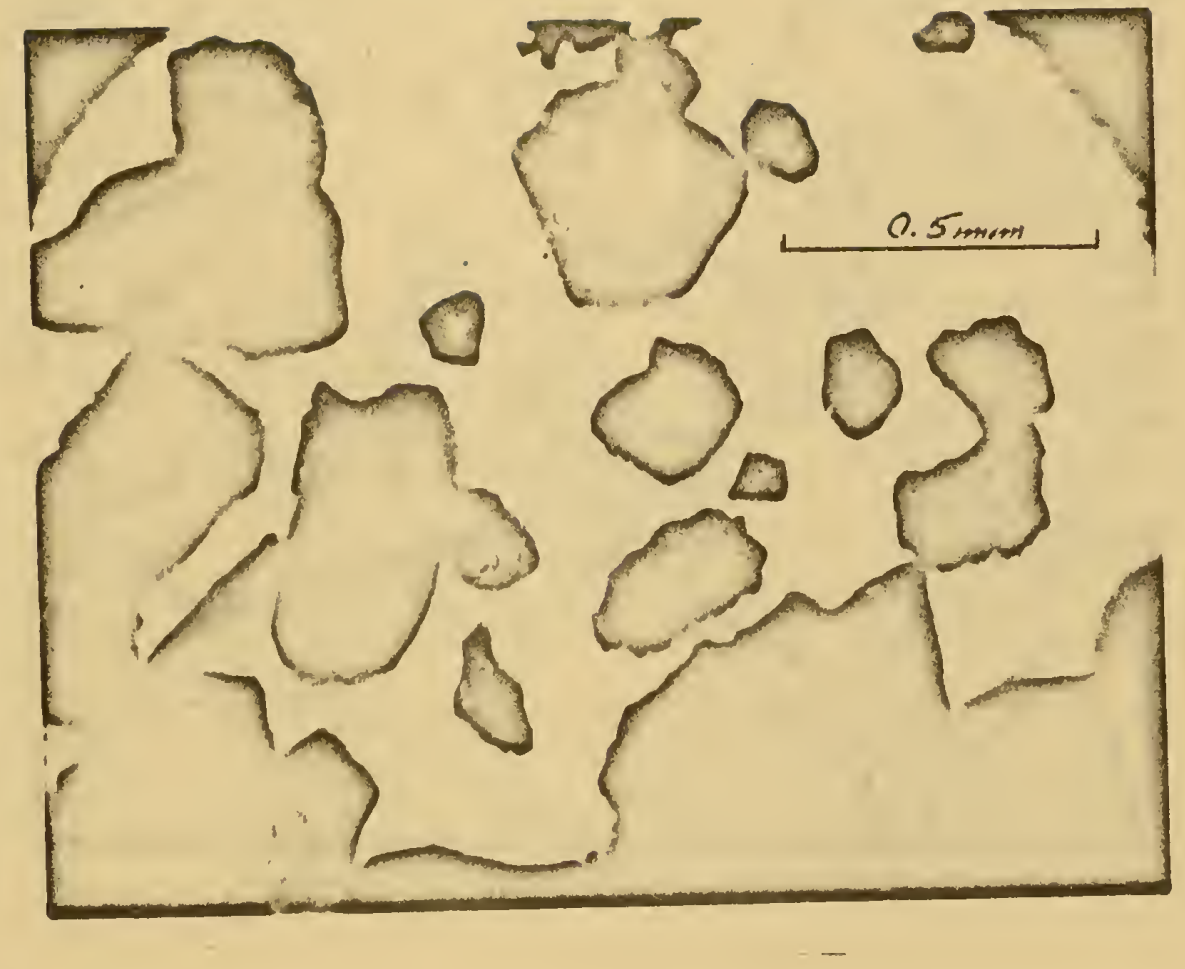

Figure 20-e. Nạragansett Bay Sand. 



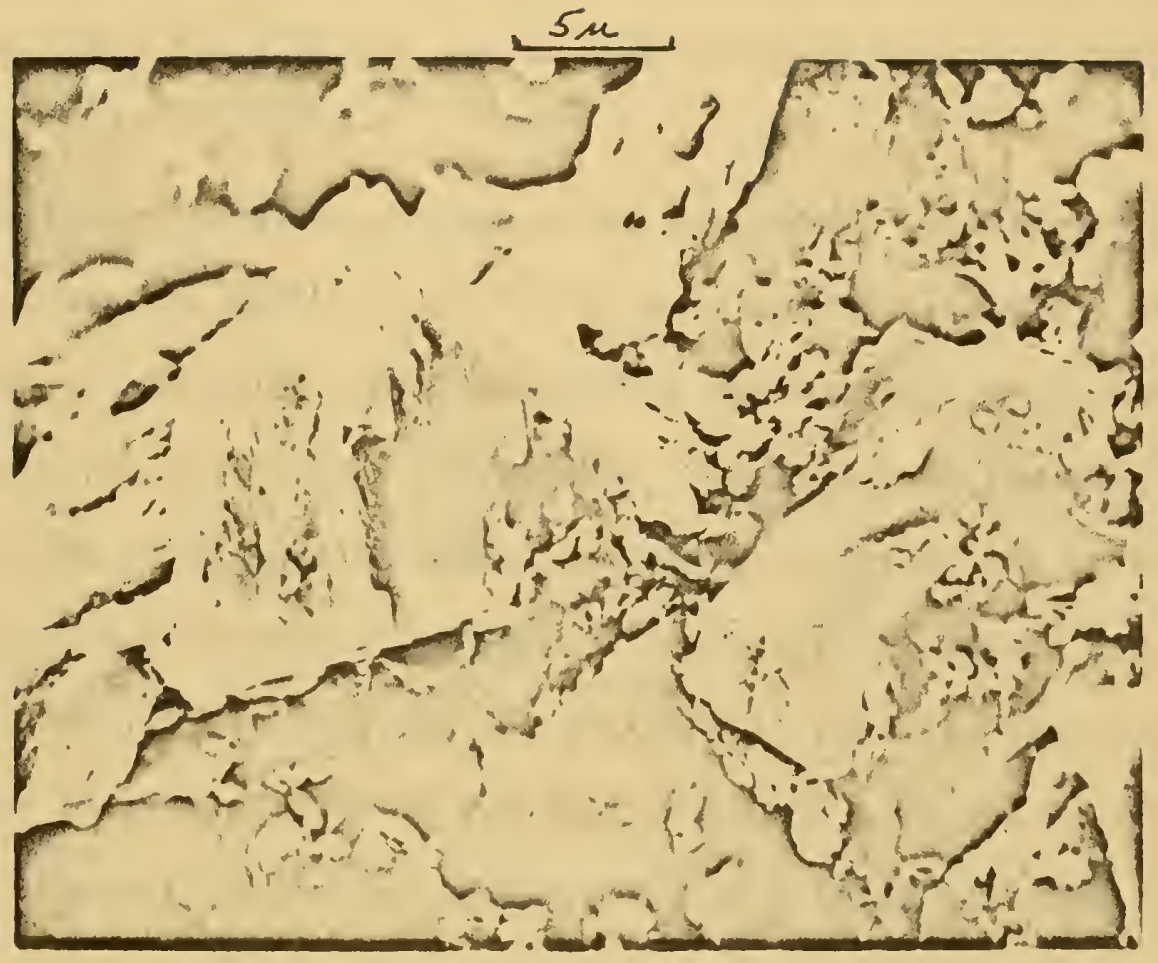

Figure 20-f. Providence silt. 

porosity. The sphericity was $1.0,0.8$, and 0.6 respectively. The Formation Factor in their work seems to increase as sphericity decreases. However the particle size was not held constant. The particle size of the glass spheres was $3 \mathrm{~mm}$ in diameter and the triangular prisms were $0.25 \mathrm{~mm}$ in diameter. As discussed previously this difference in particle size is large enough to influence the resistivity. The Formation Factor would be higher for the triangular prisms since the diameter was 12 times smaller than the glass spheres.

The influence of structure on the electrical resistivity of sands was tested by making resistivity measurements before and after densification. The electrical resistivity and porosity were changed by densification in the same proportion. The Formation Factors of the five sands at 40 percent and 32 percent porosities, the percentage change in the Formation Factor and the measure of spread are given in Table 7. For a 20 percent decrease in porosity the Formation Factor increased 19 to 24 percent. As shown in Table 7, the Formation Factors of the two sand types with a large distribution changed a little more than the sands with a small spread in particle size.

Tortuosity factors as defined by Equation 13 are given in Table 8 for loosely and densely packed sands. Tortuosity increases as density increases for those sands that have a large variety of particle sizes. Densification does not seem to affect the tortuosity of those sands with a small spread in particle size. 



\section{TABLE 7}

THE FORMATION FACTORS AT 40 PERCENT AND 32 PERCENT FOROSITY, THE PERCEINTAGE CHANGE IN FORMATION FACIOR AND THE IEASURE OF SPREAD FOR FIVE SANDS.

\begin{tabular}{|c|c|c|c|c|}
\hline Name & $\begin{array}{l}(1) \\
F F \\
40 \%\end{array}$ & $F F$ & $\begin{array}{l}\% F F \text { (2) } \\
\text { incrcased }\end{array}$ & $6_{\emptyset}^{(3)}$ \\
\hline Ottawa sand & 3.73 & 4.60 & 19 & 0.25 \\
\hline Glacial sand (1-a) & 3.85 & 4.77 & 19 & 0.34 \\
\hline Glactal sand (1-b) & 3.73 & 4.60 & 19 & 0.50 \\
\hline Glacial sand (2) & 3.96 & 5.00 & 21 & 1.31 \\
\hline $\begin{array}{l}\text { Narragansett Bay } \\
\text { sand (Station C) }\end{array}$ & 4.35 & 5.70 & 24 & 1.10 \\
\hline
\end{tabular}

(1) $\mathrm{FF}_{40 \%}$ - Formation Factor at $40 \%$ porosity.

(2) $\% F F$ increased $=\frac{F F{ }_{32 \%}-F F_{40 \%}}{F F_{32 \%}}(100)$.

(3) 6 (Dispersion measure) $=\frac{1}{2}\left(\emptyset_{84}-\emptyset_{16}\right)$, where $\emptyset_{84}$ and $\emptyset_{16}$ are cumulative percentages of the sample which is coarser grained than 84 and 16 percentiles respectively. The scale is defined as $-\log _{2}$ (diameter in millimeters). 

TABLE 8

COEFFICIETTS OE PER'AEABILITY, FORIATION FACTORS, POROSITY, TORTUOSITY, AND THE PRODUCT OF THE FORMATION FACTOR AND THE COEFFICIENT OF PERMEABILITY FOR FIVE IOOSELY AND DENSELY PACKED SANDS.

Name of Secliment Coofficiont Formation Porosity Tortuosity Kp FE of Permea- Factor (n) $(8)$ $\mathrm{FF \cdot n}$ $\frac{(\mathrm{cm} / \mathrm{sec})^{2}}{}$

\begin{tabular}{|c|c|c|c|c|c|}
\hline $\begin{array}{l}\text { Ottawa Sand } \\
\text { (100se) }\end{array}$ & 0.239 & 3.55 & 42.0 & 1.22 & 0.848 \\
\hline $\begin{array}{l}\text { Ottawa Sand } \\
\text { (dense) }\end{array}$ & 0.154 & 5.30 & 27.5 & 1.20 & 0.816 \\
\hline $\begin{array}{l}\text { Glacial Sand } \\
(1-a)(100 s e)\end{array}$ & 0.0891 & 3.43 & 45.0 & 1.24 & 0.306 \\
\hline $\begin{array}{l}\text { Glacial Sand } \\
(1-a) \text { (dense) }\end{array}$ & 0.0502 & 5.00 & 30.2 & 1.23 & 0.251 \\
\hline $\begin{array}{l}\text { Glacial Sand } \\
(1-b)(100 s e)\end{array}$ & 0.0224 & 3.32 & 44.0 & 1.21 & 0.0744 \\
\hline $\begin{array}{l}\text { Glacial sand } \\
(1-b) \text { (dense) }\end{array}$ & 0.00699 & 4.80 & 31.2 & 1.22 & 0.0336 \\
\hline $\begin{array}{l}\text { Glacial Sand } \\
\text { (2) (100se) }\end{array}$ & 0.115 & 3.50 & 44.0 & 1.24 & 0.403 \\
\hline $\begin{array}{l}\text { Glacial Sand } \\
\text { (2) (dense) }\end{array}$ & 0.0413 & 5.85 & 27.2 & 1.26 & 0.252 \\
\hline $\begin{array}{l}\text { Narragansett Bay } \\
\text { Sand (loose) }\end{array}$ & 0.0879 & 4.30 & 40.5 & 1.32 & 0.378 \\
\hline $\begin{array}{l}\text { Narragansett Bay } \\
\text { Sand (dense) }\end{array}$ & 0.0248 & 5.75 & 31.8 & 1.35 & 0.143 \\
\hline
\end{tabular}



Coefficients of permeability $(K p)$ and the corresponding Formation Factor and porosity are also presented in Table 8 . The coefficient of permeability as obtained by a variable head permeability test, was reduced as the sands densified and Formation Factors increased. The coefficient of permeability decreased as the mean particle size decreased. It decreased more for densified sands with a large distribution of particle sizes. As the porosity of a sand decreased, the coefficient of permeability decreased logarithmically and the Formation Factor increased logarithmically. Due to the cancelling effect of these two logarithmic variations, the product of Formation Factor times coefficient of permeability of densely and loosely packed sand can be plotted on a linear scale. This linear assumption, along with a Formation Factor versus porosity plot allow the coefficient of permeability to be obtained by measuring only the Formation Factor. Thus by knowing any one of the three variables (FF, $n, K p)$, the other two variables can be predicted from standard curves. The product of the Formation Factor and the coefficient of permeability (FFKp) is presented for all the sands on Table 8. The relationship between porosity and FFKp for loosely and densely packed sands is plotted in Figure 21. By assuming a poros1ty of 36 percent and using Figures 19 and 21 , the FF FFKp and the Kp for the five sands used in these tests are given in Table 9. The sands that are more common in nature have the greater slopes in Figure 21. For these sands a small change in porosity results in a larger change in FFKp than for the sorted sands. Consequently these graphs predicting porosity and permeability from electrical resisti- 



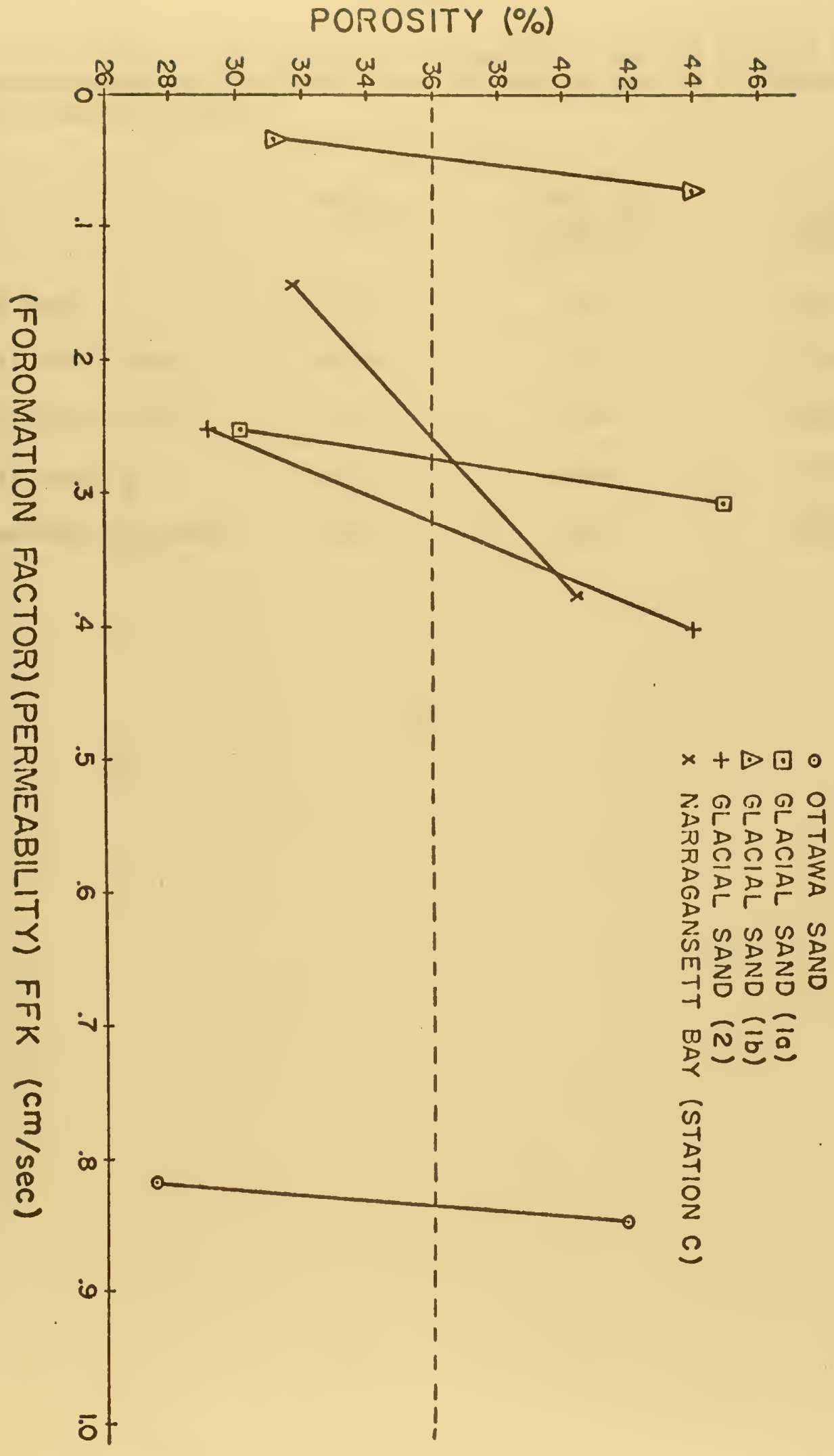

Figure 21. Porosity Versus the Product of the Formation Factor and the coefficient of Permeability $\left(F F K_{p}\right)$ for Five Sands. 

TABLE 9

FORMATION FACTORS, COEFFICIENTS OF PERMEABILITY AND THE PRODUCT OF FORMATION FACTOR AND THE COEFFICIENT OF PERMEABILITY AT 36 PERCENT POROSITY FOR FIVE SANDS.

Name

Ottawa sand

Glacial Sand (1-a)

Glacial Sand (1-b)

Glacial sand (2)

Narragansett Bay Sand
$\mathrm{FF}_{368}$

4.12

4.26

4.12

4.40

4.95

$$
\frac{F_{\mathrm{FK}} 368}{(\mathrm{~cm} / \mathrm{sec})}
$$

.834

.274

.048

.321

.258

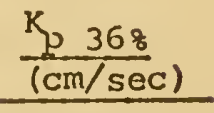

.202

.0643

.0117

.0730

.0521 

vity measurements would be very useful in a natural environment.

\section{Clays and Silt}

A Formation Factor-porosity diagram with curves of best fit for kaolinfte, 1llite, and sodium montmorillonite clays and Providence silt is shown in Figure 22. This figure includes over 200 measurements made with all three versions of the laboratory test equipment. The statistical data for this figure is presented in Table 6.

The results of this investigation on clays and silts suggest that particle shape does not influence electrical resistivity independent of porosity. Kaolinite clay $(0.6 \mathrm{~N} \mathrm{NaCl})$ and Providence silt have almost identical Formation Factors over a porosity range of 51 to 61 percent although the former is platy shaped and the latter is angular in shape. These shapes, enlarged 2000 and 10,000 times by an electron microscope, can be seen in Figures 23-a, 23-b, 20-f and 24. The particle distribution for the two sediments was similar; the measure of spread for kaolinite was 1.81 while Providence silt was 1.21. The particle size of Providence silt was approximately five times larger than kaolinite. It was suggested in the discussion on results of sands that a particle size difference of about 10 times is necessary before size difference is detectable by electrical resistivity measurements. In the results and discussion on cation exchange capacity it is indicated that cation exchange capacity would not be a factor influencing the electrical resistivity measurements of these two sediments since the salinity was high $(0.6$ normal sodium 


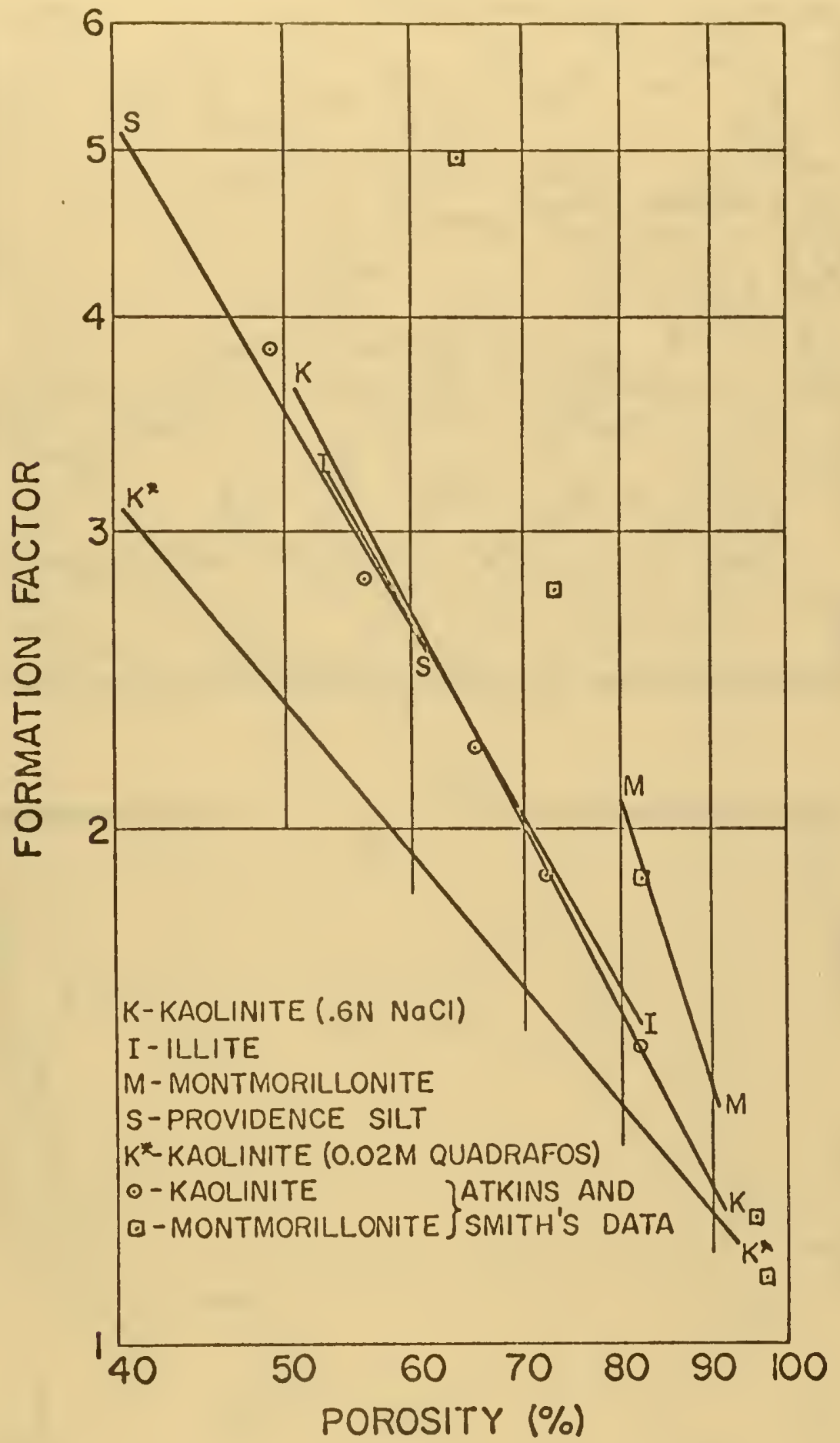

Figure 22. Formation Factor-porosity Relationships for Kaolinite, Illite and Montmorillonite Clays and Providence silt. 


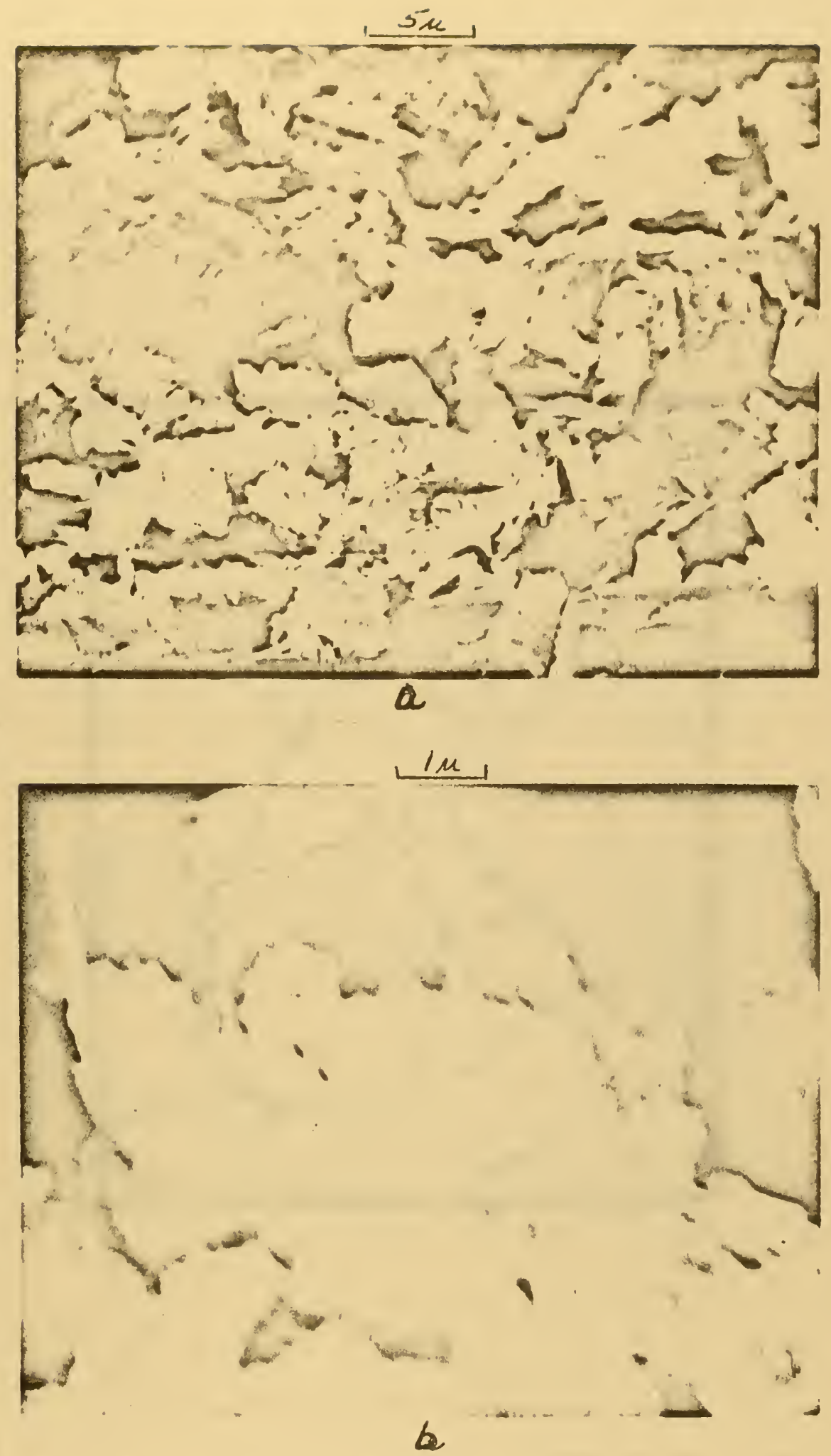

Figure 23. Photographs of (a) Kaolinite Clay Enlarged 2000 a,b Times by Elcctron Microscope, (b) Kaolinito Clay Enlarged 10,000 Times. 



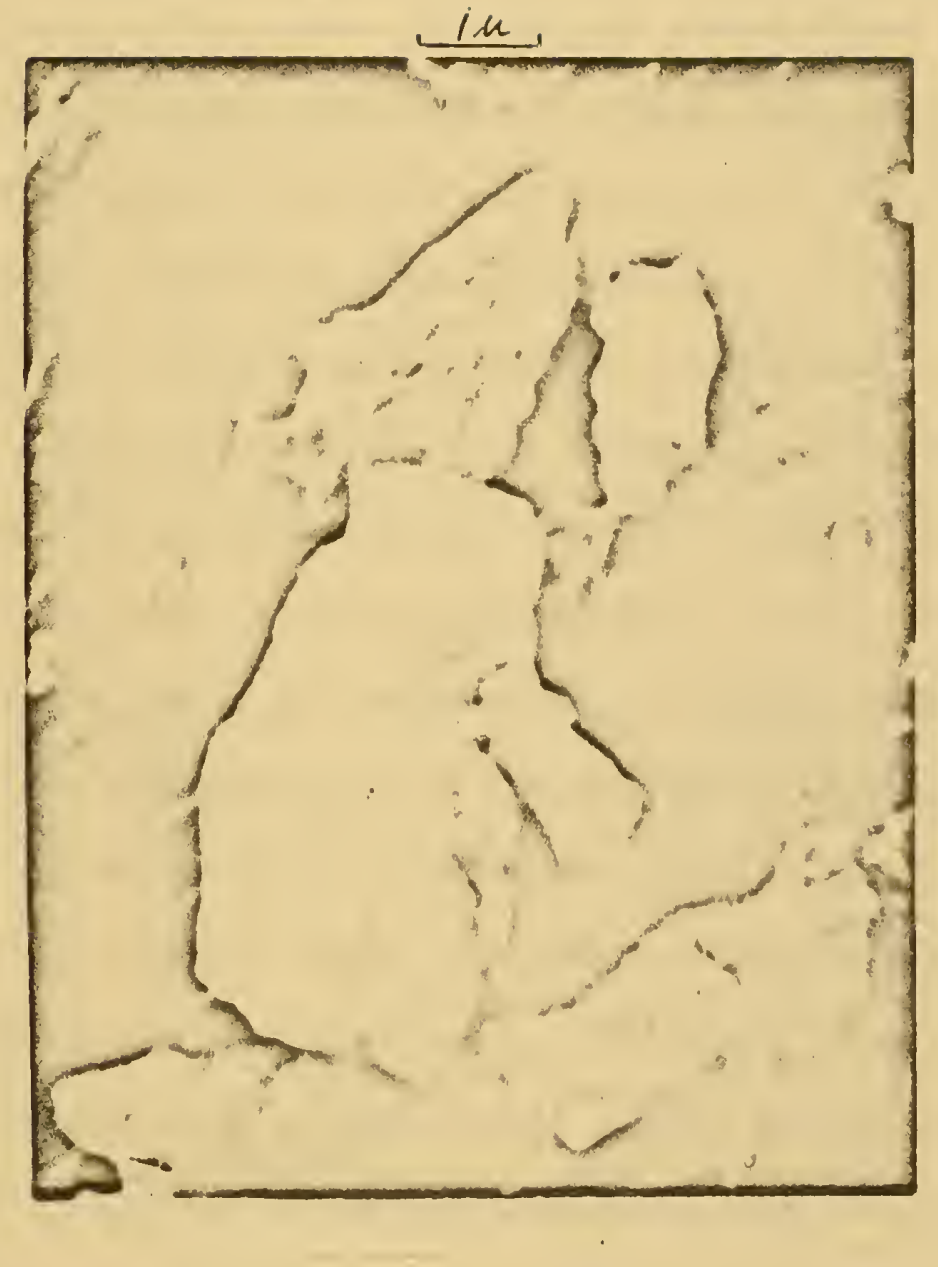

Figure 24. Photograph of Providence Silt Enlarged 10,000 Times by Electron Microscope. 

chloride). Since both would have a flocculant structure at this salinity, structure would not be a variable. Since shape is the only major variable between the two, and since the Formation Factors are nearly identical in this porosity range, it appears that particle shapes such as platy or angular do not influence electrical resistivity. The results for illite clay further substantiate this conclusion. Although illite clay is of a different mineral content from kaolinite, the Formation Factors were again almost identical. This result indicates that this difference in mineral content has little if any effect on electrical resistivity measurements. Illite clay has a platy shape that can be seen in Figure 25-a and 25-b. The mean particle size of illite clay is about the same as for kaolinite clay (five times smaller than Providence silt). The Formation Factor of illite clay and Providence silt is nearly identical though shape differs and appears to be the only major variable. The opposite is true of kaolinite clay and montmorillonite clay. Although these two have a very similar shape, the Formation Factor versus porosity relationship for these two is very different (Figure 26-a, and 26-b). For example at a porosity of 83 percent, Formation Factor of kaolinite is 1.45 while montmorillonite is 2.00 . As discussed later this difference is probably due to particle size and distribution. The results for illite and montmorillonite clays reinforce the conclusion that the influence of particle shape on electrical resistivity measurements of sediments appears to be small.

The standard deviation of particle size for illite clay was 2.99 and might appear to be a variable when compared with Providence 

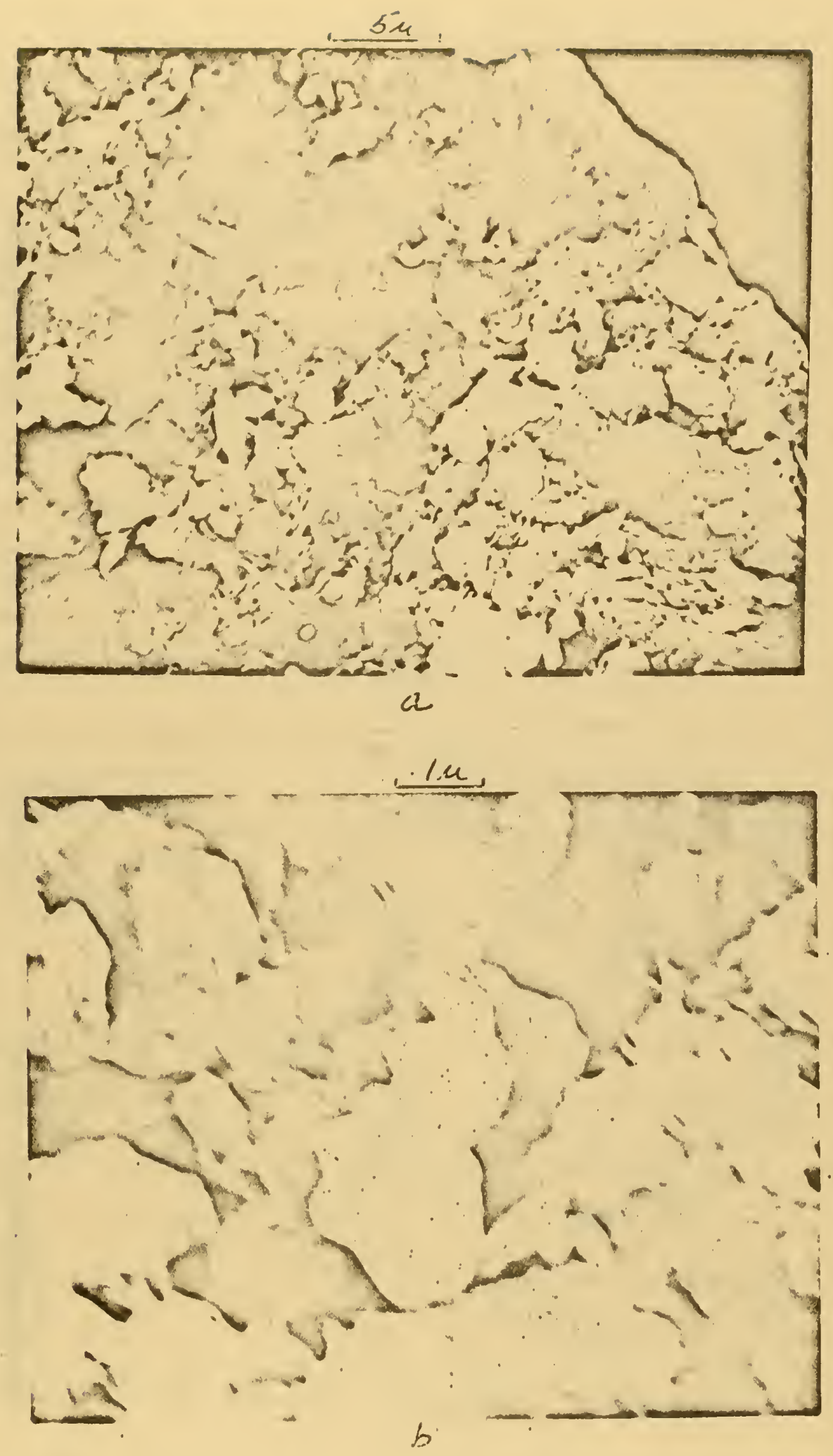

Figure 25. Photographs of (a) Illite Clay Enlarged 2000 Timos $a, b$ by Electron Microscope, (b) Illite Clay Enlarged 10,000 Times. 


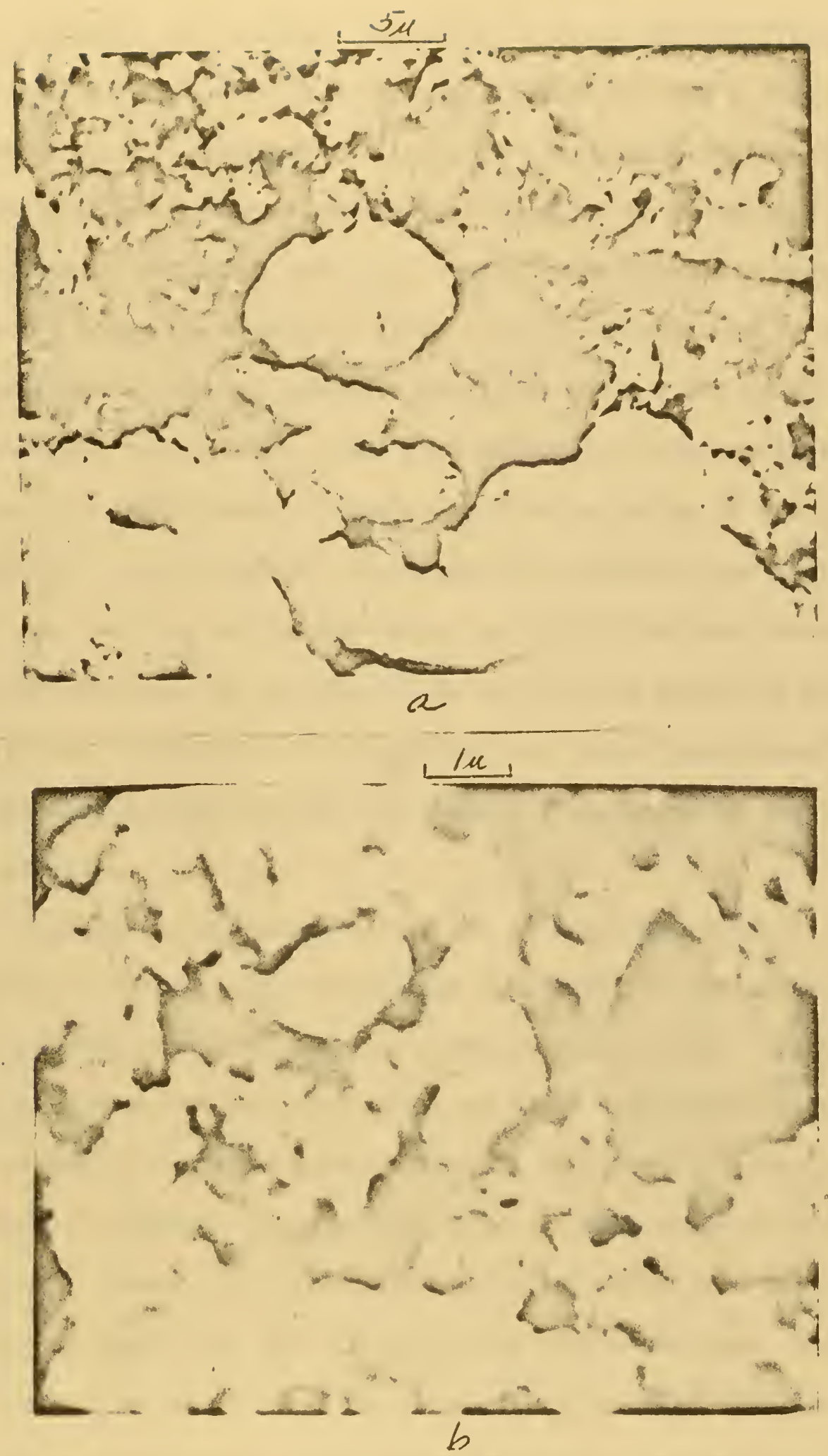

Figure 26. Photographs of (a) Montmorillonite Clay Enlarged a,b 2000 Times by Electron Microscope, (b) Montmorillonite Clay Enlarged 10,000 Times. 
silt. Although this standard deviation is twice that of Providence silt, this difference is probably not significant. As a descriptive measure of spread, standard deviation is less accurate when the sediment grains are very fine. This is due to the assumption, in the hydrometer method of analysis, that all particles are spherical and do not aggregate while settling. This assumption can be used with reasonable accuracy for most particles above $0.005 \mathrm{~mm}$ in size. However below $0.005 \mathrm{~mm}$ particles vary widely in shape and aggregate more readily. The formula for the standard deviation of the particle size $6_{\phi}$ is based on the 84 th percentile diameter (see Table 3 ). Eighty four percent of the Providence silt particles were coarser than $0.006 \mathrm{~mm}$ while 84 percent of the illite clay particles were coarser than $0.0006 \mathrm{~mm}$. It is apparent that error could have been introduced by aggregation and non-spherical particles in the 111 ite clay analysis.

Descriptive measures such as phi median diamter $\left(\phi_{50}\right)$ or ph1 deviation measure $\left(6_{\phi}\right)$ determined by a standard hydrometer method of analysis cannot be used for montmorillonite clay. ApproximateIy 80 percent of the particle sizes are below $0.005 \mathrm{~mm}$ in this clay. Other methods of analysis such as optical equipment or centrifugal methods are required. However time and cost make these methods impractical. Spread or distribution can be estimated from the percentages of sand, silt and clay that make up the sediment. Montmorillonite clay which has a large percentage of clay sized particles could be expected to have a large spread in particle sizes. A large distribution would be expected to increase Formation Factor. 
Montmorillonite was more resistive than illite and kaolinite, although size probably influenced this result also. As discussed earlier large distributions increased Formation Factor for sands when mean particle size was constant. Just as was found in the results on sands and silts, particle size appears to influence electrical resistivity measurement of clays although porosity is constant. As stated earlier higher Formation Factors were obtained for montmorillonite than for kaolinite. One of the two variables (in addition to distribution) is particle size. The mean particle diameter of montmorillonite is reported to be $\ll 0.001 \mathrm{~mm}$ while kaolinite is $0.003 \mathrm{~mm}$. According to 0 sthaus ${ }^{32}$ the particle diameters for montmorillonite clays ranged from 0.0016 to $0.00005 \mathrm{~mm}$. These measurements were made using a super-centrifuge operating at various speeds up to $50,000 \mathrm{rpm}$. This very large size difference in particle size most likely accounts for some of the difference in the Formation Factor of montmorillonite and kaolinite. At 82 percent porosity, the Formation Factor of these two clays was 2.10 and 1.48 respectively. It is doubtful that the mineral difference of these two clays influenced the Formation Factors, since both are non-conductive and the interstitial water was 0.6 normal sodium chloride.

Smaller differences in mean particle size (i.e. Providence silt $(0.016 \mathrm{~mm})$ and kaolinite $(0.003 \mathrm{~mm}))$ did not appear to influence the electrical resistivity measurements. As seen in Figure 22 the Formation Factors were nearly identical over the porosity range of 51-61 percent for these sediments. Because of the larger sized particles, Providence silt was not in a stable condition above 

61 percent porosity. If the particle size is smaller (as in kaolinite clay) the sediment exists in a stable condition at porosIties up to 84 percent. Electrical resistivity measurements were conducted up to a 91 percent porosity by producing a slurry. The data of Atkins and Smith ${ }^{11}$ for kaolinite and sodium montmorillonite clay is also presented in Figure 22. The Formation Factor-porosity data agxees well with the results obtained in this investigation. However in their work the difference between kaolinite and montmorillonite was attributed to shape and values for a given shape factor (m) were determined. As previously discussed the results of the present study on clay sediments suggest that the difference between the two is due to particle size and distribution. Meredith, ${ }^{1}$ after studying the electrical conductivity of dispersions (spheres and discs), concluded that errors as high as 10 to 20 percent were due to shape differences. Semenov found that disc shaped particles in rock resulted in higher Formation Factors than rocks of sipherical particles at equal porosities. The results of the present study indicate that shape: is not a factor influencing the electrical resistivity of sediment:s. The earlier discussion on sands and silts showed that differences between spherical and angular particiles were not detected by electrica! resistivity measurements. The results on clays and silts indicatı? that nearly identical electrical resistivity measurements resulted from sediments with angular or platy particle! shapes as the only apparent variable.

The effect of structure on electrical resistivity can be scen in Figure 22 if kaolinite $(0.6 \mathrm{~N} \mathrm{NaCl})$ is compared with kaolinite 

using 0.2 molar sodium tetra phosphate solution (Quadrafos) as the interstitial water of the sediment. The structure naturally encountered in a saline environment, a flocculant structure (sce Figure 2), resulted in a lower Formation Factor than when Quadrafos, a common deflocculating agent, was used to obtain a dispersed structure. The difference between the two increased as porosity decreased. For example at a porosity of 80 percent the Formation Factor for kaolinite $(0.6 \mathrm{~N} \mathrm{NaCl})$ was 1.33 while kaolinite (Quadrafos) was 1.55. At a porosity of 52 percent the Formation Factors were 2.30 and 3.60 respectively.

In the dispersed structure the clay particles are in a preferred orientation, that is one particle tends to be oriented to the next particle in the same manner. However in the flocculant structure the clay particles are in a randomly oriented pattern toward each other. According to Brindley ${ }^{33}$ preferred orientation will bring out or increase the intensity of $\mathrm{X}$-ray diffraction patterns of basal spacing (d-spacing) reflections. The d-spacing is the spacing between crystal lattice planes.

A side test was conducted to check if the particle orientation assumed previously could be validated by X-ray diffraction techniques. Two X-ray diffraction slides of equal thickness were prepared under identical conditions for kaolinite clay with $0.6 \mathrm{~N}$ sodium chloride as the interstitial water and kaolinite clay with $0.02 \mathrm{M}$ sodium tetra phosphate.

Using the General Electric diffractometer (model XRD-5S) in the Metallurgical Research Laboratory at the University of Rhode 

Island, each sample was scanned from 8 to 26 degrees. The procedure used is presented in Appendix C. This scan covered the two major d-spacing values of kaolinite clay; 7.2 and 3.6 Angstroms. The $X$-ray diffractograms of the two samples are presented in Figure 27. The vertical axis is a logarithmic indication of intensity corresponding to an approximate quantitative index of the mineral present. Although many factors affect intensity of the diffracted $X$-ray beams, orfentation of particle and the reinforcement of intensity caused by preferred orientation or the reduction of intensity caused by random orfentation of the same mineral particles would be a major factor determining the magnitude of intensity. The difference in intensity between the two samples is illustrated in Figure 27. An average intensity count was made at the two major d-spacing values. The results are shown in Table 10.

TABLE 10

THE AVERAGE INTENSITY COUNTS OF THE TWO MAJOR D-SPACING VALUES OF TWO STRUCTURES OF KAOLINITE CLAY

\begin{tabular}{|l|c|c|}
\hline Sample name & $\begin{array}{l}7.2 \mathrm{~d} \text {-spacing } \\
\text { Intensity (counts) }\end{array}$ & $\begin{array}{l}\text { 3.6 d-spacing } \\
\text { Intensity (counts) }\end{array}$ \\
\hline Kaolinite (0.6N NaCl) & 8758 & 8884 \\
Kaolinite (Quadrafos) & 47333 & 47842 \\
\hline
\end{tabular}

The results show that the kaolinite clay (Quadrafos) reinforced the intensity when compared with kaolinite clay $(0.6 \mathrm{~N} \mathrm{NaCl})$. These results indicate that kaolinite clay (Quadrafos) was of a dispersed 



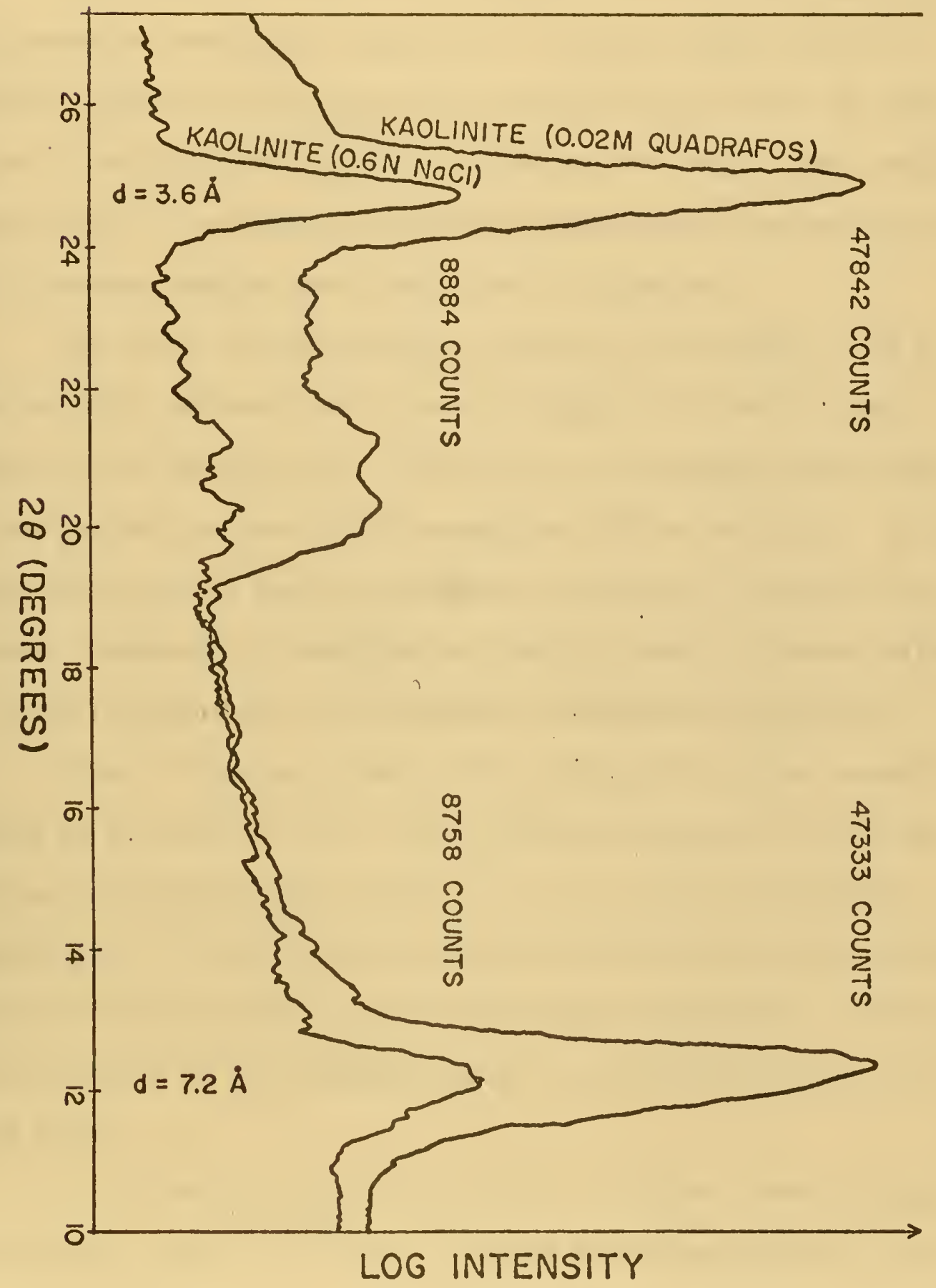

Figure 27. $x$-Ray Diffractograms of Two structures of Kaolinite Clay. 

structure while kaolinite clay $(0.6 \mathrm{~N} \mathrm{NaCl})$ was of a flocculant structure.

The salinity of marine and estuarine environments results in clay deposits formed by flocculation. Extremely high lateral or vertical pressure or perhaps even disturbance could cause the flocculant structure to collapse to a dispersed structure. These results suggest that the electrical resistivity measurements would change as the structure changed from flocculated to dispersed.

The effect of consolidation pressure on the conductivity of clay and silt sediments can be seen in Figure 28. These curves 11lustrate that the electrical conductivity is inversely proportional to the applied pressure in the range from 0.25 to $16.00 \mathrm{ps} 1$. In this range the Formation Factor increased in proportion to porosity decrease. Consequently consolidation pressure seems to have no effect on electrical resistivity of sediments independent of porosity. Figure 28 presents four curves showing illite clay consolidating at pressures of $0.25,1.00,4.00$, and $16.00 \mathrm{ps} 1$ and the resulting conductivity values of $2.7,2.5,2.0$, and $1.4 \mathrm{mho} / \mathrm{meter}$ respectively. Similar results obtained for Providence silt, kaolinite clay and montmorillonite clay, can be found in Appendix C. Porosity was determined at the beginning and end of the consolidation pressure tests.

As discussed in the Review of the Literature several studies on formation rocks $18,19,20$ have reported that Formation Factor increases much faster than the decrease in porosity. The pressures used ( 1,000 to 12,000 psig) were much greater than the 16 psi used 


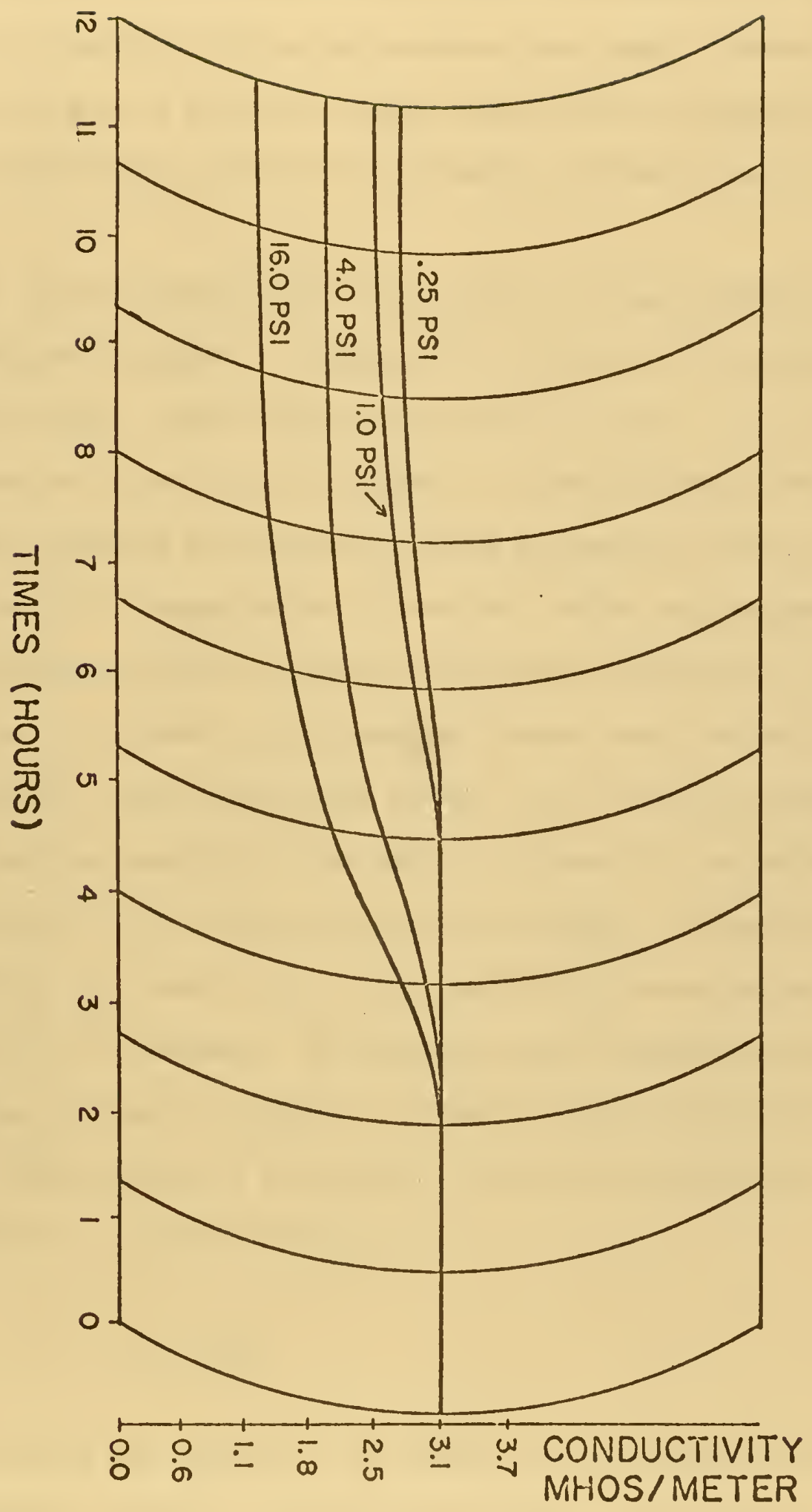

Figure 28. Conductivity versus Time Curves of Illite Clay at Consoljdation Pressures of $0.25,1.00,4.00$ and 16.00 psig. 

in this study. It would seem possible that sediments would be more casily influenced by overburden pressure than rocks. However the greater Increase of Formation Factor over porosity decrease was not found on sediments at the low consolidation pressures used in this study.

A typical conductivity versus time recording obtained by the redesigned equipment is presented in Figure 29 for kaolinite clay $(0.6 \mathrm{~N} \mathrm{NaCl})$. Most tests were run for 12 hours. At the times designated as $t_{1}$ and $t_{2}$ in the figure, a Formation Factor was obtained and compared with porosity values determined on the initial slurry and after consolidation. These two values were compared with Formation Factor-porosity values for kaolinite $(0.6 \mathrm{~N} \mathrm{NaCl})$ from Figure 22. At $t_{1}$ and $t_{2}$ the Formation Factors were 1.64 and 3.27 respectively. These values fall within the \pm 2 percent porosity error lines for kaolinite $(0.6 \mathrm{~N} \mathrm{NaCl})$ in Figure 22. The values for conductivity of the sediment sample were changed to Formation Factor by dividing the conductivity of the interstitial water by the conductivity of the sediment. By comparing these Formation Factors with those of Figure 22, values of porosity were obtained and used on the vertical scale of Figure 29. Since porosity and vold ratio (e) are uniquely related by:

$$
e=\frac{n}{1-n}
$$

the vold ratio was included as an addition on the vertical axis. For saturated sediments a relationship exists between the vold ratio 



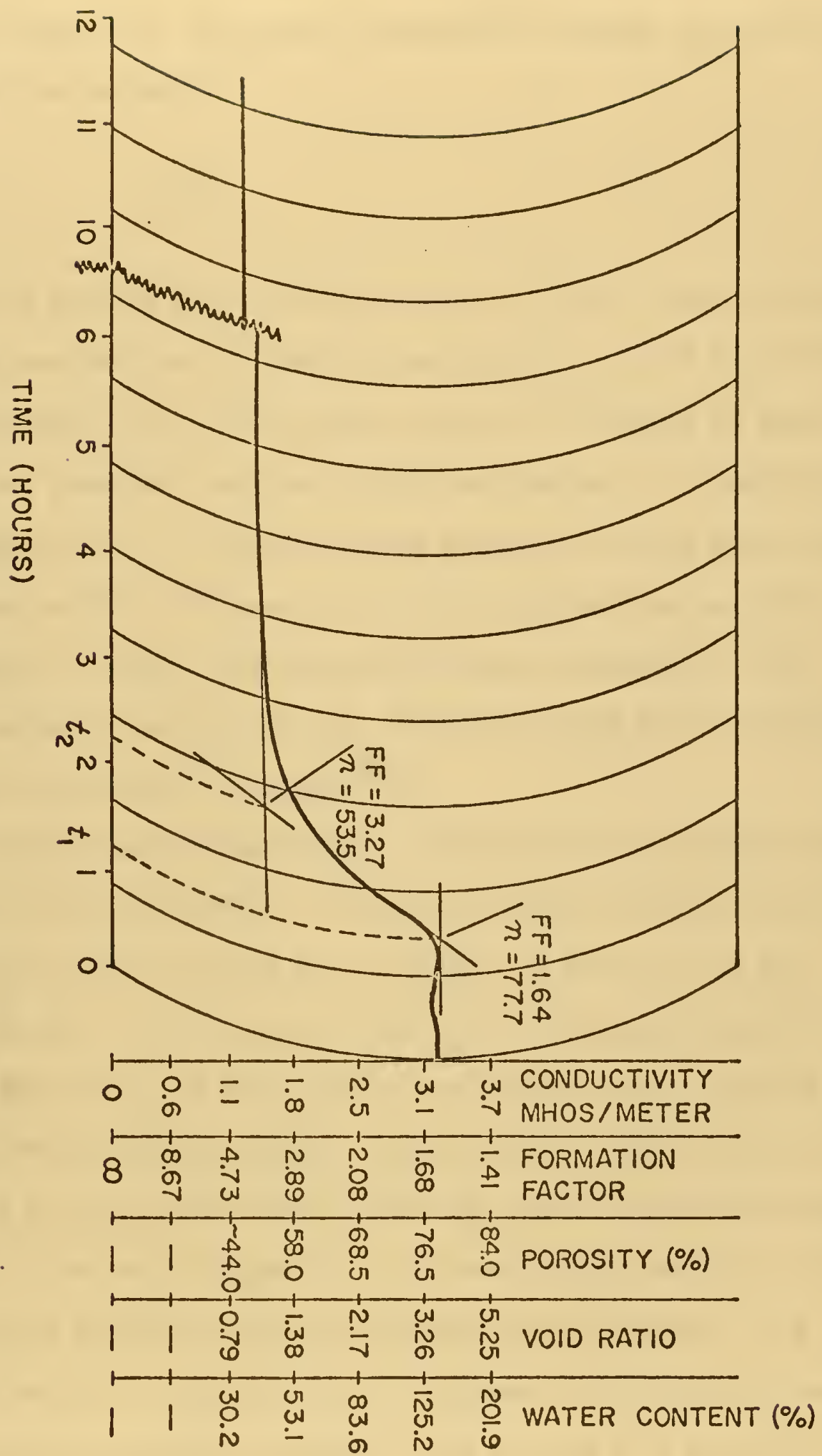

Figure 29. Conductivity, Formation Factor, Porosity, Void Ratio and water Content Versus Time of Kaolinite clay at a Consolidation Pressure of 16 psig. 

and water content (w) that can be obtained by knowing the specific gravity of the sediment:

$$
w=\frac{e}{G} \text {. }
$$

The specific gravity (G) of kaolinite clay is 2.60 . Water content was calculated and also included on the vertical axis of Figure 29. Therefore Figure 29 is a continuous record of the change in Formation Factor, porosity, void ratio and water content of a kaolinite clay sediment as it is consolidated by pressure of 16.00 psig over a twelve hour perlod. The total test time, consolidation pressure, and for times $t_{1}$ and $t_{2}$ the Formation Factors, porosities, vold ratios, and water contents for all sediments tested by the redesigned equipment are presented in Appendix $C$.

The continuous conductivity readings by the redesigned equipment can be extremely useful. If accurate Formation Factor-porosity relationships are determined for a sediment as they were in this study, then from the continuous conductivity readings (Formation Factor) the porosity, void ratio, and water content can be obtained at any point during the monitoring. Using the void ratios obtained at the end of a test, a void ratio versus the log of the consolidation pressure is plotted in Figure 30. In classical soll mechanics this type of curve is very useful in predicting consolidation. If a Formation Factor-porosity curve of a sediment is sufficiently accurate, then the redesigned equipment could be used as a consolidometer. Curves such as Figure 30 could be obtained by simply contin- 



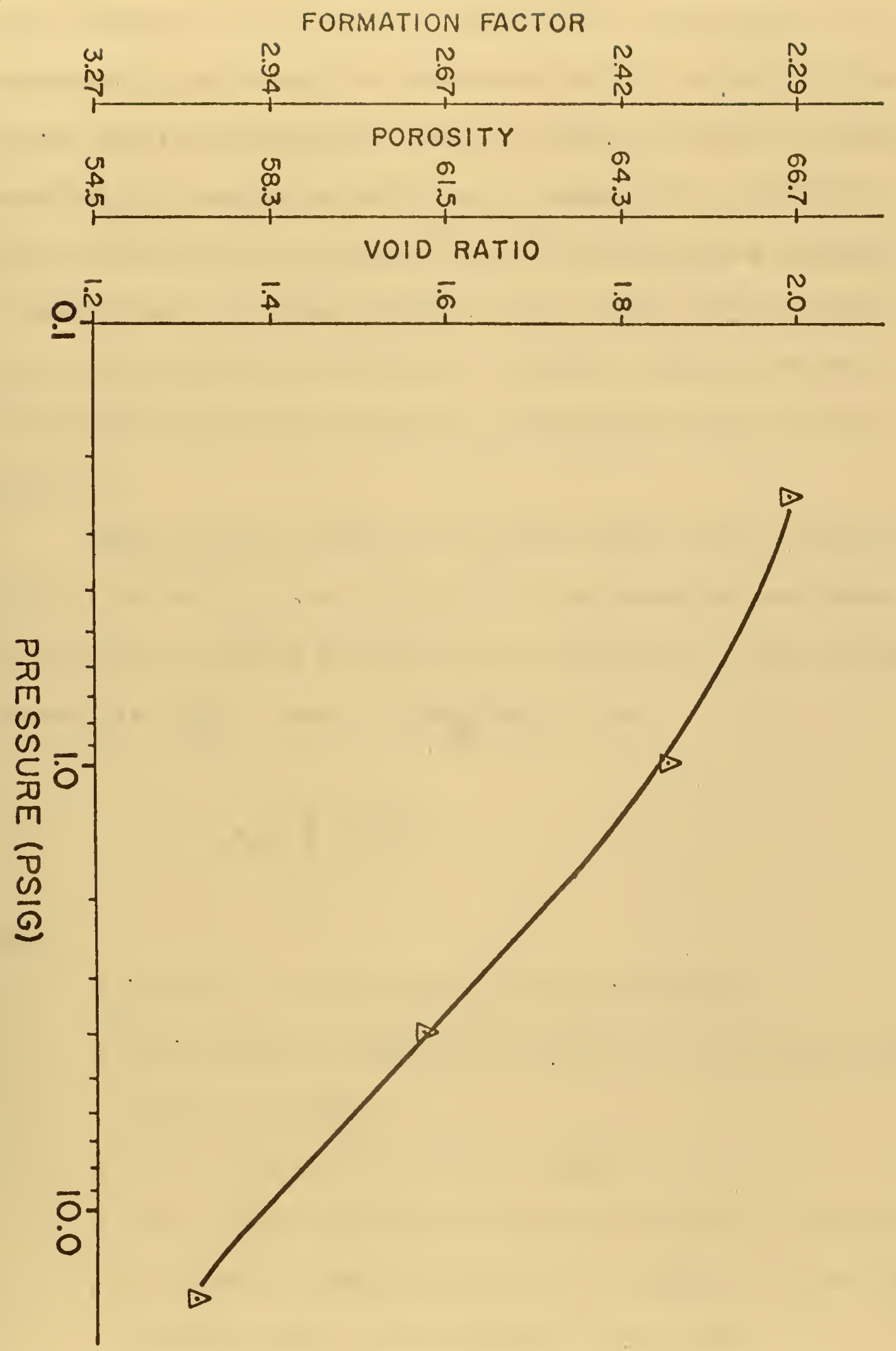

Figure 30. Formation Factor, Porosity and void Ratio Versus the $\log$ of the Consolidation Pressure of Illite clay. 

ually recording the electrical conductivity of the sample and incrementally increasing the pressure after set periods of time without removing the sample. Then by using the Formation Factorporosity relationship the porosity and consequently void ratio could be obtained and plotted versus the corresponding pressure. Currently tests are being conducted with a more advanced teflon cell in the redesigned equipment. This cell reduces side wall friction and allows more extensive and elaborate testing to be conducted.

Since the water driven out of the sample during consolidation was collected in the reservoir of the redesigned equipment, it was possible to obtain an approximate value of the coefficient of permeability $\left(K_{p}\right)$. Thus by using Darcy's Law:

$$
K_{p}=\frac{q}{t} \cdot \frac{\tilde{L}}{\Delta h} \cdot A
$$

where

$K_{p}$ is the coefficient of permeability $(\mathrm{cm} / \mathrm{sec})$,

9 the quantity of water collected in the reservoir during the test $\left(\mathrm{cm}^{3}\right)$,

$t$ the total time of the test (sec),

$\tilde{\mathrm{L}}$ the average length of the sample (obtained by measuring the Initlal length of sample and adding it to the final sample length, then dividing by two) (cm),

$\Delta h$ the pressure used in the test $(\mathrm{cm} \cdot)$,

A the cross-sectional area of the sample $\left(\mathrm{cm}^{2}\right)$. 

An example of the results of this type of calculation is presented in Figure 31. In this figure the void ratio at the end of a test is plotted against the coefficient of permeability for the illite clay. From this curve it is possible to obtain other coefficients of permeability from Formation Factors, if the Formation Factor-porosity relationship has been developed.

\section{Marine Sediments}

For the four different marine sediments tested

90 to 100 percent of the Formation Factor-porosity data points fell within \pm 2 percent of the line of best fit. This indicates that electrical resistivity measurements can accurately predict porosity of marine sediments. The values that fell outside the \pm 2 percent error lines were unusual samples usually containing pieces of coral or shells.

Two vertical profiles of a marine sediment core sample obtained by using the simple laboratory test apparatus are presented in Figures 32-a and 32-b. Porosity, water content, and sediment resistivity (corrected to a temperature of $25^{\circ} \mathrm{C}$ ) are shown. The points on the curves represent discrete measurements. The horizontal dashed line indicates where the core was cut to facilitate handling and storage.

The electrical resistivity of this sediment was inversely proportional to the water content and porosity. An exception is illustrated in Figure 32-a. A large shell approximately two inches in diameter was located at a depth of 20 inches. At this location the 



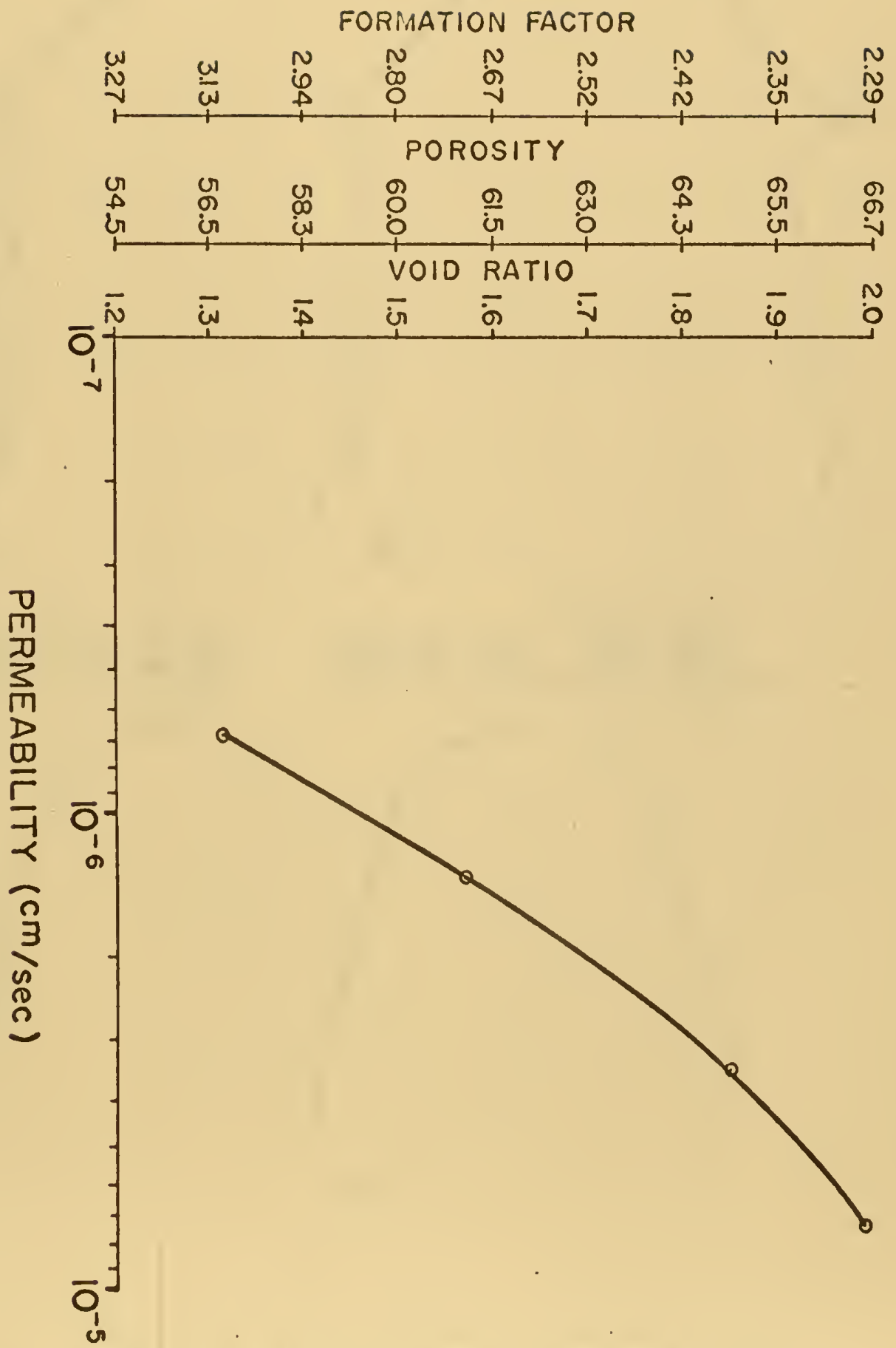

Figure 31. Formation Factor, Porosity and void Ratio Versus the coefficient of Permeability of Illite Clay. 


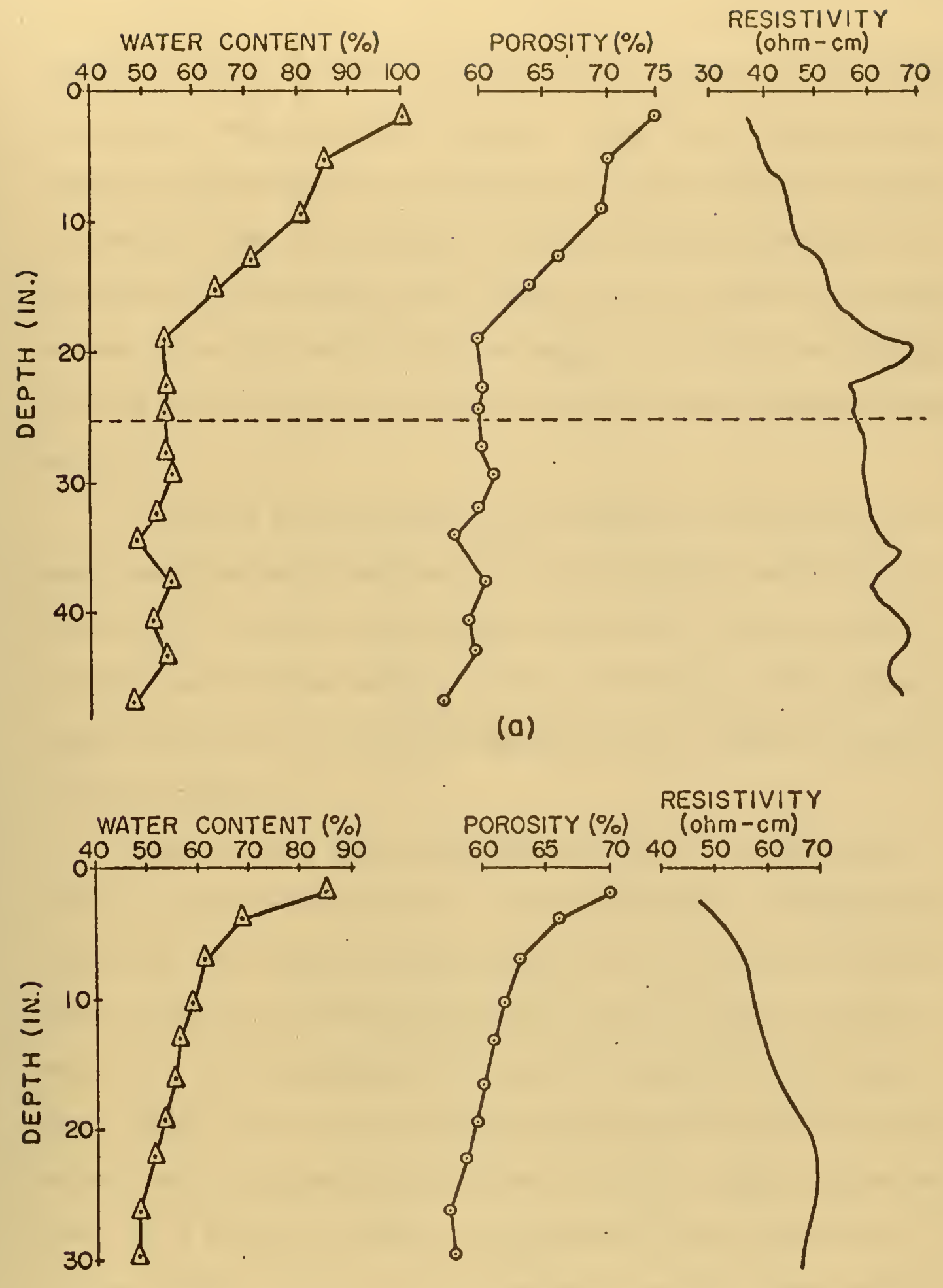

(b)

Figure 32. Two Vertical Depth Profiles of Porosity, water $\mathrm{a}, \mathrm{b}$ Content and Electrical Resistivity of a Marino sediment. 

resistivity of the sediment increased sharply, but the water content and porosity remained fairly constant. These sharp changes in resistivity are indicators of structure and fabric changes along the core sample.. One $2 \frac{1}{2}$ inch diameter core showed sharp increases in resistivity. Wet sieving a five inch section of this core through a 40 mesh sieve (the section with the highest electrical resistivity) produced over 320 grams of shells, coral and other calcium carbonate material.

Formation Factor-porosity data obtained by using both the simple and redesigned equipment for the four marine sediments and the lines of best fit are presented in Figure 33. Since some of this data was obtained using slurries, the vertical dashed lines in Figure 33 indicate the porosity below which the sediments exist in a stable condition.

Discussion of the factors which influence the Formation Factor-porosity relationship for marine sediments is difficult because with the exception of Narragansett Bay sand (Station $C$ ), the marine sediments tested were mixtures. The mixtures of particles found in a marine sediment can be seen in Figure 34. This photograph (after a $575 x$ electron microscope enlargement) of the sediment obtained at Narragansett Bay (Station B) shows a large angular sand grain and a variety of plate, rod and angular shaped particles. The purpose of this picture is not to determine particle shape which has been found to have little effect on electrical resistivity measurements of sediments, but to illustrate the wide variety of particle sizes and shapes found in a marine sediment. Measures such as $\phi_{50}$ 



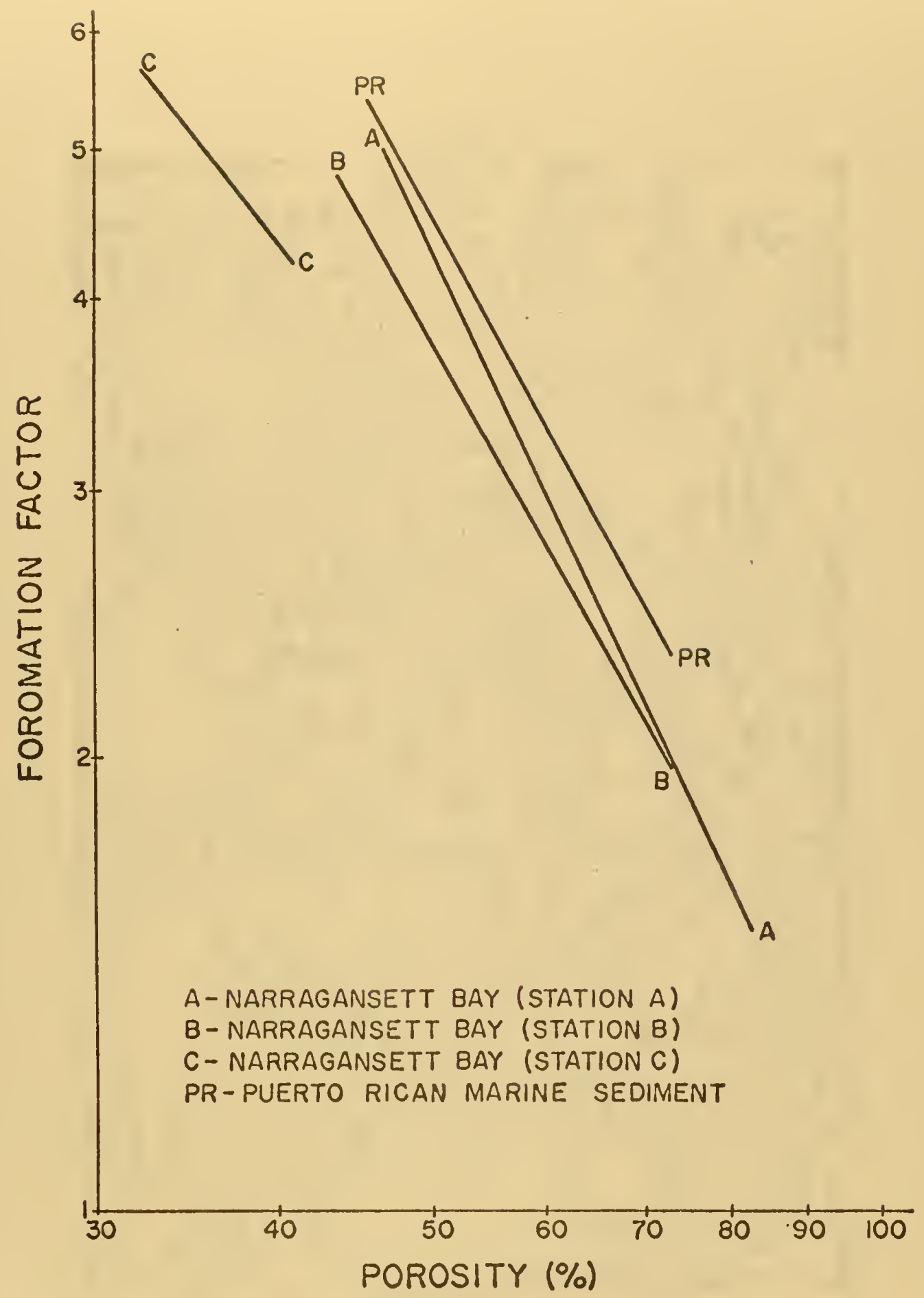

Figure 33. Formation Factor-Porosity Relationships of Four Marine Sediment:s. 



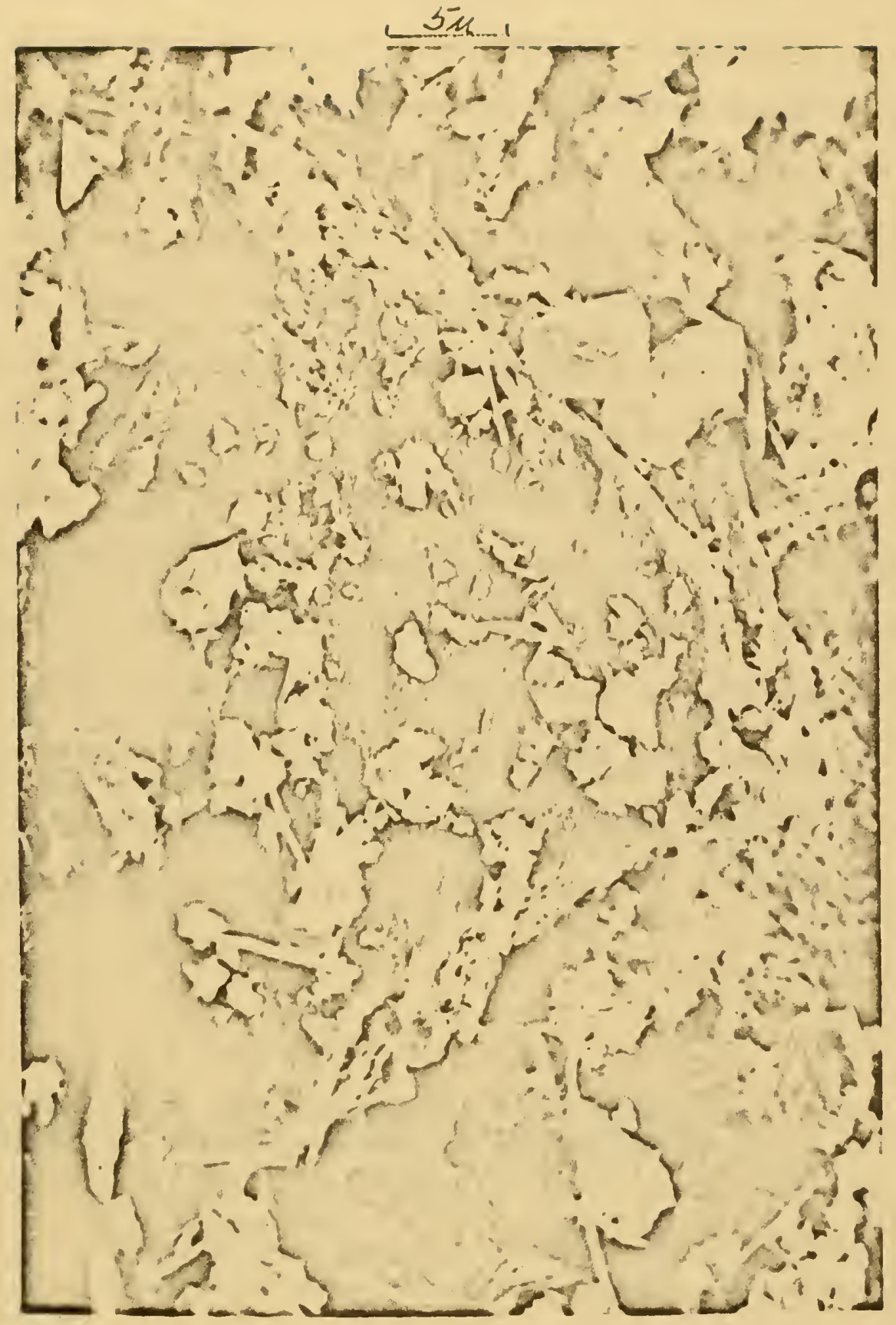

Figure 34. Photograph of a Marine sediment from station B Enlarged 575 Times by Electron Microscope. 

and ${ }_{\phi}$ can be obtained for marine sediments but the values for different sections of a marine core sample vary so widely that little can be concluded from these measurements. Consequently sediment classification, that is percentage of sand, silt, and clay, is more useful than particle size and shape when observing the effect marine sediment particles have on electrical resistivity measurements. For example it was observed that the Formation Factor of sediments with a higher sand content change less with a change in porosity than of sediments with a lower sand content. The reduction in negative slope of the Formation Factor-porosity curve for Narragansett Bay sand (Station C) can be seen in Figure 18. If the line of best fit is extrapolated to the vertical axis at a porosity of 100 percent, those sediments with a higher sand content resulted in higher intercept values. Table 11 illustrates these points by showing the Formation Factor intercept values and the negative slopes along with the percentages of sand in the marine sediments tested.

TABLE 11

FORMATION FACTOR INTERCEPT VALUES, NEGATIVE SLOPES, AND PERCENTAGE SAND OF FOUR MARINE SEDIMENTS

\begin{tabular}{|c|c|c|c|}
\hline Sediment & $\begin{array}{l}\text { (Intercepts) } \\
\mathrm{FF} \text { at } 100 \% \text { porosity }\end{array}$ & Slopes & Sand \% range \\
\hline $\begin{array}{l}\text { Narragansett Bay } \\
\text { (Station C) }\end{array}$ & 1.47 & -1.20 & $97-100$ \\
\hline $\begin{array}{l}\text { Puerto Rican } \\
\text { sediment }\end{array}$ & 1.36 & -1.77 & $70-50$ \\
\hline $\begin{array}{l}\text { Narragansett Bay } \\
\quad(\text { Station B) }\end{array}$ & 1.15 & -1.75 & $58-43$ \\
\hline $\begin{array}{l}\text { Narragansett Bay } \\
\quad(\text { Station } A)\end{array}$ & 1.00 & -2.22 & $33-41$ \\
\hline
\end{tabular}



The marine sediments which contained a higher percentage of clay were stable at a higher porosity than the sediments with less clay. This point is illustrated in Table 12, which shows the percentage of clay and the highest porosity at which the marine sediments existed in a stable condition.

\section{TABLE 12}

PERCENTAGE CLAY AND THE HIGHEST POROSITY AT WHICH THE FOUR MARINE SEDIMENTS WERE STABLE

\begin{tabular}{|l|c|c|}
\hline Name & Clay (\%) & $\begin{array}{c}\text { Highest } \\
\text { Porosity (\%) }\end{array}$ \\
\hline Puerto Rican marine sediment & $7-18$ & 74 \\
Narragansett Bay (Station A) & $7-14$ & 74 \\
Narragansett Bay (Station B) & $4-9$ & 67 \\
Narragansett Bay (Station C) & 0 & 41 \\
\hline
\end{tabular}

The sediments that can exist at a higher porosity result in a larger range of Formation Factors since the range of porosity at which electrical resistivity measurements can be made is greater.

Data such as coefficient of permeability, porosity, void ratio and water content versus time for various consolidation pressures is presented in Appendix $C$.

\section{Model Equations}

The coefficients of the empirical model equation (Equation 32) were determined for each sediment. A similar method is used by well logging engineers to determine empirical model equations for different 

rock formations. Table 13 presents the empirical models for each sediment and the range of Formation Factors and porosity determined in this investigation.

Since 94 percent of the data points used to obtain the line of best fit fell within \pm 2 percent porosity error lines (the other six percent fell within \pm 4 percent), these equations can be considered good emplrical prediction equations for each individual sediment. Kermabon et al. ${ }^{12}$ obtained a porosity error line of \pm 2.5 percent with 2500 data points used to determine a prediction equation from 21 cores taken from a 40 square mile area in the Tyrrhenian Sea. The prediction equations developed by Kermabon et al., ${ }^{12}$ Boyce, ${ }^{9}$ and Smith $^{13}$ (presented in the Review of the Literature section as Equations 41,40 , and 43 respectively), were tested with this data and predicted the porosity of Providence silt, kaolinite clay $(0.6 \mathrm{~N} \mathrm{NaCl})$, illite clay and Narragansett Bay sediment (Station $A$ and $B$ ) within \pm 5 percent in the 50 to 70 percent porosity range. Although the "Humble Formula", Equation 33, is the most widely used prediction equation for rock formations, it is not at all applicable to sediments.

The two factors which influenced Formation Factor-porosity equations the most in the saline environment of these laboratory experiments, were the mean size of particles (if the mean size differed by at least ten diameters) and the distribution or spread of particle sizes. The data in Figure 18 is grouped into two distinct areas: In one area were the sands, and in the other area were the silts and clays. As discussed previously, classification into 

TABLE 13

THE COEFFICIENTS OF THE MODEL EQUATION, POROSITY RANGE AND FORLATION FACTOR RAJGE OF THIRIEEN SEDIKENTS.

\begin{tabular}{llll} 
Name of Sediment & $\begin{array}{l}\text { Coefficients of the } \\
\text { Model Equation* } \\
F F=a n^{-m}\end{array}$ & $\begin{array}{c}\text { Porosity } \\
\text { Range (\%) }\end{array}$ & $\begin{array}{c}\text { Formation } \\
\text { Factor Range }\end{array}$ \\
\hline Ottawa sand & $F F=1.55 n^{-0.97}$ & $26-43$ & $3.5-5.7$ \\
Glacial sand (1-a) & $F F=1.57 n^{-0.96}$ & $30-47$ & $3.2-5.0$ \\
Glacial sand (1-b) & $F F=1.35 n^{-1.10}$ & $31-47$ & $3.1-4.7$ \\
Glacial sand (2) & $F F=1.45 n^{-1.10}$ & $31-46$ & $3.1-5.4$ \\
Narragansett Bay (Station C) & $F F=1.47 n^{-1.20}$ & $32-40$ & $4.3-5.7$ \\
Kaolinite clay (0.6N NaCl) & $F F=n^{-1.97}$ & $51-92$ & $1.2-3.8$ \\
Illite clay & $F F=1.08 n^{-1.82}$ & $55-81$ & $1.6-3.3$ \\
Montmorillonite clay & $F F=n^{-4.11}$ & $81-96$ & $1.4-2.1$ \\
Kaolinite clay (Quadrafos) & $F F=1.05 n^{-1.24}$ & $41-94$ & $1.1-3.1$ \\
Providence silt & $F F=1.11 n^{-1.75}$ & $41-62$ & $2.5-5.2$ \\
Narragansett Bay (Station A) & $F F=n^{-2.22}$ & $47-82$ & $1.5-5.0$ \\
Narragansett Bay (Station B) & $F F=1.15 n^{-1.75}$ & $44-74$ & $2.0-4.9$ \\
Puerto Rico marine sediment & $F F=1.36 n^{-1.77}$ & $46-74$ & $2.1-5.0$
\end{tabular}

* On double logarithmic paper (m) of the model equation is the slope of the line of best fit and (a) is the intercept of the equation's Iine with the vertical axis at 100 percent porosity. 

percentages of sand, silt and clay generally indicate mean particle size and spread. A prediction equation such as

$$
F F=1.6 / n,
$$

would approximate the porosity of the sands of this study to within \pm 5 percent porosity. A prediction equation such as

$$
\mathrm{FF}=1.1 / \mathrm{n}^{2}
$$

would best approximate the porosity of silts and clays to within \pm 5 percent porosity with the exception of montmorillonite. Montmorillonite, which has a high clay content (78 percent) resulted in increased slope value $(\mathrm{m})$. This probably can be explained by the fact that this sediment has a much smaller mean particle size and greater distribution than found in sediments containing less than 70 percent clay. A prediction equation such as:

$$
F F=1 / n^{3}
$$

or

$$
F F=1 / n^{4}
$$

would approximate montmorillonite and similar clays better. Of the four marine sediments tested in this study the porosity of three was predicted within \pm 5 percent by the equation which best approximated clays and silts, while the porosity of Narragansett Bay sand (Station C) was predicted within \pm 5 percent by the equation which best approximated sands. It appears that porosity can 

be predicted within \pm 5 percent by obtaining an electrical resistivity measurement and knowing the major type of sediment present: (a) sand (b) silt and clay (c) predominantly clay. Table 13 suggests that a more accurate prediction is possible by determining the electrical resistivity and the porosity of enough samples to obtain a Formation Factor-porosity curve (at least ten samples with a wide range of porosity), and developing an equation that approximates that specific sediment. This is easily accomplished using the redesigned equipment. This equation could then be used to predict the porosity (within \pm 2 percent) of the area by measuring only the electrical resistivity of the sediment and $i$ ts interstitial water. As discussed in the Review of the Literature section, most of the theoretical model equations were developed for dispersions or porous mediums such as rocks. However the following observations compare the results of this study with the theoretical work in the 11terature.

1. All data obtained in this investigation lie within the Parallel and Series Equation (Equations 21 and 22).

2. The equations that considered particle shape such as Maxwe11, Meredith, and Semenov (Equations 18, 27 and 37 respectively) agree with the Formation Factor-porosity relationships of this study; however the results on particle shape in this investigation show that in sediments shape is not an influential factor.

3. The non-dimensional conductivity term $\left(K_{d}\right)$ is unnecessary in a saline environment (above 18.5 parts per thousand at $25^{\circ} \mathrm{C}$ ) since 

this term approaches zero. Equations that consequently have no meaning in a saline environment are: Equations 22 and 24. However in a fresh water enviromment the term $\mathrm{K}_{\mathrm{d}} \neq 0$ and these equations may be applicable, especially if a clay with a high cation exchange capacity such as sodium montmorillonite is present.

4. Kaolinite clay with $0.02 \mathrm{M}$ sodium tetra phosphate solution as interstitial water followed the Maxwell Equation (Equation 18) for non-conducting spheres though the particle shape of this clay was platy (see Figure 23-a and 23-b). The structure of this sediment was dispersed and therefore the grains were not in direct contact with each other. As stated earlier shape does not seem to influence the resistivity of sediments. These results suggest that the Maxwell Equation is a good prediction equation for sediments of dispersed structure regardless of their shape. The dispersed structure of the kaolinite clay is close to one of the boundary equations (Parallel Equation). This is as expected since the dispersed orientation is an extreme case.

5. In the general theoretical formula (Equation 34) for resistivity of a porous medium such as a sediment, the term $f(c)$ is a factor that depends on the amount of clay/silt in the sediment. The results of this investigation indicate that the term $f(c)$ is more dependent on the mean particle size and distribution or spread than on the clay/silt shape or mineral content: . 



\section{CONCLUSIONS}

1. Formation Factor-porosity relationships were determined for three clays (kaolinite, 1111 te and montmor11lonite), Providence silt, four sands and four marine sediments. Formation Factors ranged from 1.1 to 5.9 while porosities ranged from 26 to 93 percent. The results show that the porosity of these sediments correlated well with electrical resistivity measurements. In fact 94 percent of the data points fell within \pm 2 percent of the line of best fit, while the other six percent fell within \pm 4 percent of the line of best fit.

2. Mathematical model equations and a graphical presentation of the data showed that the data grouped into two classes,

a) sands and b) silts and clays. In the mathematical equation $\left(F F=a^{-m}\right)$, the intercept value $(a)$ was higher for sands $(1,6)$ than for clays (1). The slope value (m) was approximately minus one for sands, minus two for silts and clays, and minus three or four for sediments having at least 70 percent clay sized particles. This description of (a) and (m) excludes kaolinite clay particles in a dispersed structure. While the intercept value was similar to the other clays $(1.05)$, the slope (m) was closer to that of sands than clays $(-1.24)$. Kaolinite clay particles in a dispersed structure followed the theoretical equation of Maxwe $11^{21}$ for non-conducting spheres. 

3. The cation exchange capacity influenced the electrical conductivity measurements of sodium montmorillonite and ilite clays when the conductivity of the interstitial water was 1.1 to 3.0 mho/meter. Above 3.0 mho/meter this influence was negl1gible. The cation exchange capacity of kaolinite was neglig1ble over the range of interstitial water salinities tested (1.1 to $5.6 \mathrm{mho} /$ meter).

4. The mineral difference between kaolinite and illite clays did not influence the electrical resistivity measurements in this study.

5. As the particle size of sediments decreased, electrical resistivity increased. When the mean particle size of a sediment was 30 times larger than that of a simflar sediment at the same porosity, the Formation Factors were considerably different. However small differences in particle size (about 5 times) were not detectable by electrical resistivity measurements.

6. The distribution of particle size was found to affect electrical resistivity measurements; the Formation Factor was found to increase as the spread in particle size increased.

7. The particle shape of the sand, silt and clay sediments tested did not appear to influence the electrical resistivity measurements in this study. Spherical shapes were compared with angular shaped particles and angular shapes were compared with platy shaped particles.

8. The structure of sands did not influence the electrical resistivity measurements independent of porosity. Densely packed sand 

was compared with loosely packed sand.

9. Consolidation pressure (for normally consolldated sediments) up to 16 psig did not influence the electrical resistivity measurements of the clays and silts tested independent of porosity.

10. The structure of two kaolinite clay samples did affect electrical resistivity measurements, especially at lower porosities. The flocculated structure had a much higher Formation Factor than the dispersed structure at 52 percent porosity.

11. The marine sediments varied so much in particle size, shape and distribution within core sections that percentage sand, silt and clay is a more useful classification. For the marine sediments with higher sand content the change in electrical resistivity was less with a change in porosity than the sediments with less sand,

12. Unusual marine sediment samples which fell outside the \pm 2 percent error lines of the Formation Factor-porosity line of best fit were found to contain large amounts of shell or coral.

13. The electrical resistivity measurements made with the redesigned laboratory equipment in this study allowed permeability, tortuosity, and vold ratio-log consolidation pressure to be determined. Though further study is required to validate this as a method, electrical resistivity measurements by the redesigned equipment could provide a fast, easy and inexpensive method of testing in the field of submarine soll mechanics. 

14. The redesigned laboratory equipment which consisted of a cell, an electrode array and a signal conditioner is safe, simple, easy to operate and economical $(\$ 500.00)$. Also required for these tests are a standard volt meter and recording equipment (a simple strip chart recorder is sufficient). 
II

AN ELECTRICAL RESISTIVITY MEASURING SYSTEM

FOR THE DETERMINATION OF POROSITY OF

MARINE SEDIMENTS IN SITU 



\section{INTRODUCTION}

An Electrical Resistivity Measuring System was designed, fabricated, and tested as a method of predicting porosity of in situ marine sediments. The system consists of electrode arrays, an electronic measuring circuit, and a FM multiplex telemetry data link. These three components will be added to the Deep Ocean Sediment Probe (DOSP).

The DOSP (see Figure 35) was designed and built by the University of Rhode Island under contract to the Naval Underwater Systems Center (NUSC), Newport-New London (Lewis ${ }^{30}$ ). The original mission of the DOSP was to obtain the velocity and attenuation of compressional sound waves through the ocean sediment. This was accomplished by inserting four probe legs, located at the corners of the base structure, incrementally into the sediment to a distance of five feet. In one of the legs an acoustic sparker source provides a signal which is received by hydrophones located in the other legs. In addition, a thin walled corer, centrally located equidistant from the probe legs, is used to collect a sediment sample for laboratory correlation with in situ acoustic and temperature data obtained at various probe penetrations, With a current design depth of 5,000 feet, the DOSP provides an excellent stable ocean floor platform for in situ sediment measurement sensors. In addition to the Electrical Resistivity Measuring System, other systems currently being added to the DOSP are a Nuclear Gage (Rose and Roney ${ }^{34}$ ) for 



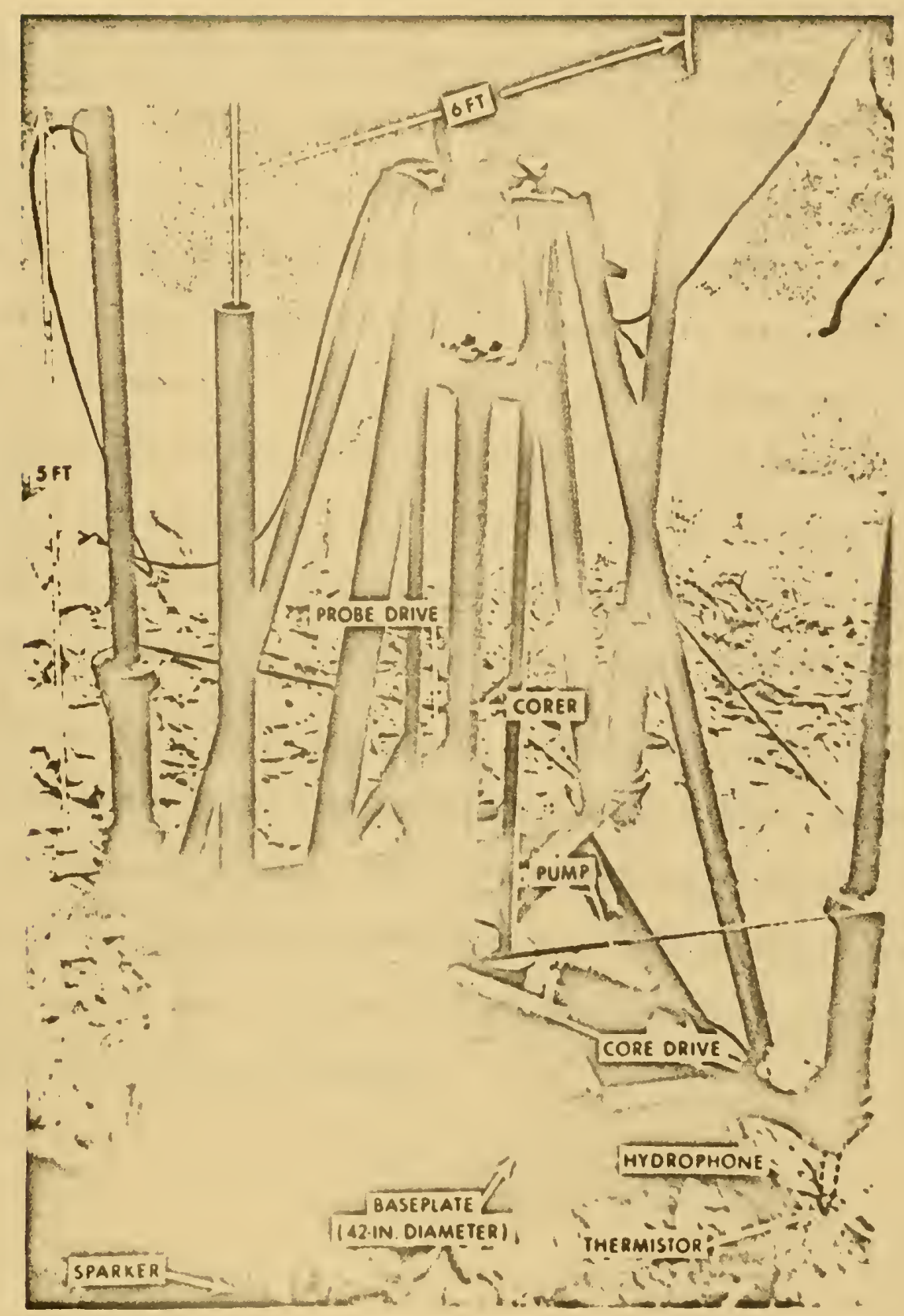

Figure 35. Photograph of the Deep Ocean Sediment Probe (DOSP). 

sediment density measurements, a geochemical probe, and a multicoring unit to obtain longer cores.

The ability of the DOSP to obtain samples with minimum disturbance for correlation with acoustical data is a major step forward. However, certain variables such as: (1) a measure of disturbance while penetrating, (2) temperature changes and possible release of gases in solution while returning the sample to the surface, and (3) sample handling on deck, enroute to the laboratory, and in the laboratory, are not monftored and therefore still leave an area for improvement. The Electrical Resistivity Measuring System will allow continuous resistivity readings to be taken while the corer barrel is penetrating the ocean bottom (both inside and outside the corer barrel) and also while the sample is being returned to the surface. It will be possible to cstimate the degree of disturb: ance during these operations and in addition to predict sediment porosity and water content. Resistivity readings could also be taken after sectioning (just before storage) and later in the laboratory prior to testing analysis, and thus allow a measure of disturbance during these handling procedures. 

Most electrical resistivity field equipment was developed by geophysicists for oll or other mineral prospecting. Dakhnov ${ }^{25}$ reviewed almost all the geophysical well logging equipment used before 1962. A detailed description of all the electronics and electrode arrays used is included. When and where each electrode array is best used while surveying is also discussed. Books and pamphlets of more recent equipment used in geophysical well logging are available from Schlumberger Ltd., P. O. Box 2175, Houston, Texas, 77001. Electrical resistivity measuring equipment and interpretation of electrical resistivity logs are included. Fisher ${ }^{35}$ suggests that the unique hardware which has been developed for the radical changes in pressure and temperature that occur in 011 well bore holes could have useful application in the ocean as well. The application of two different geophysical methods in order to determine the physical properties of land solls has been described by Borowczyk and Krol1kowski. 36 These authors combined electrical resistivity and radioactive isotopic methods in one probe called the "Universal Probe". This probe consisted of a steel tube with electrical resistivity electrodes located in the tube head. The probe was introduced into the soil by either a vibrating hammer or drill rig - pile driver which used a tripod for vertical support. While sinking the probe into the ground at intervals of 10 or $20 \mathrm{~cm}$, , electrical resistivity measurements were taken. After these measurements 

radioactive isotopic transmitting and detecting equipment were lowered down the steel tube (inner diameter $3.5 \mathrm{~cm}$ ) and the intensity of the scattered gamma radiation was determined. The authors concluded that the Universal Probe allowed accurate soll water contents and porosities to be predicted by nuclear measurements, soil bed and thickness identification by electrical resistivity measurements, and approximate soil strength by the penetration resistance measurements made during probe insertion. These conclusions were arrived at by correlating the measurements made by the probe with known stratigraphy and soil properties obtained by borings.

The electrical resistivity surveying techniques that were first developed by Wenner ${ }^{37}$ were used in a land survey by Perret. ${ }^{38}$ With a simple apparatus consisting of batteries, a double commutator, a null indicator potentiometer, and the necessary cables, reels and steel electrodes, he was able to determine the depth of a marine clay which underlies the lower Mississippi Valley. At four check points the electrical resistivity data agreed with boring data within 3.5 percent. By using electrical resistivity surveying techniques, 1t was possible to use boring intervals of 5,000 feet instead of the usual 1,000 feet. This resulted in an 80 percent reduction in time and a 59 percent reduction in cost when compared with surveying the site only by boring techniques.

The standard geophysical laboratory or field electrical resistivity equipment used on land can be used to measure the resistivity of marine sediments. The first resistivity measurcnents made on marine sediments were conducted on board ship after cores had been 

taken. Cell modification was required to handle sediments instead of formation rocks. More extensive equipment modifications are necessary in order to measure resistivity of marine sediments in situ. Since bore holes are not provided, a penetration type probe is required. Deep penetration is not usually possible since power sufficient to drive a probe deep into the bottom is not avallable on the deep ocean floor. Since a stable platform is usually unavalable, distance of probe penetration is difficult to measure accurately. Either the electronics and power must be encased in a water tight pressure vessel or long lengths of electrical cable must be provided.

Boyce ${ }^{9}$ measured electrical resistivity of Bering Sea cores on board ship and in the laboratory. The original plastic core liner served as the cell. A copper ring was securely glued on a circular jacket. Four silver alloy needles were soldered to the copper ring. The needle electrodes were geometrically spaced 90 degrees apart around the ring. When the circular jacket was clamped to the core liner, the needle electrodes penetrated the core liner and made contact with the sediment. Four of the circular jackets were vertically spaced along the core liner. This configuration is similar to four ring electrodes in which the current electrodes are the outer two rings and the inner rings are the potential electrodes. The electronics consisted of a FRL Resistivity meter (Type 3320, manufactured by Scientific Services Laboratorles, Inc., Dallas, Texas). This instrument was basically a potentiometric nulling circuit. The device was nulled manually and the resistance of the sediment was di- 

rectly read on the meter. The resistance reading was then corrected for temperature and multiplied by a cell constant to give a resistivity value corrected to $25^{\circ}$ Centigrade. Interstitial water was squeezed out in a press and salinity was measured by an induction salinometer. Although sediment resistivities were obtained both on board ship and in the laboratory, the resistivity of the interstitial water obtained in the laboratory was used to obtain Formation Factor. for both the sediment at sea and in the laboratory.

The apparatus used by Pautot $^{26}$ to measure electrical resistivity, of sediment cores taken from both the sea and a lake environment was a quadripole electrode arrangement which was moved along the vertical axis of the core. The quadripole electrodes were of the Wenner arrangement. A Tellohm resistance meter measured the resistance directly. The resistance reading was multiplied by a geometric constant to obtain the resistivity.

Willams, ${ }^{39}$ in order to determine bottom types (sand, silt and clay) designed, built and tested a device that measured the In situ Formation Factor at the water sediment interface. The Formation Factor measuring electrodes consisted of a mutually shared copper ring electrode placed on the perimeter of a non-conducting plastic disc. Two copper point electrodes were pläced on each side in the center of the disc. The point electrodes were insulated from each other. The disc was placed at the water-sediment interface to locally isolate the water and sediment for separate resistance measurements. Since the upper and lower electrode geometry was Identical, the ratio of the resistance at the terminals was 

equal to the Formation Factor. The elcctronics of the system consisted of a ratio bridge circuit that was manually nulled to directly read the Formation Factor. These Formation Factor measurements are based on the assumption that the resistivity of the water immediately above the sediment is the same as the resistivity of the interstitial water in the adjacent surface sediments. The temperature of the sediment and water are also assumed to be the same.

Since electrical resistivity measurements on cores are time consuming and expensive, Bouma et al. 27 and Chmelik et al. ${ }^{28}$ modified an electrical well logging system to be used with a specially designed in situ probe. The in situ probe consisted of a heavy stainless steel tube 12 feet in length with stabilizing fins welded to the upper end. The electrodes consisted of brass rings mounted to the nose of the stainless steel tube. Rings of PVC insulated the electrodes from each other and from the stainless steel rod. The electrode wiring which was encased in a water tight cabling was brought up through the stainless steel tube to the well logging electronics located on board the research vessel. The electrodes were designed to operate in the normal mode and in a guard mode. The normal mode is an array in which the distance between the measuring electrode is large compared to the distance between the current source and the closest measuring electrode. The guard mode is an array in which a thin center current electrode is placed between two guard current electrodes. This configuration causes the current flow from the center electrode to be limited to a horizontal plane rather 

than spreading out. The measuring electrodes are usually located between the guard electrodes and the center current electrode.

The in situ probe was lowered on a steel cable and allowed to fast fall the last ten feet by releasing the brake. A spoked wheel (18 inches in diameter) which contained magnets in the wheel hub was lcosely fitted to the stainless steel probe tube. As the probe penetrated the bottom the wheel remained at the water sediment interface. Magnetic proximity switches were placed at one foot intervals on the probe. Depth of probe penetration was obtained by an overriding spike signal caused by the closing of the proximity switches as they passed through the magnetic field located in the wheel hub. As the probe was extracted an excitation current and the return signal were sent over a separate cable to obtain the resistivity measurements.

Electrical resistivity measurements were made on the cores using the same electrical well logging system, but the electrodes were mounted to a sliding carriage which was in synchronous movement with a recorder. Cores were vertically cut in half and one section was placed in a rack. The electrodes, consisting of brass pins, were lowered into the sediment. The equipment was energized and the electrodes raked the sediment as the carriage moved down the length of the core section. A continuous electrical resistivity reading versus core length was recorded.

It is difficult to interpret the results obtained with this equipment since temperature is not accounted for and interstitial water salinity and bottom water salinity were not given. Consequent- 

ly Formation Factors could not be obtained and the work could not be compared with other research work.

New equipment proposed by Bouma et al. ${ }^{27}$ eliminates the need of the wheel depth indexing device. This is accomplished by having a series of point electrodes arranged in a spiral on a fiberglass barrel so that there is a 1.1 inch vertical spacing between electrodes. After the probe penetrates the bottom only sequential switching would be required to obtain an electrical resistivity versus depth measurement.

Kermabon et al. ${ }^{12}$ developed both laboratory and in situ equipment. The resistivity cell used in the laboratory experiments had an electrode array consisting of four electrode rings. A $16 \mathrm{~Hz}$ square wave alternating current was fed through the two outer ring electrodes and the potential difference was read across the two inner ring electrodes. The same $16 \mathrm{~Hz}$ square wave current was used in the in situ resistivity probe. The electrode array was a four point electrode system mounted on a plastic pad located at the end of the probe. The outer two point electrodes were the current electrodes while the inner two electrodes measure the potential difference.

The electrical resistivity probe weighed 100 kilograms in water and was 13 meters in length. Since the probe was designed for deep sea work, all the electronics were encased in a large pressure housing. The electronics consisted of a battery power supply, an electrical resistivity circuit, a depth monitoring circuit and a magnetic tape recording unit. The operating principles of the in situ probe were as follows: 

1. The probe was lowered to 10 meters from the sea floor.

2. The probe was released and allowed to free fall and make bottom penetration.

3. Upon penetration the reference platform remained on the surface of the sea floor while the probe continued its downward thrust.

4. After the completed penetration the probe was extracted; electrical resistivity measurements were made with the four point electrode array and the penetration was measured via a mechanical pulley hookup to the reference platform.

5. The electrical resistivity versus penetration data was stored on tape for later playback on a X-Y recorder in the laboratory. To obtain Formation Factors, Kermabon et al. ${ }^{12}$ assumed the electrical resistivity of interstitial water was the same as bottom water resistivity. Bottom water resistivity values were obtained by measuring bottom water salinity and temperature. It also had to be assumed that the temperature of the bottom water was the same as that of the sediment to a depth of 13 meters. This equipment has been transferred from SACLANT ASW Research Centre Laboratory at La Specia, Italy, to the Marine Science Laboratories University College of North Wales for further testing. Smith ${ }^{13}$ reported on resistivity measurements made in the laboratory and in situ by using commercially available electrical prospecting equipment and the Schlumberger 4-electrode arrangement. To obtain Formation Factors from the in situ measurements, the resistivity of the bottom water was measured before penetrating the sediment, then this resistivity value was assumed to be the same as 

the interstitial water. In the laboratory the resistivity of the interstitial water was calculated from knowledge of its salinity. If porosity of marine sediments is to be accurately predicted by an Electrical Resistivity Measuring System, a convenient way of measuring the resistivity of the interstitial water must be found. One method involves the use of a consolidometer to squeeze out the. interstitial water in order to determine salinity which is then easily converted to resistivity. The squeezing process is laborious, time-consuming, and requires large sediment samples. Since samples must be analyzed in the laboratory at a later date, desiccation may occur and introduce error. Also it is possible that squeezing causes error by filtering the water, particularly if clay is present. A simpler method is to measure the bottom water salinity and assume that this is the same as the salinity of the interstitial water. The accuracy of each of these methods has been considered. Boyce $^{9}$ squeezed the interstitial water from cores and found that this.salinity was not the same as the salinity of the bottom water. He found that salinity of the interstitial water varied with location and depth. However since the measurements were made three to five months after the cores were taken, Boyce stated some desiccation probably occurred. The maximum difference between the interstitial water salinity from that of overlying bottom water was 2.3 parts per thousand while the typical difference was 1.2 parts per thousand.

Siever et al. ${ }^{40}$ squeezed the water from twenty-two cores. taken in six different areas and concluded that the variatlons within 

a core can be significant. However his data indicates that in most cases the average value of interstitial water salinity for a core was very close to the bottom water salinity for the area. Smirnov ${ }^{41}$ studied a large amount of empirical data which was collected in the 1950's and 1960's (including the data of Siever et $a 1 .{ }^{40}$ ) and concluded that the salinity of the interstitial water of marine sediments does correspond to the salinity of the bottom sea water. He had previously proved this point theoretical1y. Data by Kullenberg ${ }^{42}$ agrees that the difference in salinity between the two is small. After studying Pacific red clay, Atlantic red clay, calcareous ooze, claying mud, varved clay, and lacustrin mud, the largest difference between the salinity of the interstitial water and that of bottom water was 0.8 parts per thousand. The data of Kermabon et al. ${ }^{12}$ also suggests the error introduced by assuming these salinities to be the same is very small; for 2500 resistivity measurements with depths down to 13 meters the Formation Factorporosity line of best fit had only a 2.5 percent error.

In order to predict the porosity of marine sediments accurately by an Electrical Resistivity Measuring System, it is important to use an electrode array that restricts the volume of the sediment sampled. Past work with in situ measurements has been done with electrode arrays that encompass a large volume of sediment. Bouma et al. ${ }^{27}$ found that less detail was recorded with the in situ. probe than on deck measurements with laboratory equipment. The reduced detail was attributed to the in situ probe's electrode array which sampled a larger area than desired. Consequently equipment 

was planned that was expected to reduce the area sampled.

Kermabon et al. ${ }^{12}$ used the four-electrode system by Wenner 37 in the nose of the resistivity probe. A detailed derivation of the Wenner electrode configuration is presented in Appendix A. A current was passed between the outer two electrodes, and the difference in potential between the inner two electrodes was measured. Theoretically, if the medium surrounding the electrodes was of uniform, isotropic, homogeneous resistivity, the calculation of the true resistivity could be obtained from the knowledge of the current, the potential difference, the geometric arrangement, and the separation of the electrodes. Therefore if the electrodes were equidistant and the distance between electrodes was large in comparison with electrode penetration into sediment, the true resistivity would be:

$$
r_{T}=\frac{2 \pi a \Delta V}{I}=K \frac{\Delta V}{I}
$$

where $r_{T}$ is the true resistivity assuming a homogeneous, isotropic, uniform media;

a, the electrode spacing;

$\Delta V$, the potential difference between the voltage electrodes;

I, the current;

$K$, the geometric coefficient for the particular electrode array.

However, the medium around the electrode array is not usually homogeneous, isotropic, and uniform; therefore the value computed in equation 54 becomes the apparent resistivity $\left(\mathrm{r}_{\mathrm{A}}\right)$. The apparent re- 

sistivity may be larger than, less than, or equal to the true resistivity. The difference between the apparent resistivity and the true resistivity will depend greatly on the volume of sediment encompassed by a specific electrode array while the resistivity measurement was being obtained. Using the skin depth conduction theory, Ball ${ }^{29}$ showed the volume sampled by a Wenner electrode configuration was directly proportional to the distance between current electrodes and inversely proportional to the frequency of the current, and the conductivity of the medium. Then, using a frequency of $1000 \mathrm{~Hz}$ and a current electrode spacing of $3 \mathrm{~cm}_{0}$, Ball determined the volume of material through which a $1000 \mathrm{~Hz} \mathrm{~A}$.C. current passes as a function of the conductivity of the material. Higher frequencies are undesirable due to A.C. impedance effects. Using this electrode configuration and a normal range of marine sediment conductivities $\left(0.015\right.$ to $\left.0.035 \mathrm{mho} / \mathrm{cm}_{0}\right)$ the volume of materfal that the $1000 \mathrm{~Hz}$ A.C. current could encompass would range from 0.6 to 1.2 cublc meters. However a volume much smaller than 0.6 cubic meters would be desirable if accurate porosity predictions are to be made. It is possible to limit the volume by insulating it from its surrounding environment (inside the corer barrel) or by focusing an electrode array (outside the corer barrel) in such a way as to direct the current patterns to a confined volume. 



\section{IN SITU MEASURING SYSTEM}

The Electrical Resistivity Measuring System was built in the Ocean/Civil Engineering Laboratory of the University of Rhode Island for the DOSP. It consists of three components: electrode arrays, an electronic measuring circuit and a FM multiplex telemetry data link.

\section{Electrode Arrays}

The Electrical Resistivity Measuring System for the DosP has two types of electrode arrays: the electrode array used inside the corer tube and the electrode array used outside the corer tube. The electrode array used inside the corer tube (see Figure 36) consists of four brass ring electrodes vertically spaced along the inner wall of the corer tube. The corer tube of the DOSP is a continuous five foot section of transparent acrylic tubing (O.D. 3 in., I.D. $23 / 4$ in.). An additional 14 inches of acrylic tubing (O.D. $31 / 4$ in., I.D. 3 in.) is fused to the lower end of the corer tube. This allows the adaptation of a corer cutter-catcher assembly and provides additional structural strength in the vicinity of the inner electrode array. The placement of the inner corer tube electrodes was difficult because. the inner corer tube electrodes had to be placed flush against the inner corer wall. Electrode extension into the sediment causes sample disturbance when the sediment sample is taken while recessing the electrodes reduces the electrical contact with the medium sampled. 



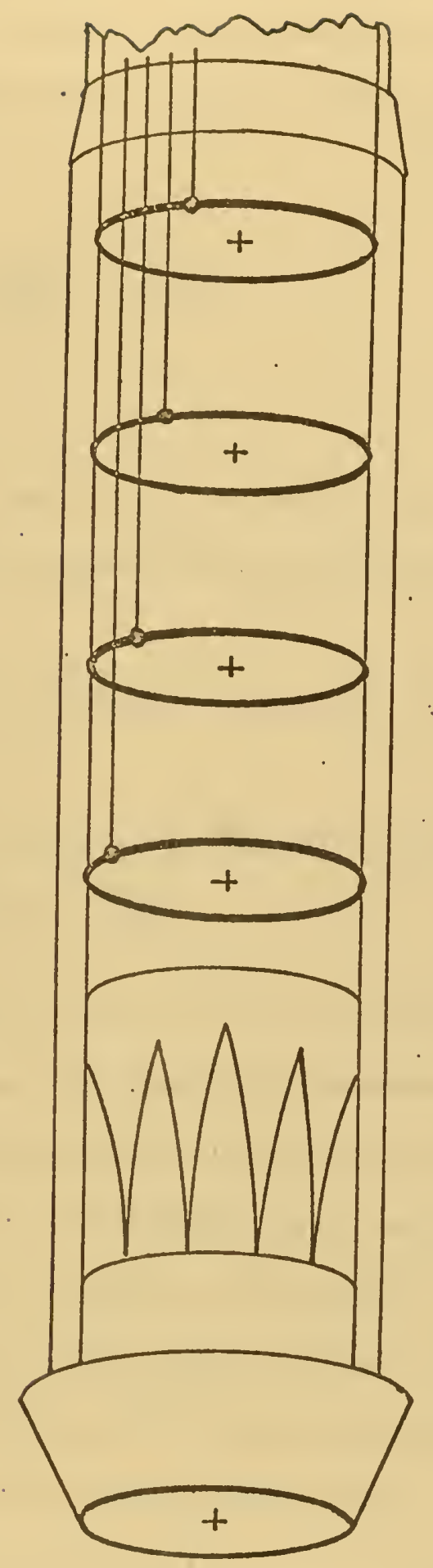

Figure 36. Nose of the DOSP Corer Tube with the Inner Corer Ring Electrode Array and the Corer Cutter-Catcher Assembly. 

In addition the inner ring electrodes require extra acrylic tubing material for structural support. The apparent resistivity $\left(r_{A}\right)$ of a marine sediment sample through the corer tube is calculated by the following formula:

$$
\dot{r}_{A}=\frac{\pi d^{2} \Delta V}{4 a I}=K \frac{\Delta V}{I}
$$

where:

d is the inner diameter of the corer tube;

a, the separation between the inner two potential electrode rings;

$\Delta V$, the potential difference between the voltage electrodes;

I, the current,

$K$, the geometric coefficient for the particular electrode array is equal to $\frac{\pi d^{2}}{4 a}$.

Equipotential surfaces for a vertical cross section of the inner corer tube electrode array are shown for a homogeneous medium in Figure 37. From the equipotential surfaces an estimate of the volume contributing to 80 percent of the total resistance involved in a resistivity measurement is 580 cubic centimeters.

The electrode array used outside the corer tube is based on the principle used in the oll well logging device called the Microlateralog. The Microlateralog was introduced by $D o 11^{43}$ of the Schlumberger Well Surveying Corporation. The device was designed to Indicate the resistivity of a small volume of material immediately In front of the electrode array. The Microlateralog (see Figure 38) 



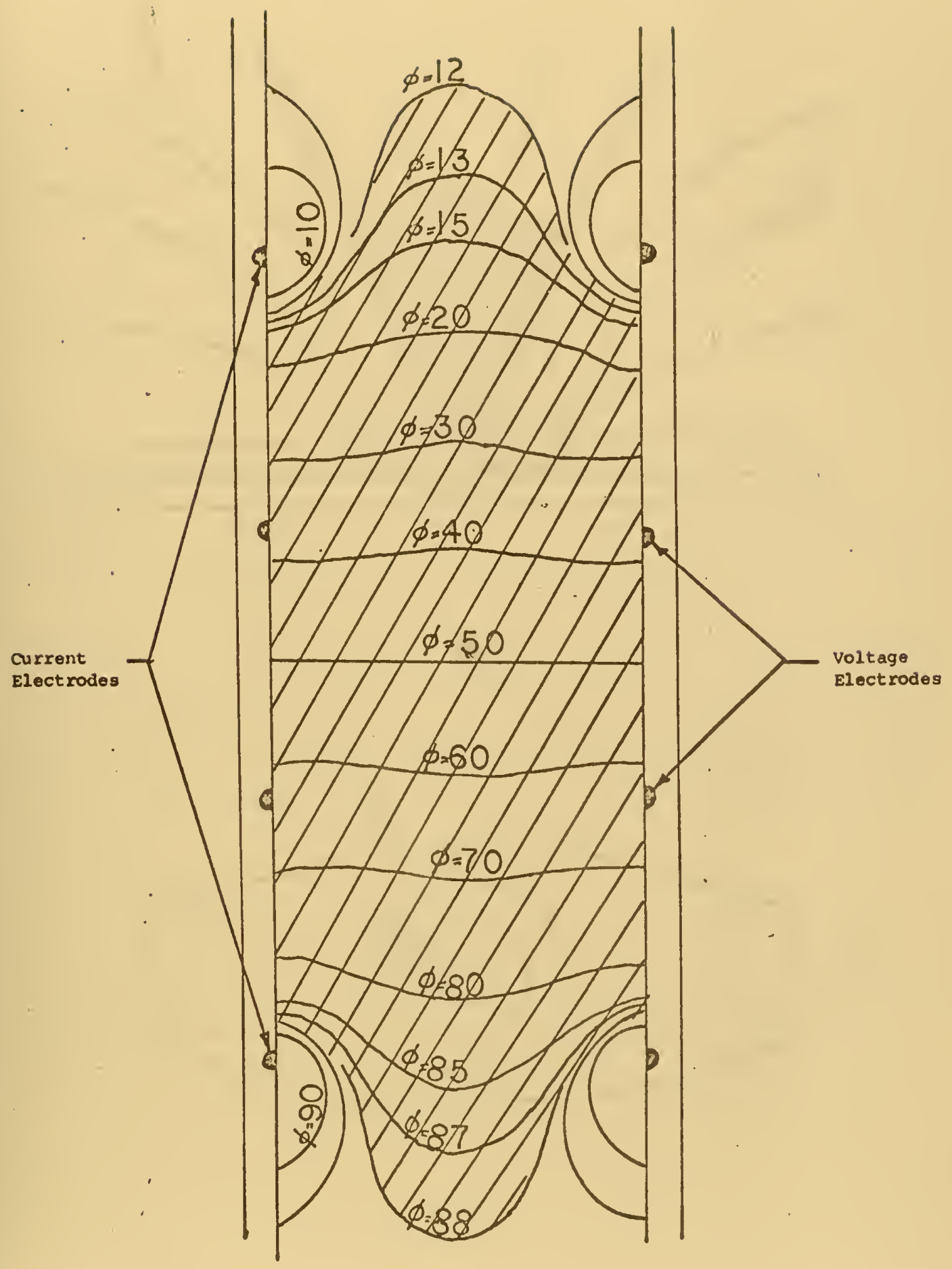

Figure 37. Vertical Cross Section of the Inner Corer Ring Electrode Array and Equipotential Lines.

(shaded area is approximately 80 percent of the total ohmic arop of potential). 



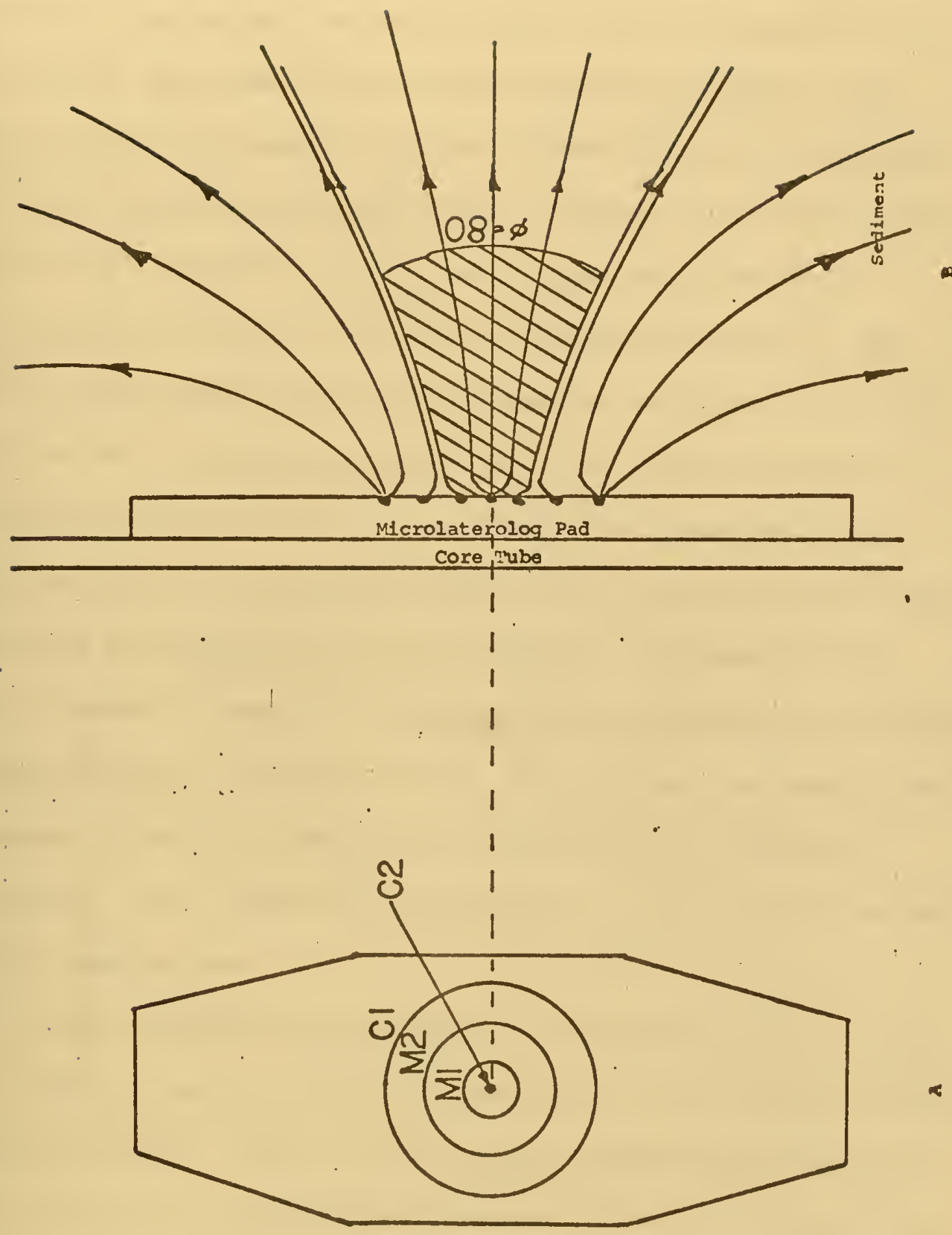

Figure 38. Microlateralog Pad Electrode Array and the 80 $a, b$ Percent Equipotential Line. (Shaded area is approximately 80 percent of the total ohmic drop of potential). 

consists of a center current electrode and three circular ring electrodes. The largest or outer ring is the other current electrode and the inner two rings are the voltage electrodes. The electrodes are fabricated out of non-corrosive monel and embedded in an insulating supporting material. The small pad can be easily mounted either outside the corer barrel just above the corer cutter-catcher assembly, or on one of the DOSP probe legs. The vertical cross section showing the direction and shape of the current lines for a homogeneous medium are also shown in Figure 38. The dark equipotential surface represented in Flgure 38 is such that 80 percent of the potentlal drop in the current pattern occurs between the electrode pad and this surface. Consequently, the volume of material confined within the pattern extends to a distance of approximately 3.5 inches from the electrode pad and contributes 80 percent of the total resistance involved in the resistivity measurement. This volume for a homogeneous medium is approximately 380 cubic centimeters.

Since both the Inner and outer corer barrel electrode arrays require wire connection along the corer tube to the measuring instrumentation, a flat, 9 conductor, polyester insulated, transmission cable, manufactured by the Burndy Tape Cable Div., 15 Linden Park, Rochester, N. Y., is used to transmit the current from the signal conditioner to the current electrodes and to send the potential difference from the voltage electrodes back to the signal conditioner (see Figure 39). Four of the conductors are signal cables and five are ground cables; each signal cable is separated by a ground cable. 



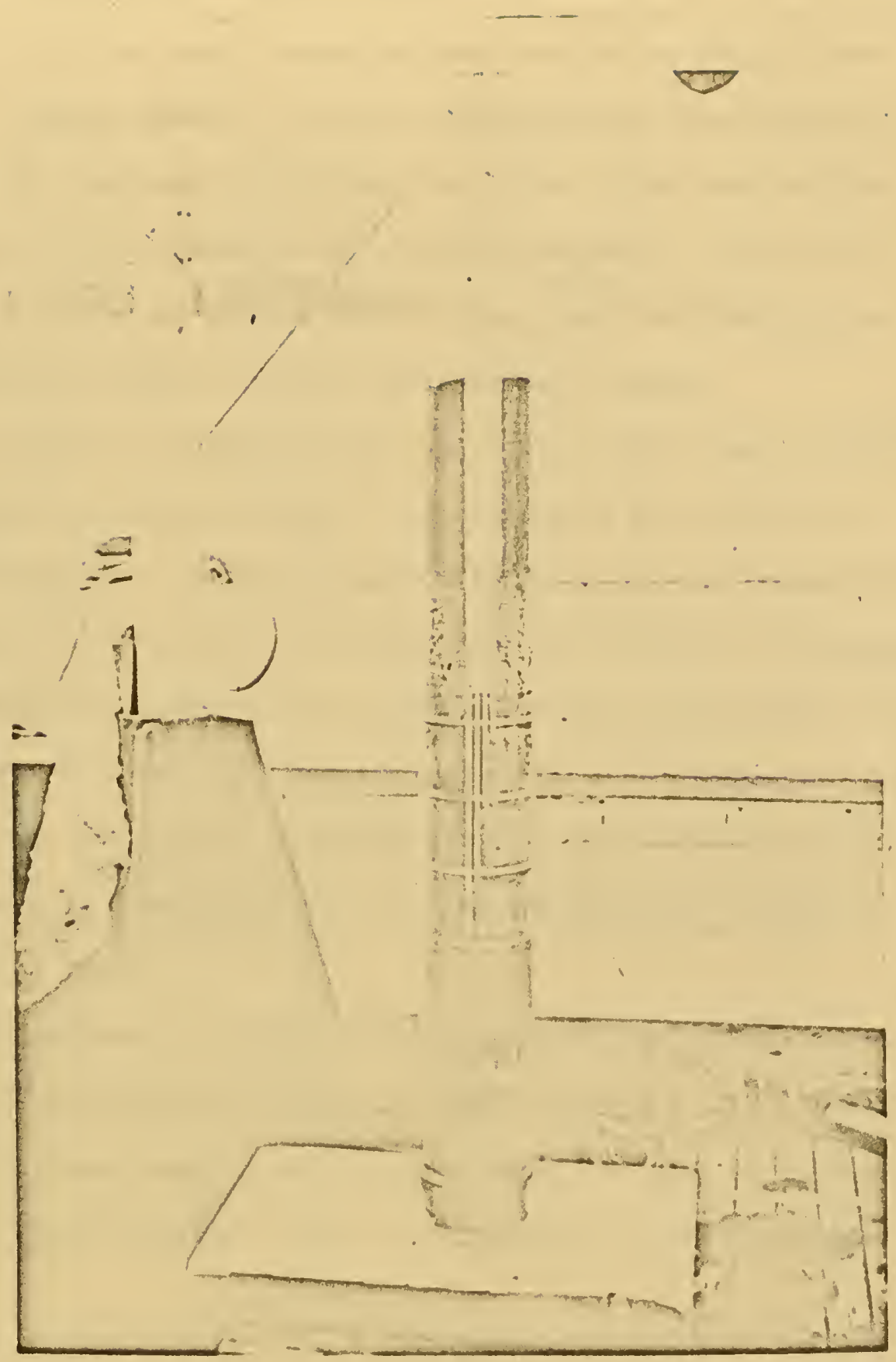

Figure 39. Photograph of the Inner Corer Ring Electrode Array with the Flat Transmission Cable Hook Up. 

The flat transmission cable thickness is 0.0085 inches. The cable was fastened to the corer tube with three successive thin filmed coatings of epqxy cement. With this configuration the connecting wiring to the electrode arrays does not hinder corer penetration nor will the wiring break due to abrasive materials. When the Microlateralog pad was placed on the corer tube, the same type of flat transmission cable was used for electrode hookup.

In addition a miniature guard mode electrode array, described In the Literature Review section, was fabricated for laboratory testing. Seven thin platinum wire electrode rings were vertically spaced on a plastic probe five inches long and $1 / 4$ inch in diameter. Thin wire connecting the platinum ring electrodes to the electronic circuit was embedded in the plastic probe head. The miniature guard mode electrode array probe was not tested at sea since the plastic material used in fabrication was not considered sturdy enough to withstand sea tests.

A photograph of a Microlateralog pad and the plastic probe with a guard mode electrode array is shown in Figure 40. A photograph of the inner corer ring electrode array is shown in Figure 41. Any of the three electrode arrays can be used with the electronic circuit.

The acrylic corer tube with its inner brass electrode rings was fabricated by Plastic Fabricators Inc., East Greenwich, R. I. The Microlateralog pad and guard mode probe used to measure resistivity outside the corer barrel were fabricated at the Naval Underwater Systems Center, New London, Conn. 



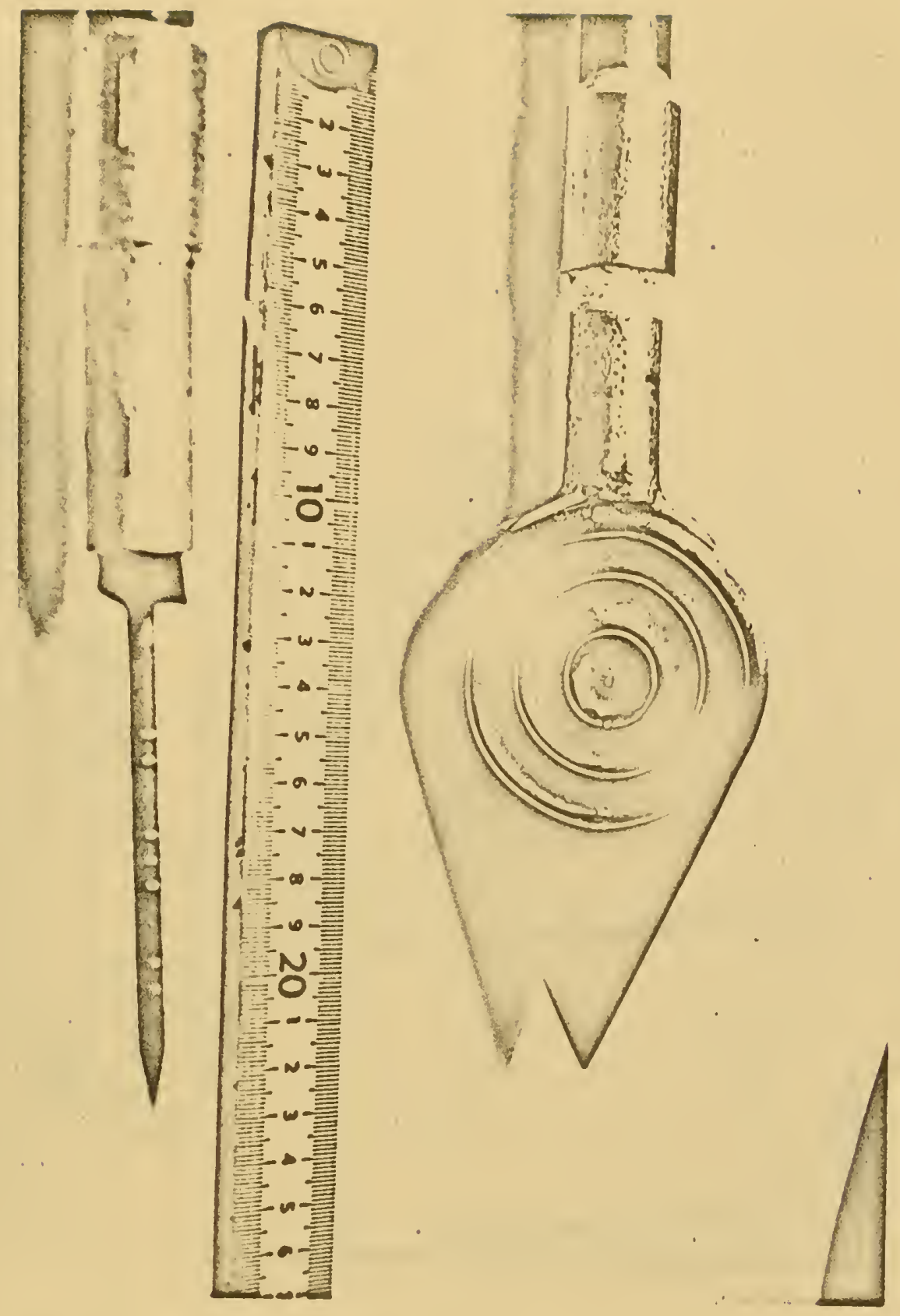

Figure 40. Photograph of the Microlateralog Pad Electrode Array and the Miniature Guard. 



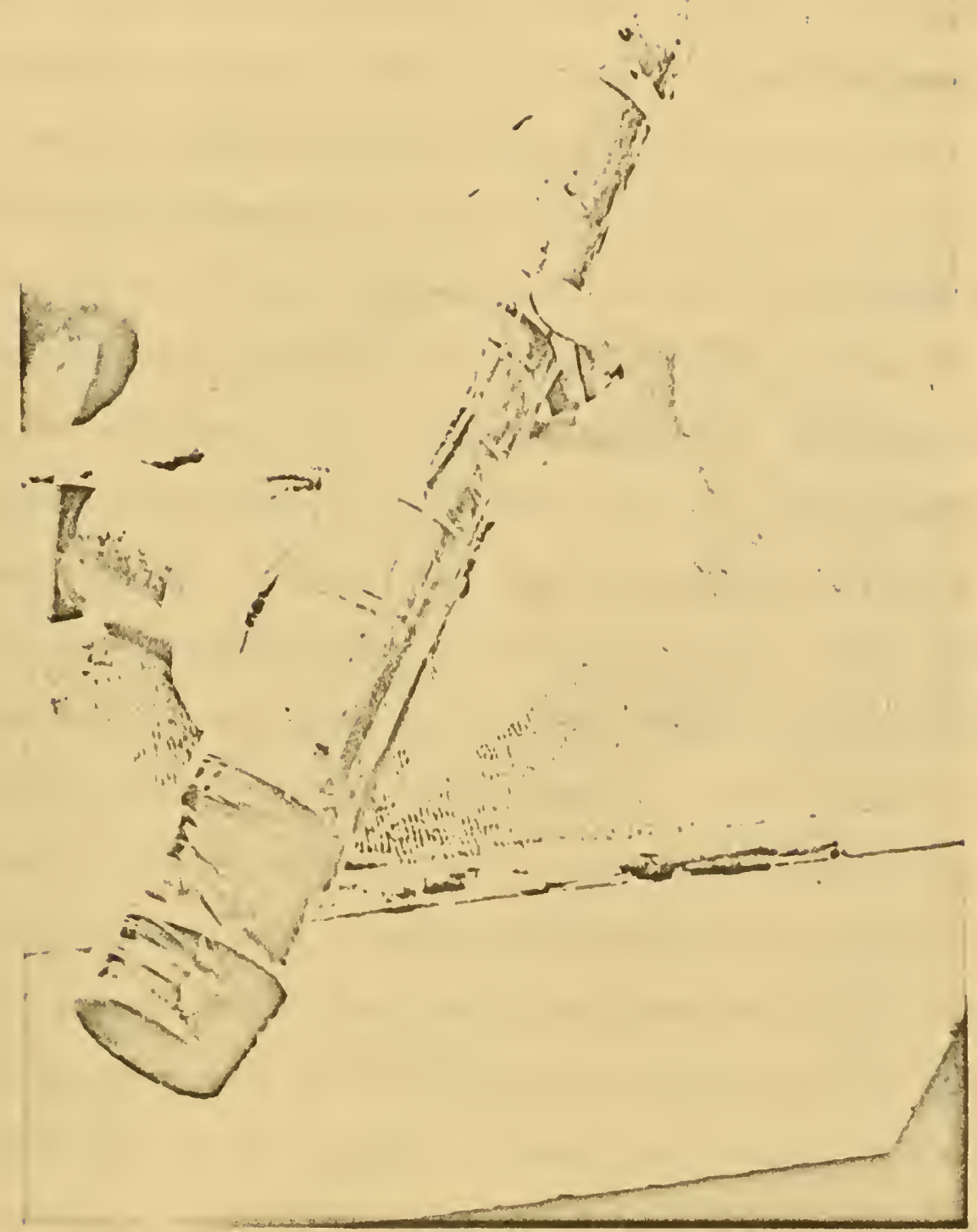

Figure 41. Photograph of the Inner Corer Ring Electrode Array. 



\section{Electronic Measuring Component}

The Electronic Measuring Component consists of an electrical conductivity signal conditioner, DC/AC inverter, a constant voltage transformer and a thermistor assembly. All of the above components are located in a pressure case. (see Figure 42), with the exception of the thermistor assembly which is located in a separate housing that is threaded into the upper end-cap of the pressure case.

The pressure case with the electronics will be mounted on the DOSP. The pressure case is cylindrical with an inside length of 24 inches and inside diameter of 6 inches. The top end-cap is tapped to allow the threading of the electrical connectors (manufactured by Vector Cables Corporation, 5615 Lawndale, Houston, Texas) and the thermistor housing. Through these electrical connectors the electronic instrumentation receives 12 volts, 1 amp. D.C. power from the DOSP batteries. In addition, signals are transmitted and received from electrode arrays through these connectors; and a D.C. data signal is sent to the FM telemetry system for transmission to the surface. Both pressure case end-caps are removable and the electronic components are mounted on trays which are connected to the top endcap. The pressure case wall thickness is $1 / 2$ inch for the cylinder and $1-1 / 2$ inches for the end-caps. Since fabrication is out of 6061-T6 aluminum, a thickness diameter ratio of 0.083 will permit a hydrostatic pressure of 5000 psig with a safety factor of 1.30 . The end-caps have the same pressure capabllities. The pressure case is tested repcatedly to 3000 psig in the University of Rhode Island hydrostatic test tank before actual sea tests. The procedure for 

0

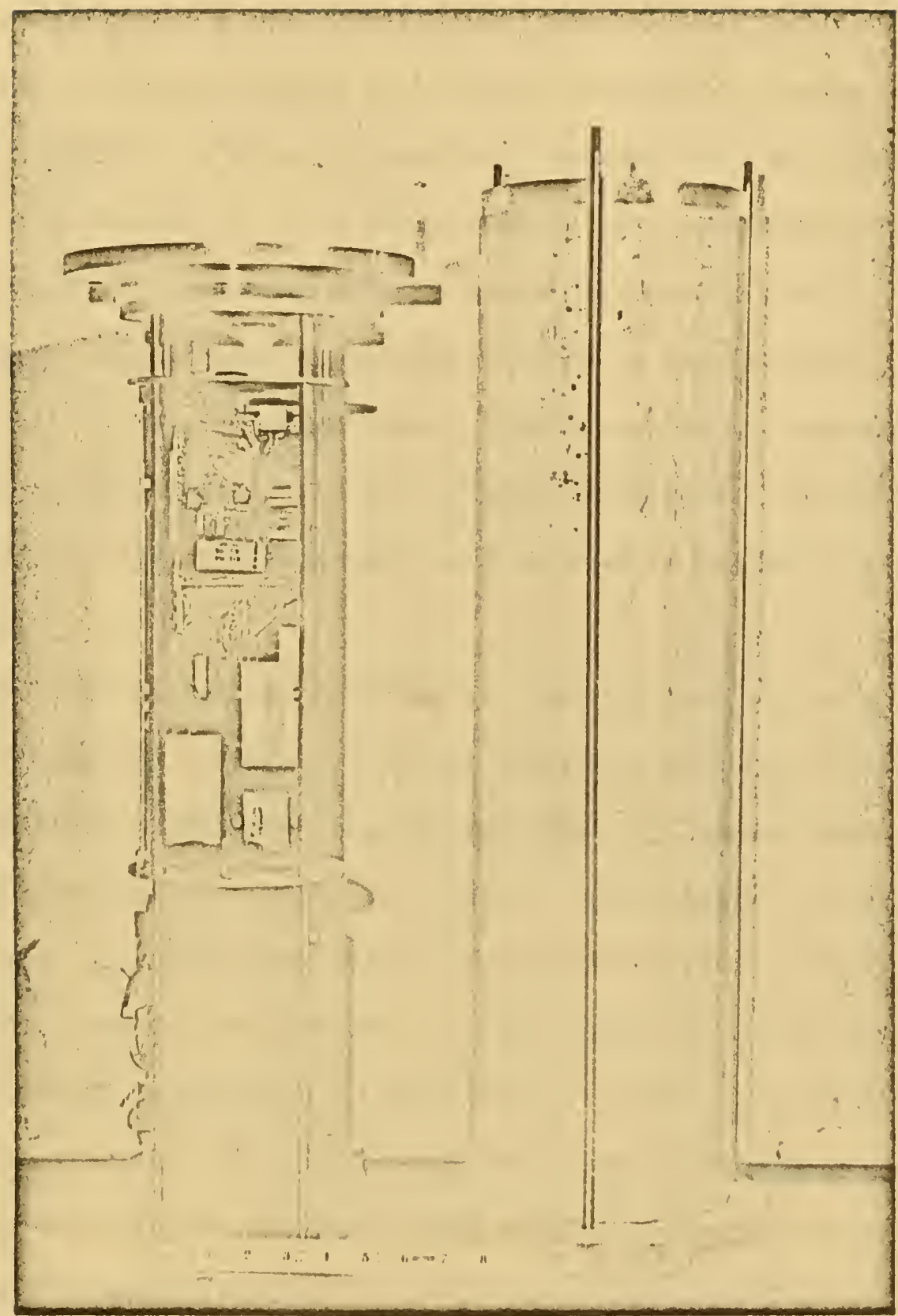

Figure 42. Pressure Case and Electronic Measuring Components: Signal Conditioner, DC/AC Inverter, Constant voltage Transformer and a Thermistor Assembly. 

safety testing pressure cases on the DOSP is more thoroughly discussed in Lewis. 30

The conductivity signal conditioner, manufactured by Honeywell Inc., Fort Washington, Pa., (Model description number 552022-1002-10Q-000), is a solid state null balance A.C. amplifier. It supplies the voltage to drive the sensor array, and compares the resultant output of the sensor voltage electrodes with a stable reference voltage A differential voltage is used to regulate the drive current. The signal conditioner produces an output linearly proportional to the conductivity of the measured medium. The output signal range is 0 to 5 volts D.C. and is sent to the FM telemetry system.

The signal conditioner operates as a potentiometer. An A.C. current $I_{c}$ is applied through two sensor current electrodes, $\mathrm{Cl}$ and C2 (see Figure 43). The resulting voltage drop, $V_{0}$, across two measuring electrodes, $M 1$ and $M 2$, is compared with a fixed A.C. reference voltage, $V_{R}$. When they differ, the resulting error voltage, $V_{c}$, alters the sensor drive current $I_{c}$. The amplifier system then changes its output to maintain $V_{0}$ equal to $V_{R^{\circ}}$ since $V_{0}$ is held constant, the drive current $\left(I_{c}\right)$ is (by Ohm's Law) inversely proportional to the medium's resistance and directly proportional to its reciprocal conductivity.

Because of the large measuring error which would be introduced by polarization of the sensor electrodes, A.C. rather than D.C. current is employed. The voltage required for the signal conditioner is from 107 to 127 volts A.C. at 50 or $60 \mathrm{~Hz}$. This is the same 



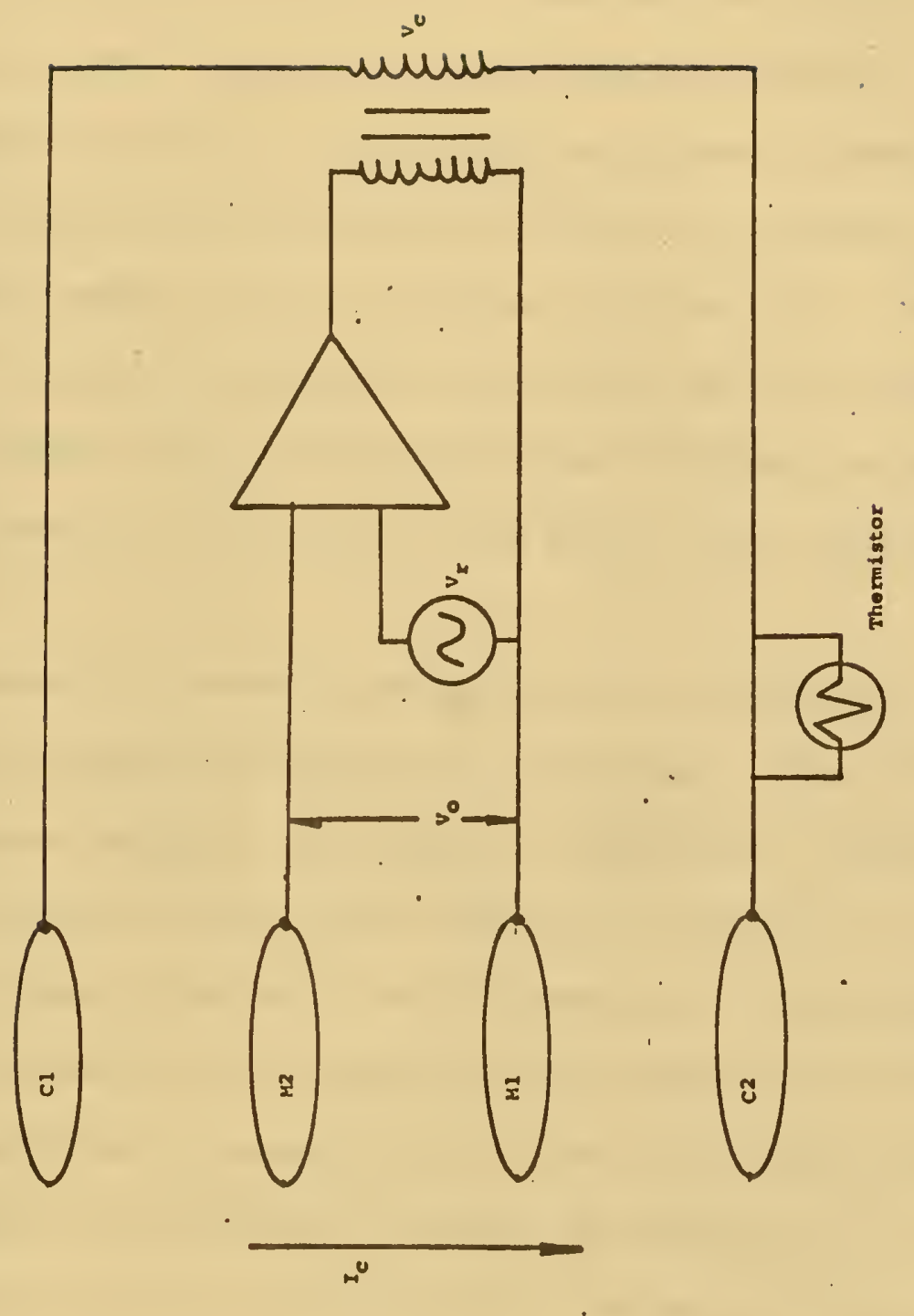

Figure 43. Skematic Diagram of Electronic Measuring system and the Inner Corer Ring Electrode Array. 

frequency supplied to the sensor electrodes and is high enough to prevent polarization. The A.C. power requirement of the signal conditioner makes an inverter necessary. The inverter, a 12 volt D.C. Input, square wave $60 \mathrm{~Hz}$ output, is manufactured by Fork Standards, Inc., West Chicago, I11. (Model number 32A057d). Before the signal is sent on to the signal conditioner, a constant voltage transformer (produced by Solar Electric Co., Chicago, Ill. catalog number 30498 ), is used to smoothe the signal out. The inverter and constant voltage transformer allow the use of the DOSP battery power supply. This permits the Electrical Resistivity Measuring System to be used on the ocean floor in water depths of 5000 feet.

The thermistor assembly and housing (type number H66), is manufactured by Fenwal Electronics Inc., Framingham, Mass. The nominal pressure rating of the housing is 10,000 psig. The thermistor automatically corrects the conductivity readings to a reading for $25^{\circ}$ Centigrade. The thermistor is connected to an adjustable compensation network in the signal conditioner which alters the reference voltage to match sensor output versus input voltage charge with the medium's temperature. The range of adjustment in the signal conditioner is from 1.4 to 2.5 percent per degree Centigrade. For most marine conditions, 2.5 percent per degree Centigrade is chosen since this is the temperature coefficlent usually used for sea water. For shallow water tests the thermistor was embedded into the acrylic corer barrel next to the brass electrodes. The thermistor was wired to the cable wire and sealed with epoxy cement. 



\section{FM Multiplex Telemetry Component}

The development of a telemetry component for the DOSP was conducted by Barry ${ }^{41}$ under contract with the Naval Underwater Systems Center. The system was designed to command the DOSP from a remote location on a surface ship, and receive and transmit data signals from the DOSP in ocean depths to 6000 feet. All signals are sent and received via coaxial cable by means of a frequency multiplexed (FM) technique.

The FM telemetry system for the DOSP can be divided into three distinct spectra: touch tone signals (25 to $115 \mathrm{~Hz}$ ), the slowly varying channels ( 370 to $15.5 \mathrm{kHz}$ ), and the acoustic channels (150 to $450 \mathrm{kHz}$ ). Resistivity is one of the slowly varying data channels with a channel center frequency of $1300 \mathrm{~Hz}$.

The Electrical Resistivity Measuring System's signal condit1oner provides the necessary voltage level ( 0 to 5 volts) to drive the voltage controlled oscillator of the telemetry system. After the signals have been frequency modulated they are multiplexed with acoustic data and touch tone commands. This technique allows all data to be transmitted simultaneously. 



\section{PROCEDURE}

\section{Laboratory Tests}

Laboratory tests were conducted after the Electrical Resistivity Measuring System was fabricated in order to test its performance prior to sea tests. For analysis and calibration all three components (electrode array, electronic circuits and FM telemetry data 1 ink) were connected together and data recorded. The full range voltage ( 0 to 5 volts $D_{\text {. C. }}$ ) signal that is accepted by the FM telemetry data link was supplied by the signal conditioner. This full range was obtained by increasing the salinity of the solution that the electrode array was sampling. The full scale conductivity range that may be sampled is from 0 to $60,000 \mu \mathrm{mho} / \mathrm{cm}$.

The inner corer ring electrode array was calibrated by filling the corer tube with standard solutions of known conductivity while the Microlateralog pad and miniature guard mode electrode arrays were immersed in the standard solutions. The voltage output for each electrode array in the standard solutions was read on the signal conditioner.

When the Electrical Resistivity Measuring System was used Independently of the DOSP for testing in the laboratory or in shallow water, the FM multiplex telemetry component was no longer required. Under these conditions power was supplied either by D.C. battery or by standard 115 volts, A.C. $60 \mathrm{~Hz}$ that have passed the 

Inverter. Thus wiring to the electrode array and a volt meter to read the signal conditioner output voltage were the only items required to make the conductivity measurements.

Ottawa sand and Providence silt were used in the laboratory tests in order to compare the results of measurements obtained with the different electrode arrays with the data from earlier laboratory experiments. The procedure for testing the inner corer ring electrode array was as follows: a sodium chloride solution of known conductivity was first poured into the corer tube which had been capped to prevent leakage. A measurement of the conductivity of this solution $\left(k_{c}\right)$ was then taken in the corer tube. A known weight of Ottawa sand was then added slowly. The sand settled out rapidly In a loosely packed configuration. The length and the conductivity of the sand-water matrix $\left(k_{m}\right)$ were measured and recorded for later porosity calculations. On completion of this measurement, the corer tube was tapped five times to densify the sand. Conductivity measurements were again taken and the length of the sand-water matrix was again recorded. This procedure was repeated until the conduct1vity and length measurements became constant. The sand was then in a closely packed configuration.

The Microlateralog (pad) and the miniature guard mode electrode array (probe) was tested by using a large acrylic tube chamber five feet long and one foot in diameter filled with 40 inches of Providence silt and 10 inches of saline water ( 30 parts per thousand). The pad and the probe were placed, one at a time, in the water directIy above the sediment interface and the water conductivity $\left(k_{c}\right)$ was 

measured. In turn both the pad and probe were lowered into the silt ard at six inch increments the conductivity of the sediment $\left(k_{m}\right)$ was measured. The larger size of the pad required greater force to penetrate the sediment; consequently it was only inserted to a depth of one foot. The probe was inserted the entire length of the silt column. Laboratory analysis of the marine sediments was conducted in order to compare the results with those of the in situ sea tests. Water content, vold ratio, shear strength, specific gravity, organic content, $\mathrm{pH}$, grain size analysis, liquid limit and plastic limit were determined. In addition X-ray diffractograms were obtained for the clay-silt size fraction of each marine sample. Details of the above analysis are presented in Appendix C.

The interstitial water salinity was obtained after the water content of the marine sample was analyzed. The dried sample was mixed with twice as much distilled water as was originally present. The slurry was repeatedly mixed and allowed to settle out, then a conductivity measurement of the solution was taken with a Beckman conductivity meter. Since the number of ions in solution remained constant and conductivity changes are linear with dilution change, the original conductivity of the interstitial water can be determined by doubling the conductivity reading of the dilute solution. These measurements were compared with in situ and laboratory measurements of bottom water salinity.

Part of the marine sediment was diluted into a slurry using bottom water obtained from the core sites and then was re-consolidated to pressures of $0.25,1.60,4.00$ and $16.00 \mathrm{psig}$ in the rederigned 

laboratory equipment described earlier. This allowed a Formation Factor-porosity relationship to be obtained. Comparisons were also made with both the in situ Formation Factor and porosity values obtained from laboratory analysis of the marine sediment from the Electrical Resistivity Measuring System corer.

\section{Sea Tests}

Shallow water sea tests were conducted in Narragansett Bay at the following locations, which were chosen for convenience and for the bottom type variety found there:

Station A $41^{\circ} 34.1^{\prime} \mathrm{N}-71^{\circ} 25.4^{\prime} \mathrm{W}$
Station B $41^{\circ} 29.5^{\prime} \mathrm{N}-71^{\circ} 24.7^{\prime} \mathrm{W}$
Station C $-41^{\circ} 22.7^{\prime} \mathrm{N}-71^{\circ} 30.6^{\prime} \mathrm{W}$

The inner corer ring electrode array was tested at Station A. Station $A$ had a sandy silt bottom with a 7 to 18 percent clay fraction. Since the depth of the water was approximately 20 feet, the corer barrel was attached to two ten foot sections of $1 \frac{1}{2}$ inch diameter galvanized pipe. The procedure at this station was as follows: The research vessel was moored with bow and stern anchors and the station location was confirmed by a visual fix. The salinity and temperature of the water column were measured by a Beckman model RS5-3 in situ salinometer-temperature meter. While the corer barrel was lowered slowly to the bottom the conductivity was continuously measured. Since the FM telemetry component was not needed in shallow water, a voltmeter was used to read voltage output directly from the signal conditioner. As the corer barrel penetrated the bottom, 

conductivity was measured every six inches. The corer barrel was then pulled out and continuous conductivity readings were made unt11 the core was stored on deck. Conductivity readings were again taken in the laboratory.

Station B, the site of the future Department of Ocean Engineering underwater laboratory, had a silty sand bottom with a

4 to 9 percent clay fraction. The depth of the water was approximately 40 feet. Both the inner corer ring electrode array and the Microlateralog pad array were tested at this station. A six foot section of one inch diameter galvanized pipe was securely mounted to the Microlateralog pad which was then carried down, positioned, and inserted into the bottom by two trained scuba divers. The ring electrode array in the corer barrel was also taken down by the scuba divers. An attempt was made to systematically survey the area. Using the pattern shown in Figure 44, Microlateralog penetrations were made at radial distances of 25 and 50 feet from where the corer was inserted. The numbers circled in Figure 44 were the positions that were measured before the scuba divers' air supply was depleted. The procedure was the same as that used for Station $\Lambda$, except that the scuba divers handled the corer barrel and the Microlateralog pad. White tape was placed at six inch intervals on the corer barrel (see Figure 45) and every 12 inches on the Microlateralog pad to allow visual observation of penetration depth. The positions had been premarked with weighted cans. The divers held the pad in the water prior to penetration to enable a bottom water conductivity measurement. The Microlateralog pad was inserted into the bottom at 

+(2)

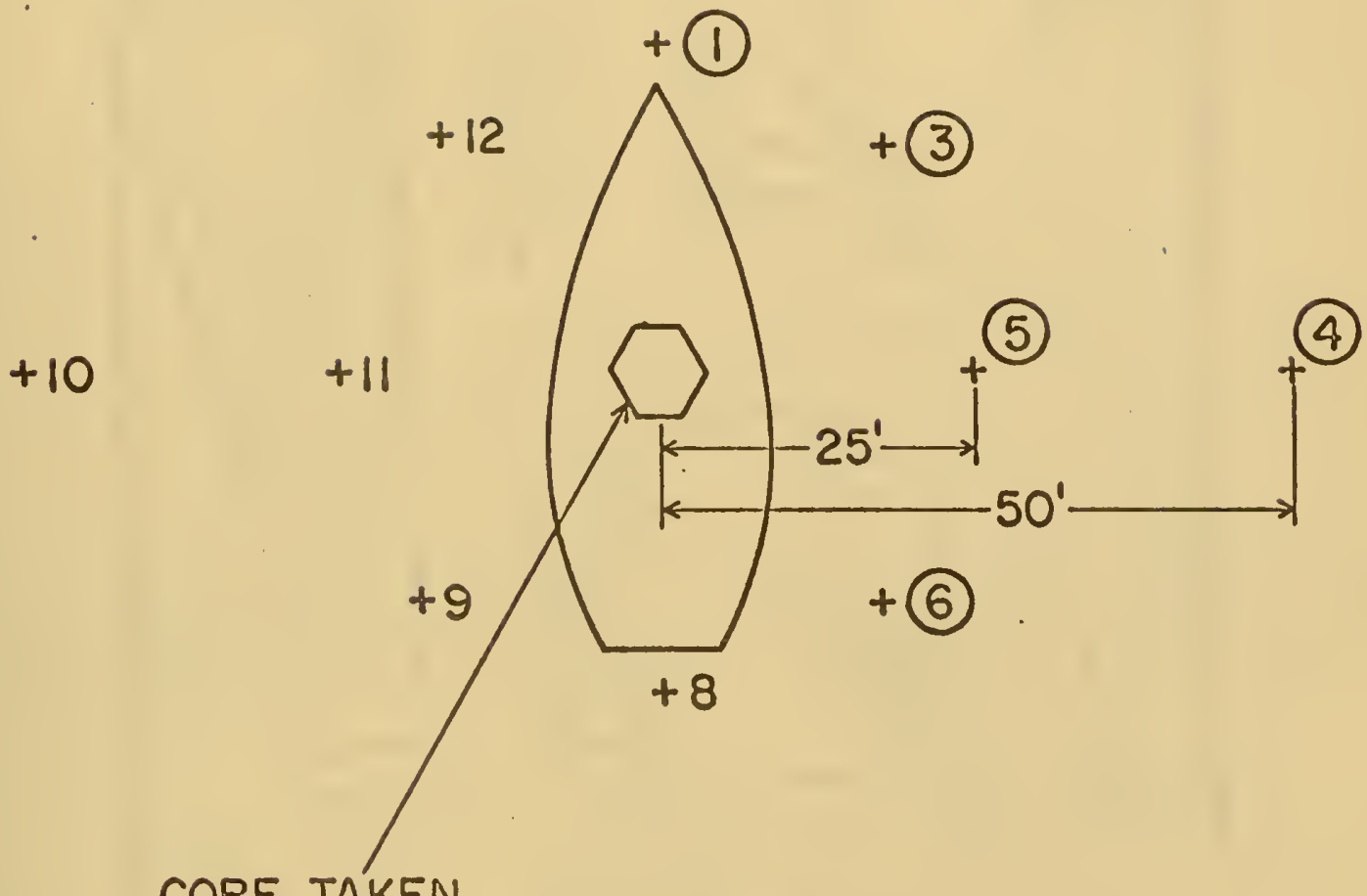

CORE TAKEN

$+7$

Figure 44. Survey Pattern Planned for Narragansett Bay station B. 



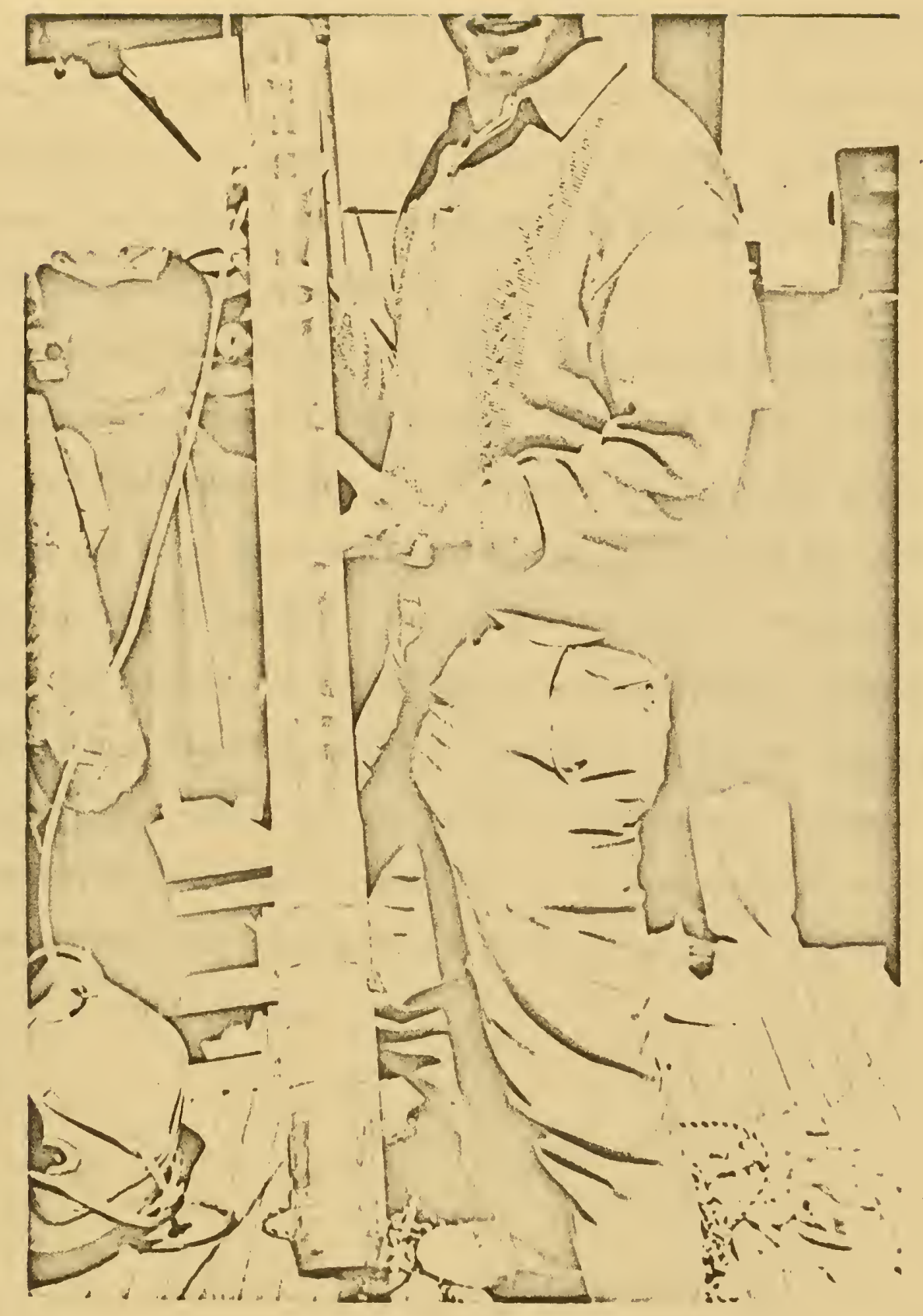

Figure 45. Corer Barrel with white Tape Marks Every six. Inches. 

one foot increments. A communication line notified the divers (by a number of pulls) that the measurement was complete, and then the probe was inserted an additional foot. Since the Microlateralog pad did not have a thermistor, it was assumed that the temperature of the sediment was the same as the temperature of the bottom water. From the later temperature measurement, the conductivity readings were corrected to $25^{\circ}$ Centigrade.

Station C, a shallow water area near Succotash Point, Jerusalem, R. I., had a sandy bottom. The water was 0 to $5 \mathrm{feet}$ deep. Both the inner corer ring electrode array and the Microlateralog pad array were tested at Station C. The pad was attached to the six foot galvanized pipe used at Station $B$. The procedure used was the same as for the other two stations, except that the instrumentation was left on shore, the corer barrel and the pad were carried out by a wader, and measurements were made at random. The sand bottom was very hard, consequently the core obtained was approximately one foot and the Microlateralog pad could only be inserted to 6 and 12 inches. 



\section{RESULTS AND DISCUSSION}

\section{Laboratory Tests}

The results of the calibration of the total system (all three components) are presented in Figure 46. Figure 46 shows that the 0 to 5 volt D.C. output signal which was sent through the FM telemetry component and 6000 feet of coaxial cable was transformed linearly to a range of -1.5 to 1.5 volts D.C. Calibration curves for the inner corer ring electrode array, the Microlateralog pad array and miniature guard mode array are shown in Figure 47. These curves indicate that, for each electrode array, an individual linear relationship exists between the conductivity of the medium sampled and the signal conditioner output voltage. Consequently Equation 7 can be written as:

$$
F F=\frac{r_{m}}{r_{c}}=\frac{k_{c}}{k_{m}}=\frac{V_{c}}{V_{m}},
$$

where $V_{c}$ is the signal conditioner output voltage when the electrode array is sampling the continuous phase (water),

and $V_{m}$ is the signal conditioner output voltage when the electrode array is sampling the mixture (sediment).

Therefore if these two voltages represented in Equation 7 are measured with temperature compensation, the Formation Factor of a sediment can be readily obtained. 



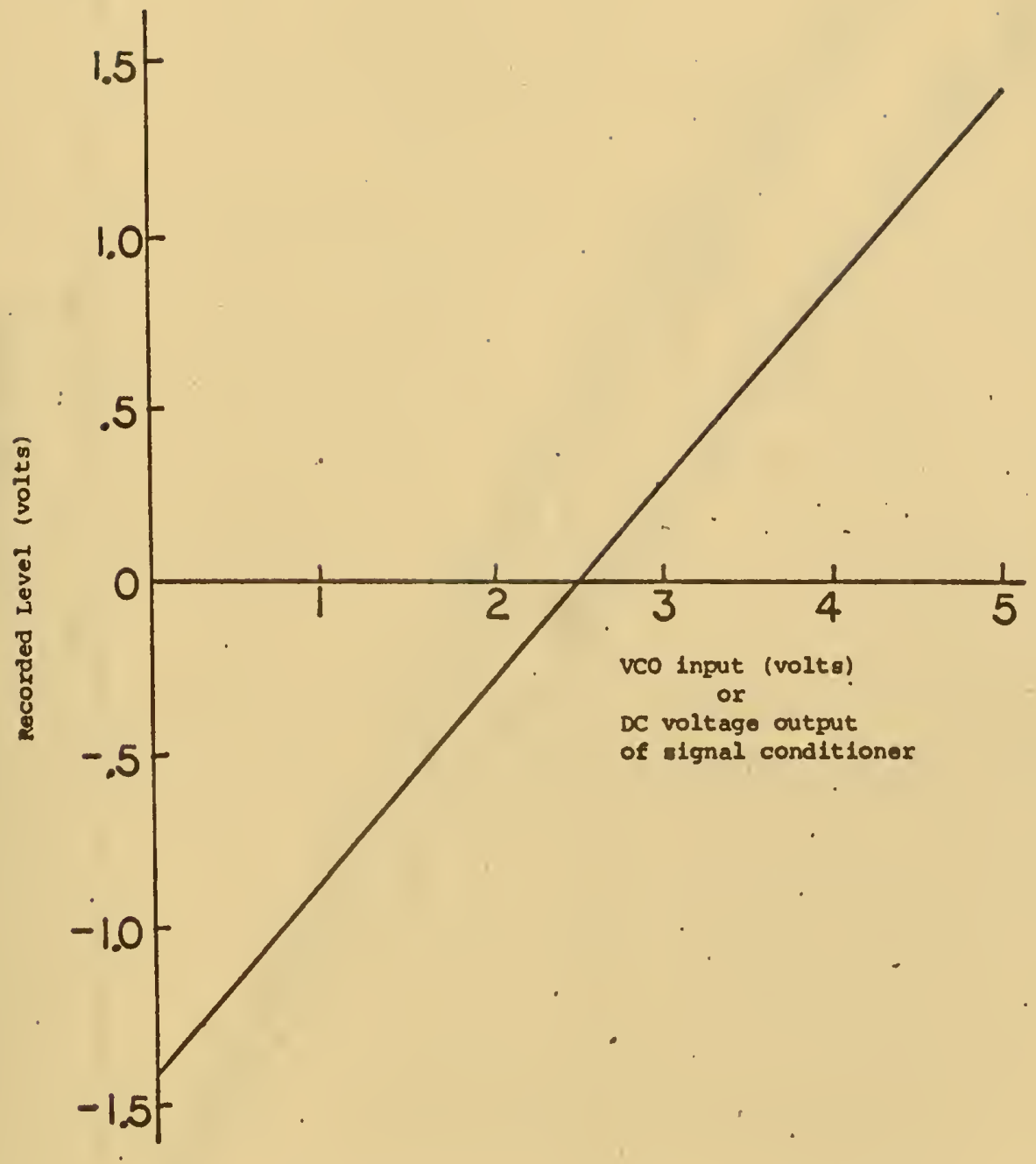

Figure 46. Calibration of FM Telemetry Channel showing voltage Input from the Signal conditioner and the Response Recorded Through FM Telemetry Channel. 



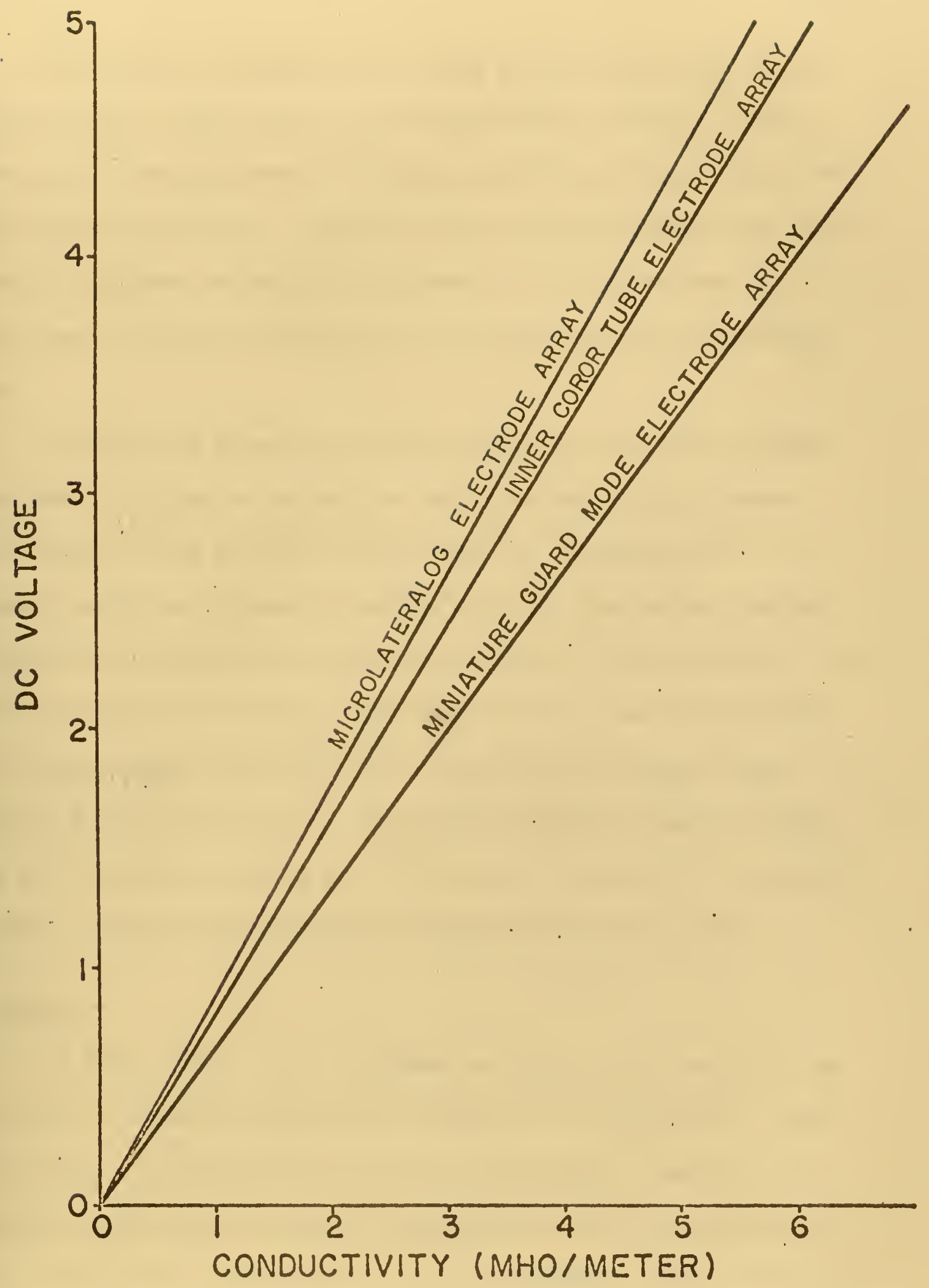

Figure 47. Calibration Curves for the Inner corer Ring Electrode Array, Nicrolateralog Pad Electrode Array and the Guard Mode Electrode Array. 

The results of laboratory testing of the inner corer ring electrode array with Ottawa sand compared well with the results of the laboratory equipment described earlier (see Figure 48). The data from the inner corer ring electrode array are shown to be within the \pm 2 percent porosity error lines of the line of best fit determined earlier for Ottawa sand by 47 Formation Factor-porosity tests.

In Figure 49 Formation Factors obtained with the miniature guard mode electrode array and the predicted porosity (obtained from Figure 22) are plotted versus depth for Providence silt. A sediment sample was obtained from the surface, the center, and the bottom of the Providence silt column for porosity determination. As shown in Figure 49 the value agrees well with the predicted value. Three measurements were taken with the Microlateralog pad array probe to a depth of one foot. These three Formation Factors along with the predicted porosity are also shown in Figure 49 as a function. of depth, and agree well with other data on Providence silt.

\section{Sea Tests}

In Figure 50 ten in situ Formation Factors for Station $\mathrm{A}$ and five in situ Formation Factors for Station B are plotted as a function of the porosity determined in the laboratory. The lines of best fit which were determined from 28 measurements for Station $A$ and 11 measurements for Station $B$ by the redesigned laboratory equipment are also shown in this figure. Two thirds of the in situ Formation Factors fell within \pm 2 percent of the lines of best fit while 



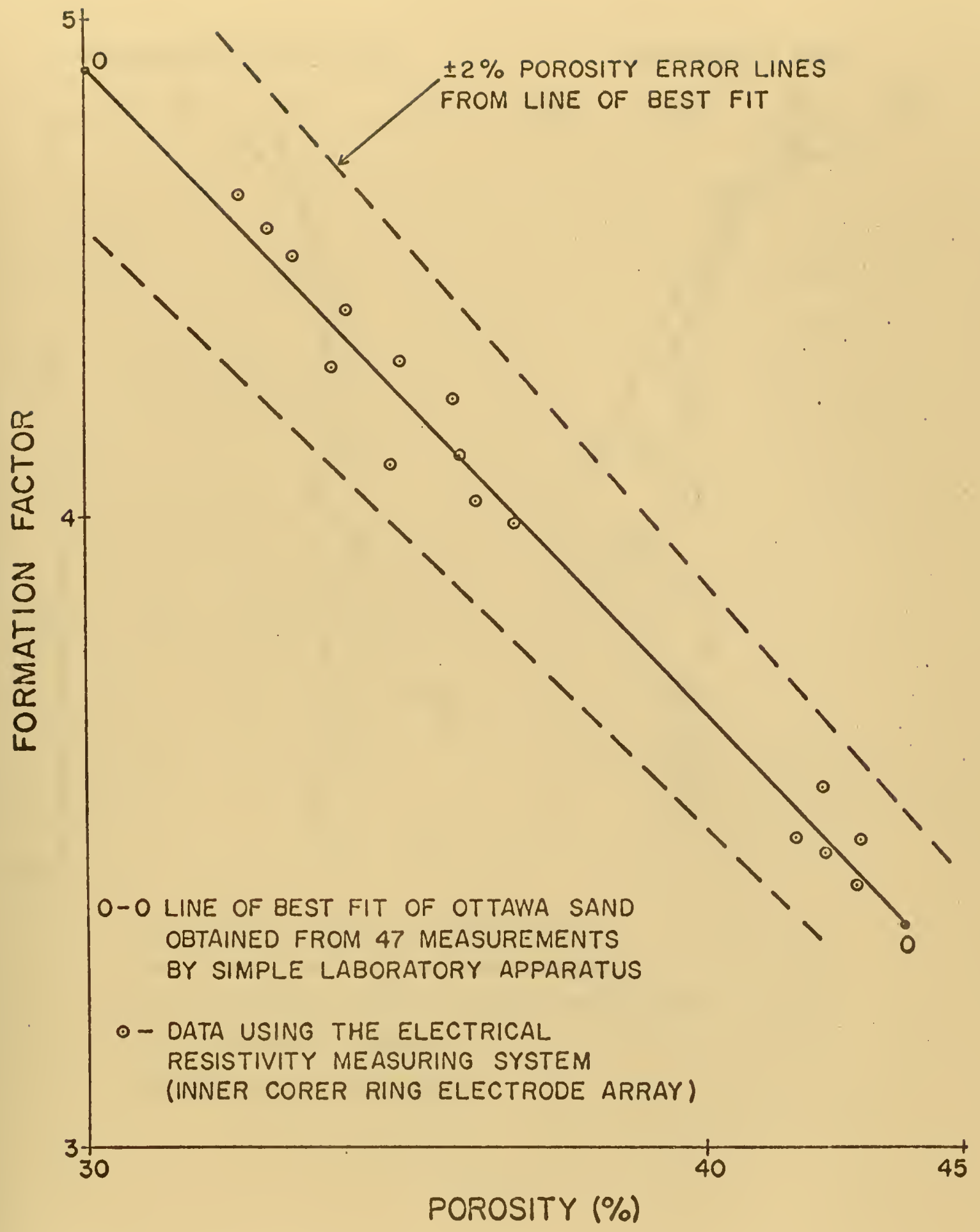

Figure 48. Formation Factor-Porosity Data Points of Otcawa Sand obtained with the Inner corer Ring Electrode Array and the Line of Best Fit from Earlier Laboratory Data of Ottawa Sand. 

FORMATION FACTOR

POROSITY (\%)

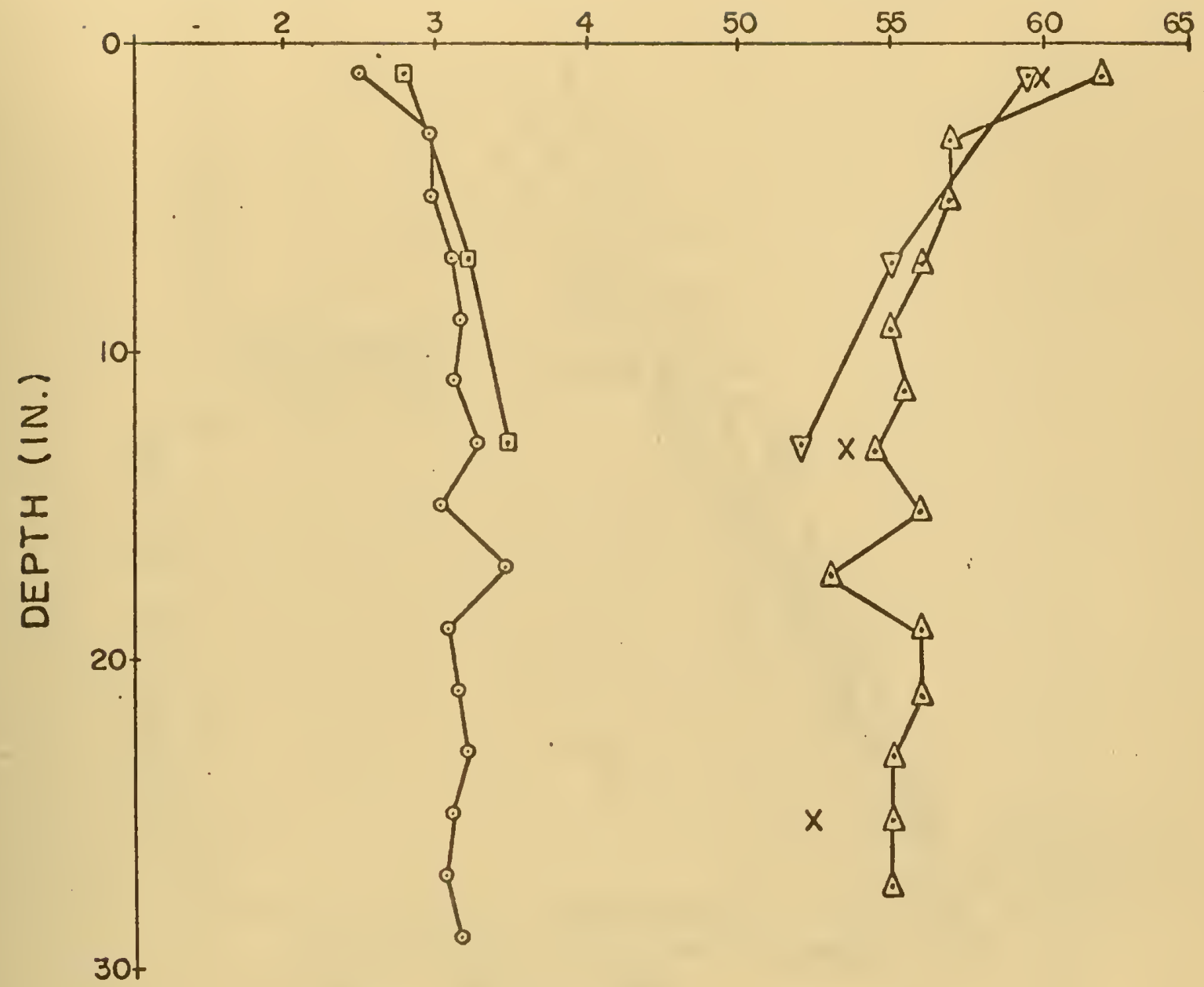

$X$-ACTUAL POROSITY MEASUREMENT

- FORMATION FACTOR (GUARD MODE)

$\square$-FORMATION FACTOR (MICROLATERALOG)

$\triangle$ - PREDICTED POROSITY

$\nabla$-PREDICTED POROSITY

Figure 49. Formation Factors Versus Depth obtained with the Miniature Guard Mode Electrode Array, the Corresponding Predicted Porosity and the Measured Values of Porosity. 



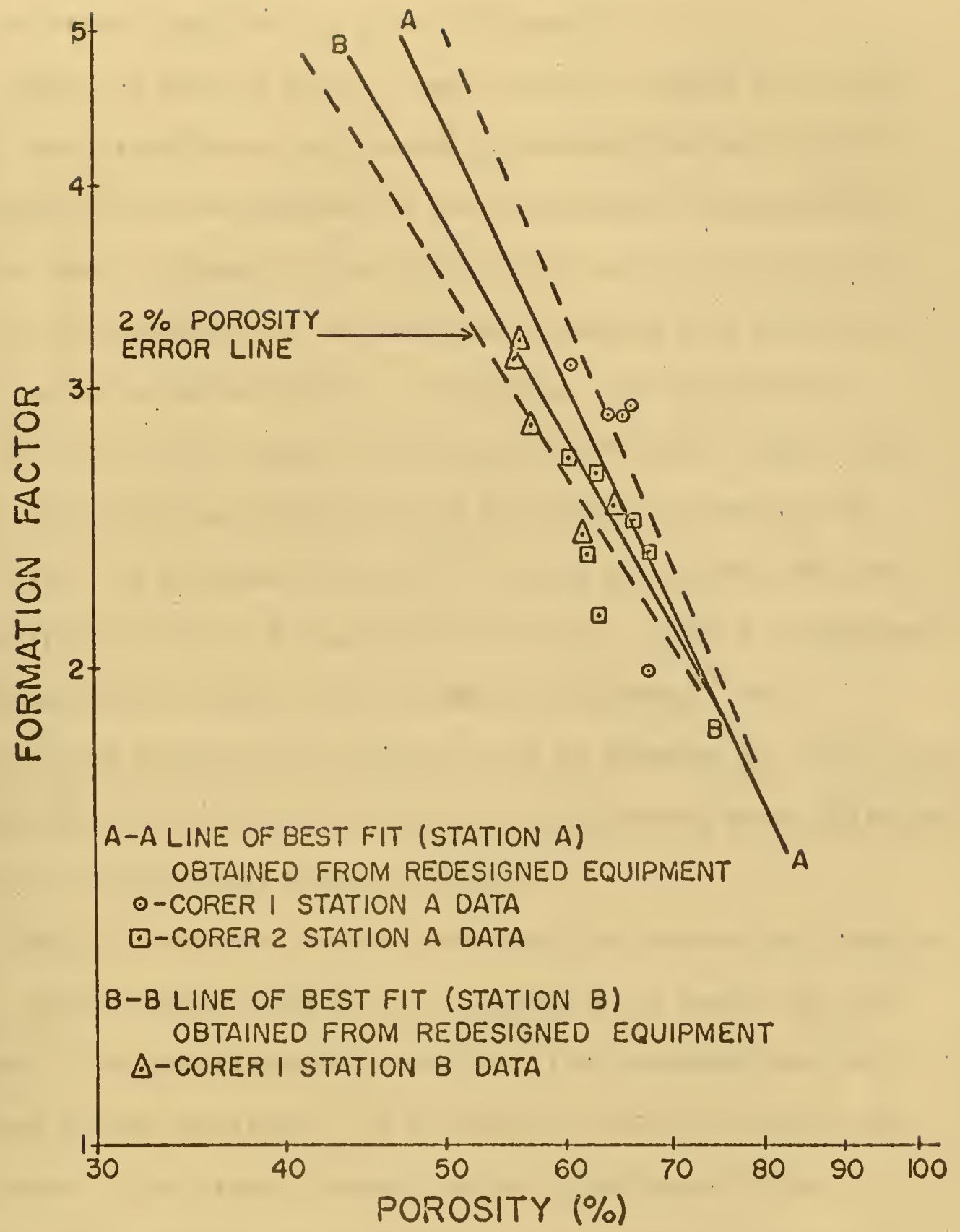

Figure 50. In-situ Formation Factors Obtained with the Inner Corer Ring Electrode Array Versus the Measured Lahoratory Porosity Values for Station $A$ and $B$ and the Lines of Best Fit for stations $A$ and $B$ Obtained From the' Redesigned Laboratory Equipment. 

one third were within \pm 4 percent. This same information is presented versus depth of the core in Figure 51.

There are several factors that could have caused this variation. The variation was not caused by assuming the interstitial water conductivity was the same as the bottom water conductivity, since as shown in Figure 52 the interstitial water salinity deter-. mined in the laboratory on the cores taken compare well with the in situ bottom water salinities. For example the interstitial water salinity of the second core taken from Station A ranged from 31.0 to 31.8 parts per thousand while the values obtained by the inner corer ring electrode array, the in situ salinometer and the laboratory conductivity bridge were $31.2,31.1$, and 31.0 respective1y. These results agree with the work of Kullenberg ${ }^{42}$ and Smirnov, ${ }^{41}$ and justify the assumption used by Kermabon et al. ${ }^{12}$ that Formation Factors could be determined by using bottom water salinity in place of interstitial water salinity.

The fact that one third of the Formation Factors fell outside the \pm 2 percent error lines would not appear to be caused by the equipment since the laboratory tests with this equipment did not have such a wide variation. The presence of shells' is another possible cause of variation. However sample disturbance before the porosity of the sample was deternined in the laboratory appears to be the most reasonable explanation. Although disturbance was intended to be monitored by continuous conductivity readings during core retrieval, this did not occur at Stations $A$ and $B$ due to an error. introduced by the temperature thermistor. The thermistor was de- 



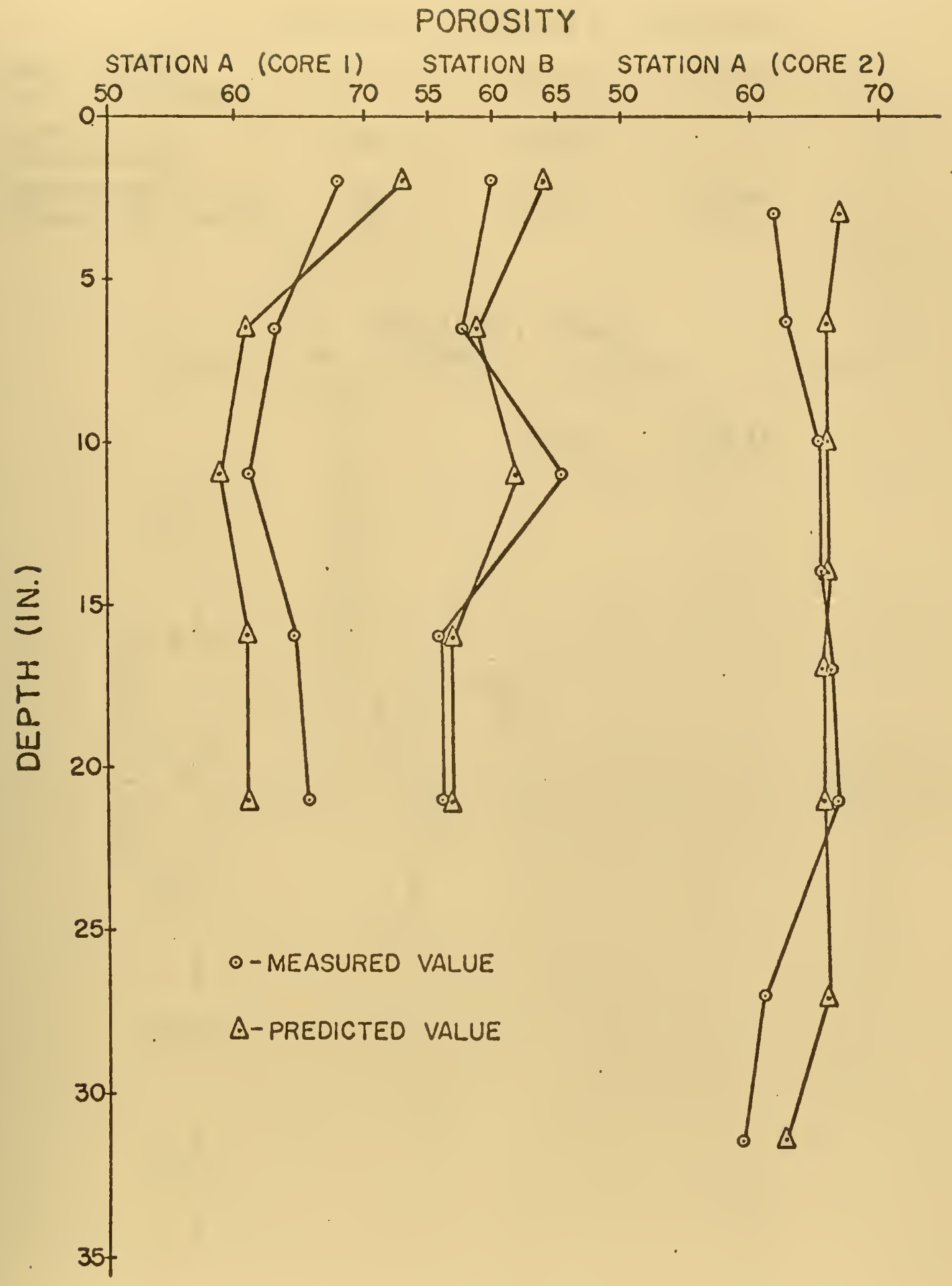

Figure 51. Measured Porosity and Predicted Porosity Versus Depth for the Cores Taken at stations $A$ and $B$ With the Inner Corer Ring Electrode Array. 

STATION A STATION B STATION C

INNER CORER

RING ELECTRODES

$31.2 \quad 31.0 \quad 31.0$

IN SITU -

SALINOMETER

31.1

30.3

LABORATORY

CONDUCTIVITY METER

31.0

30.6

30.8

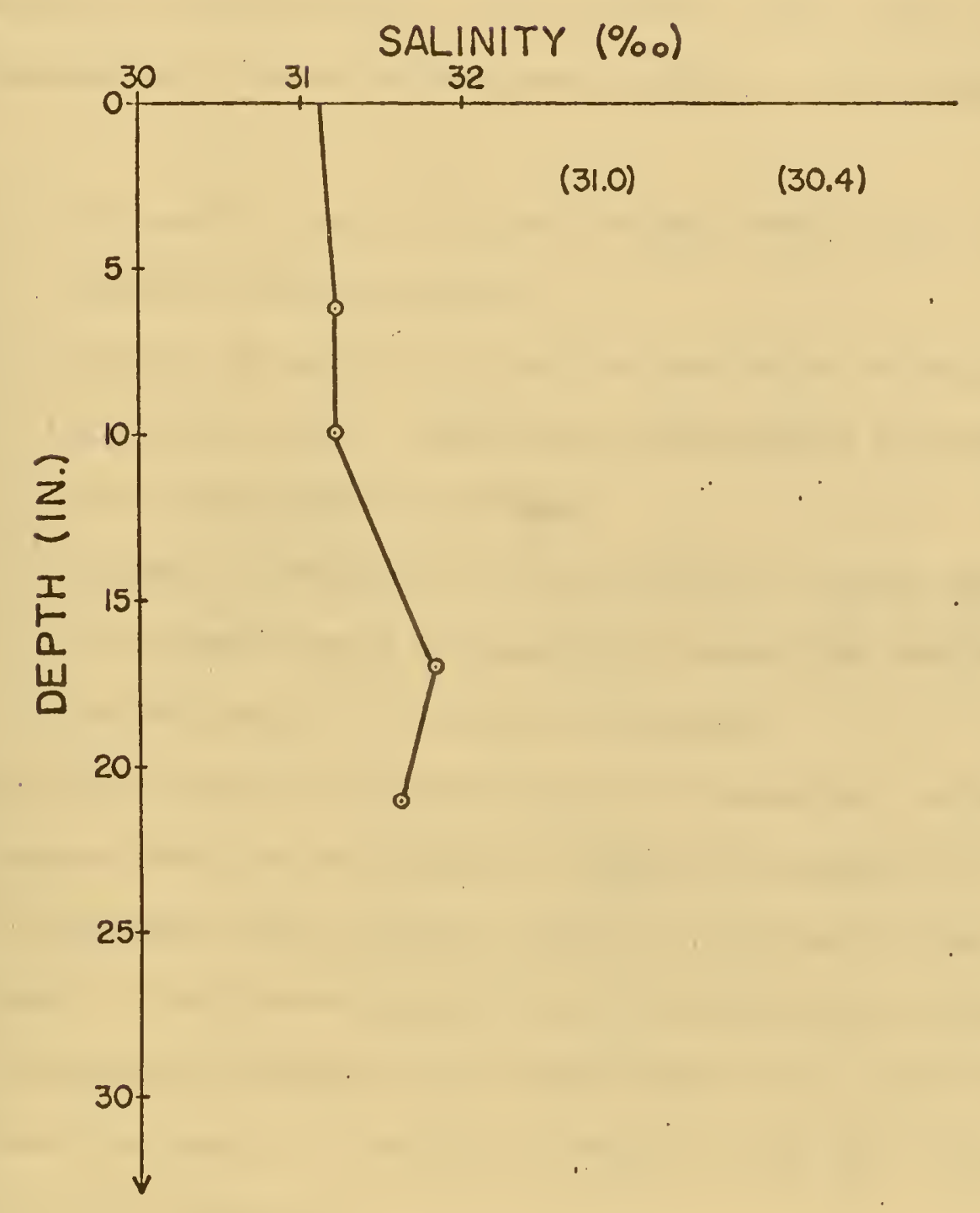

Figure 52. Measurements from Three Mcthods of Determining Bottom water Salinities and the Interstitial water Salinity of the Cores Taken at the Threo stations. 

signed to automatically correct the conductivity readings to $25^{\circ}$ Centigrade, and the error was introduced whenever the temperature sensing element embedded in the acrylic corer barrel was different from the temperature of the sediment. This was observed as the cores were retrieved from Stations A and B after the cores were removed from the refrigerator in the laboratory. This error could be eliminated and disturbance adequately monitored in the following ways:

1. Measure the conductivity of the core sample after it has reached room temperature.

2. Measure the conductivity of the core sample in the refrigerator (or ship's reefer) after the sediment has reached the refrigerator temperature.

3. Bypass the thermistor in the electronic circuit; measure the temperature of the sample and correct the conductivity measurement to 25 degrees Centigrade.

If the thermistor was bypassed and the temperature corrected to 25 degrees Centigrade by taking the temperature manually, the conductivity changes upon retrieval could be considered due to. disturbance. If this were repeated in the laboratory, any changes in the conductivity readings would be most likely due to disturbance. Disturbance Indicated by a setting of about one inch was observed on the core from Station $B$.

Proof that disturbance of the samples before the porosity was determined could have caused the wider variation in porosity prediction of the sea tests is shown in Figure 53. The sediment column 



\section{FORMATION FACTOR}

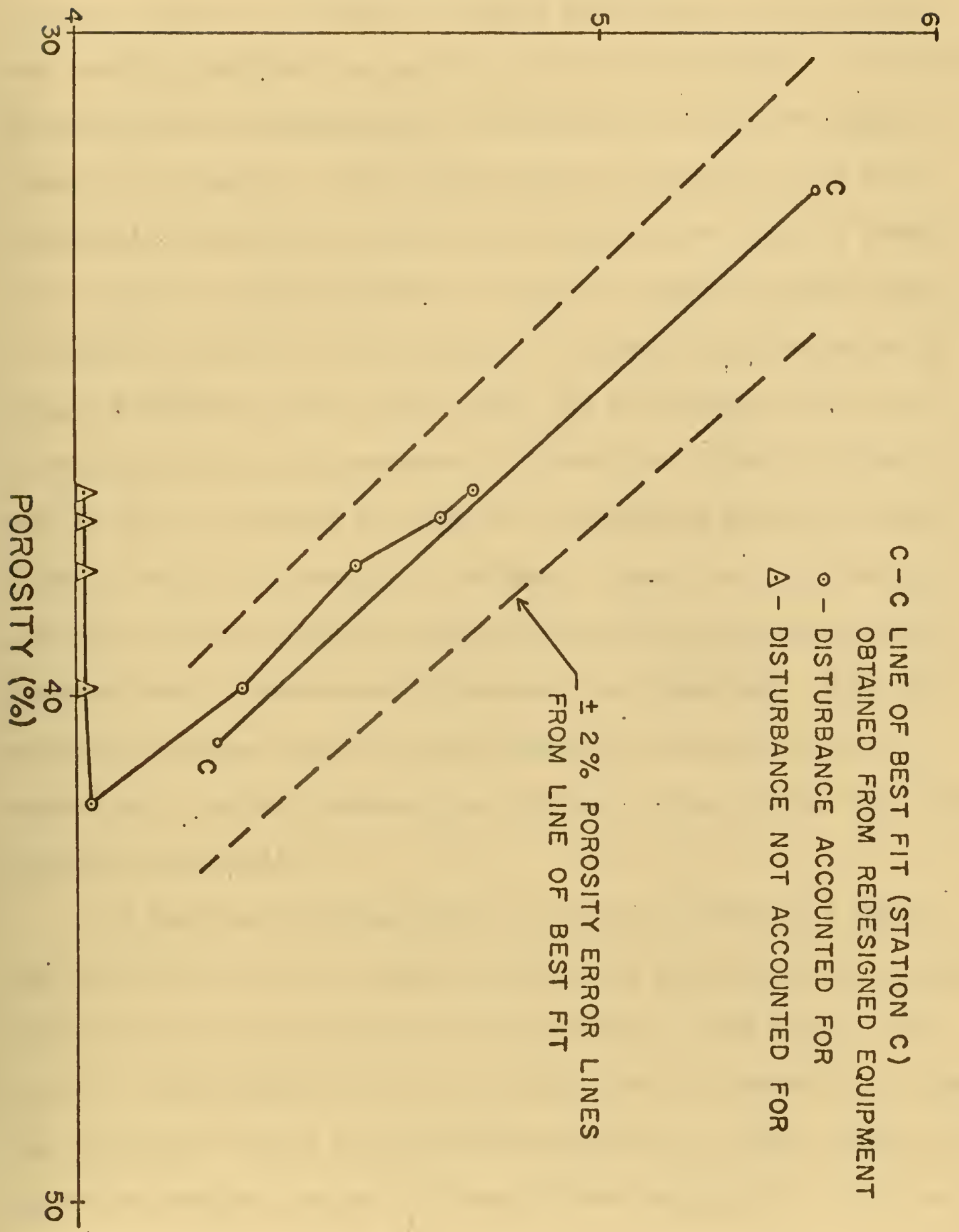

Figure 53. Formation Factor-Porosity Relationship at Different Stages of sediment Disturbance in the Inner Corer Ring Electrode Array and the Line of Best Fit of the Same Sediment Obtained by Using the Redesigned Laboratory Equipment. 

height decreased $2.2 \mathrm{~cm}$, and the porosity decreased from 41 percent to 38 percent after the corer from Station $C$ was hit and dropped. As seen in Figure 53, Formation Factors that are not corrected for this sample disturbance lie on the \pm 4 percent error line. The line of best fit was determined for 13 measurements by the redesigned laboratory equipment. Five Formation Factor-porosity values were determined at different stages of disturbance after the core stood for 24 hours at room temperature. Since the sediment column height was taken at each disturbance stage, the porosity was determined by using the diameter of the corer barrel and the weight of the soll. A sample calculation is presented in Appendix C. Figure 53 shows that if this disturbance is taken into account the porosity predictions lie within \pm 2 percent of the line of best fit. This shows that the inner corer ring electrode detected the disturbance when the error due to temperature differences was eliminated. When the porosity determinations were correlated with resistivity measurements taken after disturbance, the Formation Factors agreed well with the line of best fit.

An important advantage of the Electrical Resistivity MeasurIng System corer was discovered when the core cutter-catcher assembly did not work and the core was lost at Station B. The loss of the core was immediately detected by the fact that the conductivity reading changed to that of the surrounding sea water. Thus in deep sea operations another core can be taken without bringing the corer to the surface.

The inner corer ring electrode array can be used to $A$ snthe 

the salinity of the water column. At Station A the conductivity readings of the water column indicated a salinity of 30.5 parts per thousand while the in situ salinometer read 30.2 parts per thousand. The predicted porosity determined by the Formation Factor measurements made by the Microlateralog pad was obtained by using the line of best fit for Station B shown in Figure 50. These pre- . dicted porosity values are shown as a function of depth (to $5 \mathrm{feet}$ ) for six positions at Station B in Figure 54. For comparison, porosity as determined in the laboratory, of the two foot core obtained from the Electrical Resistivity Measuring System corer is also shown in Figure 54. The porosity values do not agree as well as expected. For example at a depth of one foot, the predicted porosity value of position one ( 25 feet from the core) was 72 percent while the value determined on the core was 66 percent. However the predicted porosIty determined by the Formation Factor measurements made by the Microlateralog pad for six positions at Station $C$ and the line of best fit for Station C (see Figure 53) was in good agreement with the porosity determined in the laboratory. The average predicted value was 42 percent for six inch pad penetration and 40 percent for one foot penetration while the porosity values determined in the laboratory ranged from 38 to 41 percent. Since the penetration was limited to one foot in the hard sandy bottom of Station C, a vibrating or pneumatic hammer similar to Borowczyk's and Krolikowski's 36 Universal Probe would have to be used for deeper penetrations.

The Formation Factors determined in situ and the laboratory determinations of porosity, water content, vold ratio, cone penetra- 



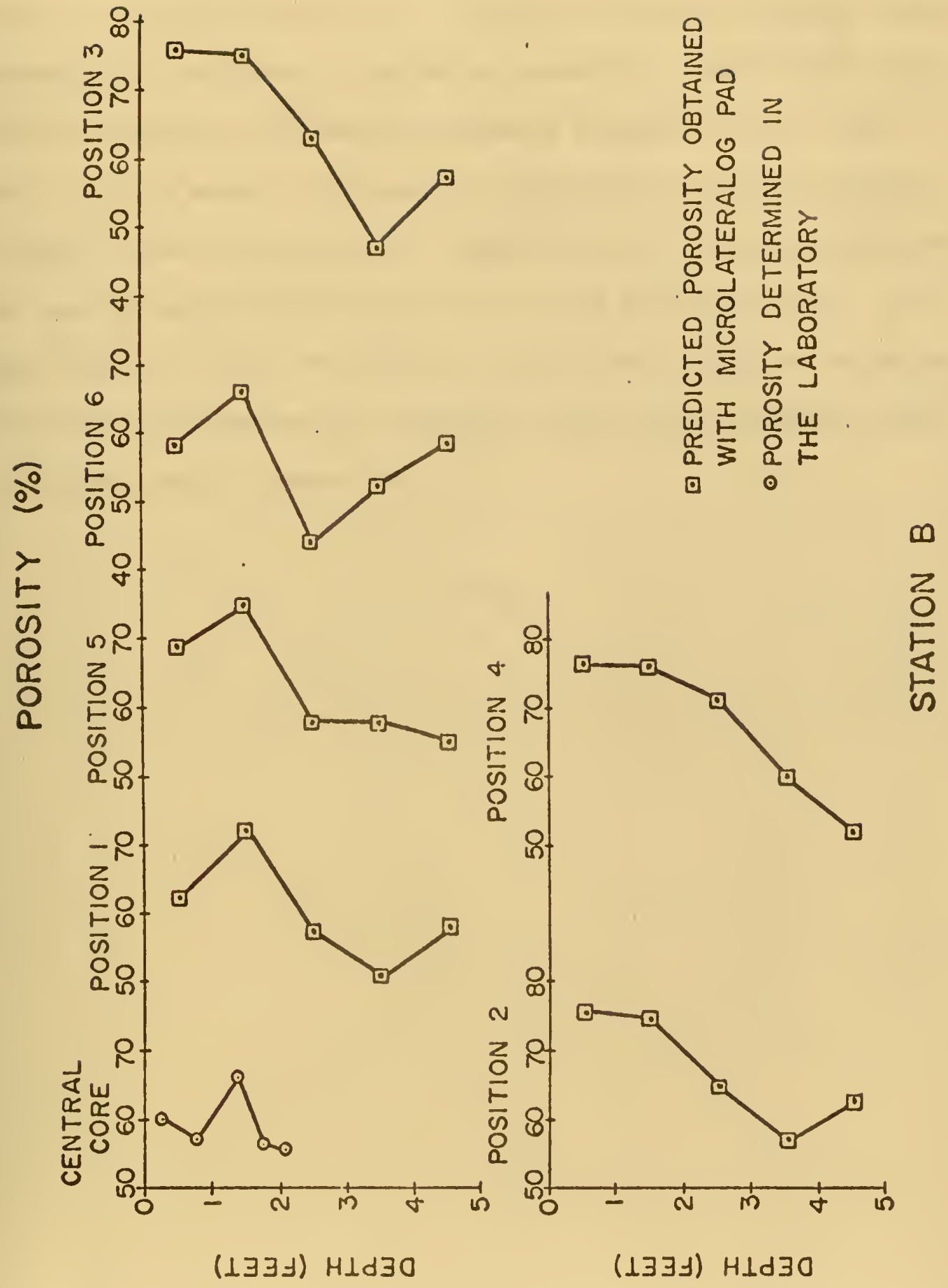

Figure 54. Predicted Porosity Versus Depth for Six Positions at Station B Obtained by Using the Microlateralog Pad and the: Measured Laboratory Porosity. 

meter, organic content, Atterberg limits and $\mathrm{pH}$ data on the two cores from Station $A$ and the one core from Station $B$ are shown in Figures 55 and 56 respectively. The in situ Formation Factor varied inversely with the porosity and water contents. These results agree with the findings on the marine sediments discussed in the first section of this paper. Although the laboratory analysis presented in these figures help define the sediment type at these stations, no other soil property correlations can be made from this data. If a larger number of cores were taken, it might be possible to correlate resistivity with another soil property such as shear strength, bulk density and acoustic properties. 



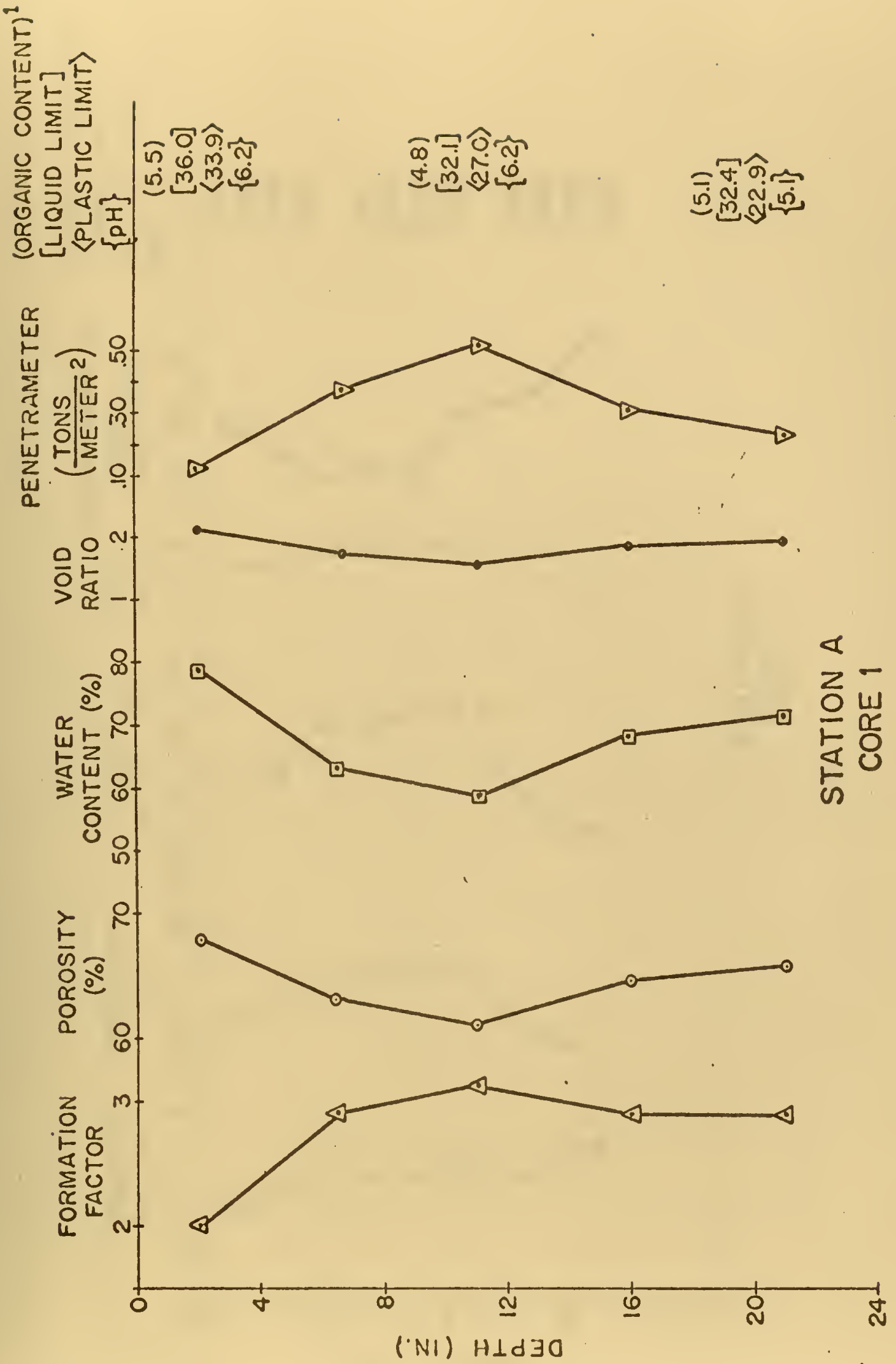

Figure 55. In situ Formation Factors Porosity, water Content, Void Ratio, Cone Penetrameter, Organic Content, Atterberg Limits, and pll of .Two cores from station A. IOrganic content, Atterberg Limits and pil were determined from top, bottom and midale core scctions) 



\section{}

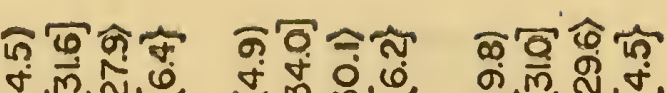

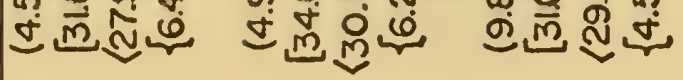
O웜

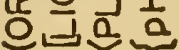

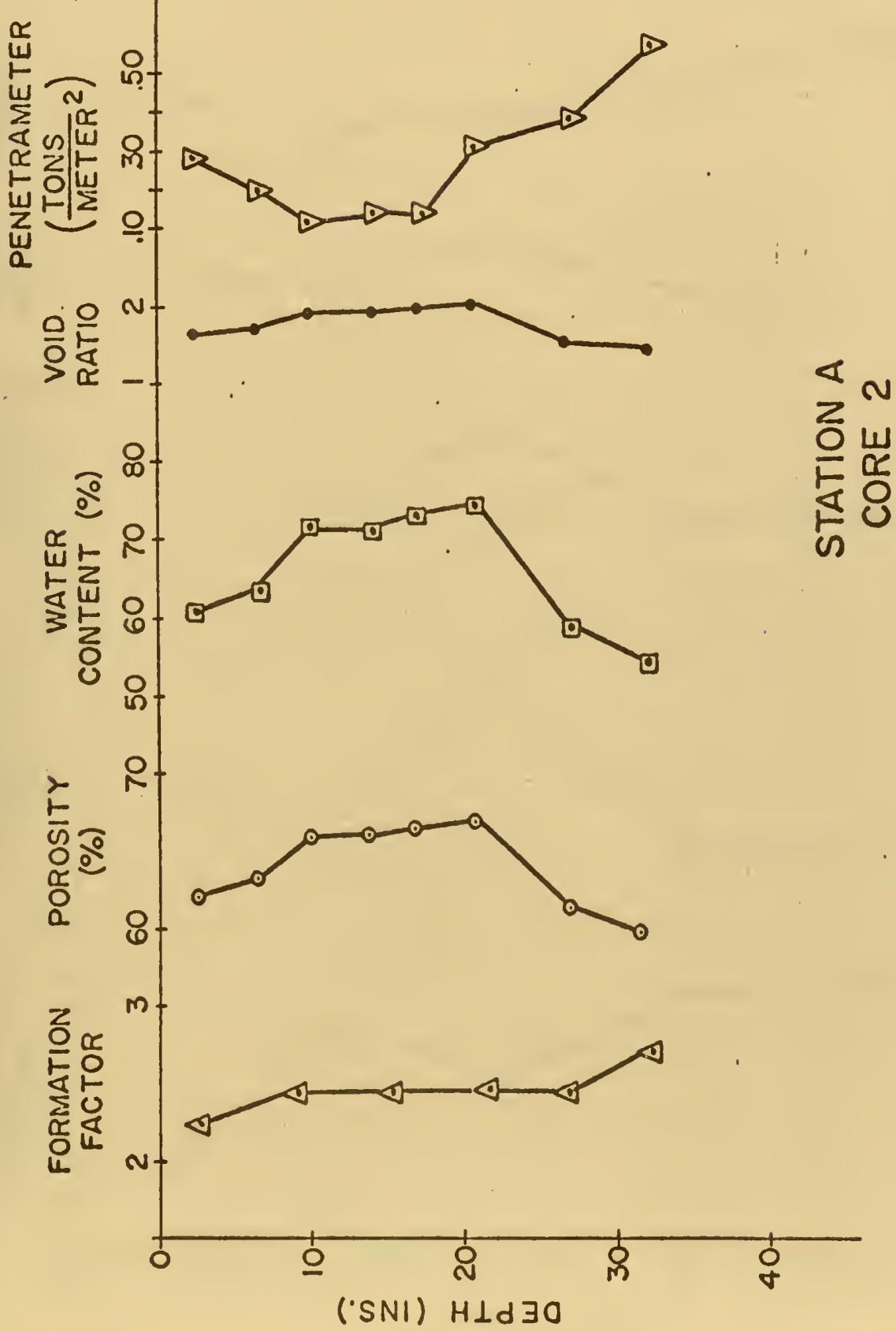

Figure 55. (con't) (Organic content, Atterberg Limits and pls were dețermined from top, bottom and middle core sections) 



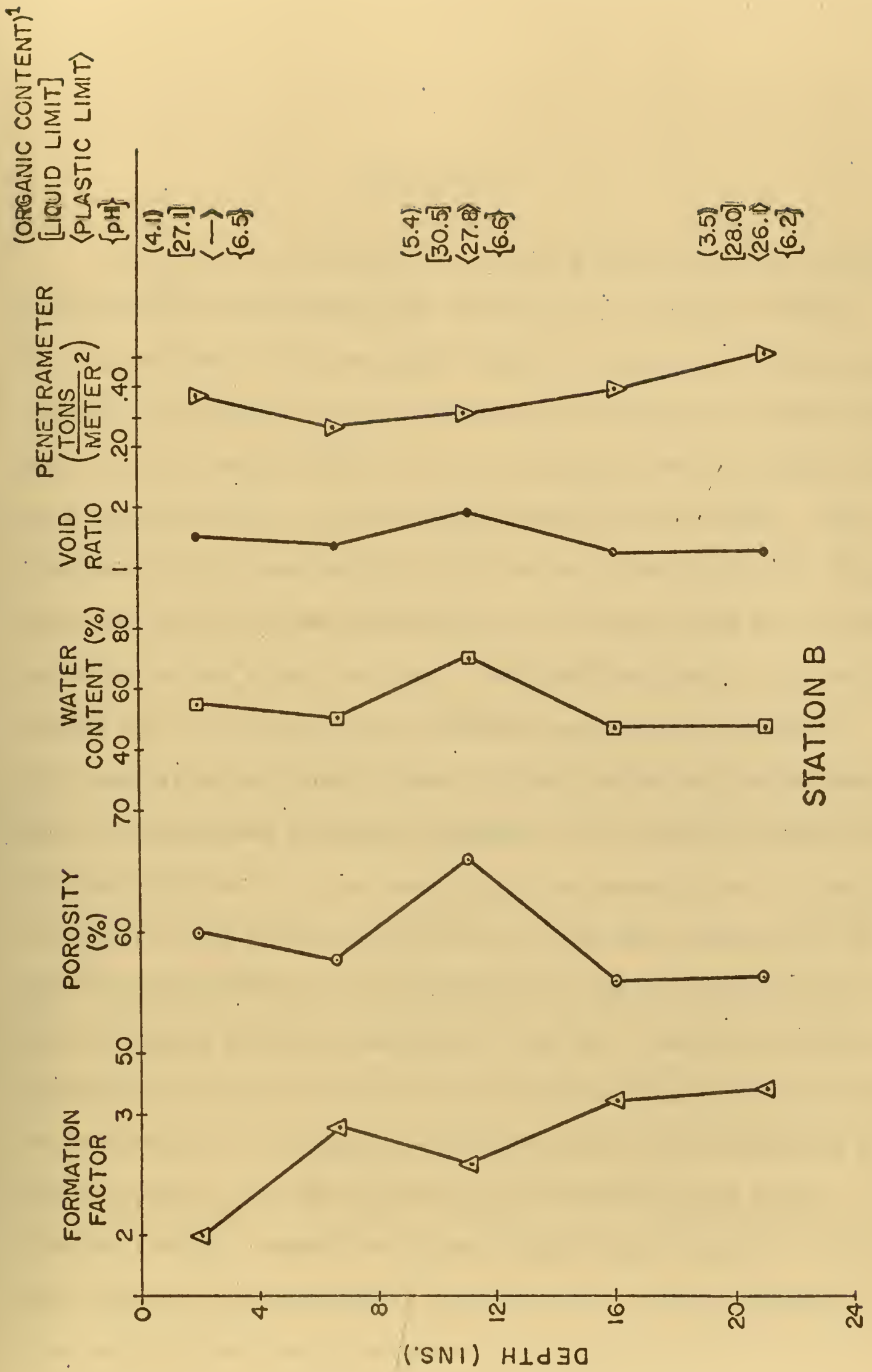

Figure 56. In Situ Formation Factor, Porosity, water Content, void Ratio, cone Fenetrameter, Organic Content, Atterberg Limits and $\mathrm{pl}$ l of the core from station $\mathrm{B}$. (Organic content, Attesberg Limits and pH were determined from top. bottom and midale core sections) 

CONCLUSIONS

1. The Electrical Resistivity Measuring System that was designed and fabricated was successfully tested in the laboratory and in Narragansett Bay. The system was tested by connecting the electrode array, the electronic circuits, and the FM telemetry data Iink with 6000 feet of coaxial cable in order to simulate the requirements for deep ocean testing on the Deep Ocean Sediment Probe (DOSP). Three electrode arrays were fabricated and tested: the inner corer ring electrode array, the Microlateralog pad electrode array and the miniature guard mode electrode array. The predicted porosity values obtained with the system in the laboratory were in good agrement ( \pm 2 percent of the 1 ines of best $f i t$ ) with values determined earlier with the redesigned laboratory equipment. The system was tested in the shallow water of three locations in Narragansett Bay. Using the inner corer ring electrode array most of the data obtained was in good agreement with the data obtained later in the laboratory with the redesigned laboratory equipment. The data that was not in good agreement ( \pm 4 percent of the line of best $f i t$ ) could have been due to disturbance of the sample before the porosity was determined in

the laboratory. The Microlateralog pad electrode array needs further testing. Though the porosity prediction using the line of best fit was in good agreement with laboratory porosity values at Station C, a wider variation was found at Station B. 

2. The conductivity, readings of the inner corer ring electrode array on the water column and the bottom sea water converted to a salinity very similar to the readings of an in situ salinometer, 30.5 and 30.2 parts per thousand respectively. The salinity of the bottom water as determined by the inner corer ring electrode array was in good agreement with the interstitial water salinity determined in the laboratory, 31.2 and 31.1 parts per thousand respectively.

3. The Electrical Resistivity Measuring System was found to be an excellent monitoring system. The System indicated that the bottom was reached by showing a marked change in conductivity readings. In the same way the loss of a core was immediately detected. This ability would be especially valuable for a deep ocean corer. Tests in the laboratory with a sediment in the Electrical Resistivity Measuring System corer showed that the resistivity measurements detected sample disturbance.

4. The Electrical Resistivity Measuring System costs approximately $\$ 1,500$, not including the FM telemetry data link component which is shared by other systems aboard the DOSP. This relatively low cost does not include the 50 man hours required to connect the system, but does include all the electronic circuits, electrode arrays (including the corer barrel), pressure housing, thermistor housing, electrical connectors and wiring. Since the electronics of the Electrical Resistivity Measuring System and the redesigned laboratory equipment are the same, module components of these systems can be interchanged. This duplicity affords quick back-up spare parts whenever necessary. 

The Electrical Resistivity Measuring System and its components could be adapted to a probe, coring device or any deep sea platform. It could be used in the deep ocean or in shallow coastal waters. If hard sandy bottom is encountered, a vibrating probe would be required for deep penetration. 



\section{FURTHER STUDIES}

1. The results of this study indicate that electrical resist1vity measurements could be used to determine the cation exchange capacity of individual clays. For example clays with a high cation exchange capacity could be expected to have Formation Factors of less than one at low interstitial water conductivities. Clays with a low cation exchange capacity would always have Formation Factors greater than one and the Formation Factors would remain constant regardless of the interstitial water conductivity (assuming porosity remained the same). The Formation Factors of the individual clays could be correlated with the cation exchange capacity obtained by standard methods. Once established, the electrical resistivity method would be easier and less time consuming than the standard method. 2. The development of an induction type Electrical Resistivity Measuring System should be pursued for in situ sediment measurements. This type of measuring system would eliminate direct metal electrode contact of the sediment and could result in greater accuracy. 3. The combination of the Resistivity, Acoustic, Nuclear, Thermal and Geochemical measuring systems on the DOSP offer a unique opportunity to further study and determine accurately in situ properties such as porosity, water content, sound velocity and bulk wet density. In addition the ability of the Electrical Resistivity Measuring System to monitor such situations as touch down, core loss, and sample 

disturbance make the system even more valuable for deep water. These side assets should be further studied in future deep sea tests.

4. The use of the Electrical Resistivity Measuring System in pollution detection should be studied further. For example a continuously monitored water pollution detection device could be simply attached to a buoy. The cell would consist of two small tubes each having an inner ring electrode array. One tube containing water of desired qualities would be sealed. The other tube, adjacent to the first, would be a flow-through tube sensing the environmental water. The instrumentation would work on the Formation Factor concept, 1.e. If the environmental water exactly met standards the Formation Factor would be one. Any large variation from unity would give warning of a possible polluting situation.

Perhaps a similar Formation Factor device could be used to measure the cleansing or infusion of pollutants in bottom sediments. These residual pollution effects in bottom sediments could be monltored continuously and over long periods of time.

5. New electrode arrays similar to the probe described by Bouma et $a 1.27$ could be tested for a wide range of uses. For example, these probes could be inserted to considerable depths (20 feet) at various positions in an estuary such as Narragansett Bay, and seasonal variations in porosity could be detected.

This same electrode array placed on the legs of an oil rig platform or Texas tower could serve as a warning system for such phenomena as bottom erosion and scour. 

6. The ability of electrical resistivity measurements to predict other submarine soil properties in situ should be pursued. For example, undrained shear strength measured in situ by vane shear or a penetrameter could be correlated with electrical resistivity measurements. Also relationships could be developed between electrical resistivity measurements and acoustic properties of soils or geochemical properties such as Eh and $\mathrm{pH}$.

7. The possibility of attaching an electrical resistivity electrode array to a telescoping or vibrating deep ocean floor penetrating device (50 feet or more) merits further study since properties such as porosity, water content and density could be predicted to these depths. This knowledge would be very useful to ocean engineering projects such as ocean floor foundations.

8. A sample could be monitored by the Electrical Resistivity Measuring System while it is returned to the surface from the deep ocean if a second temperature sensing element was provided. Since a thermistor is located in the tip of one of the DOSP's probes, a second temperature of the water column could be used to adjust the conductivity measurement to a correct value, and the disturbance of a sample during retrieval could be detected. This method of monitoring disturbance could be checked by the nuclear gauge suggested by Rose and Roney ${ }^{34}$ or an acoustic corer. 45

9. Electrical resistivity measurements could be used to determine sediment grain size. This could be accomplished by fabricating a 30 inch long, one inch diameter plastic tube with three or four sets of Inner ring electrode arrays placed vertically along the inner wall 

of the tube.

A slurry contalning a known amount of soll, water and deflocculating agent would be added to the cell tube and electrical resistivity measurements would be made at definite time increments. As the soll particles settled, the resistivity of the lower array would increase while the resistivity of the upper arrays would decrease. If the same assumptions used in a hydrometer analysis are applied to this method, the electrical resistivity measurement could then be related to particle size. This method would be easier than the hydrometer method since the measurements could be made electrically and a graphical record could be made automatically. 10. Electrical resistivity measurements could be used to monitor consolidation in situ. This could be accomplished by placing an electrode array under an object or structure with the electrodes' current fleld in the direction of the sediment. Changes in the porosity due to the weight of the structure would be detected by the electrical resistivity measurements. Since the cost of electrode arrays is low, several could be placed to monitor changes both continuously and periodically. 



\section{APPENDICES}





\section{APPENDIX A}

\section{DETAILED DEVELOPMENT OF SOME EQUATIONS}

1. Development of "Parallel" Equation

Assume that the mediurn consists of a series of plates, all parallel to the direction of current flow. Then the plates may be thought of as individual resistors in parallel. (Some of the plates are sheets of interstitial water.) To find the total conductivity, the Individual conductivities are surmed, but weighted by their volumes:

$$
k_{m} V_{m}=k_{c} V_{c}+k_{d} V_{d}
$$

where:

$V_{m}$ is the volure of the mixture (sediment),

$V_{c}$ is the volume of the continuous phase (water),

$V_{\alpha}$ is the volume of the dispersed phase (soil).

dividing by $v_{m}$.

$$
k_{m}=k_{c} n+k_{d}(1-n) \text {. }
$$

where $n$ is the porosity, and dividing by $k_{c}$.

$$
\frac{k_{m}}{k_{c}}=K_{m}=n+K_{s}(1-n) \text {. }
$$

or the Formation Factor (FF) is,

$$
F F^{-1}=R_{n}^{-1}=n+R_{s}^{-1}(1-n)
$$

2. Development of "Series" Equation

Assume medium consists of series of plates, all perpendicular to 

direction of current flow. To find the conductivity of the mixture, the individual resistivities are weighted according to their volumes and surmed:

$$
r_{m} V_{m}=r_{c} V_{c}+r_{d} V_{d}
$$

dividing by $V_{m}$.

$$
r_{m}=r_{c} n+r_{d}(1-n) \text {. }
$$

dividing by $x_{c}$.

$$
\frac{r_{m}}{r_{c}}=n+\frac{r_{d}}{d_{c}}(1-n)
$$

or,

$$
F F=R_{m}=n+R_{d}(1-n) .
$$

3. Detalled Derivation of the Resistivity Equations for the Wenner and the Schlumberger Configurations of Electrodes

The most direct approach to measurement of the value of sediment aggregate resistivity is by the four-electrode method. The four-electrode systern of measuring earth resistivity is quite old, having been developed by Wenner ${ }^{37}$ of the National Bureau of Standards in 1915. Referring to Figure A-1 a known current is passed between the outer two electrodes, and the difference in potential between the inner two electrodes is measured. The resistivity can be calculated from knowledge of the current, the potential difference, and the geometric arrangement of the electrodes. Assuming a point current source in a homogenous mediurn, the Laplace equation may be written as: 



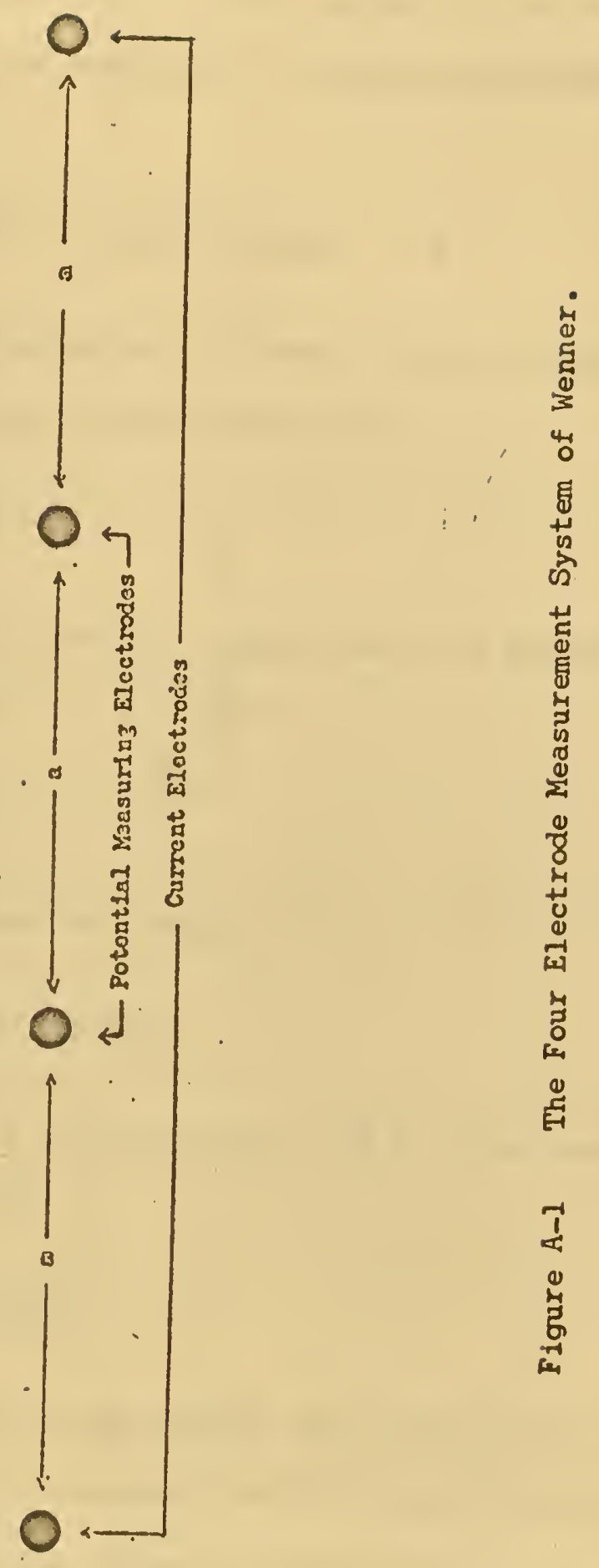





$$
\nabla^{2} v=0
$$

If there is no angular dependence (i.e. the resistivity of the sediment is not, in general, perfectly isotropic) the Laplace equation can be. written as

$$
\left(d^{2} V / d R^{2}\right)+(2 / R)(d V / d R)=0
$$

where $V$ is the electric potential at a distance $R$ from the point source. The solution to this equation is well known and is

$$
V=\left(C_{1} / R\right)+C_{2} \text {. }
$$

To determine the constants $C_{1}$ and $C_{2}$, assume that as $R$ extends to infinity, $V$ tends to zero. Thus, $C_{2}=0$, and so

$$
V=C / R \text {. }
$$

By definition, the resistivity of a medium is

$$
I=-(A / I)(d V / d R)
$$

where $I$ is the resistivity, I is the current, and $A$ is the area through which it flows. Now from (1),

$$
\mathrm{dV} / \mathrm{dR}=-\mathrm{C} / \mathrm{R}^{2}
$$

If it is assurned that a point is the source, then the current flows through a sphere surrounding the source, and the area of this sphere is simply $4 \pi R^{2}$. Substituting this value and equation (3) into equation (2), it becomes: 



$$
x=-\left(4 \pi R^{2} / I\right)\left(-C / R^{2}\right)=4 \pi C / I
$$

or

$$
C=2 I / 4 \pi:
$$

Substitution of this value into (1) gives

$$
V=x I / 4 \pi R
$$

A current source implies a current $\underline{\text { sink, }}$, and the potential of such a sink is just the negative of (4). By superposition, the potential at a point $p, V(p)$, is

$$
V(p)=V^{+}(p)+V^{-}(p)
$$

where $V^{+}(p)$ and $V^{-}(p)$ are the potentials at point $p$ due to the current source and the current sink, respectively. Thus,

$$
V(p)=(x I / 4 \pi)\left(R_{1}^{-1}-R_{2}^{-1}\right) \ldots
$$

where $R_{1}$ and $R_{2}$ are the distances fran the point $p$ to the current source and sink, respectively.

In practical situations, one measures the difference in potential between two points a finite distance from the source and the sink, as in the figure below. 



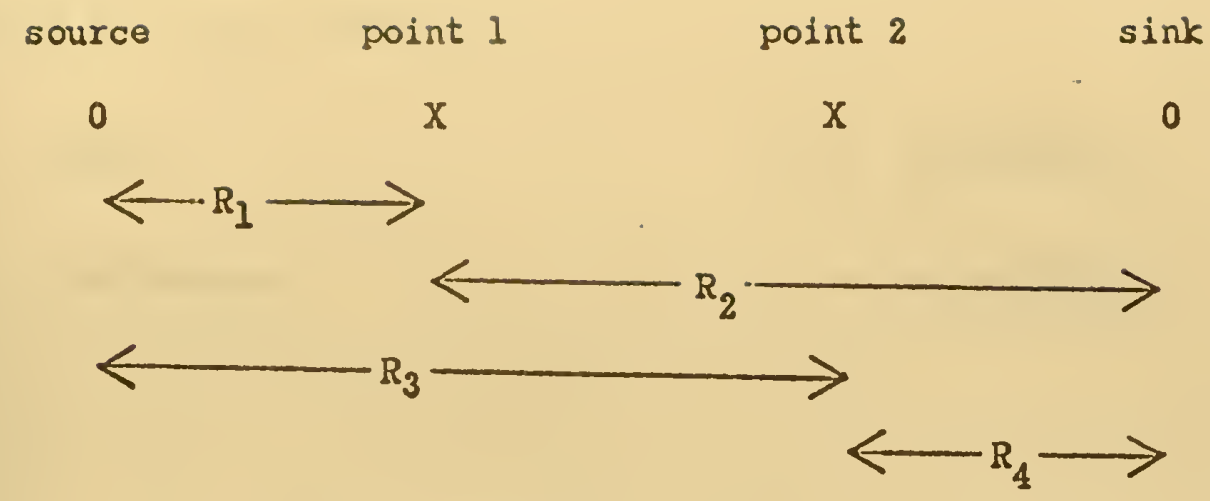

If $\Delta V$ is 'defined as:

$$
\Delta V=(\text { potential at point } 1)-(\text { potential at point 2) } .
$$

Then

$$
\Delta V=\frac{r I}{4 \pi}\left[\frac{1}{R_{1}}+\frac{1}{R_{4}}-\frac{1}{R_{2}}-\frac{I}{R_{3}}\right]
$$

The choice of the electrode spacing is somewhat arbitrary. The two most common are the "Wenner" and the "Schlumberger" configurations. These are defined by:

Wenner

$R_{1}$
$R_{2}$
$R_{3}$
$R_{4}$ a

$2 a$

$2 a$

a
Schlumberger

a

$3 a$

$3 a$

a

where $a$ is a convenient unit of spacing. 

Equation (5) then reduces to

Wenner

Schlumberger

$$
r=4 \pi a(\Delta V / I)
$$

$$
r=3 \pi a(\Delta v / I) .
$$





\section{APPENDIX B}

\section{DETAILS OF EQUIPMENT AND CALIBRATION}

The basic features of the laboratory and in situ equipment, with descriptive photographs, have been discussed in the text. Also calibration procedures were discussed and in some cases calibration curves were presented. This section will present some detalled drawings of this equipment, block diagrams of electronics, some flow patterns developed by the electrode arrays and calibration curves not previously given in the text.

\section{Drawings of Cells and Electrode Arrays.}

A. Simple Cell Apparatus.

Figures 7,8 and 9 in the text are photographs of the simple cell apparatus. Figure $B-1$ is a drawing of the simple cell with two types of top electrodes used in testing.

B. Modified Apparatus.

Figures 11 and 12 in the text are photographs of one sediment cell and chamber respectively. A detailed drawing of one cell tube is given In Figure B-2. Other components of the modified apparatus such as support frame, piston rod, piston head and bottom cap can be obtained from plan no. G-120 on file in the University of Rhode Island Engineering Instrument Shop.

C. Redesigned Apparatus.

A photograph of the redesigned apparatus is presented in Figure 14. A drawing of the redesigned cell and pressures vessel is shown in Figure B-3. 



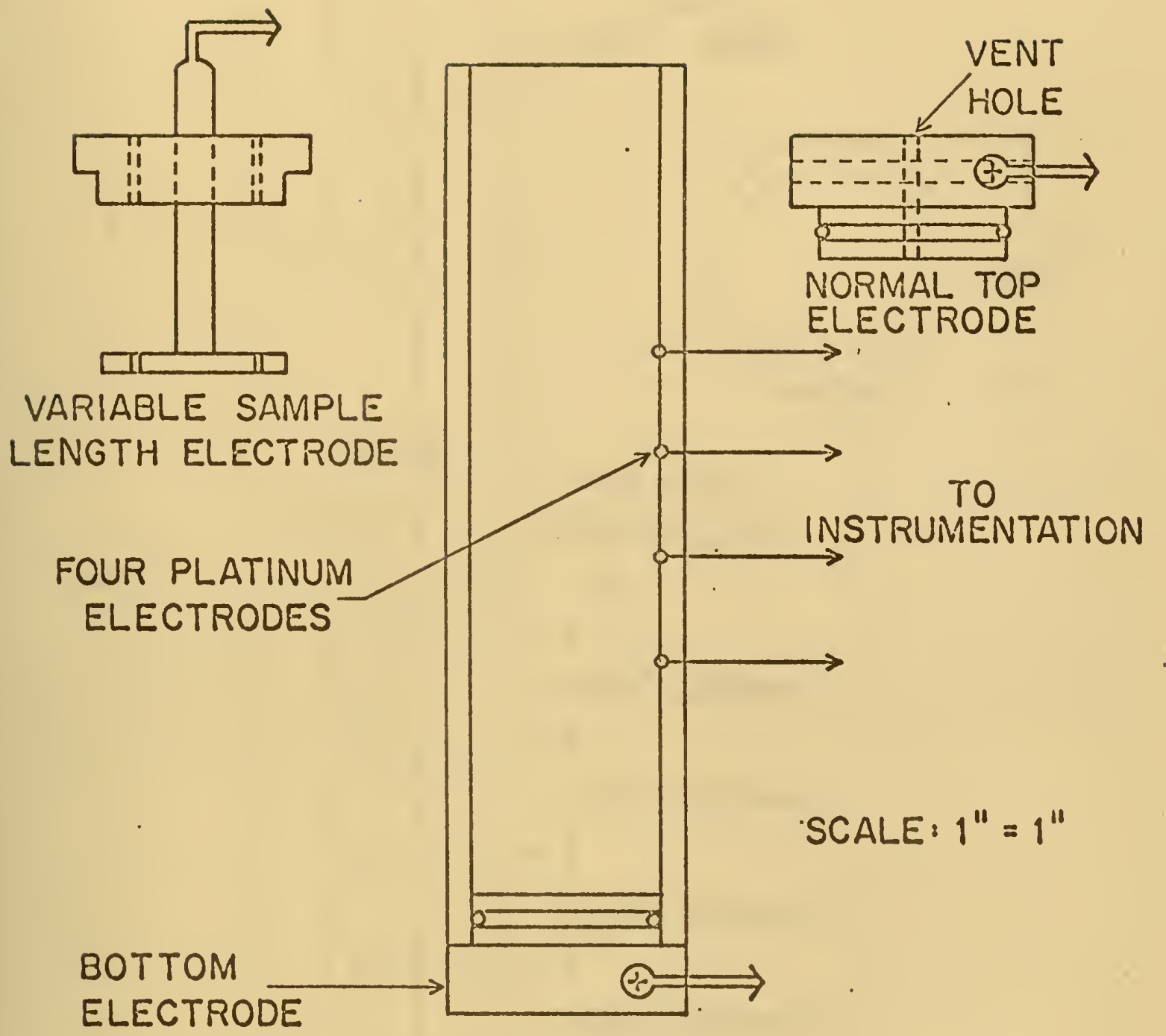

Figure B-1 Simple Apparatus Test Coll with Variable Sample Length Electrode and Nomal Top Electrode. 



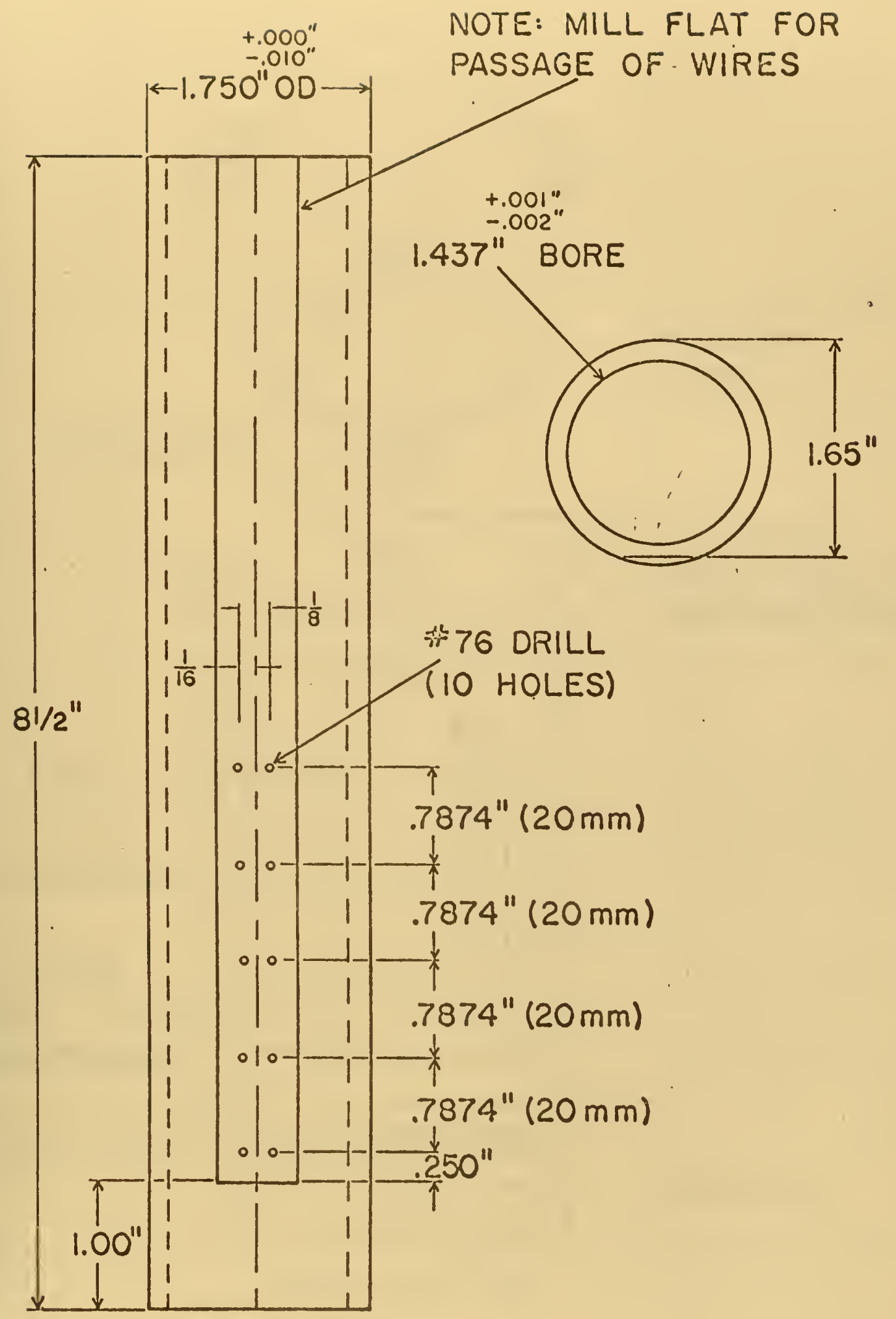

Figure B-2 Modified Apparatus Test Cell. 



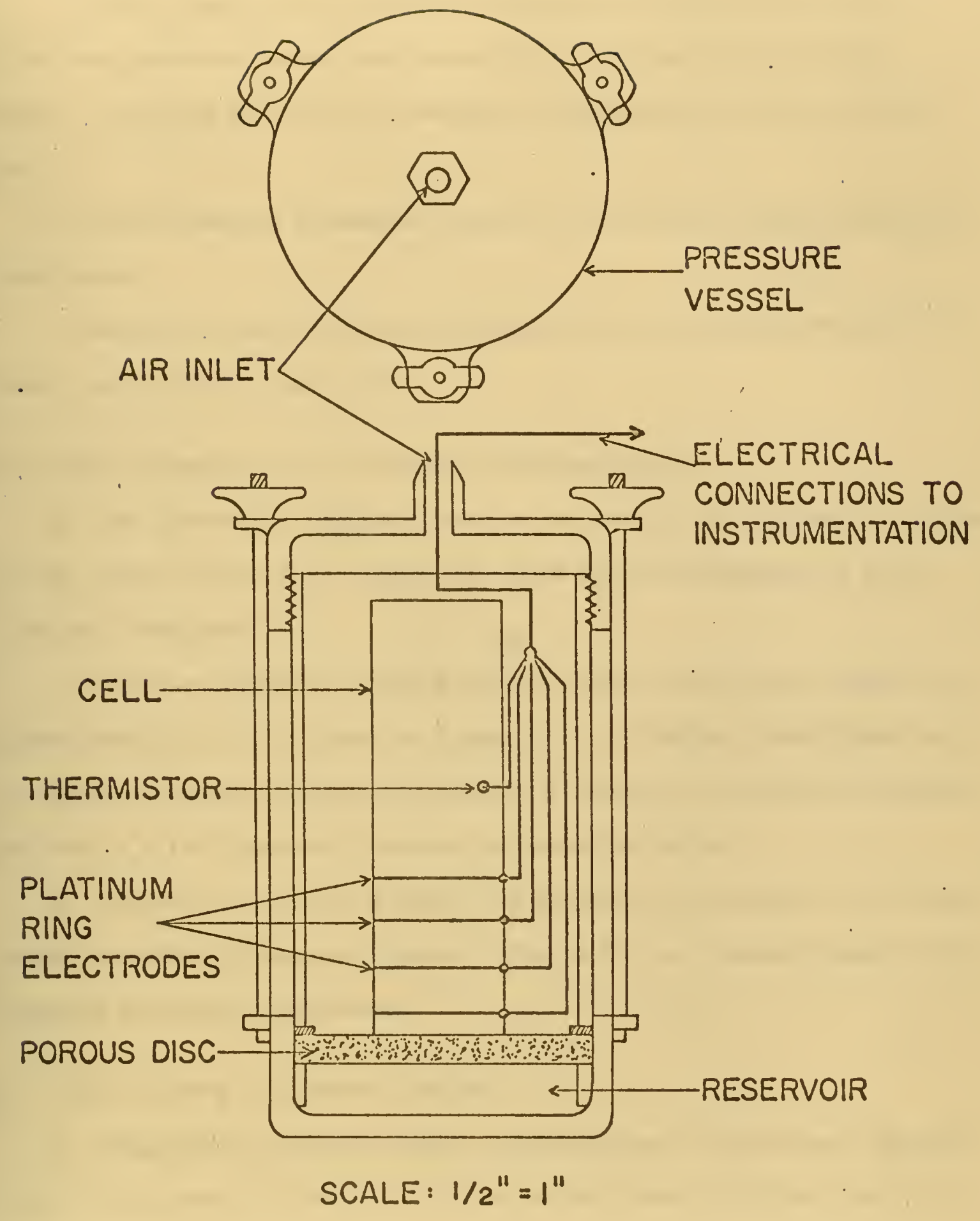

Figure B-3 Redesigned Apparatus Pressure Vessel and Test Cell. 



\section{Inner Corer Ring Electrode Array.}

In the text Figure 36 shows a descriptive drawing of the inner corer ring electrode array and Figure 39 is a photograph of the same array. A drawing giving the dimensions of this array is shown in Figure B-4.

E. Microlateralog Electrode Array and the Miniature Guard Mode Electrode Array.

Descriptive and dimensional detail is shown in the photographs of these two arrays in Figure 40.

2. Block Diagrams of the Electronic Instrumentation.

A. The electronic equipment used in the simple and modified apparatus can be seen in Figure 13. Figure Bas gives the block diagram of this electronic equipment.

B. The block diagram of the Honeywell Signal Conditioner (model no. 552022-1002-100-000) is shown in Figure B-6. The signal conditioner was the basic electronic component used in the redesigned laboratory apparatus and the in situ Electrical Resistivity Measuring System.

C. Figure 42 in the text shows the electronic components of the Electrical Resistivity Measuring System. Figure B-7 is a block diagram of the syster's electronic components.

3. Flow Patterns of Electrode Arrays.

A. Simple cell electrode array for the current flow between top and bottom electrodes resulted in the flow pattern shown in Figure B-8. If the current was allowed to flow between the top and bottom platinum point electrodes the flow pattern shown in Figure B-9 developed. 



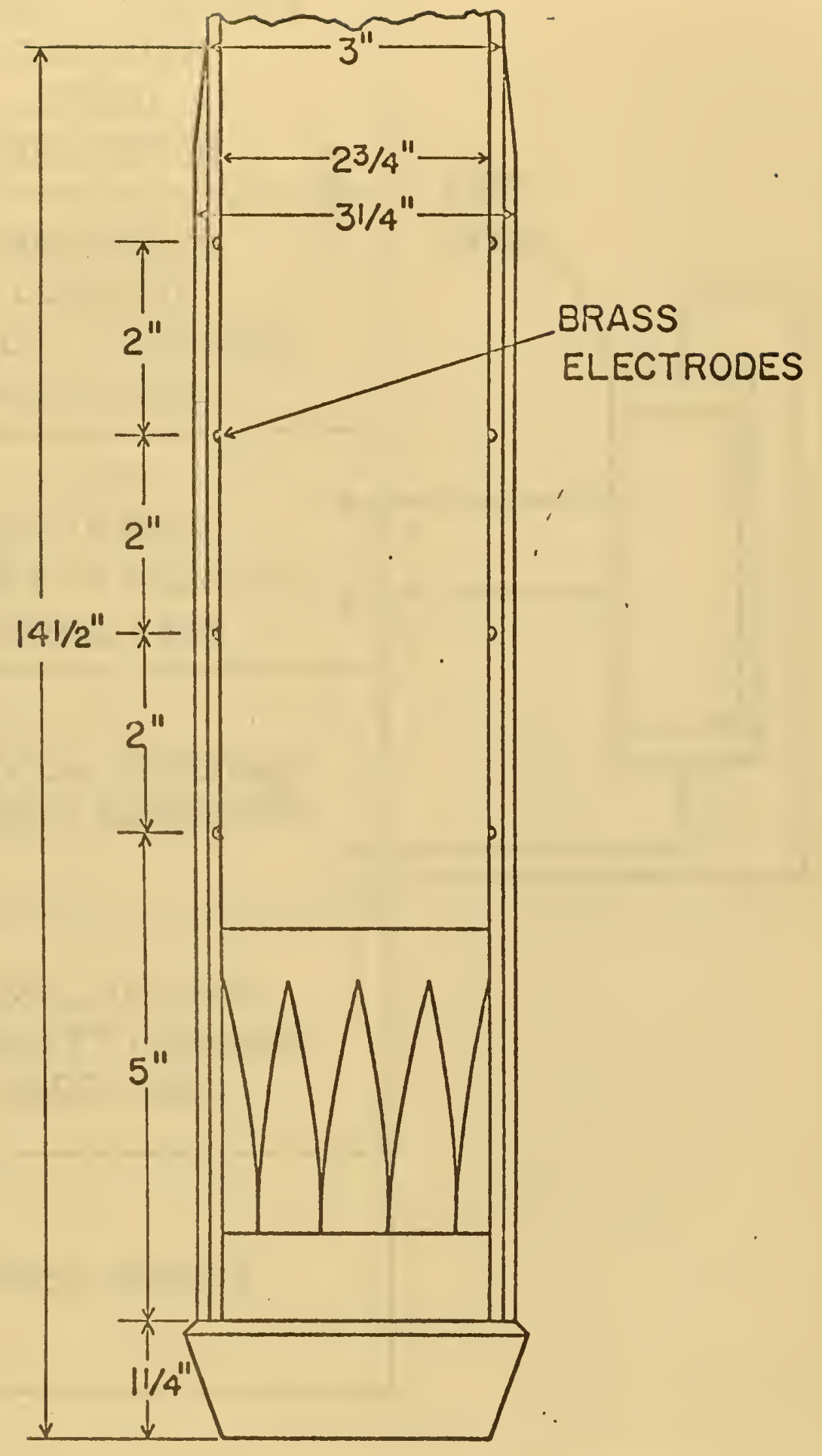

Figure B-4 Inner Corer Ring Electrode Array. 



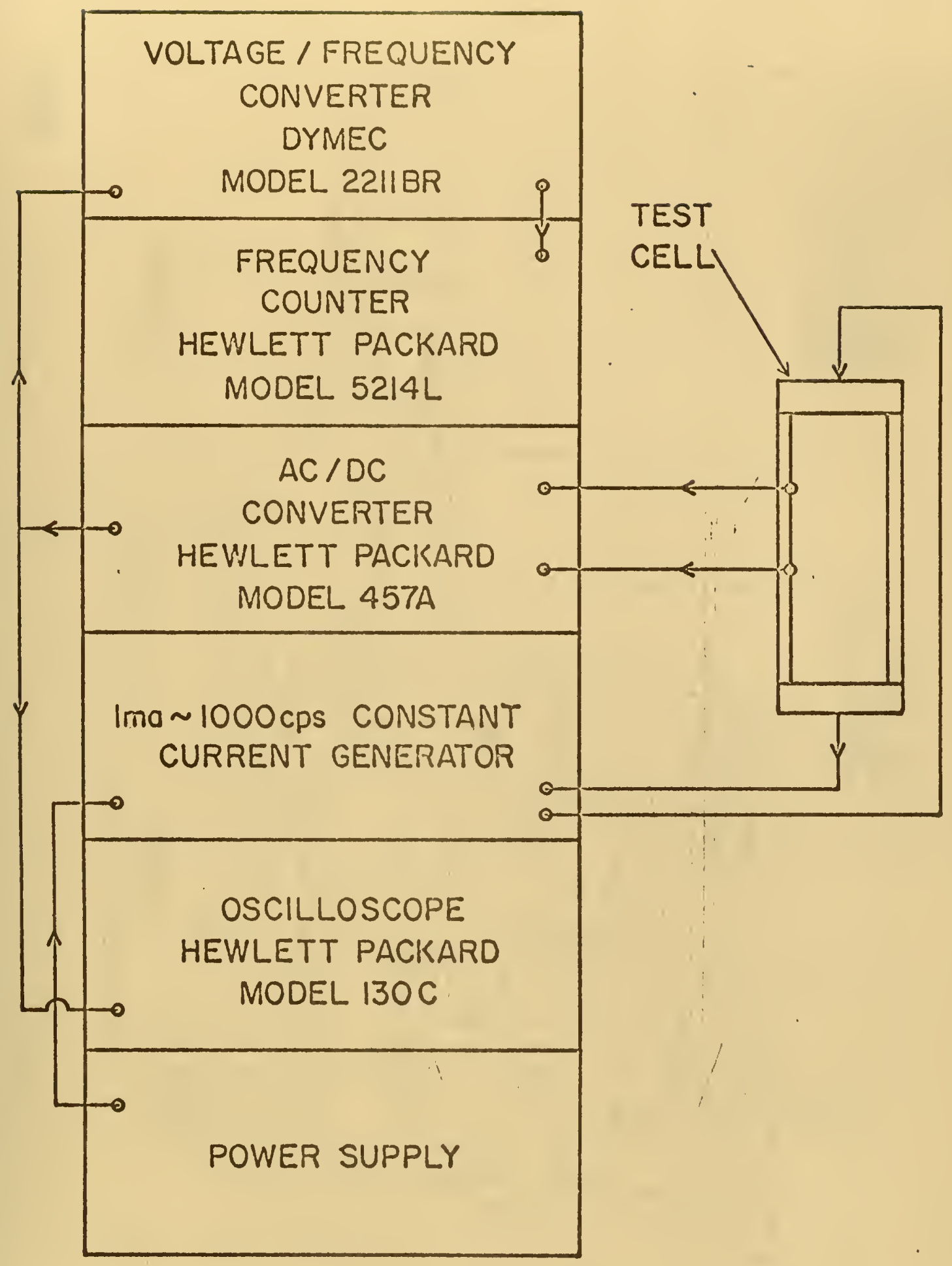

Figure B-5 Electronic Block Diagram of the Simple and Modified Apparatus. 



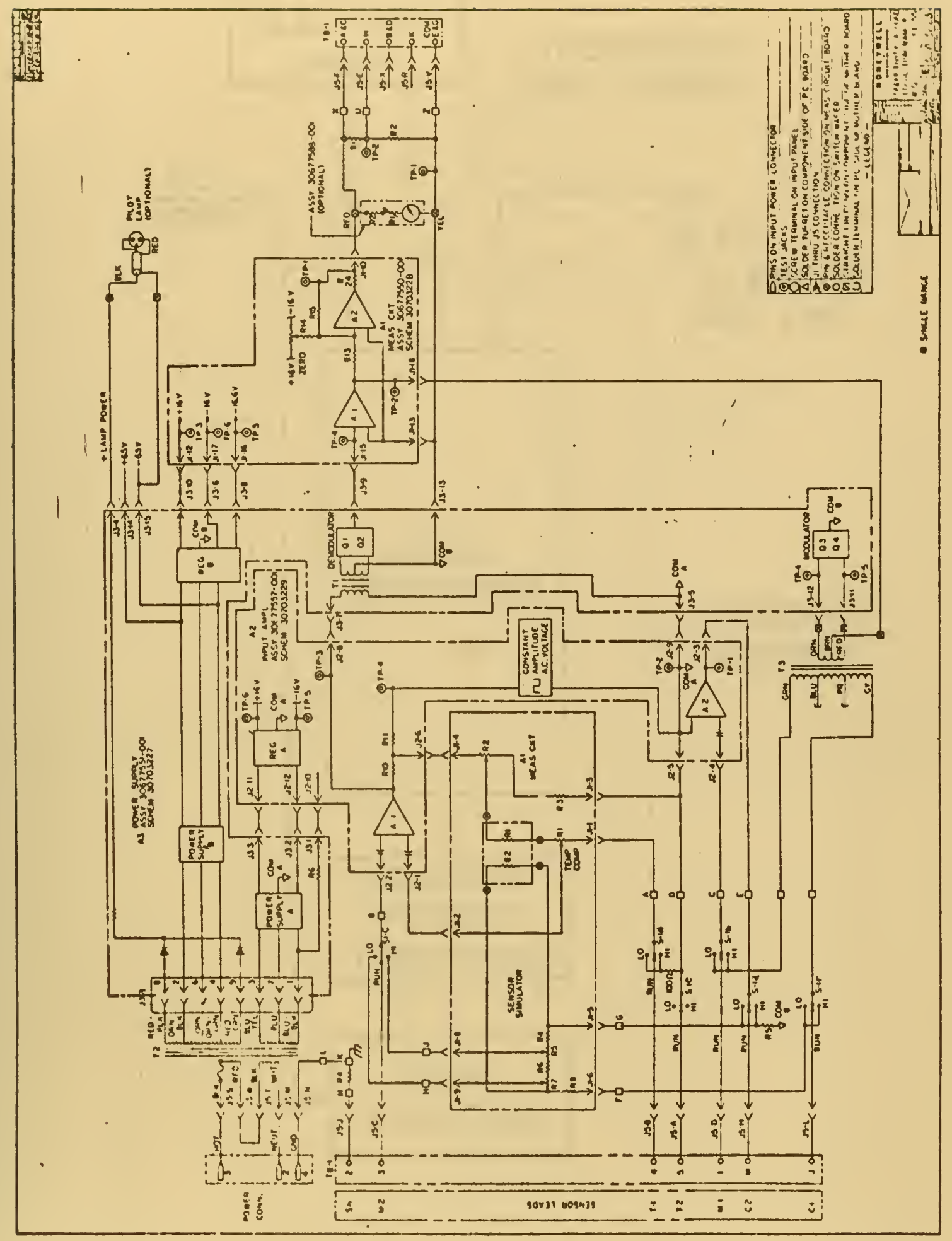

Figure B-6 Electronic Logic and Block Diagram of the Honeywell, Ino. Signal Conditioner Model Number 552022-1002-100-000. 



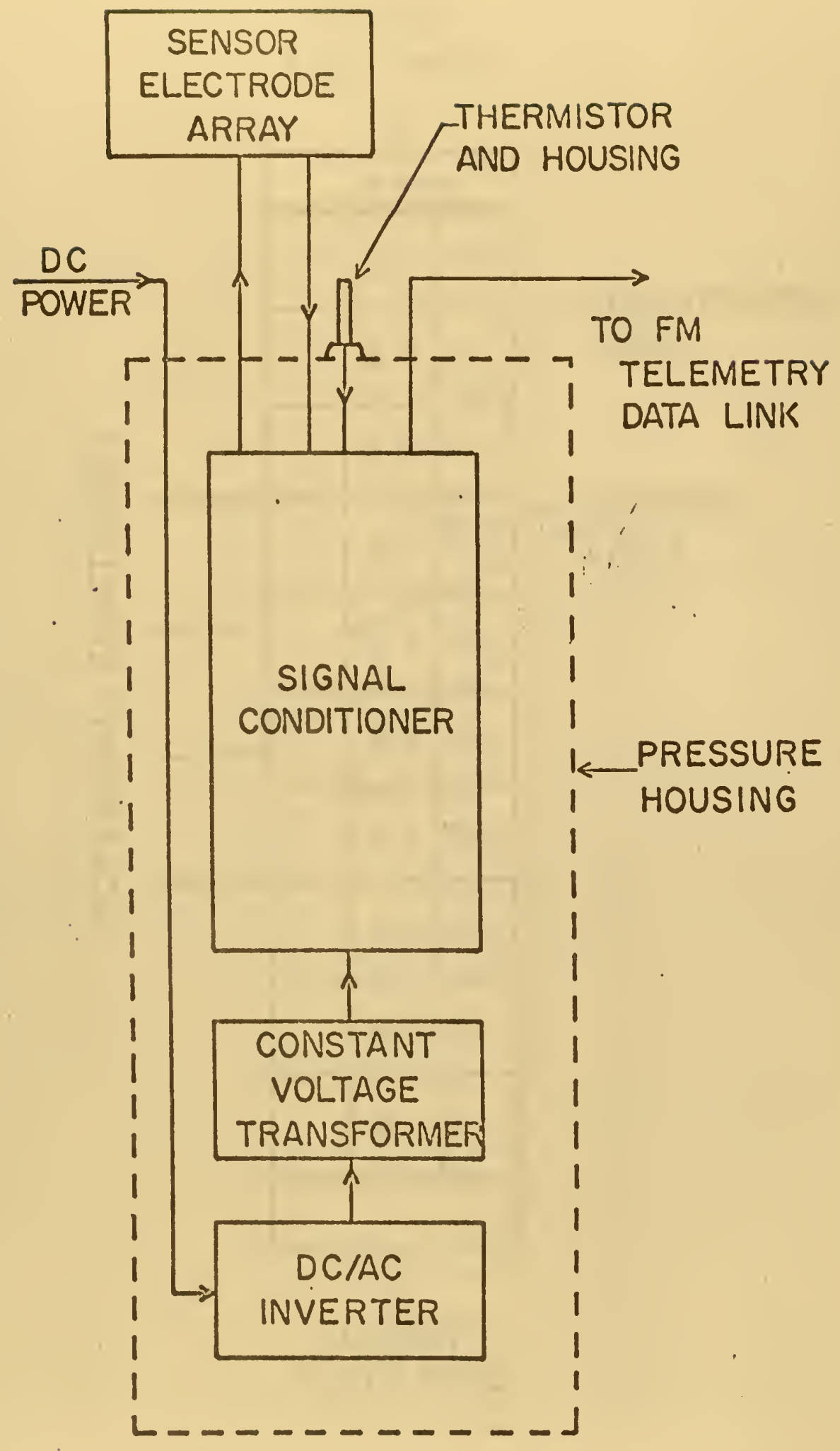

Figure B-7 Electronic Block of In Situ Measuring System. 



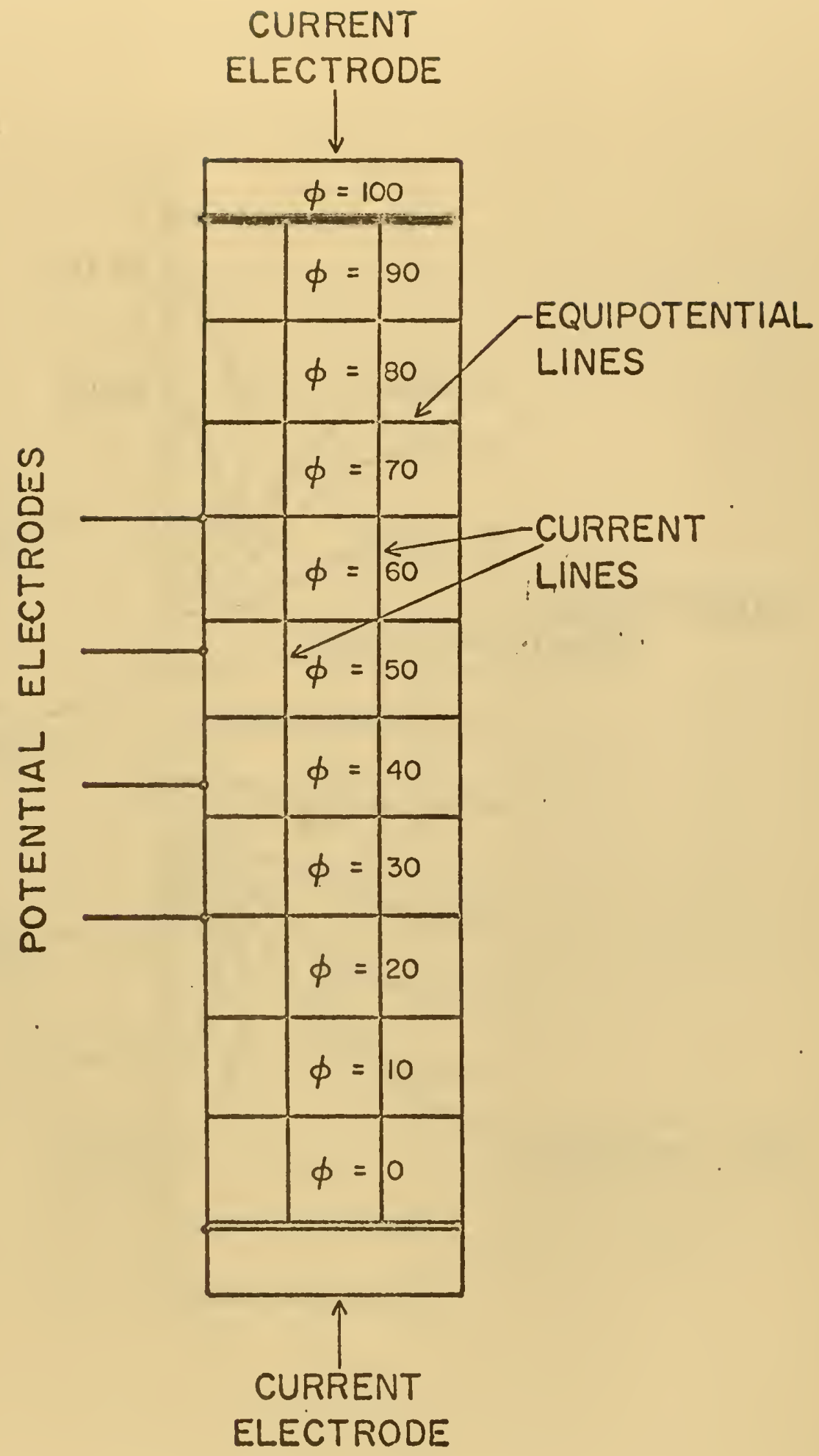

Figure B-8 Vertical Cross Section of the Current Lines and the Equipotentlal Lines for the Simple Cell Using the Top and Bottom Electrodes as Current Electrodes. 



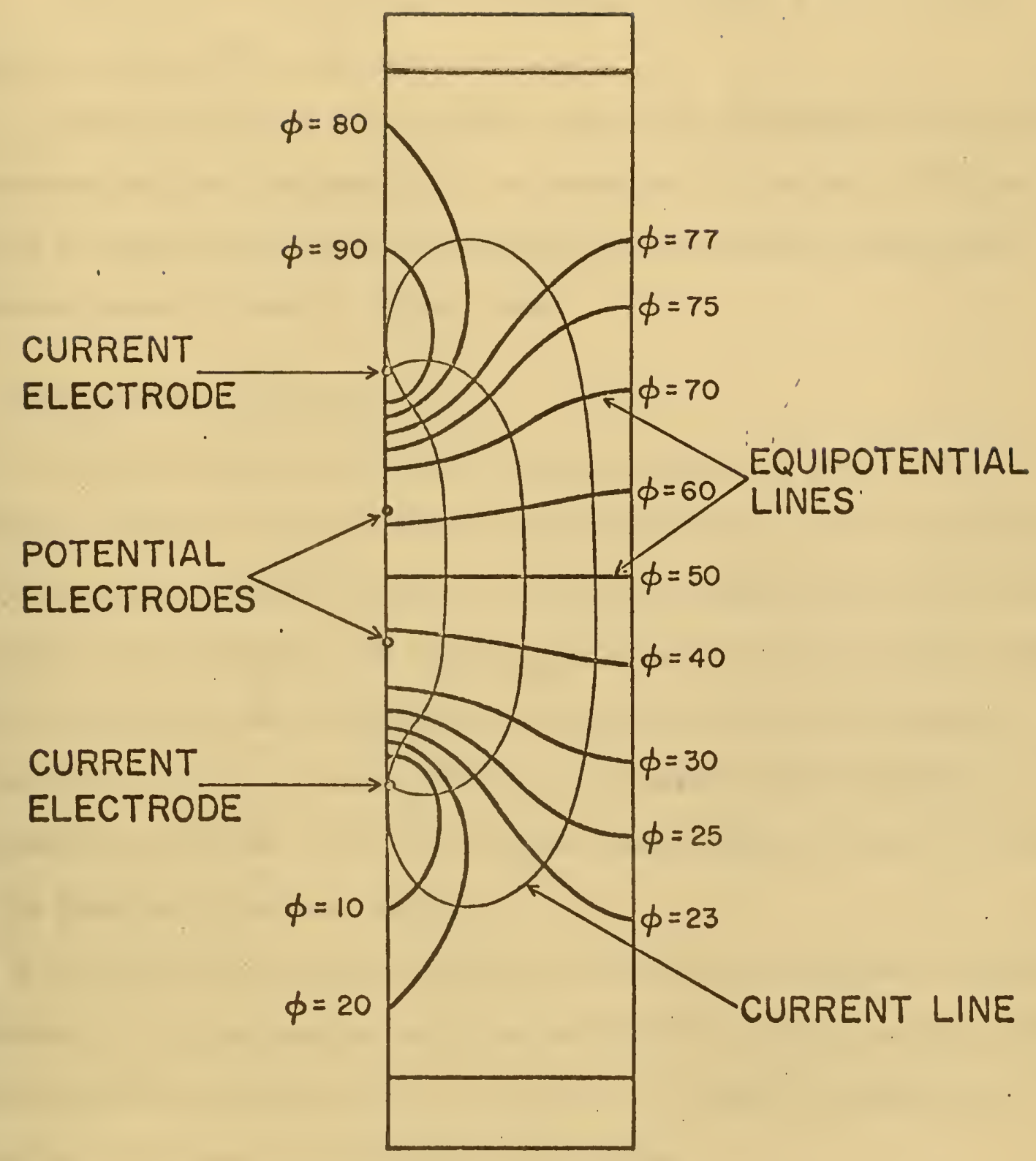

Figure B-9 Vertical Cross Section of the Current Lines and the Equipotential Lines for the Modified Cell Using the Outer Two Platinum Point Electrodes as Current Electrodes. 

B. The flow pattern developed in the modified apparatus was similar to Figure B-9.

C. The cell of the redesigned apparatus developed a flow pattern - imilar to Figure 37 in the text.

D. The flow pattern for the inner corer ring electrode array and the microlateralog pad electrode array are presented in the text in Figures 37 and 38 respectively. The flow pattern for the miniature guard mode electrode array is shown in Figure B-10.

4. Calibration of Equipment.

A. Using equation 46 of the text and measuring the resistivity of standard solutions with the Beckman Conductivity Meter the cell constants for the various electrode configurations of the simple and modified testIng cells were obtained. The various solutions used, with measured resistivity, resistance and cell constants for two elcctrode configurations are given in Table $B-1$. Also given are the geometric cell constants obtained from equation 46 by dividing the cross sectional area of the cell by the potential electrode spacing.

B. Figure B-II is the calibration curve for the redesigned testing apparatus. This calibration curve was obtained by filling the cell with solium chloride solutions of $0.1,0.15,0.2,0.5$ and 0.6 nomality and measuring the signal conditioner output voltage.

C. Figure 47 in the text shows the calibration curve for the inner corer ring electrode array, the microlateralog pad electrode array and the miniature guard mode electrode array. 



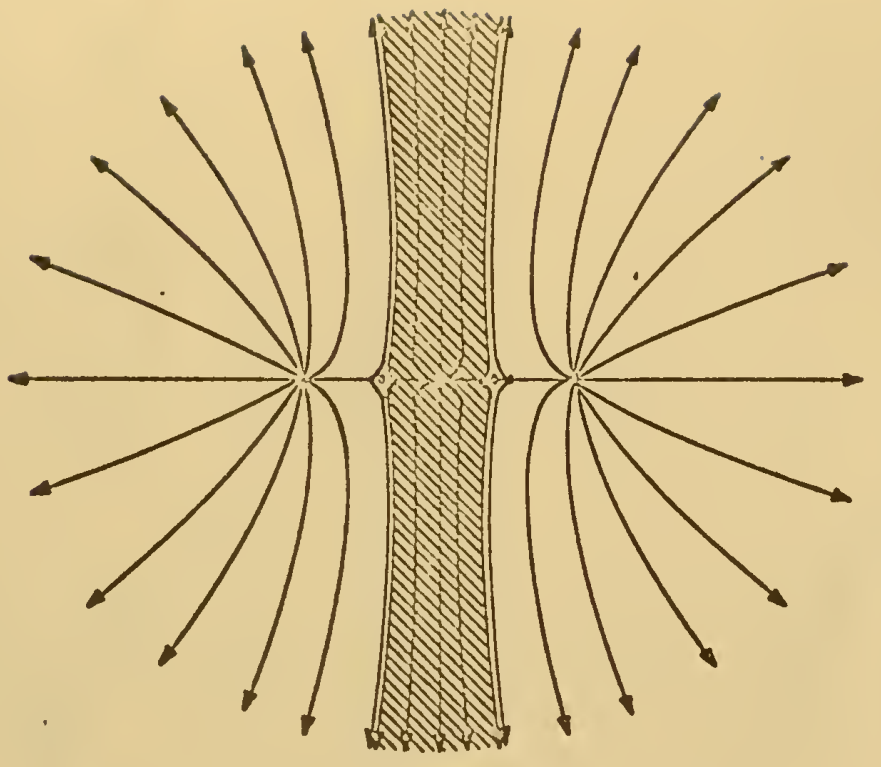

它这

(4)

क्ष

我

उ.

告

पै

ชั

4

苟落

$\rightarrow>$

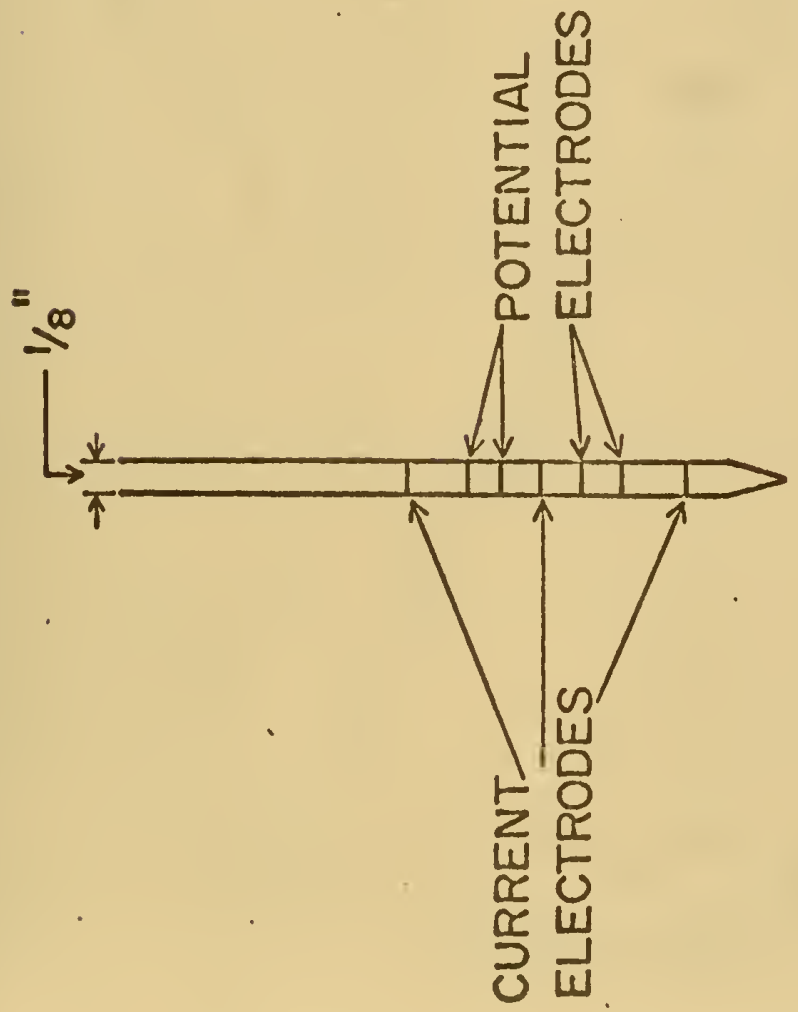

$=$

$\underline{N}$

\&

$8+$

ช 总

ठำ

苛范

0 .

- $)$

马ु 类

$+10$

- 15

装沓

总岀

움

है 



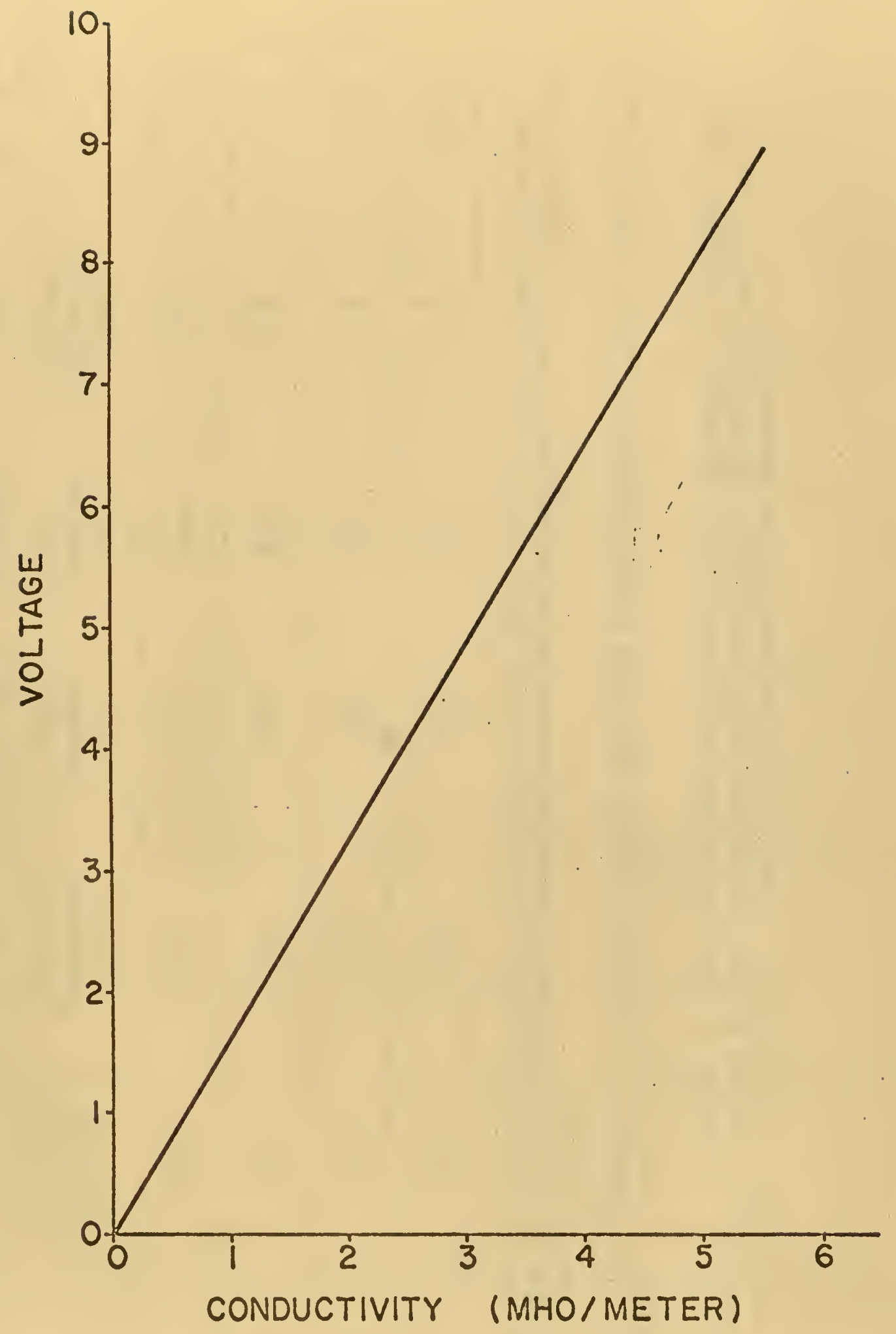

Figure B-l1 Calibration Curve for the Redesigned Apparatus. 



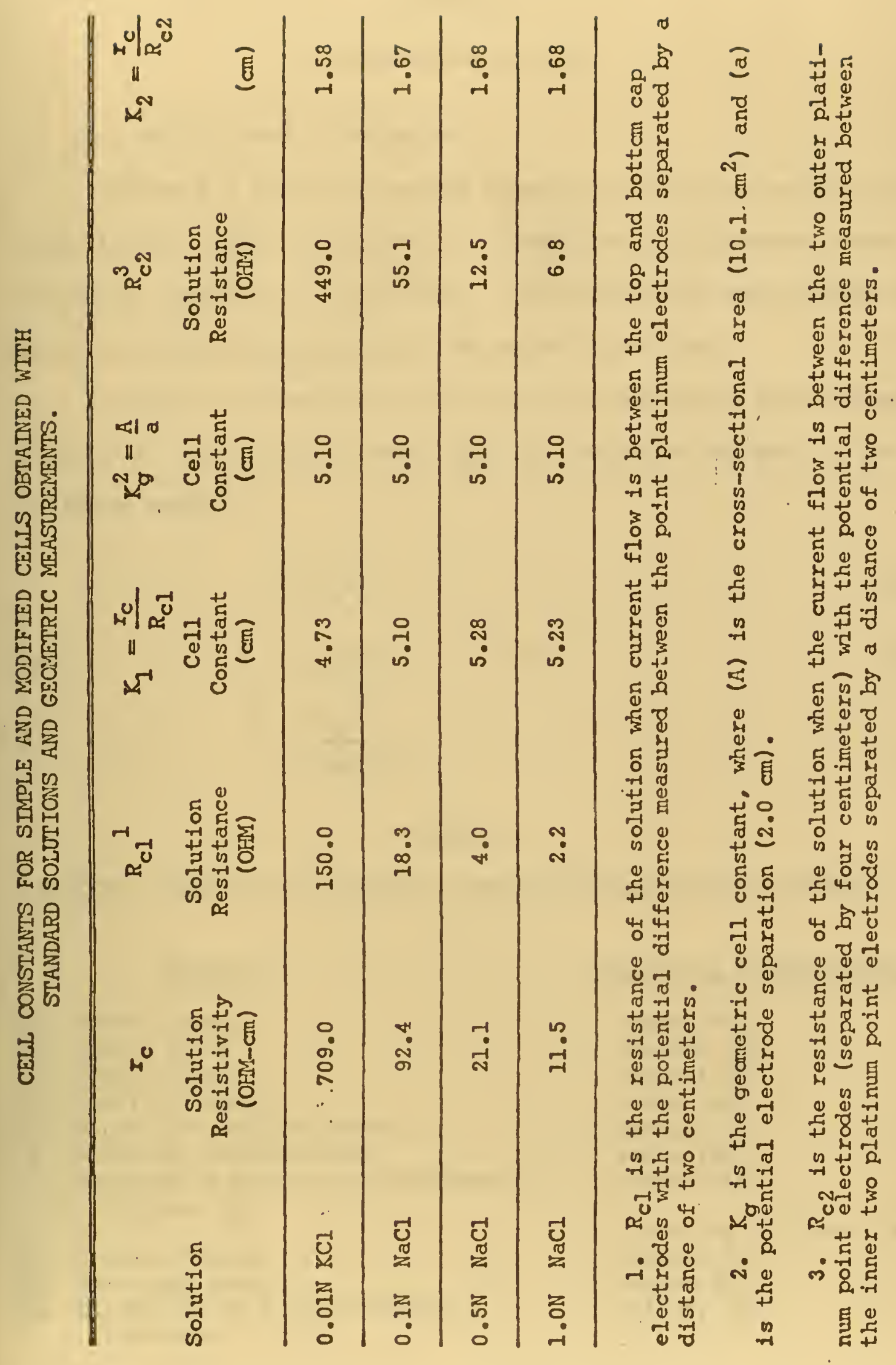





\section{APPENDIX C}

TEST METHODS AND DATA

1. Test Methods Used on Sediments.

Figure C-l lists the general properties of the sediments determined in this investigation and also identifies the references where the procedural method used is outlined. Data obtained by these methods are given in Table 3 and Figures 27, 55 and 56 of the text.

Porosity $(n)$ and void ratio $(e)$ can be determined from the water content (W) and specific gravity $\left(G_{s}\right)$ of a saturated sediment by the following method:

$$
e=G_{s} w \text {. }
$$

and,

$$
n=\frac{e}{e+1}
$$

or.

$$
n=\frac{\mathbf{G}_{s} w}{G_{s} w+1} \text {. }
$$

TABLE C-1

SEDIMENT PROPERTY AND PROCEDURAL METHOD REFERENCE USED IN TESTING.

\section{Property}

1. Water Content

2. Liquid Limit

3. Plastic Limit

4. Specific Gravity

5. Grain Size and Hydrometer

6. Sediment Classification

7. Descriptive Grain Size Measurements

8. $\mathrm{pH}$ $\left(\phi_{50}\right.$ and $\left.6 p\right)$

9. Organic Content

10. Undrained Shear

11. Mineralogy by X-ray Diffraction Technique

\section{Procedural Method Reference}

Lambe (46)

Olmsted (47)

Lambe (46)

Lambe (46)

Lambe (46)

Lambe (46)

Shepard (48)

Greweling and Peech (49)

Ackroyd (50)

Hansbo (51)

Cullity (52) 

2. Experimental liethods and Data Obtained.

A. Simple Cell Apparatus.

The porosity was determined in the simple cell by measuring the length of the sediment sample in the test cell $\left(\mathrm{L}_{8}\right)$, the diameter of the cell $\left(D_{s}\right)$, the weight of soil in the test cell $\left(W_{s}\right)$ and the specific gravity of the soil $\left(G_{s}\right)$. Then the total volume of the sample $\left(V_{T}\right)$ is,

$$
V_{T}=\frac{\pi}{4} D_{s}^{2} L_{s}=V_{s}+V_{v}
$$

where:

$$
\begin{aligned}
& v_{8} \text { is the volume of the soil, } \\
& v_{V} \text { is the voluse of the voids, }
\end{aligned}
$$

and, $\quad v_{s}=\frac{W_{s}}{G_{s}}$.

Then,

$$
v_{v}=v_{T}-v_{s}
$$

and the porosity $(n)$ is,

$$
n=\frac{V_{V}}{V_{T}} .
$$

The procedure described in the text was used to measure the resistivity of the sediment and interstitial water. Formation Factors were determined by using equation 3 in the text. Table C-2 lists Formation Factor - porosity values obtained for various sediments with the simplo cell apparatus.

B. Modified Apparatus.

The porosity was determined in the modified cell by measuring the 

FORMATION FACTOR - POROSITY DATA OBTAINED WITH THE SIMPLE CELL FOR: OTTAWA SAND, GLACIAL SAND (1-a), GLACIAL SAND (1-b)

GLACIAL SAID (2), NARRAGANSETT BAY SAND, PROVIDENCE SILT, KAOLINITE CLAY, AND ILLITE CLAY.

OTTAWA SAIND

$\begin{array}{cc}\text { Porosity (\%) } & \begin{array}{c}\text { Formation } \\ \text { Factor }\end{array} \\ 40.5 & 3.54 \\ 40.0 & 3.69\end{array}$

40.4

40.9

34.9

34.0

35.4

35.4

41.1

41.6

42.4

42.1

34.6

34.2

35.3

36.8

40.5

35.7

32.3

29.9

27.3

35.7

31.2

28.7

26.0

41.2

35.9

33.8

33.3

32.8

40.7

34.0

41.1

35.0

41.3

35.8

41.9
6.00

3.74

4.26

4.44

4.44

4.36

3.49

3.50

3.48

3.42 .

4.24

4.24

4.31

4. 20

3.73

4.56

4.82

5.03

5.09

4.43

4.69

4.88

5.06

3.43

4.18

4.50

4.54

4.61

3.50

4.26

3.48

4.27

3.56

4.25

3.52
GLACIAL SAND (1-a)

\begin{tabular}{cc} 
Porosity $(\%)$ & $\begin{array}{r}\text { Formation } \\
\text { Factor }\end{array}$ \\
\hline 46.0 & 3.19 \\
46.7 & 3.14 \\
46.5 & 3.23 \\
47.6 & 3.10 \\
39.5 & 3.87 \\
39.9 & 3.83 \\
40.4 & 3.97 \\
43.9 & 3.47 \\
39.6 & 4.04 \\
35.7 & 4.46 \\
31.2 & 4.71 \\
29.9 & 4.80 \\
39.6 & 4.00 \\
36.7 & 4.29 \\
33.5 & 4.46 \\
31.2 & 4.63 \\
40.5 & 3.88
\end{tabular}

GLACIAL SAND (1-b)

Porosity (\%) $\begin{gathered}\text { Formation } \\ \text { Factor }\end{gathered}$

46.8

3.14

47.0

3.08

46.9

3.17

46.9

3.11

44.0

3.21

44.6

3.21

44.6

3.35

43.9

3.18

43.9

3.43

41.4

3.57

39.6

3.80

35.7

4.25

32.3

4.63

31.2

4.80 

TABLE C-2 (CONT.)

\begin{tabular}{cc}
\multicolumn{2}{c}{ OTTAWA SAND } \\
Porosity (\%) & $\begin{array}{c}\text { Formation } \\
\text { Factor }\end{array}$ \\
\hline 35.9 & 4.13 \\
42.7 & 3.55 \\
35.9 & 4.32 \\
39.4 & 3.76 \\
37.6 & 4.05 \\
35.6 & 4.32 \\
34.4 & 4.38 \\
33.8 & 4.44 \\
41.1 & 3.19 \\
33.3 & 4.54
\end{tabular}

GLACIAL SAND (2)

Porosity $(\%) \quad \begin{gathered}\text { Formation } \\ \text { Factor }\end{gathered}$

45.6

41.4

38.8

37.6

36.5

34.4

31.0

45.2

40.7

38.2

36.7

35.5

34.3

43.9

42.4

36.4

35.2

33.0

45.1

41.3

38.2

36.6

35.0

34.4

45.5

40.2

38.1

36.6

35.0

33.4
3.27

3.50

3.72

3.98

4.20

4.58

4.67

3.47

3.65

4.08

4.29

4.55

4.91

3.62

3.79

4.25

4.50

4.86

3.62

3.84

4.18

4.35

4.48

4.75

3.56

3.93

4.2 .3

4.51

4.74

5.05
GLACIAL SAND (I-b)

\begin{tabular}{cc} 
Porosity $(\%)$ & $\begin{array}{c}\text { Formation } \\
\text { Factor }\end{array}$ \\
\hline 38.7 & 3.83 \\
36.7 & 4.16 \\
34.6 & 4.53 \\
31.2 & 4.77
\end{tabular}

\begin{tabular}{cc}
\multicolumn{2}{c}{\begin{tabular}{c}
\multicolumn{2}{c}{ NARRAGANSETT BAY } \\
STATION
\end{tabular}} \\
\hline Porosity (\%) & $\begin{array}{c}\text { Formation } \\
\text { Factor }\end{array}$ \\
\hline 40.5 & 4.21 \\
35.7 & 4.97 \\
33.5 & 5.50 \\
32.3 & 5.66 \\
31.2 & 5.77 \\
35.7 & 4.94 \\
34.6 & 5.26 \\
33.5 & 5.47 \\
31.2 & 5.73 \\
39.1 & 4.53 \\
38.5 & 4.55 \\
37.0 & 4.73 \\
34.8 & 5.02
\end{tabular}

PROVIDENCE SILT

Porosity (\%) $\begin{gathered}\text { Formation } \\ \text { Factor }\end{gathered}$

60.5

2.58

59.9

2.86

57.7

3.08

57.5

2.89

\section{KAOLINITE CLAY}

Porosity (\%) $\begin{gathered}\text { Formation } \\ \text { Factor }\end{gathered}$

91.0

1.20

89.7

1.24

88.0

1.25

87.7

1.28

84.0

78.7

1.40

1.53 

TABLE C 2 (CONT.)

- GLACIAL SAND (2)

Porosity $(\%) \quad \begin{gathered}\text { Formation } \\ \text { Factor }\end{gathered}$

42.3

37.7

33.5

28.7

27.3

34.6

32.3

29.9

27.3

37.9
3.74

4.32

5.00

5.54

5.69

4.85

5.19

5.62

5.77

4.02
ILLITE CLAY

Porosity $(\%) \quad \begin{gathered}\text { Formation } \\ \text { Factor }\end{gathered}$

81.0

80.0

78.7

1.60

1.63

1.76 

height of the sediment column at the end of the test $\left(h_{f}\right)$ and the weight of the soil $\left(W_{s}\right)$. Then knowing the cross-sectional area of the sample $(A)$ and the specific gravity of the soil $\left(G_{S}\right)$ the total volume $\left(V_{T}\right)$ can be written as:

$$
V_{T}=h_{f}^{A}
$$

and,

$$
v_{v}=v_{T}-v_{s}
$$

or.

$$
V_{v}=V_{T}-\frac{W_{s}}{G_{B}} .
$$

and dividing by $\mathrm{V}_{\mathrm{T}}$,

$$
n_{f}=\frac{V_{v}}{V_{T}}=1-\frac{W_{s}}{G_{s} A h_{f}} .
$$

or,

$$
n_{f}=1-\frac{C}{h_{f}}
$$

where,

$$
c=\frac{W_{s}}{G_{s}^{A}}
$$

and $n_{f}$ is the porosity of the sediment colurn of height $h_{f}$. The porosity at other consolidation pressure helght increments can be obtained by using equation $\mathrm{Cll}$ and the corresponding height recorded at each pressure 

increment. Then the water content $(w)$ and void ratio (e) can be obtained by the following equations:

$$
=\frac{n}{1-n} \text {. }
$$

and,

$$
W=\frac{e}{G_{s}} \text {. }
$$

Electrical resistivity measurements of the sediment were made at each pressure increment and Formation Factors'were detemined by assuming the resistivity of the interstitial water was that of the chamber water. Table C -3 contains the incremental height of the sediment column and the corresponding consolidation pressure, Fomation Factor, porosity, void ratio, water content, and C-constants (equation $\mathrm{Cl} 2$ ) for illite and koolinite clays obtained with the modified testing apparatus.

C. Redesigned Apparatus.

Porosity was determined at the beginning and at the end of a test by measuring the water content and specific gravity of the soil and using equation C3. These porosity values were then compared to Formation Factor values determined by the method described in the text. Figure 29 in the test is an example of the recorded data obtained with the redesigned equipment. If the total test time $\left(t_{T}\right)$ is known, along with the time prior to rapid decrease in Formation Factor values $\left(t_{l}\right)$ and the time Formation Factor values again became relatively constant $\left(t_{2}\right)$, and if the corresponding Formation Factors at these two times $\left(t_{1}\right.$ and $\left.t_{2}\right)$ is also known, then the recorded curves, such as Figure 29, can be produced. 



\section{TAELE C-3}

INCREYEITAL SEDIIENT SAMPLE HEIGHT WITH CORRESPONDING COISOLIDATION PRESSURE, FORILATION FACTOR, POROSITY, VOID RATIO, WATER CONTENT, AND C-CONSTANT FOR KAOLINIT'E AND ILLITE CLAY OBTAINED WITH THE MODIFIED TESTING APPARATUS.

(Kaolinite Clay)

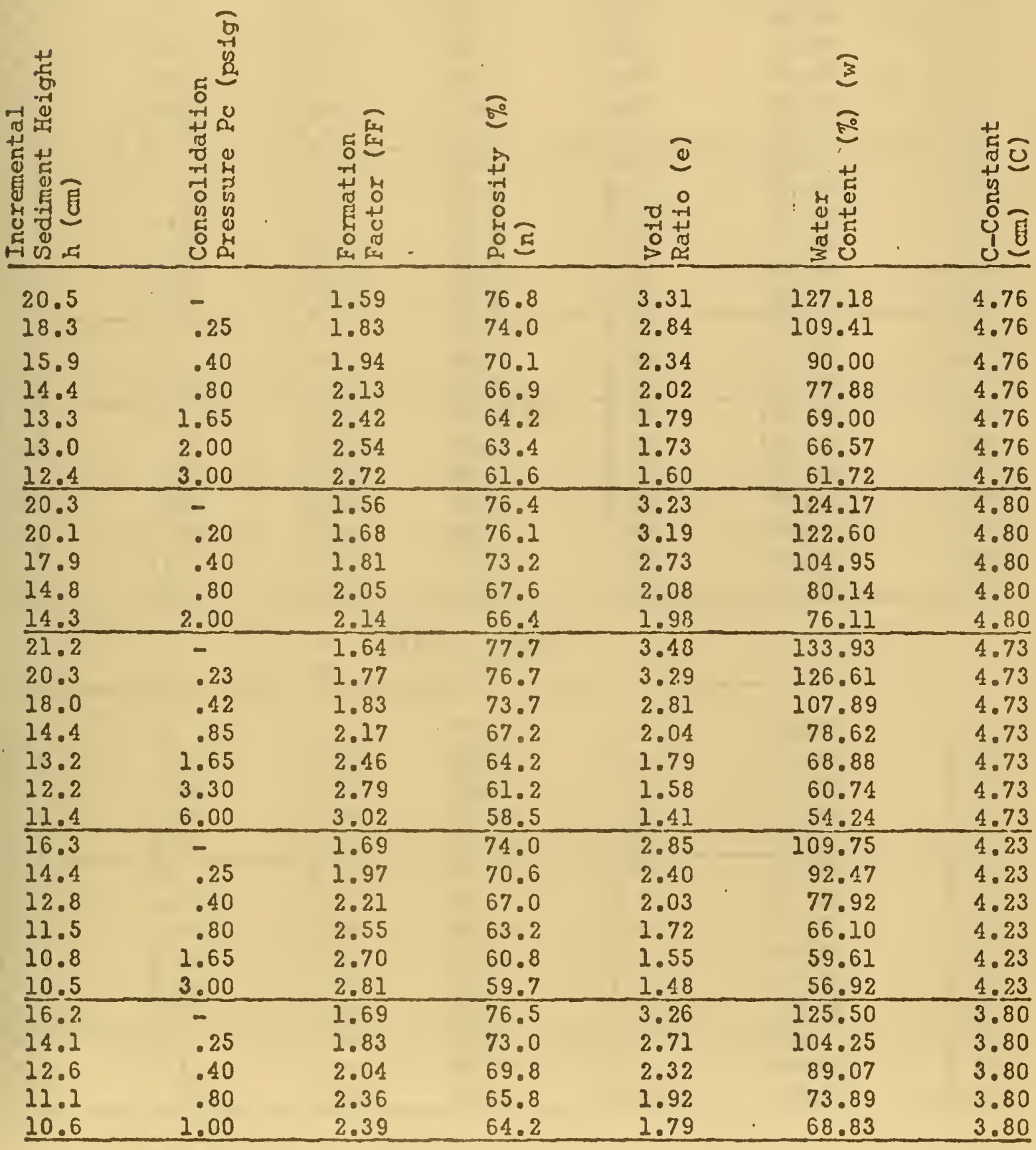



TABLE C-3 (CONT.)

(Kaolinite Clay)

\begin{tabular}{lcccrrr} 
h & PC & FF & n & e & w & c \\
\hline 16.1 & - & & & & & \\
14.4 & .25 & 1.63 & 74.6 & 2.94 & 112.94 & 4.09 \\
12.5 & .40 & 2.14 & 71.6 & 2.52 & 96.95 & 4.09 \\
11.3 & .80 & 2.46 & 63.3 & 2.06 & 79.09 & 4.09 \\
10.5 & 1.70 & 2.68 & 61.1 & 1.76 & 67.80 & 4.09 \\
16.8 & - & 1.67 & 74.8 & 2.57 & 60.28 & 4.09 \\
14.7 & .25 & 1.92 & 71.2 & 2.47 & 113.93 & 4.24 \\
13.2 & .40 & 2.22 & 67.9 & 2.11 & 94.88 & 4.24 \\
12.0 & .80 & 2.55 & 64.7 & 1.83 & 70.39 & 4.24 \\
11.0 & 1.65 & 2.84 & 61.5 & 1.59 & 61.32 & 4.24 \\
10.5 & 3.30 & 2.89 & 59.6 & 1.48 & 56.79 & 4.24 \\
15.9 & - & 1.70 & 73.4 & 2.76 & 106.11 & 4.23 \\
14.5 & .25 & 1.83 & 70.8 & 2.43 & 93.38 & 4.23 \\
13.2 & .40 & 2.10 & 68.0 & 2.12 & 81.68 & 4.23 \\
11.9 & .80 & 2.32 & 64.5 & 1.81 & 69.74 & 4.23 \\
11.0 & 1.65 & 2.59 & 61.5 & 1.60 & 61.56 & 4.23 \\
10.7 & 2.00 & 2.65 & 60.5 & 1.53 & 58.83 & 4.23 \\
16.2 & - & 1.65 & 74.9 & 2.98 & 114.62 & 4.07 \\
11.8 & .80 & 2.41 & 65.5 & 1.90 & 73.05 & 4.07 \\
10.6 & 1.65 & 2.79 & 61.6 & 1.60 & 61.71 & 4.07 \\
\hline 20.6 & - & 1.80 & 75.9 & 3.15 & 121.28 & 4.96 \\
20.3 & .25 & 1.80 & 75.6 & 3.09 & 118.95 & 4.96 \\
15.8 & .40 & 2.03 & 68.6 & 2.19 & 84.06 & 4.96 \\
14.4 & .80 & 2.29 & 65.6 & 1.90 & 73.20 & 4.96 \\
13.3 & 1.65 & 2.56 & 62.7 & 1.68 & 64.67 & 4.96 \\
12.5 & 3.30 & 2.78 & 60.3 & 1.52 & 58.47 & 4.96 \\
11.6 & 6.60 & 3.10 & 57.2 & 1.34 & 51.49 & 4.96 \\
\hline
\end{tabular}

(Illite Clay)

\begin{tabular}{lcccccc}
$\mathrm{h}$ & $\mathrm{PC}$ & $\mathrm{FF}$ & $\mathrm{n}$ & $\mathrm{e}$ & $\mathrm{w}$ & $\mathrm{c}$ \\
\hline 19.7 & - & 2.05 & 70.2 & 2.36 & 84.59 & 5.91 \\
18.8 & .40 & 2.16 & 68.6 & 2.18 & 78.30 & 5.91 \\
17.7 & .80 & 2.28 & 66.6 & 1.99 & 71.47 & 5.91 \\
16.9 & 1.65 & 2.38 & 65.0 & 1.86 & 66.56 & 5.91 \\
16.6 & 2.00 & 2.50 & 64.0 & 1.78 & 63.72 & 5.91 \\
\hline 20.1 & - & 2.12 & 70.2 & 2.42 & 86.60 & 5.98 \\
19.5 & .40 & 2.14 & 69.4 & 2.27 & 81.29 & 5.98 \\
18.3 & .85 & 2.20 & 67.3 & 2.06 & 73.77 & 5.98 \\
17.3 & 1.70 & 2.28 & 65.4 & 1.89 & 67.75 & 5.98 \\
16.2 & 3.30 & 2.78 & 63.1 & 1.71 & 61.29 & 5.98 \\
15.9 & 4.00 & 2.90 & 62.4 & 1.66 & 59.48 & 5.98 \\
\hline 19.3 & - & 2.08 & 70.8 & 2.42 & 86.91 & 5.64 \\
18.6 & .40 & 2.20 & 69.7 & 2.30 & 82.15 & 5.64 \\
17.1 & .70 & 2.39 & 67.0 & 2.03 & 72.77 & 5.64 \\
\hline
\end{tabular}



TABLE C 3 (CONT.)

(Illite Clay)

\begin{tabular}{lrrrrrr}
$h$ & PC & FF & n & e & w & C \\
\hline 19.6 & - & 1.94 & 70.5 & 2.39 & 85.66 & 5.78 \\
18.8 & .20 & 1.97 & 69.3 & 2.26 & 80.91 & 5.78 \\
18.2 & .45 & 2.20 & 68.2 & 2.14 & 76.87 & 5.78 \\
17.4 & .85 & 2.28 & 66.8 & 2.01 & 72.11 & 5.78 \\
16.6 & 1.65 & 2.40 & 65.2 & 1.87 & 67.15 & 5.78 \\
15.6 & 3.30 & 2.63 & 62.9 & 1.70 & 60.77 & 5.78 \\
14.7 & 6.00 & 2.93 & 60.7 & 1.54 & 55.36 & 5.78 \\
18.5 & .20 & 2.09 & 69.2 & 2.25 & 80.69 & 5.69 \\
16.3 & .85 & 2.16 & 65.1 & 1.86 & 66.83 & 5.69 \\
15.4 & 1.65 & 2.28 & 63.1 & 1.71 & 61.16 & 5.69 \\
14.6 & 3.30 & 2.44 & 61.0 & 1.57 & 56.13 & 5.69 \\
14.2 & 5.00 & 2.60 & 59.9 & 1.50 & 53.61 & 5.69 \\
\hline 18.2 & .20 & 2.14 & 68.4 & 2.16 & 77.41 & 5.76 \\
17.7 & .40 & 2.16 & 67.4 & 2.07 & 74.30 & 5.76 \\
16.9 & .85 & 2.21 & 65.9 & 1.93 & 69.32 & 5.76 \\
16.1 & 1.65 & 2.33 & 64.2 & 1.80 & 64.34 & 5.76 \\
15.2 & 3.30 & 2.56 & 62.1 & 1.64 & 58.74 & 5.76 \\
14.1 & 6.00 & 2.80 & 60.0 & 1.50 & 53.76 & 5.76 \\
\hline 19.5 & .20 & 1.95 & 69.6 & 2.29 & 82.22 & 5.92 \\
19.2 & .40 & 1.98 & 69.2 & 2.24 & 80.40 & 5.92 \\
17.0 & .85 & 2.05 & 65.2 & 1.87 & 67.08 & 5.92 \\
16.1 & 1.65 & 2.20 & 63.9 & 1.77 & 63.45 & 5.92 \\
16.2 & 2.00 & 2.27 & 63.5 & 1.74 & 62.24 & 5.92 \\
17.7 & .20 & 2.08 & 67.9 & 2.11 & 75.65 & 5.69 \\
17.3 & .10 & 2.16 & 67.1 & 2.04 & 73.13 & 5.69 \\
16.5 & .85 & 2.21 & 65.5 & 1.90 & 68.10 & 5.69 \\
15.6 & 1.65 & 2.36 & 63.5 & 1.74 & 62.42 & 5.69 \\
14.7 & 4.00 & 2.64 & 61.3 & 1.58 & 56.76 & 5.69 \\
\hline 20.8 & .25 & 2.00 & 68.7 & 2.15 & 77.06 & 6.61 \\
20.7 & .40 & 2.13 & 68.1 & 2.13 & 76.34 & 6.61 \\
20.6 & .85 & 2.14 & 67.9 & 2.12 & 75.85 & 6.61 \\
18.3 & 1.65 & 2.21 & 63.9 & 1.77 & 63.39 & 6.61 \\
17.2 & 3.30 & 2.39 & 61.6 & 1.60 & 57.42 & 6.61 \\
16.3 & 6.00 & 2.63 & 59.5 & 1.47 & 52.55 & 6.61 \\
\hline 20.8 & .20 & 2.09 & 68.4 & 2.17 & 77.62 & 6.57 \\
20.2 & .40 & 2.19 & 67.5 & 2.08 & 74.37 & 6.57 \\
19.9 & .80 & 2.19 & 67.0 & 2.03 & 72.71 & 6.57 \\
19.6 & 1.00 & 2.40 & 66.5 & 1.98 & 71.09 & 6.57 \\
\hline 20.5 & .20 & 1.98 & 68.2 & 2.15 & 77.01 & 6.51 \\
18.6 & .40 & 2.09 & 65.0 & 1.86 & 66.56 & 6.51 \\
18.4 & 1.00 & 2.22 & 64.6 & 1.83 & 65.47 & 6.51 \\
18.0 & 2.00 & 2.26 & 63.8 & 1.76 & 63.25 & 6.51 \\
\hline 1 & & & & & &
\end{tabular}



Table C-4 contains the data obtained with the redesigned equirment, the total test time, $\left(t_{T}\right)$, times $t_{2}$ and $t_{2}$, along with the corresponding Formation Factors, porosity, void ratios and water contents for these times. Also In this figure is the length of the sediment column at the beglining and at the end of a test, the water collected in the reservoir and the consolidation pressure used in each test.

D. Statistical Technique and Methods.

Statistical analysis of data was accomplished with a statistical package of computer programs called * STATPACK (53). The computer programs are available at remotely located teminals and prior knowledge of computer or progranming is not necessary. The analyses of STATPACK used in this study were:

Transformation to obtain logarithmic functions of Formation Factor and porosity data.

Regression to obtain a functional relationship among Formation Factor (FF) and porosity ( $n$ ). The relationship considered here is of the form:

$$
\log F F=\log a-m \log n,
$$

where $F F$ is called the dependent varioble and $n$ the independent variable. The slope of the line is $(m)$ and the intercept value is $(a)$. Line of best fit and the coefficients $m$ and $a$ were determined by the method of least squares. Other statistics such as, correlation coefficlent, suro of squares, attributed to the 



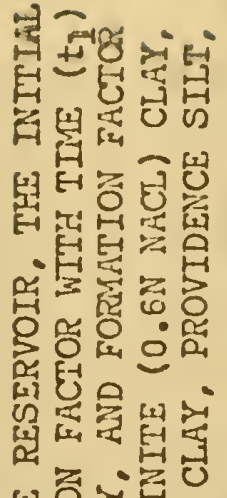

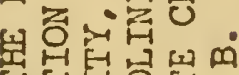

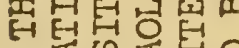

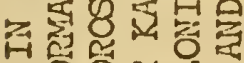

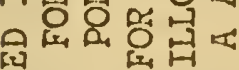

四

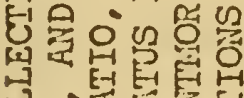

话嵒

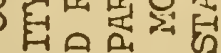

J

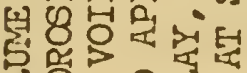

空

䟚密留

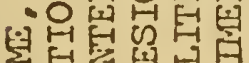

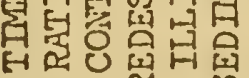

40

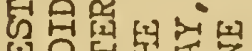

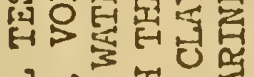

분단

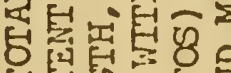

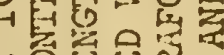

ज耐鼠

倩觜客

出崖垔

魚雷

a 0 .

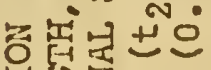

更

t5

可率的昌昆

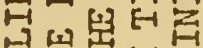

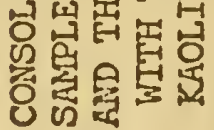

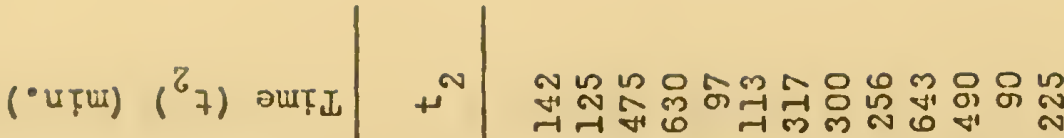

("uт̧ur) ( ${ }^{\top} 7$ ) อurț

(

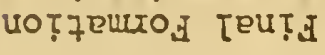

(\%) $\left.r^{2} u\right)$

07 T!SOIOd TEUT:

$\left(z_{\theta}\right)$

orfeg pron teutid

(\%) $\left({ }^{2} M\right)$

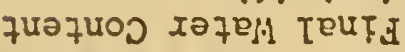

(०) ( ${ }^{2} \mathrm{~T}$ )

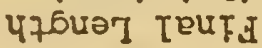

Th 10700 过

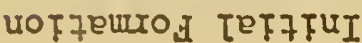

(\%) $\tau_{\mathrm{u}}$

S7TSOJOd TET7TUI

$\left(\tau_{\theta}\right)$

Oт7еg ptos Tет7тUI

$(\%)\left(T_{M}\right)$

7иәquор хә7еM [ет7тUI

( ( • (

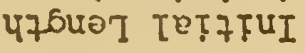

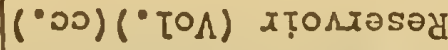

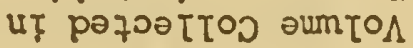

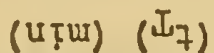

ourT. 750 工 [อ70I

(Eisd)

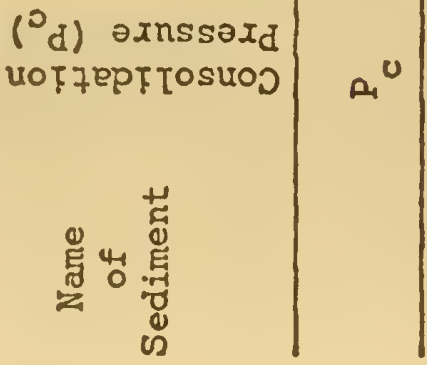

$\dot{\circ}$

आ a $N$ N 0 W जक नमम

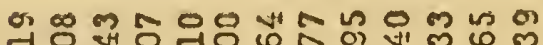

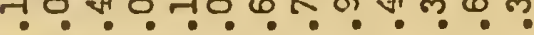
m

HUNm

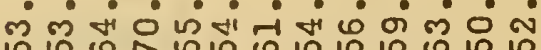

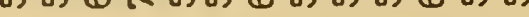

आ

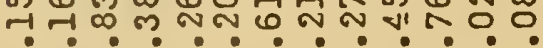
मान

4 H H

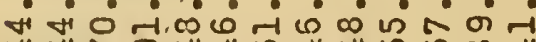
A म n 00 , 0 m

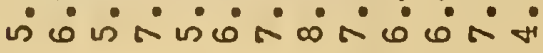
แ $\infty 0$ थ

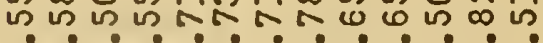

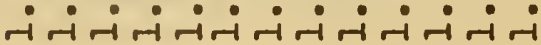
HN

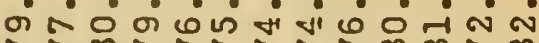
TIN

N H m मांगत

DNNO MA 0 N 0 U 0 . ए 4 $m$ in 0 क

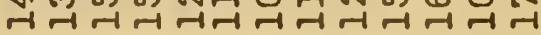

00 H Mn

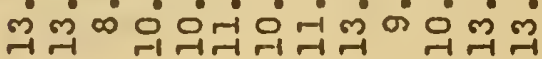

ต ก ก

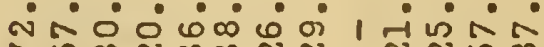
ำ

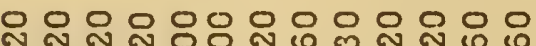
소승 888 น $88888 \%$

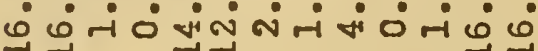

i)

tu

तु

न्न

io

बै 



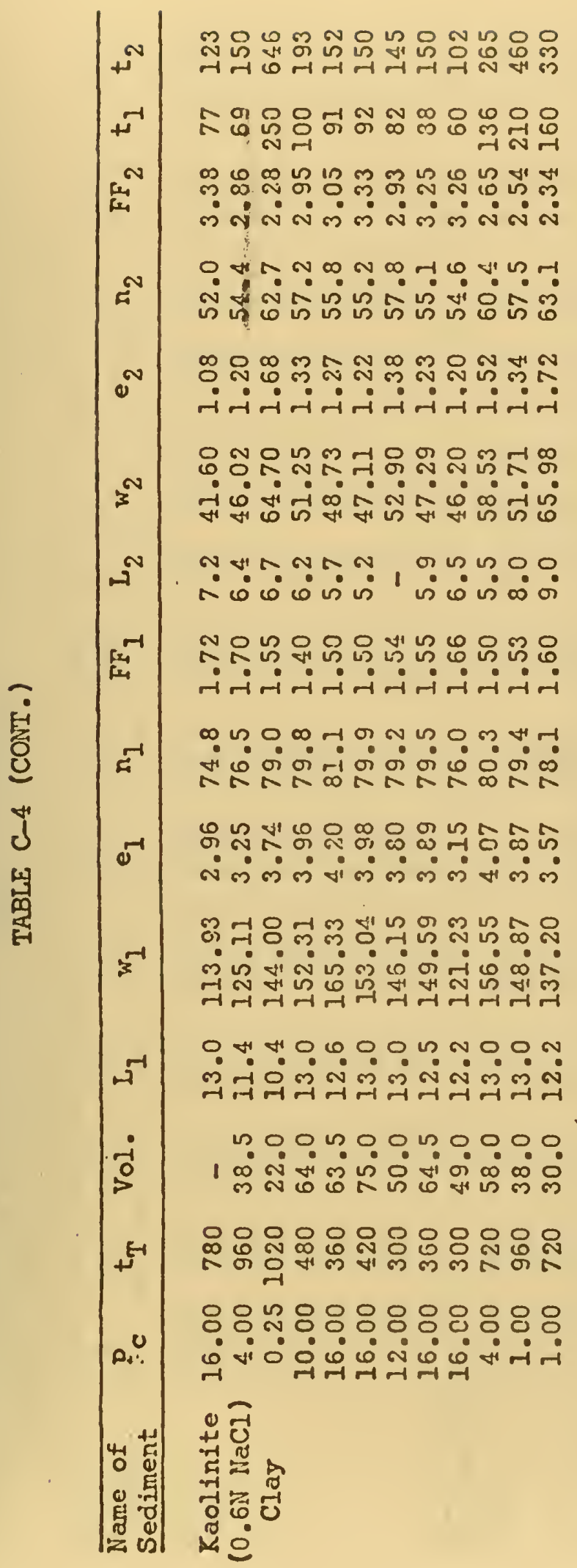

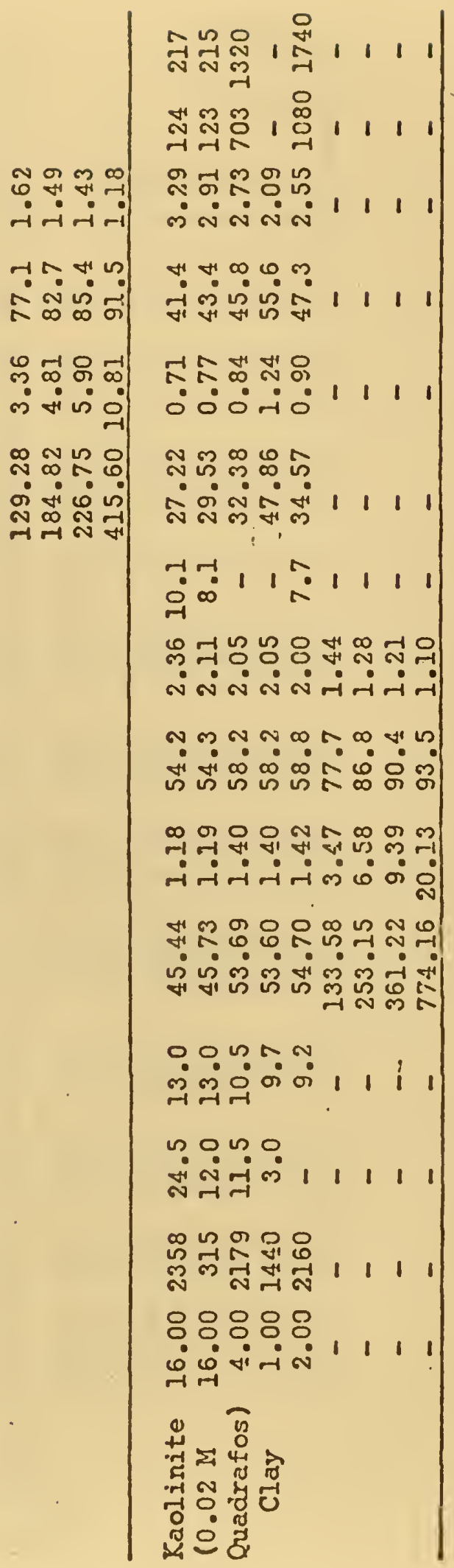





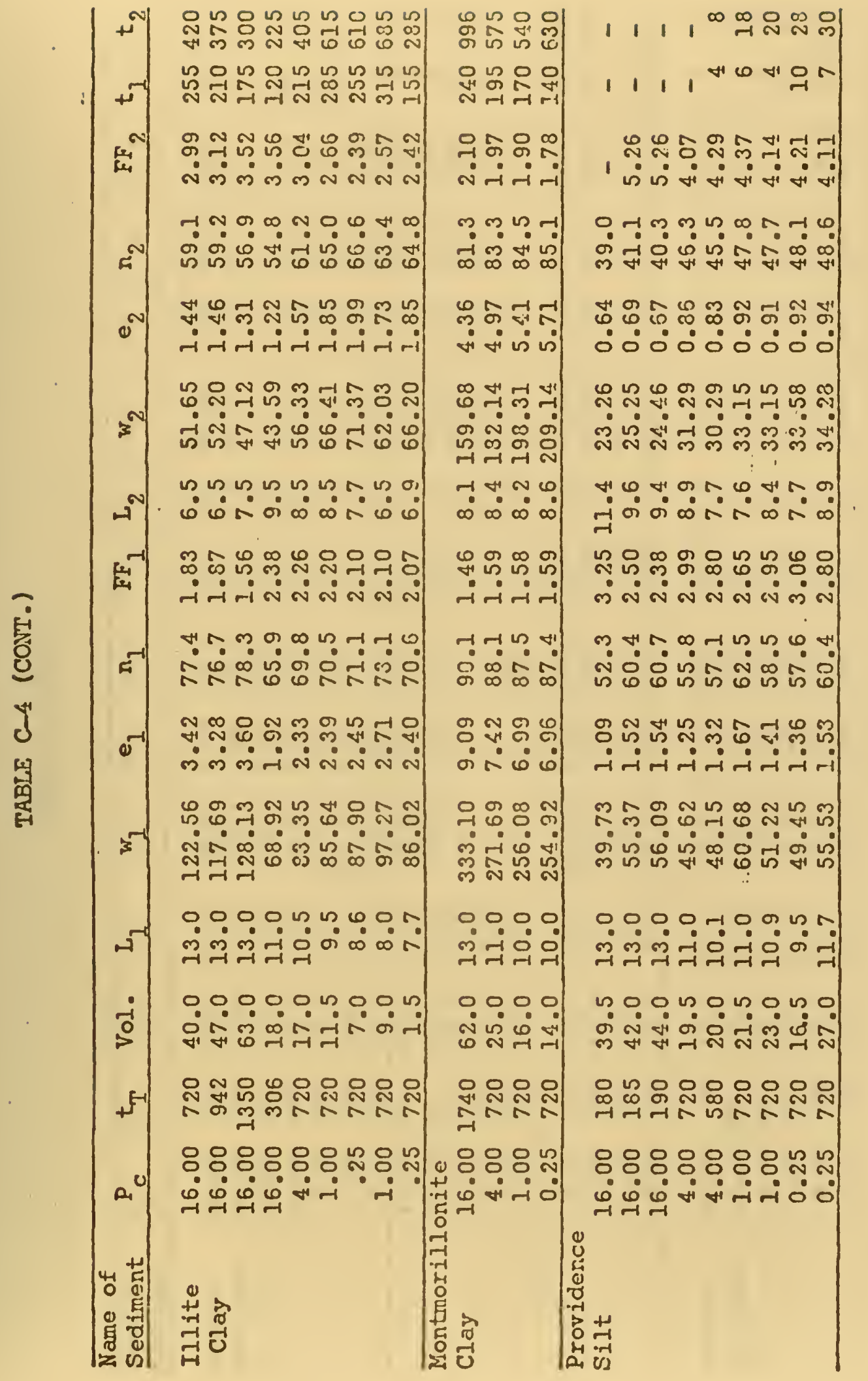





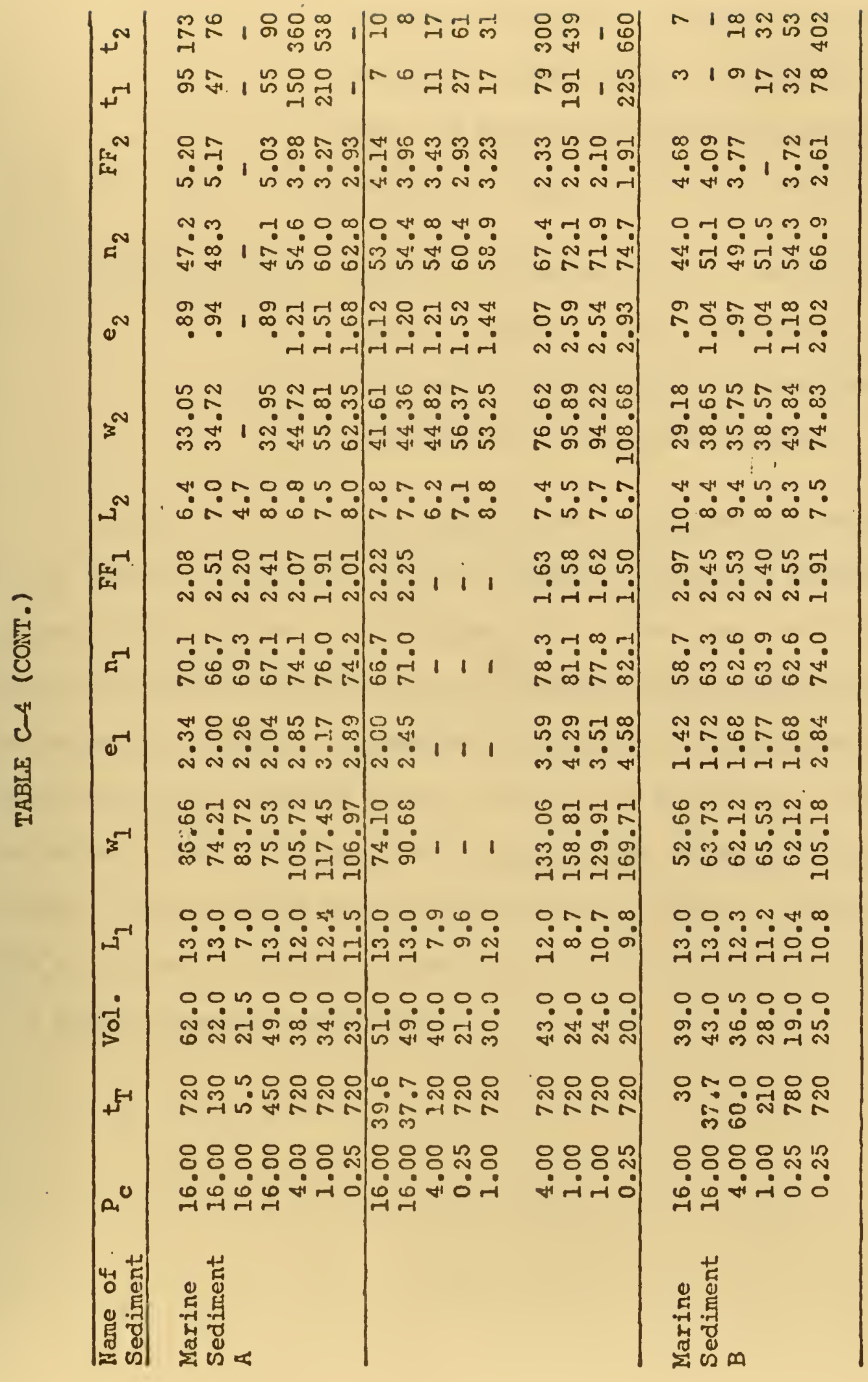



regression, sum of the squares of deviations from the regression, F-values for analysis of variance, standard error of estimate, standard error of regression coefficient, computed tvalue, and residuals were also obtained.

\section{Scatter Diagram to obtain Formation Factor - porosity printed scatter diagrams of data. The line of best fit and the \pm 2 percent porosity error line were also placed on the scatter diagrams.}

Tables C-5 and C-6 along with Figure C-1 outline the procedure used on all sediments analyzed. Table C-5 shows the values of Formation Factor porosity data obtained for Providence silt. Also given are the values of the logarithmic transformation of the Formation Factor and porosity. Table C-6 shows the intercept, regression coefficient, standard error of regression coefficient, computed t-value, correlation coefficient, standard error of estimate and the analyssi of variance for the regression technique. Figure $\mathrm{C}-1$ is a scatter diagram of the Formation Factor - porosity data. The solid line is the line of best fit and the two dashed lines are the I 2 percent porosity error lines. 



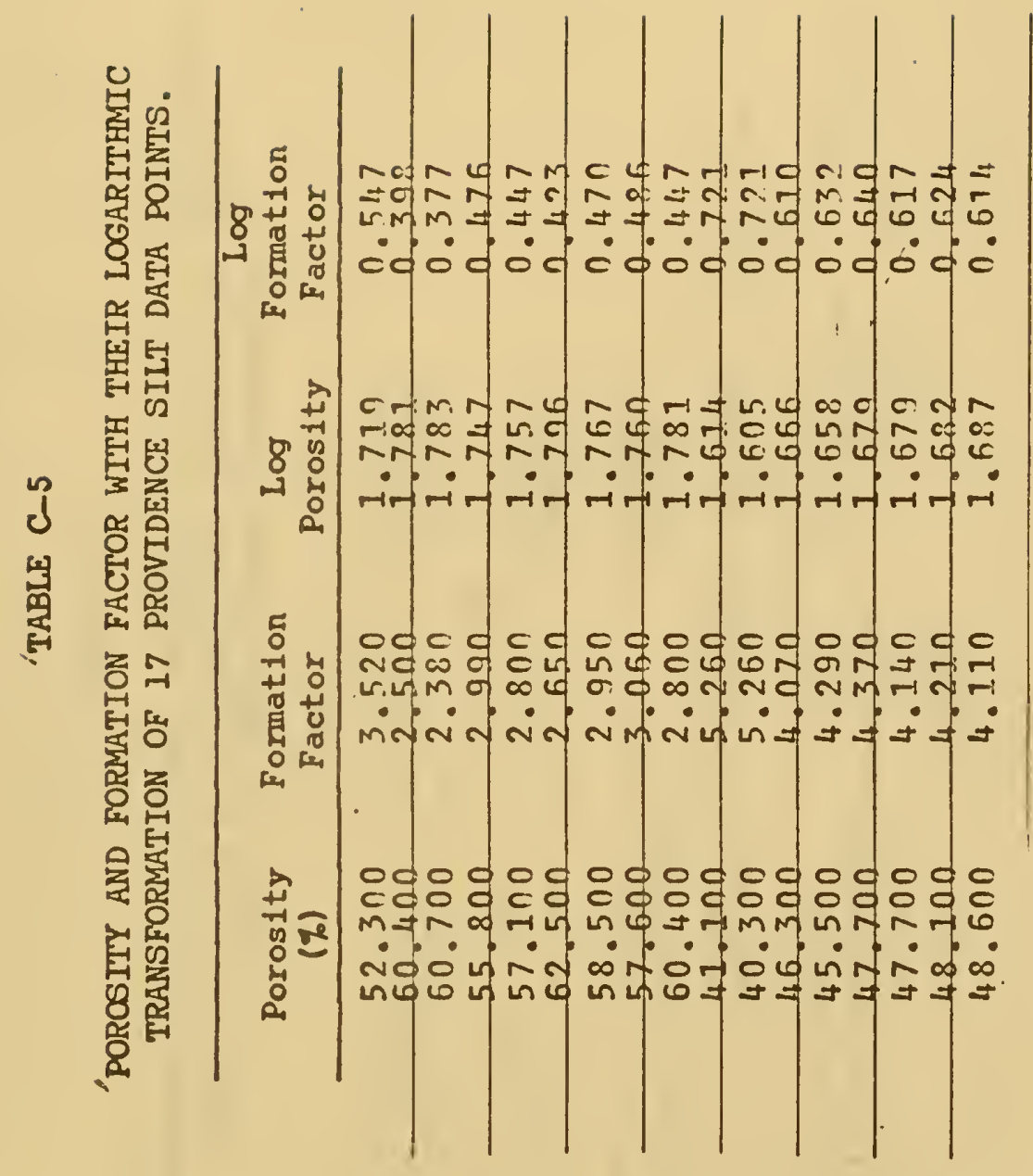





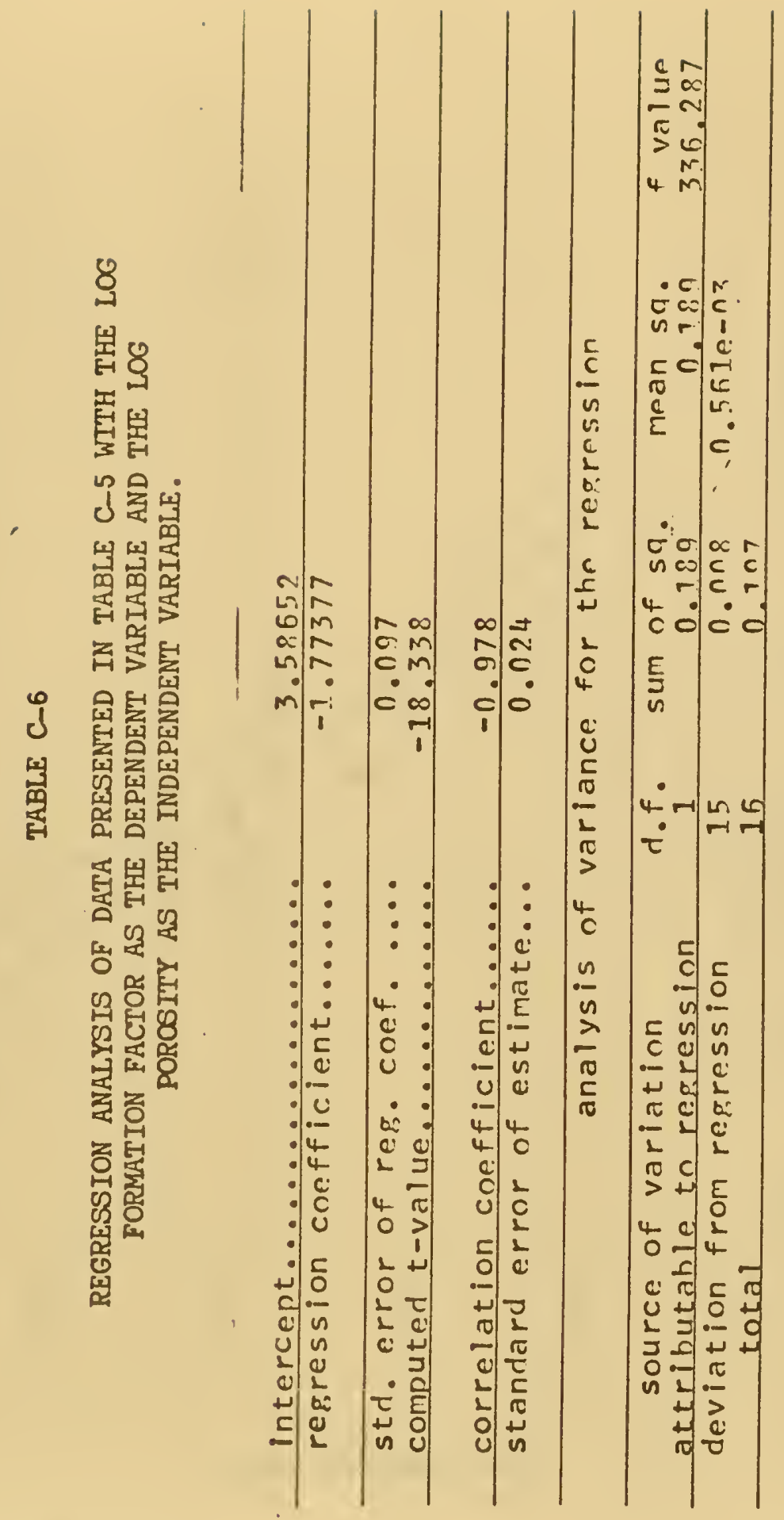





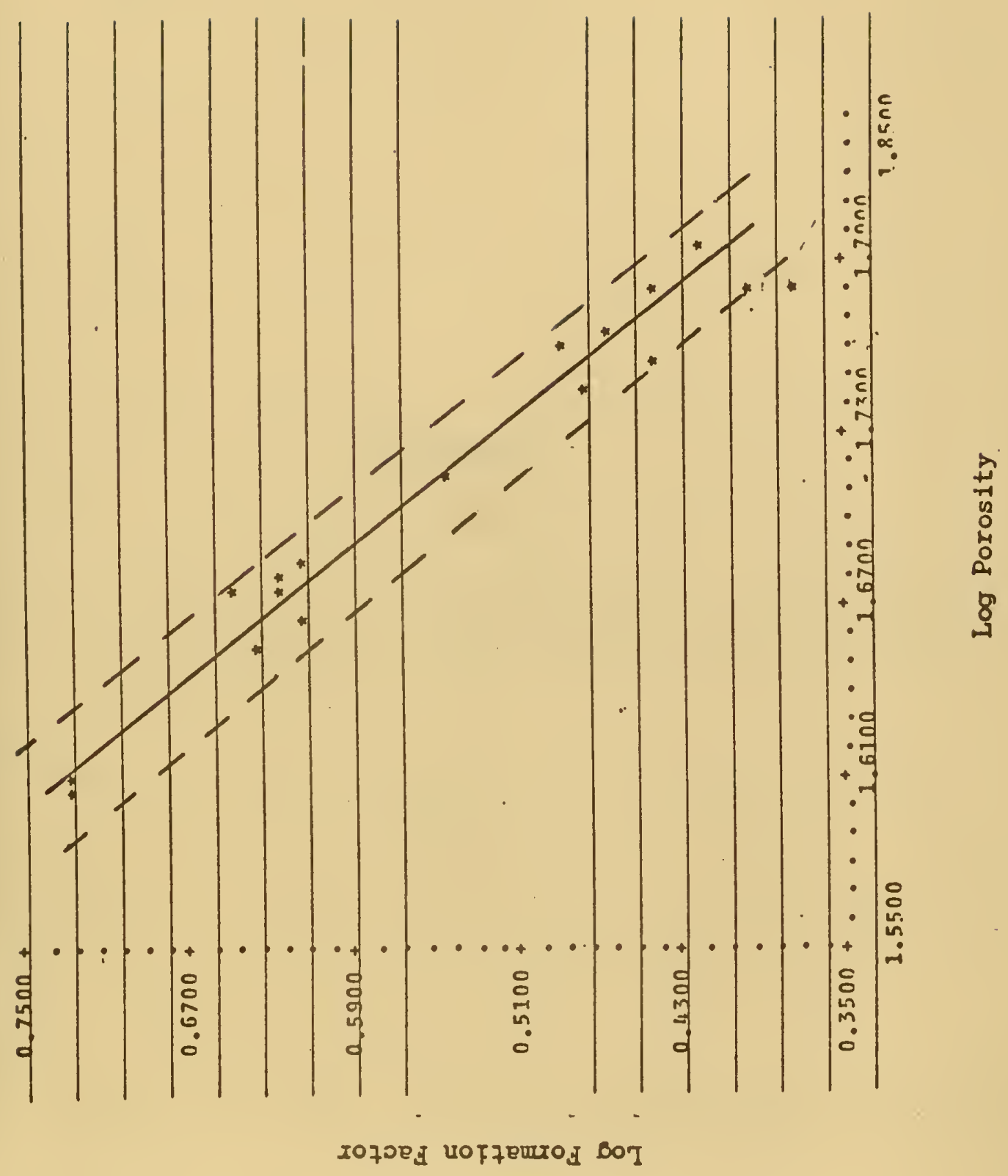

Figure C-2 Scatter Plot of the Data in Table C-5 with Log Formation Factor as the Horizontal Variable and the Log Porosity as the Vertical Variable. 

REFERENCES 

1. Meredith, R. E., (1959) "Studics on the Conductivitics of Dispersions", Lawrence Radiation Laboratory, Berkeley, Califormia.

2. Patten, E. P. and Bennet S. D., (1963) "Application of Electrical and Radioactive Well Logging to Ground water Hyrology", G00logical Survey water Supply Paper 1544-D, U. S. Government Printing Office, Washington, D. C.

3. Wu, T. W., (1966) Soil Mechanics, Allyn and Bacon, Inc., Boston, Massachusetts, P. 402 .

4. Iambe, W. T. and Whitman, R. V., (1969) Soil Mechanics, John Wiley \& Sons, Inc., New York, New York, pp. 18-60, 281-293.

5. Winsauer, W. O., and MCCardell, W. M., (1953) "Ionic Double-Layer Conductivity in Reservoir Rock", Petroleum Transactions, Vol. 198, pp. 129-134.

6. Hill, N. M. and Milburn, E. D., (1956) "Effect of Clay and water Salinity on the Electrochemical Behavior of Reservoir Rocks", Journal of Petroleum Technology, vol. 207, pp. 65-72.

7. Berg, J. W. (1952) "Conductivity Study of Agueous Kaolin Na Cl Mixtures", Producers Monthly, January, pp. 36-4l.

8. Sheeler, J. B., Picaut, J. S. and Demirel, T., (1962) "Electrical Resistivity of soil-sodium Chloride systems", Physico-Chenical Phenomena in Soils, Highway Research Board Bulletin 349, National Academy of Sciences-National Research Council, washington, D. C.

9. Boyce, R. E., (1967) "Electrical Resistivity of Modern Marine Sediments from the Bering Sea", Naval Undersea Warfare Center, San Diego, California.

10. Fritsch, V. and Tauber, A. J., (1969) "Beitrag yur Untersuchung des Einflusses wassriger Lusunger auf den spezifischen widerstand geologischer Leiter", Acta Hydrophysica, Vol. 14 ( $\left.\frac{2}{2}\right)$, pp. 79-94.

11. Atkins, E. R., Jr., and Smith, G. H., (1961) "The significance of Particle Shape in Formation Resistivity Factor morosity Relationships", J. of Petroleum Technology, Vol. 13, pp. 285291.

12. Kermabon, A., Gehin, C., and Blavier, P., (1969) "A Deep-Sea Electrical Resistivity Probe for Measuring Porosity and Density of Unconsolidated Sediments", Geophysics, vol. 34, No. 4, pp. 554-571. 

13. Smith, D. T., (1971) "Acoustic and Electric Techniques For Sca-Floor Sediment Identification", Procecdings: The Internationa I Symposiurn on the Engineering Properties of Sea-Floor Soils and Their Geophysical Jdentification, University of Washington, Seattle, Washington.

14. Wyllie, M. R. J., and Gregory, A. R., (1953) "Formation Factors of Unconsolidated Porous Media: Influence of Particle Shape and Effect of Cementation", Petroleum Transactions, Vol. 198, pp. 103-110.

15. Semenov, A. S., (1948) "The Effect of structure on the Resistivity of Aggregates", Materiali VSEGEI, Geofizika, Vol. 12, Gosgeoliydat.

16. Hutt, J. R. and Berg J. W., (1968) "Thermal and Electrical Conductivities of Sandstone Rocks and Ocean Sediments", Geophysics, vol. 33, No. 3, pp. 489-500.

17. Schopper, J. R., (1966) "A Theoretical Investigation on the Formation Factor/Permeability/Porosity Relationship Using a Network Model", Geophysical Prospecting, Vol. 14, pp. 301-341.

18. Fatt, J., (1958) "Pore Volume Compressibilities of Sandstone Reservoir Rocks", Journal of Petroleum Technology, Vol. 213, pp. 362-364.

19. Wyble, D. O., (1958) "Effect of Applied Pressure on the Conductivity, Porosity and Permeabil.ity of Sandstone", Journal of Petroleum Technology, Vol. 213, pp. 430-432.

20. Glanville, C. R., (1959) "Laboratory Study Indicates Significant Effect of Pressure on Resistivity of Reservoir Rocks", Journal of Petroleum Technology, April, pp. 20-26.

21. Maxwell, J. C., (1881) "A Treatise on Electricity and Magnetism", Oxford: Clarendon Press, p. 435.

22. Wiener, O., (1904) "Lamellare Doppelbrechung", Physikalische Zeitschrift, vol. 5, No. 12, pp. 332-338.

23. Woodside, W. and Messmer, J. H., (1961) "Thermal Conductivity of Porous Media. I. Unconsolidated Sands", Journal of npplied Physics, Vol. 32, No. 9, pp. 1688-1691.

24. Archie, G. E., (1942) "The Electrical Resistivity Log as an Aid in Determining some Reservoir Characteristics", American Institute of Mining and Metallurgical Engineers Inc., Technical Report No. 1422, Petroleum Technology, January 1942.

25. Dakhnov, V. N., (1962) "Geophysical Well Logging", Quarterly of the Colorado School of Mines, Vol. 57, No. 2.

26. Pautot, G. (1967) "Mesures de resistivities electriques sur des carottes de sediments marins et lacustres", Bull. Inst. oceanogr.. Monaco, Vol. 67, No. 1376. 

27. Bouma, A. H., Sweet, W. E., Chmelik, F. B., and Huebmer, G. I., (1971) "Shipboard and In-Situ Electrical Resistivity Logging of Unconsolidated Marine Sediments", Proc. Third Annual Offshore Tcchnology Confecence, (Paper 1351).

28. Chmelik, F. B., Eouma, A. H., and Rezad, R., (1969) "Comparison of Electrical Logs and Physical Parameters of Marine sediment Cores", Transactions - Gulf Coast Association of Geological societies, Vol. XIX.

29. Ball, J. R., (1970) "Determination of Occanic Sediment Porosity by Elcctrical Conductivity", Marine Technology 1970, vol. 2, pp. 1475-1480.

30. Lewis, L. F., (1971) "An Investigation of Occan Scdiments Using the Deep Occan Sediment Probe", Doctor of Philosophy Thesis, Ocean Engineering, University of Rhode Island.,

31. Maus, L. D., (1971) "Gamma-Ray Measurement of Changes in Sediment Samplc Water content", Master of Science Thesis, Ocean Engineering, University of Rhode Island.

32. Osthaus, B. B., (1955) "Interpretation of Chemical Analysis of Montmorillonites", Clays and Clay Technology Bulletin 169, Division of Mines, San Francisco, pp. 95-100.

33. Bxindley, G. W., (1955) "Identification of Clay Minerals By X-ray Diffraction Analysis", Clays and Clay Technology, Bulletin 169, Division of Mines, San Francisco, pp. 119-129.

34. Rose, V., and Roney, J., (1971) "A Nuclear Gage for In Placc Measurement of Sedinent Density", Proc. Third Annual Offshore Technology Conference (Paper 1329).

35. Fisher, S., (1962) "Application of well Logging Techniques to the Marine Sciences", Proc. of the IRE, Vol. 50, pp. 2243-2251.

36. Borowczyk, M., and Krolikowski, C., (1964) (Romitet Inzynierii Ladowcj PAN oraz Katedra Mcchaniki Gruntow i Fundamentowania Politechniki Lodzkicj Warszawa/Lodz), pp. 165-177.

37. Wenner, F., (1915) "A Method of Measuring Earth Resistivity", Bulletin of the Bureau of Standards, Vol. 11, pp. 469-478.

38. Berret, W. R., (1948) "Elcctrical Resistivity Exploration as a Compliment To Boring in Deep Alluvial Deposits", Proc. Sccond Annual conference on soil Mcchanics and Foundation Engincering, Vol. 7, Rotterdam, June, pp. 80-84.

39. Williams, Cecil E., (1970) "In-situ Formation Factor Mcasurcment at the water sediment Interface", A paper prescntcd at INTEROCEAN 170, Dusseldorf, Gcrmany, November 10-15, 1970. 

40. Siever, R., Beck, K. C., and Bcrncr, R. A., (1965) "Composition of Interstitial Waters of Modern Sediments", Journal of Gcology, vol. 73, pp. 39-72.

41. Smimov, S. J., (1968) "Gecchenical History of Interstitial Waters of sediments of ilarine origin", International Goology Roview, vol. 11, No. 9, pp. 993-1003.

42. Kullenberg, B., (1952) "On The Salinity of the Water contained in Marine Sediments", Suteborg, Kungl. Velenskaps Och Vitterhets Samhalles Handlingar. pp. 1-37.

43. Dol1, H. G., (1953) "The Microlateralog", Journal of Petroleum Technology, Technical Paper $3492^{\circ}$.

44. Barry, W. A., (1971) "Deep Sea Telemetry System", Master of Science Thesis, Ocean Engineering, University of Rhode, Island.

45. Status Report No. I Under Texas A \& M Research Foundation, P.O. No. $R F-11743$ and Office of Naval Research Contract N00014-70-A-0166.0005, (1 January - 1 July 1971).

46. Lambe, W., (1961) Soil Testing for Engineers, John Wiley and sons, New York, 165 p.

47. Olmsted, F., (1964) "Suggested Method for securing the Liquid Limit of Soils Using One-Point Data", in Procedures for Soils 4th Ed. American Society of Testing Materials, Committee $D-18$, pp. 151-153.

48. Shepard, F., (1963) Submarine Geology, 2nd Ed., Harper and ROW, New York, pp. 101-151.

49. Greweling, T., and Peech, M., (1965) "Chemical soil Tests", Cornell University Agricultural Experiment station Publication, Ithaca, New York, pp. 31-33.

50. Akroyd, T., (1939) Laboratory Testing in Soil Engineering, soil Mechanics Ltd., Iondon.

51. Hansbo, S., (1957) "A New Approach to the Determination of the Shear Strength of Clay by the Fall-Cone Test", Royal Swedish Gcotechnical Institute Proceedings, No. 14, stockholm, pp. 1-47.

52. Cullity, B., (1967) Elements of X-ray Diffraction, Addison-Wellslcy, New York, pp. 177-215.

53. Call/360: Statistical Package (STATPACK) Version 2, Edition G3201009-1, (1970), Intermational Business Machines Corporation, 112 East Post Road, White Plains, New York. 



\section{INITIAL DISTRIBUTION LIST}

1. Defense Documentation Center Cameron Station

Alexandria, Virginia 22314

2. Library Naval Postgraduate School

No. Copies

Monterey, California 93940

3. Nava1 Oceanographic Office Attn: Library Washington, D. C. 20390

4. Office of Naval Research Department of the Navy

1 (Original)

1 (Copy)

1 (Copy)

Attn: Geophysics Branch (Code 416)

Washington, D. C. 20390

1 (Copy)

1 (Copy)

5. Department of Ocean Engineering Naval Civil Engineering Laboratory

1 (Copy) Port Hueneme, California 93043 



\section{DOCUMENT CONTROL DATA. R \& D}

(Security classilication of tille, body of abstract and indexinf annotalion must be onfered when the overall report is classilled, ORIGINA TIRC ACTIVITY (CORPOBate author)

Iniversity of Rhode Island ingston, R.I. 02818 2A. REPORT SECURITY CLASSIFICATION Unclassifjed REFORT TITLE

the Use of Electrical Resistivity to Determine Porosity of Marine iediments

OESCRIPTIVE NOTES (TYPO of sepor? and inclusive dates)

loctor of Philosophy Theis, January 1972 AUTHOR(S) (First name, middlo inilial, last namo)

ionald Anton ERCHUL

\begin{tabular}{|c|c|c|}
\hline $\begin{array}{l}\text { REPORT DATE } \\
\text { anUaTY } 1972\end{array}$ & $\begin{array}{c}\text { 7a. TOTAL NO. OF PAGES } \\
193\end{array}$ & $\begin{array}{l}\text { 7b. NO. OF REFS } \\
53\end{array}$ \\
\hline $\begin{array}{l}\text { CONTRACT OR GRANTNO. } \\
\text { PROJECTNO. } \mathrm{n} / \mathrm{a}\end{array}$ & $\begin{array}{l}\text { 90. ORIGINATOR'S REPORT } \\
-n / a\end{array}$ & $B E R(S)$ \\
\hline & $\begin{array}{l}\text { O8. OTHER REPORT NO(S) } \\
\text { (nits rCPORt) }\end{array}$ & thet numbots that may be usolened \\
\hline
\end{tabular}

DISTRIBUTION STATEMENT

istribution of this document is unlimited SUPPLEMENTARY NOTES

one

U. S. Navy

\section{ASTKACT}

A method using electrical resistivity measurements to determine the n situ porosicy of marine sediments was investigated in the laboratory, nd equipment for this purpose was designed, fabricated and tested. For ation Factor-Dorosity relationships determined in the laboratory for hree clays (kaclinite, illite, and montmorillonite), Providence si]t, our sanci, nd Eour marine sediments showed that porosity was predicted itnin - Z percent. The Formation Factors ranged from 1.1 to 5.9 while orosity ranged from 26 to 93 percent. The particle size and distribuion influenced the electrical resistivity of these sediments indepondert f porosity while particle shape did not. The laboratory equipment was cononical, safe, easy to operate and could be used to determine permebility, tortuosity and void ratio-log consolidation pressure of sedients.

The Electrical Resisirity Measuring System designed for the Deen cean Sediment Probe consists of three interchangeablo electrode arrays, he electronic circuit and the FM telemetry data link with 6000 feet of oaxial cable. The predicted porosity values obtained with the system $n$ the laboratory were within +2 percent of the 1 ine of best fit obtuin 



\section{Unclassified}

The inner corer ring electrode array read continuous conductivity through the water/sediment column thus permitting a value of salinity to be obtained. The bottom water salinity obtained in this way was in good agreement with the interstitial water salinity of the cores. The system detected a core loss, touch down, and sample disturbance. This relatively low cost system allows accurate, quick in situ porosity determination and shows promise in other areas such as the monitoring of pollution, the prediction of other bottom sediment properties and as a warning system on ocean structures. 



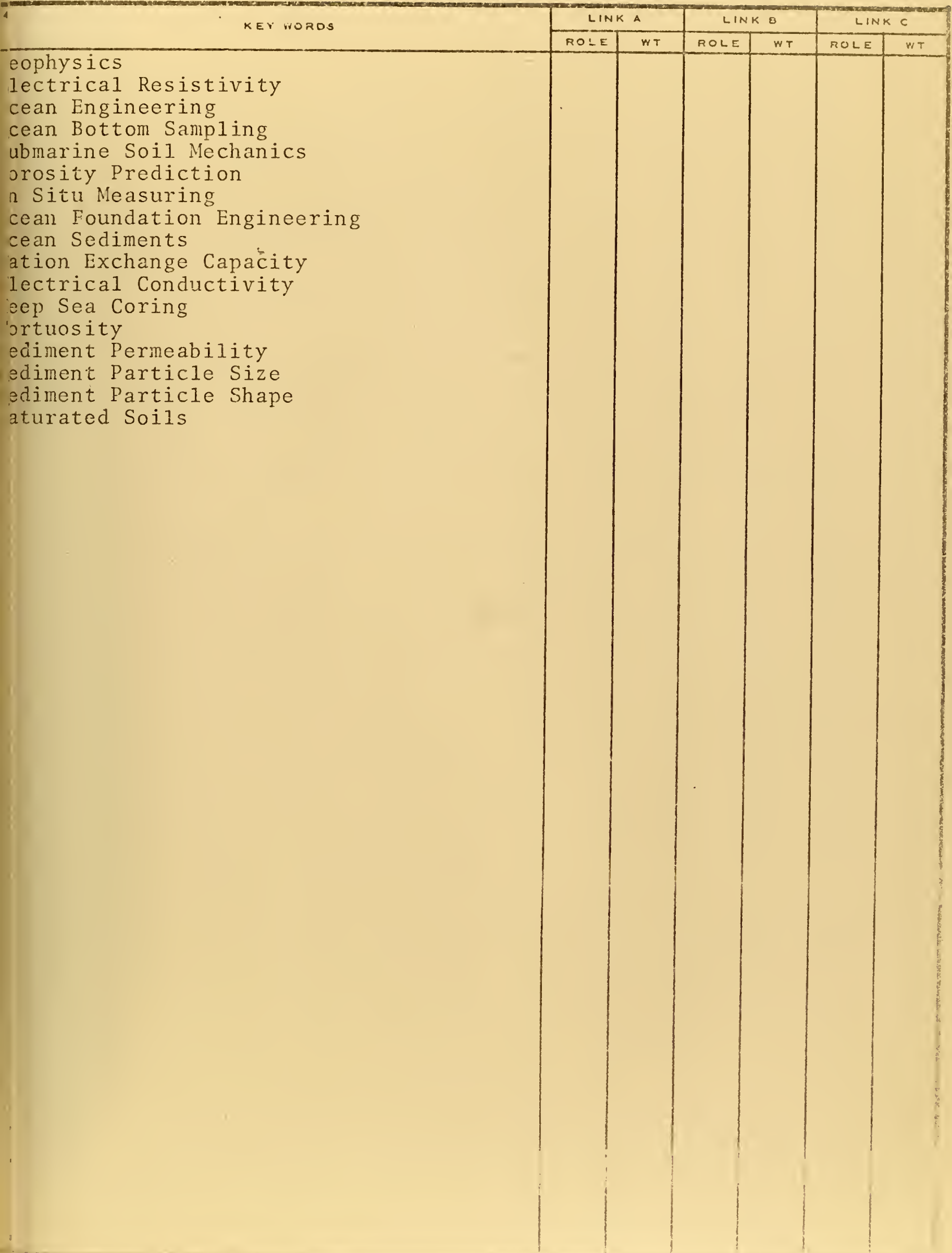







Thes is

E5662 Erchul

133589

The use of electric$\Rightarrow$ resistivitv to determine porosity of marine sediments. 
The use of electrical resistivity to det

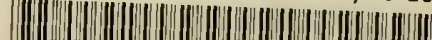

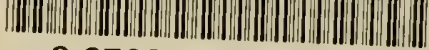

32768002062010

DUDLEY KNOX LIBRARY 